\title{
Towards microbial safety of fresh vegetables in Rwanda
}

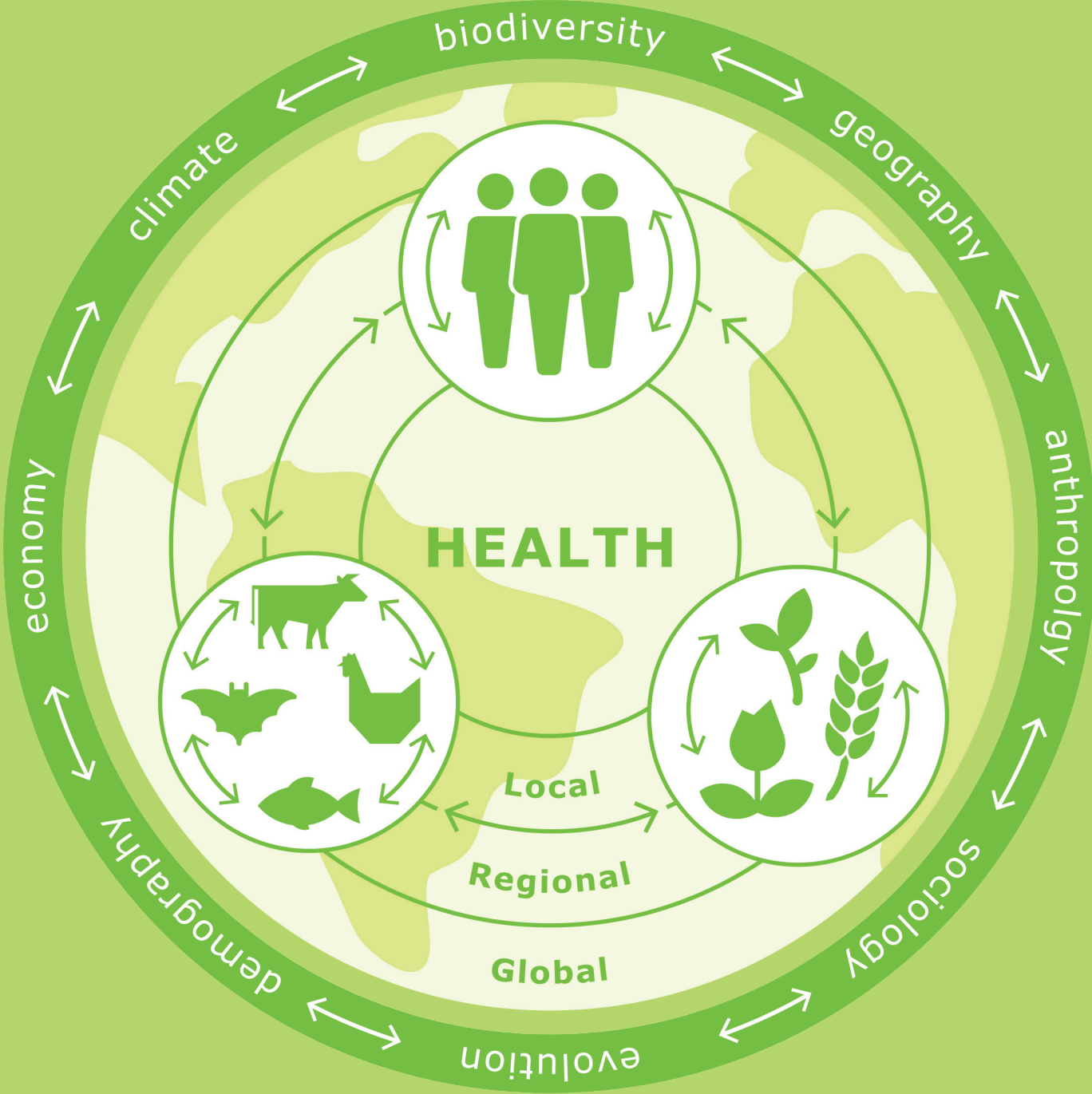

\section{James Noah Ssemanda}

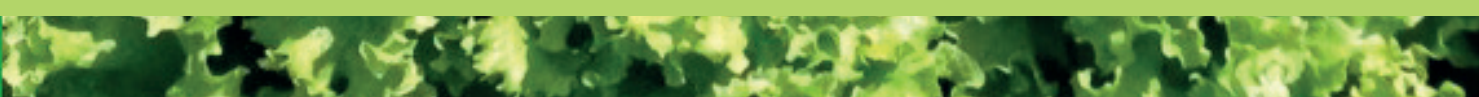

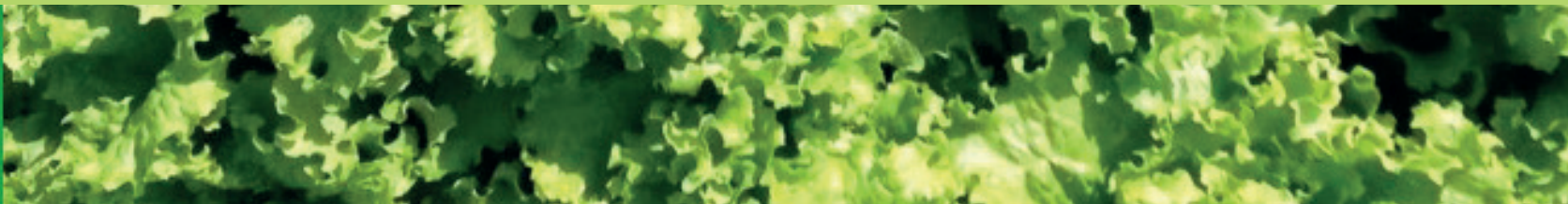

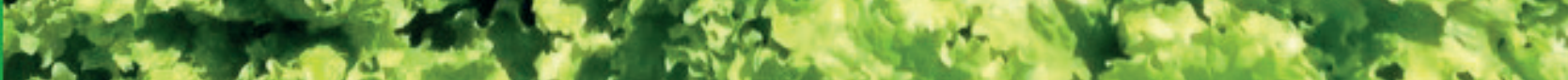

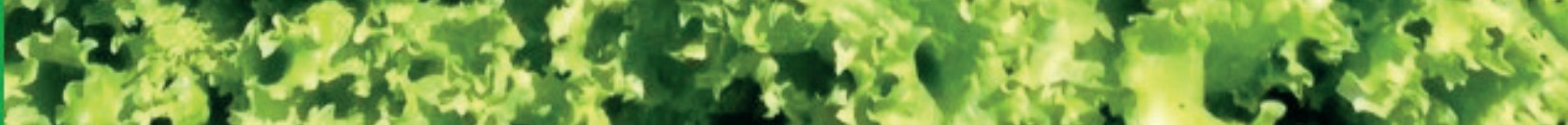



Towards microbial safety of fresh vegetables in Rwanda

James Noah Ssemanda 


\section{Thesis committee}

\section{Promotors}

Prof. Dr M.H. Zwietering

Professor of Food Microbiology, Wageningen University \& Research

Prof. Dr H.M.L.J. Joosten

European Chair in Food Safety Microbiology, Wageningen University \& Research

\section{Co-promotor}

Dr M.W. Reij

Assistant professor, Laboratory of Food Microbiology, Wageningen University \& Research

\section{Other members}

Prof. Dr E.J. Woltering, Wageningen University \& Research

Prof. Dr L. Jacxsens, Ghent University, Belgium

Dr I. van der Fels-Klerx, Wageningen University \& Research

Dr J.A. Haagsma, Erasmus Medical Center, Rotterdam

This research was conducted under the auspices of the Graduate School VLAG (Advanced studies in Food Technology, Agrobiotechnology, Nutrition and Health Sciences) 


\section{Towards microbial safety of fresh vegetables in Rwanda}

\section{James Noah Ssemanda}

\section{Thesis}

submitted in fulfilment of the requirements for the degree of doctor at Wageningen University

by the authority of the Rector Magnificus,

Prof. Dr A.P.J. Mol,

in the presence of the

Thesis Committee appointed by the Academic Board

to be defended in public

on Monday 10 September 2018

at 11 a.m. in the Aula. 
James Noah Ssemanda

Towards microbial safety of fresh vegetables in Rwanda

215 pages.

$\mathrm{PhD}$ thesis, Wageningen University, Wageningen, the Netherlands (2018)

With references, with summary in English

ISBN 978-94-6343-793-6

DOI https://doi.org/10.18174/452828 


\section{Table of Contents}

\section{Chapter 1}

General introduction and outline of the thesis

\section{Chapter 2}

Estimates of the burden of illnesses related to foodborne pathogens as from the syndromic surveillance data of 2013 in Rwanda

\section{Chapter 3}

Indicator microorganisms in fresh vegetables from "farm to fork" in Rwanda

\section{Chapter 4}

Foodborne pathogens and their risk exposure factors associated with farm vegetables in Rwanda

\section{Chapter 5}

Reduction of microbial counts during kitchen scale washing and sanitization of salad vegetables

\section{Chapter 6}

General discussion, conclusion and future perspectives

Summary

Acknowledgements

About the author

List of publications 



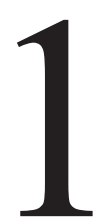

General introduction and outline of the thesis 


\section{Foodborne illness}

Foodborne illnesses originate from ingesting contaminated food. Acute symptoms of foodborne illnesses include mild and self-limiting watery diarrhea, vomiting, headache, nausea, abdominal pain and severe symptoms like bloody diarrhea, paralysis and abortion (1). In long term, foodborne illnesses can also include reactive arthritis, Guillain Barré Syndrome and hemolytic uremic syndrome (HUS) $(2,3)$ and in some cases, cancer (4). Foodborne illnesses are caused by bacteria, parasites, viruses, toxins, metals, and prions (5). This study focused on bacterial agents and Figure 1.1. shows examples of the pathways through which these agents can cause foodborne illnesses.

Historically, foodborne illnesses can be traced back to ancient time (6). In their study, doctors at Maryland University (US) in 1998 postulated that "Alexander the Great" may have died of typhoid fever at Babylon around 323 B.C., though by that time it was considered as poisoning due to rivalry $(6,7)$. Other notable figures in history that are reported to have succumbed to foodborne illnesses include King Henry I of England year 1135 and US President Zachary Taylor, year 1850 (6). While people continued to suffer from these foodborne illnesses, knowledge about particular pathogens was still limited until the late $19^{\text {th }}$ century $(8)$. Indeed most major foodborne pathogens were only discovered during the last two centuries i.e. Trichinella spiralis in 1835, Salmonella in 1885, Staphylococcus aureus 1914, Clostridium perfringens 1945, Campylobacter jejuni, Yersinia enterocolitica, Escherichia coli O157:H7 and Vibrio cholerae in period between 1975 to 1985 (8).

From historical to present times, foodborne pathogens continue to cause substantial morbidity and mortality in the world, and do hamper social-economic development (9). Factors highlighted to contribute to this burden of illness include: the lack of implementation of known preventive and control measures, the emerging and re-emerging of foodborne pathogens such as the emergence of microbial antibiotic resistant strains, the increasing potential of spread due to fast tracked globalization, and the surging number of susceptible population $(3,10-14)$.

While a lot of progress has been made in studying food borne pathogens, known pathogens continue to re-emerge by occupying different niches and or acquire virulence genes while in some cases completely new pathogens emerge (11). On new emerging pathogens, a good example is pathogenic E. coli. In the early 1980s focus was on E. coli O157: H7 (15) but other serotypes have now also caused severe outbreaks like the E. coli O104: H4 in Germany in 2011 (16). Furthermore, the continued use of antibiotic agents such as amoxicillin and tetracycline in human medicine to treat infectious diseases $(12,15)$ and antibiotics massively used to treat farm animals, has led to the emergence and spread of antimicrobial resistant strains. Although most foodborne illnesses are self-limiting, the use of antibiotics against antibiotic resistant strains has in some cases led to ineffective treatment, and prolonged duration of illness 


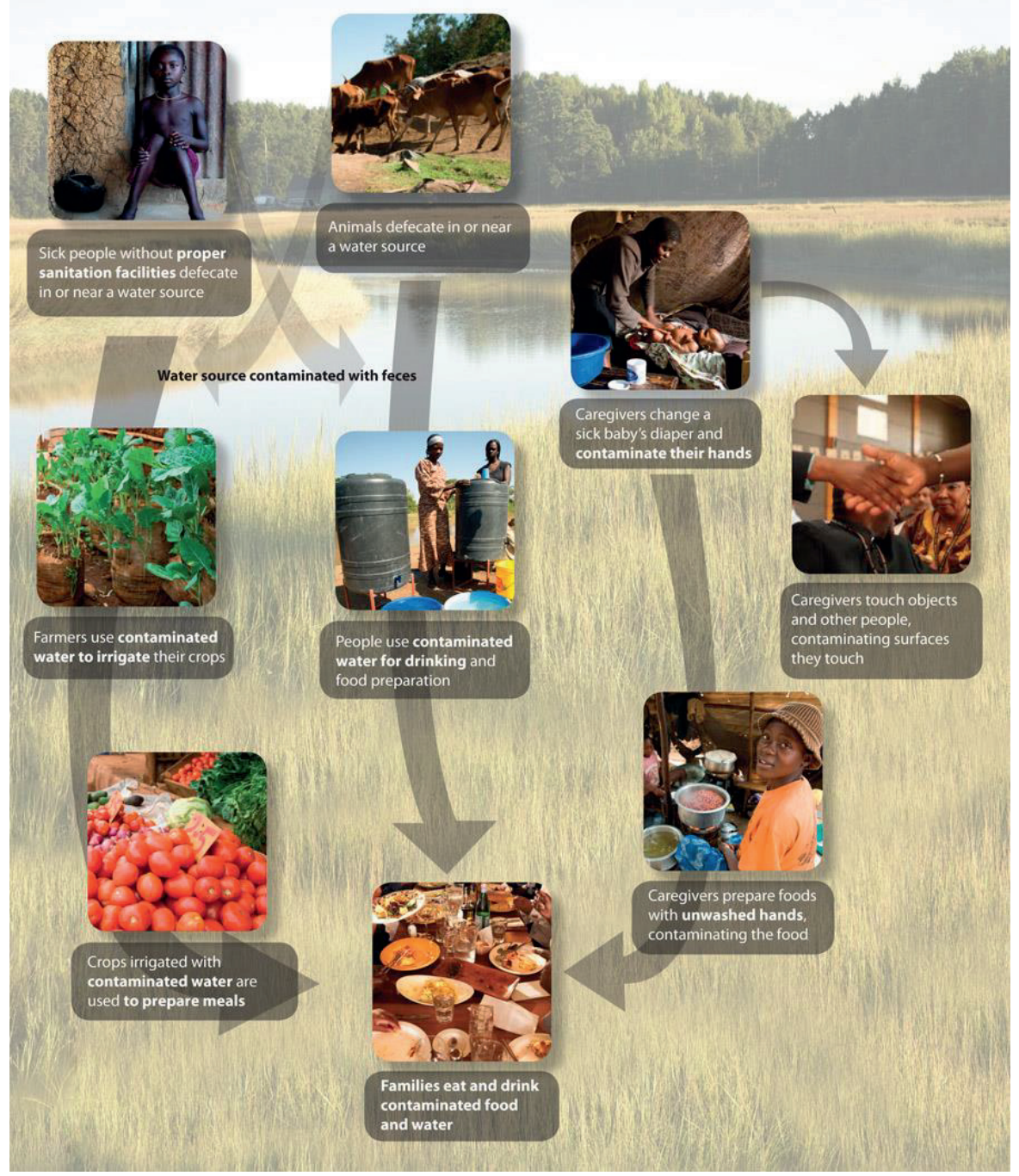

Figure 1.1: Example of pathways to foodborne diseases [ source: CDC, 2012 (17)].

and deaths. Researchers from different countries have continued to isolate antibiotic resistant strains and genes in food, water and environment. For example, in the US, Salmonella Newport isolates from surface waters were reported to be multidrug resistant (18). In China, $L$. monocytogenes (19), Salmonella spp. (20), enterotoxigenic E. coli (ETEC) (21) were isolated from ready to eat foods and were also to found to be antibiotic resistant to a number of antibiotic agents. In Africa, antibiotic resistant strains of pathogenic E. coli (22, 23), Salmonella spp. (24), Enterococcus spp. (25) have also been isolated.

Globalization has led to increased chances of spread of human pathogens (11). Food supply chains have been internationalized ie. a "Rwandan", "Dutch" or "French" salad can be prepared from vegetables imported from another country with different levels of implementation of food safety standards. In some cases, outbreaks have spread from one country to another (26-28) or 
in many USA states (29-31) due to imported foods and movement of people. It is anticipated that globalization will even be more intensified in future and addressing the associated foodborne illness will require a global approach.

Food illnesses especially from opportunist pathogens like L. monocytogenes may in future become very important due to increased size of the population at risk. The recent successes in medicine have led to a rise in the population of immuno-compromised individuals. HIV/AIDS and cancer patients now live longer than before and these individuals are very susceptible to foodborne pathogens. Another predisposing factor is the increasing use of antacid drugs (13) that have been reported to have a protective role to some foodborne pathogens against gastric acids and enhance susceptibility to infection $(13,14)$.

Consumption of meals away from homes is on the rise and food handlers in food service establishments have continued to be implicated in foodborne outbreaks (32-36) and associated with food borne pathogens (36-38). Although people can also get ill due to contaminated food prepared in households, the contamination of food at food service is more likely to affect a larger number of consumers and to be recognized as a food related outbreak. Moreover it has been argued that in most food service establishments, food handlers are low income earners who may work even when they are ill (12) thereby increasing the chances of food contamination.

\section{Disease surveillance systems}

Public health authorities in various countries have developed disease surveillance systems to get a view of the magnitude of the health burden, and eventually to prioritize control measures and interventions. The level of development of these surveillance systems is greatly influenced by availability of economic resources. Surveillance systems are systematically and continuously operated to collect, consolidate and analyze disease epidemiological data so as to generate information for public health action $(1,39)$. Figure 1.2 summarizes components of an effective surveillance system. The major role of a disease surveillance system is to monitor trends of the target disease or illness over time to identify high-risk groups, locations, seasons, outbreaks, route(s) of transmission and risk factors (40).

The Food and Agriculture Organization (FAO) and the World Health Organization (WHO) of the United Nations are at the fore front of coordinating international efforts to detect, control and prevent foodborne illnesses. Globally the WHO takes a pivotal role in coordinating a "network of networks" which links together existing formal and informal local, regional, national and international networks of laboratories and medical centres (41). In Rwanda, disease surveillance and response duties are mandated to Rwanda biomedical center (RBC) which in turn coordinates with WHO through the Ministry of Health (42). Other examples of these networks are the European centre for disease prevention and control (ECDC) (43), the US Centres for Disease Prevention and Control (CDC, Fig. 1.3) (44), the newly launched Africa Centres for Disease Prevention and Control (Africa CDC) (45). Figure 1.3 shows an example of data sources and data flow through a national notifiable disease surveillance system to WHO (46). 


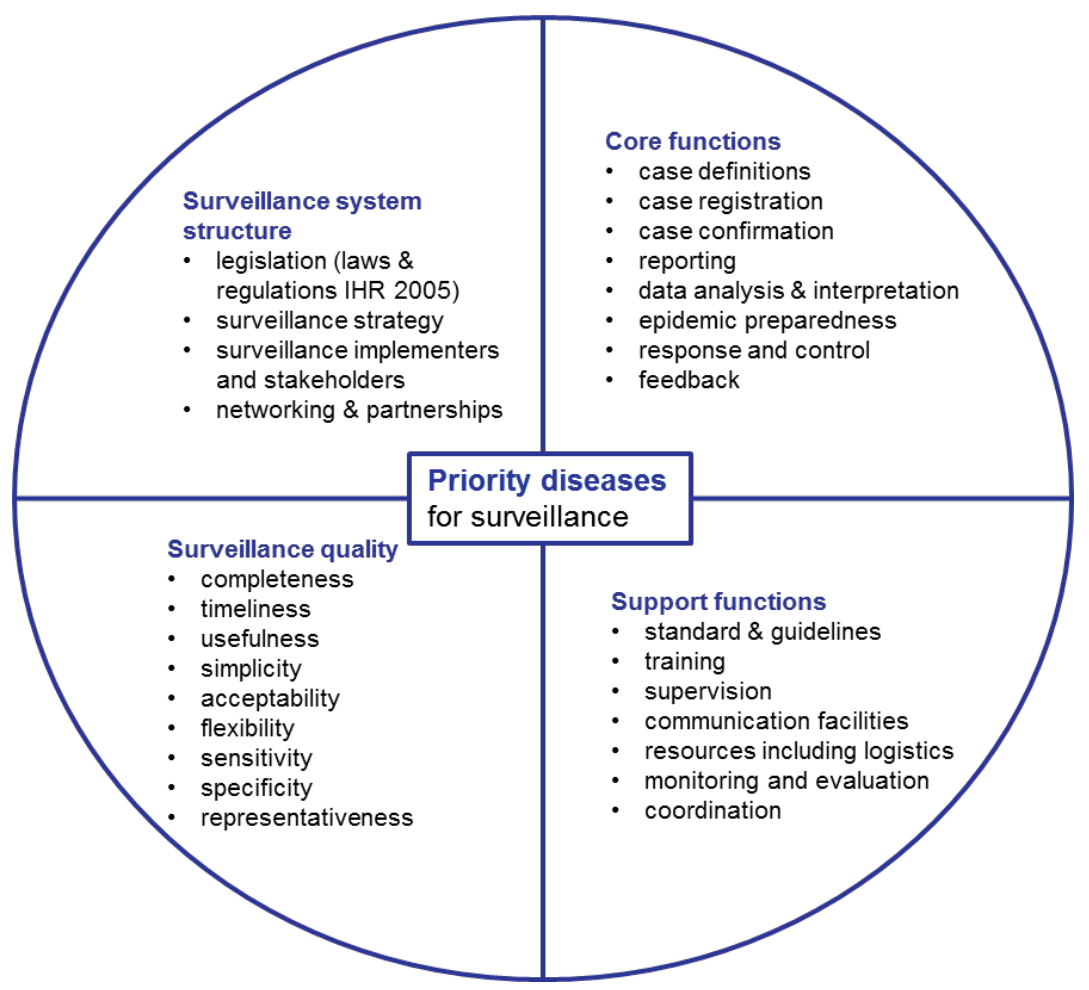

Figure 1.2: Components of surveillance and response systems [source: WHO, 2006 (47)]. IHR= International Health Regulations.

National Notifiable Diseases Surveillance System Data Flow

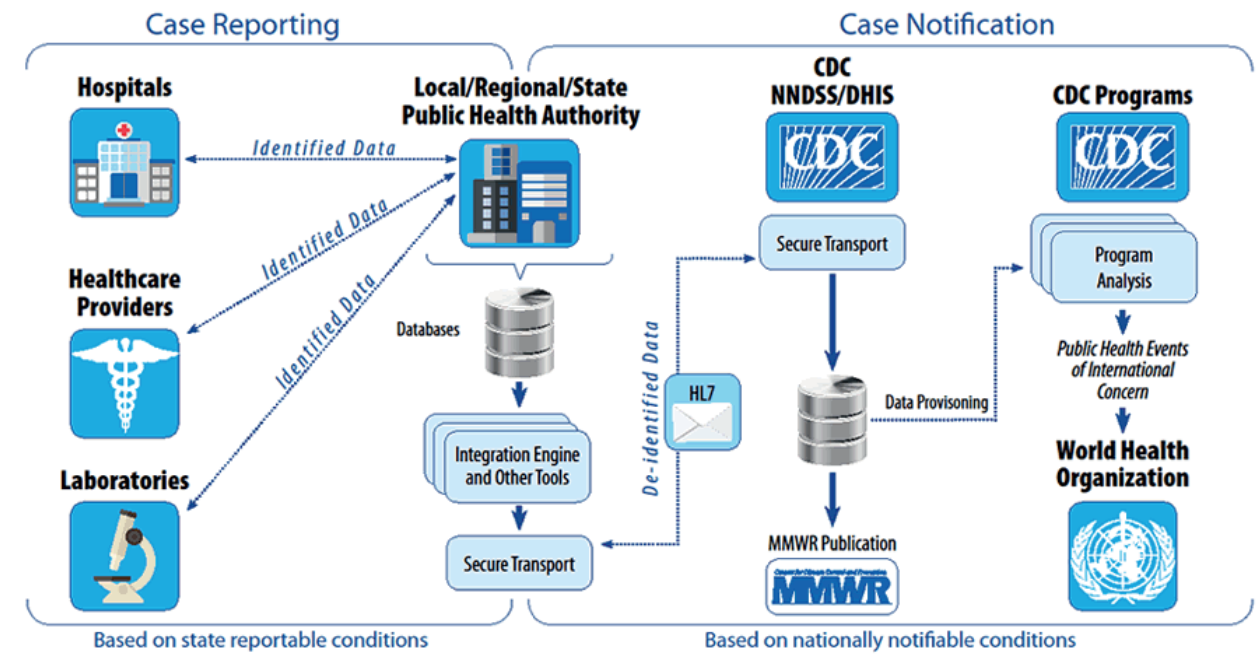

Figure 1.3: Data flow in the United States national notifiable disease surveillance system (NNDSS), [ source: CDC, 2016 (46)]: $\mathrm{CDC}=$ centres for disease prevention and control, MMWR= Morbidity and mortality weekly report, DHIS= Division of health informatics and surveillance. 
Data collection in a disease surveillance system can be classified as active, sentinel or passive surveillance (48). In active surveillance, designated active surveillance staff regularly visit health facilities in person to search for suspected cases, talking to health-care providers and reviewing medical records to identify suspected cases of disease under surveillance. When a case is found, the active surveillance staff then investigate, document clinical and epidemiological data, arrange to send appropriate laboratory specimens and report the information rapidly, in accordance with the national policy. Passive surveillance relies on the cooperation of health-care providers, laboratories, hospitals, health facilities and private practitioners to report the occurrence of a vaccine-preventable disease to a higher administrative level where data once received, are compiled and analyzed to monitor disease patterns and possible outbreaks. Sentinel surveillance involves the deliberate collection of high-quality data from a limited network of carefully selected reporting sites with a high probability of seeing cases of the disease in question, employing good laboratory facilities and experienced wellqualified staff.

In the African region, the WHO has classified surveillance systems into four categories: i) no formal surveillance, ii) syndromic, iii) laboratory based and iv) integrated food chain disease surveillance systems (1). No formal surveillance as a system is typical of countries where there is political instability, recent history of war or extreme poverty to an extent that a public health system is generally not a priority or inexistent. Certain aspects of disease surveillance are often undertaken by external agencies such as nongovernment organizations (NGOs). Syndromic surveillance makes use of data from work and school absenteeism, emergency calls, hospitals, over-the-counter drug sale records, internet searches, and other data sources to detect unusual disease patterns. Laboratory based surveillance systems is made up of various country wide clinical laboratories that test, report or collect specimens (stool or blood) to identify disease causing agents in a location, season or risk population. The generated data or collected specimens are sent to the national reference laboratory. Lastly, in the integrated food chain disease surveillance system, epidemiologic data from animals, food and humans is collected, analyzed and interpreted to inform public health action. In this system, it is possible to attribute the burden of foodborne illnesses to a particular etiological agent and food source. Recently in Rwanda a surveillance system for infectious diseases has been established and Chapter 2 of this thesis explores to what extent the burden of food related illnesses can be estimated.

\section{Methods for estimating burden of foodborne illnesses}

Data generated from foodborne surveillance systems have to be computed and reorganized in a way usable by public health policy makers to compare the health of different populations, inform on priorities for health service delivery and planning, and to analyze the costeffectiveness of health interventions, among others $(49,50)$. To obtain estimates of the burden of foodborne illnesses from surveillance data, summary measures of population health (SMPH) have been employed (5, 9, 51-54). SMPH are classified into two broad families: health expectancies and health gaps $(49,55)$. Examples of health expectancies SMPH include the HLE (healthy life expectancy), DFLE (disability-free life expectancy), QALE (quality adjusted life expectancy) $(49,55)$ while health gaps summary measures include the QALY (quality adjusted life years) and the DALY (disability adjusted life years) (56). Among these SMPH, the DALY 
metric has gained wide recognition internationally (57) and is for instance used in the global and national studies of the burden of disease $(5,9,51-54)$. DALYs are healthy life years lost, calculated by adding the adjusted number of years lived with disability (YLDs) and the number of years of life lost due to premature mortality (YLLs) (58) where:

YLD $=$ Number of cases $\times$ duration till remission or death $\times$ disability weight

YLL $=$ Number of deaths $\times$ life expectancy at the age of death

$$
\mathrm{DALY}=\mathrm{YLD}+\mathrm{YLL}
$$

Global estimates from the Foodborne Disease Burden Epidemiology Reference Group (FERG) of the WHO in 2010 indicate that 33 million DALYs were due to the studied 31 foodborne hazards (9). Diarrheal disease agents caused nearly $70 \%$ of this burden and $31 \%$ of the DALYs were from sub-Saharan Africa. According to Havelaar et al. (9), the global burden of foodborne diseases is comparable to major infectious diseases of "the big three"; HIV/AIDS, malaria and tuberculosis. Major etiological agents with individual DALY losses of 1 to 10 million DALYs in the 2010 FERG study were non-typhoidal Salmonella enterica, Salmonella Typhi, enteropathogenic E. coli, Taenia solium, Norovirus, Campylobacter spp., enterotoxigenic E. coli, Vibrio cholerae, Hepatitis A Virus and Shigella spp.

\section{Vegetables and foodborne illnesses}

Risk managers require information on the relationship between food and foodborne pathogens from farm to consumption in order to develop evidence based food safety policies. In developing these policies, risk managers should be able to attribute cases of foodborne illnesses to the food vehicle(s) or other sources responsible for illness (59) and this activity is referred to as food attribution when food items are involved. Depending on the availability of resources and data, different food attribution approaches can be employed, i.e. analysis of outbreak data, case-control studies, microbial subtyping and source tracking methods, expert elicitation, risk assessments (59). Due to the resource demanding nature of food attribution, most studies so far have only been conducted in high income countries viz. Netherlands (60), United states (6163), UK (64), New Zealand (65), Scandinavian countries (66-68). Before conducting a food attribution exercise, it is important that food items are put in categories agreeable to the stakeholders (risk managers, researchers and consumers) (59). In line with the topic of this study, discussions on food attribution focused on the illness due to consumption of vegetables.

In the United States, Painter et al. (63) conducted a food attribution study from foodborne outbreak data from 1998 to 2008 for 17 food commodities (Fig.1.4) and reported that leafy vegetables, dairy products and poultry products caused the highest number of foodborne illnesses, hospitalizations and deaths respectively. In the Netherlands, vegetables were ranked $4^{\text {th }}$ among 11 food items by expert elicitation in 2008 for transmission of 17 common foodborne pathogens (69) while globally, vegetables were estimated to be responsible for 60 to $80 \%$ of illness from foodborne parasites in 2015 (70). From these food attribution studies, it is evident that vegetables are reported among the major food items associated with foodborne illnesses 
and indeed studies on reported foodborne outbreaks and on the prevalence of foodborne pathogens associated with vegetables, support this ranking.

From studies on foodborne outbreaks, viz. in the United States (63) and the European Union (71), the number of reported foodborne illnesses linked to fresh vegetables has been increasing. In Table 1.1, examples of selected outbreaks linked to fresh vegetables for the last decade are presented. Most notably is the German incident in 2011 in which a total of 4075 reported cases, including 54 deaths were registered due to enterohemorrhagic E. coli O104:H4 with sprouts being implicated as the food vehicle (72). Occurrence and pathogenic significance of these pathogens in vegetable/produce-associated outbreaks seem to vary with time and location. Sivapalasingam et al. (73) reported that in 2004 in the US, $60 \%$ of the produce-associated outbreaks were caused by bacterial pathogens, of which $48 \%$ were caused by Salmonella spp. Callejon et al. in 2015 (71), highlighted that norovirus was the main pathogen responsible for $59 \%$ and $53 \%$ of these outbreaks in the United States and the European Union respectively, followed by Salmonella (18\% in the United States and 20\% in European Union). It should be noted that most of the outbreaks reported in Table 1.1. are from developed countries. Likely reasons for this overrepresentation are the developed systems and availability of resources to detect and investigate outbreaks up to the level of identifying the food source.

There is an increasing number of studies in which foodborne pathogens have been isolated from fresh vegetables (74-76). In Table. 1.2, the prevalence of foodborne pathogens in fresh vegetables from selected studies around the globe is summarised. Generally, the range of pathogenic microorganisms associated with fresh produce can be classified into three categories: bacteria such as Salmonella spp., pathogenic E. coli, L. monocytogenes), viruses like Hepatitis A, norovirus, and parasites viz. Entamoeba histolytica, Cryptosporidium parvum, Cyclospora cayatenensis. 


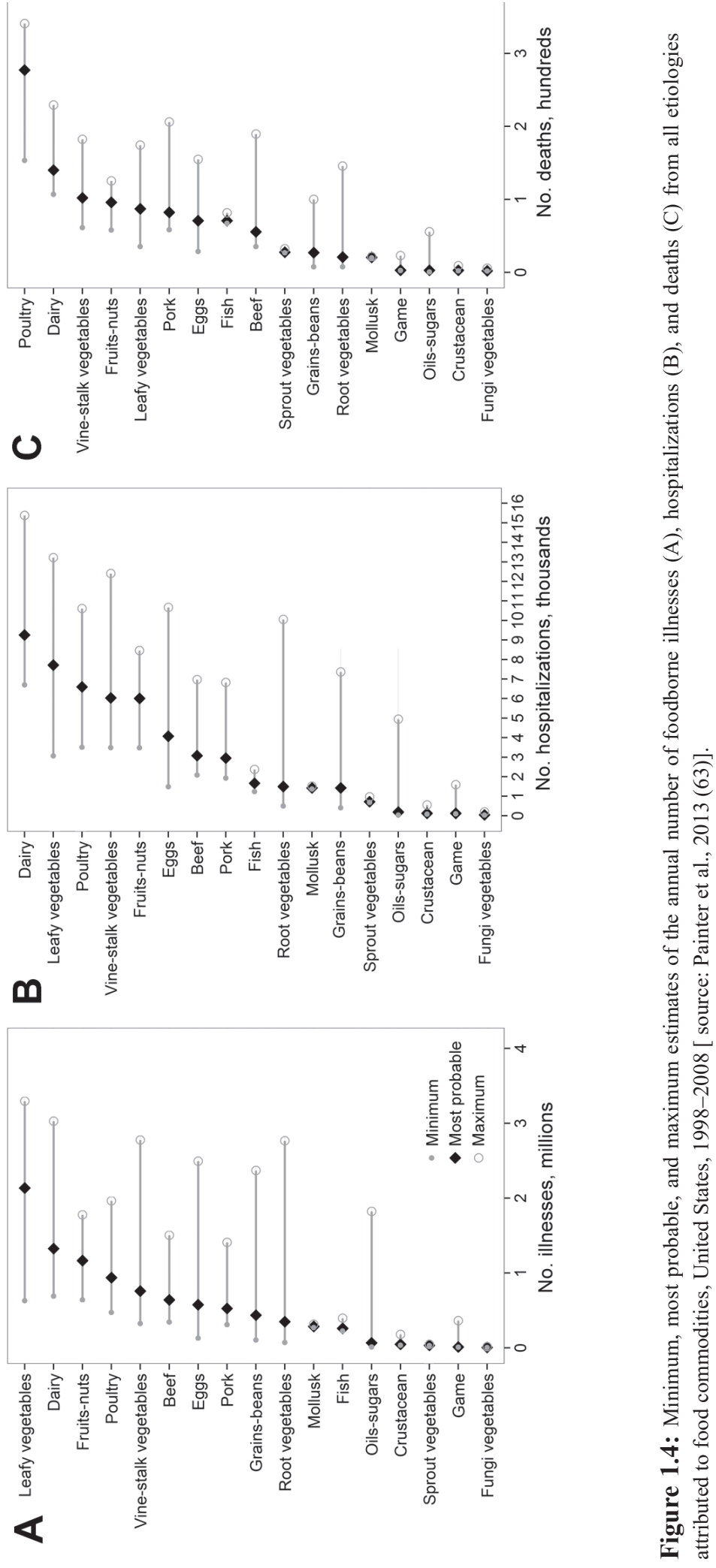




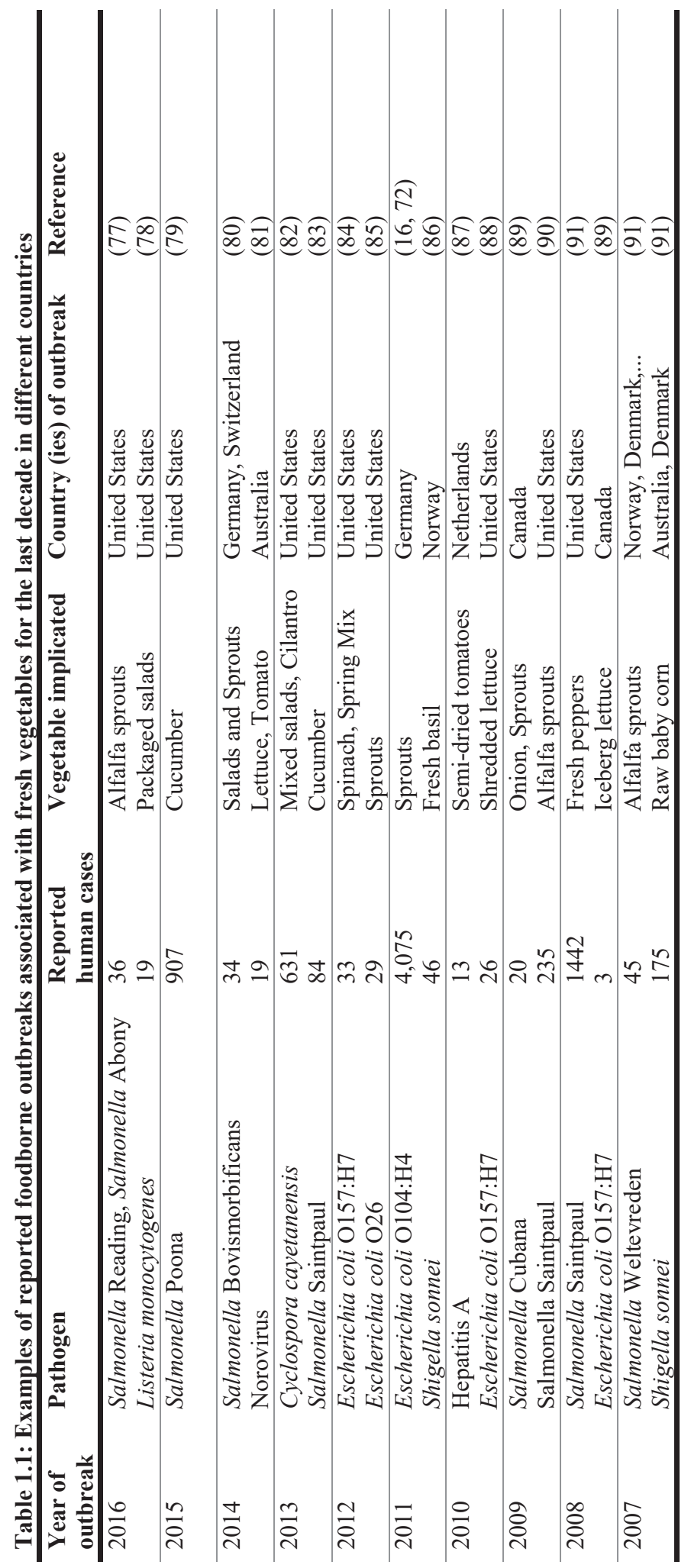




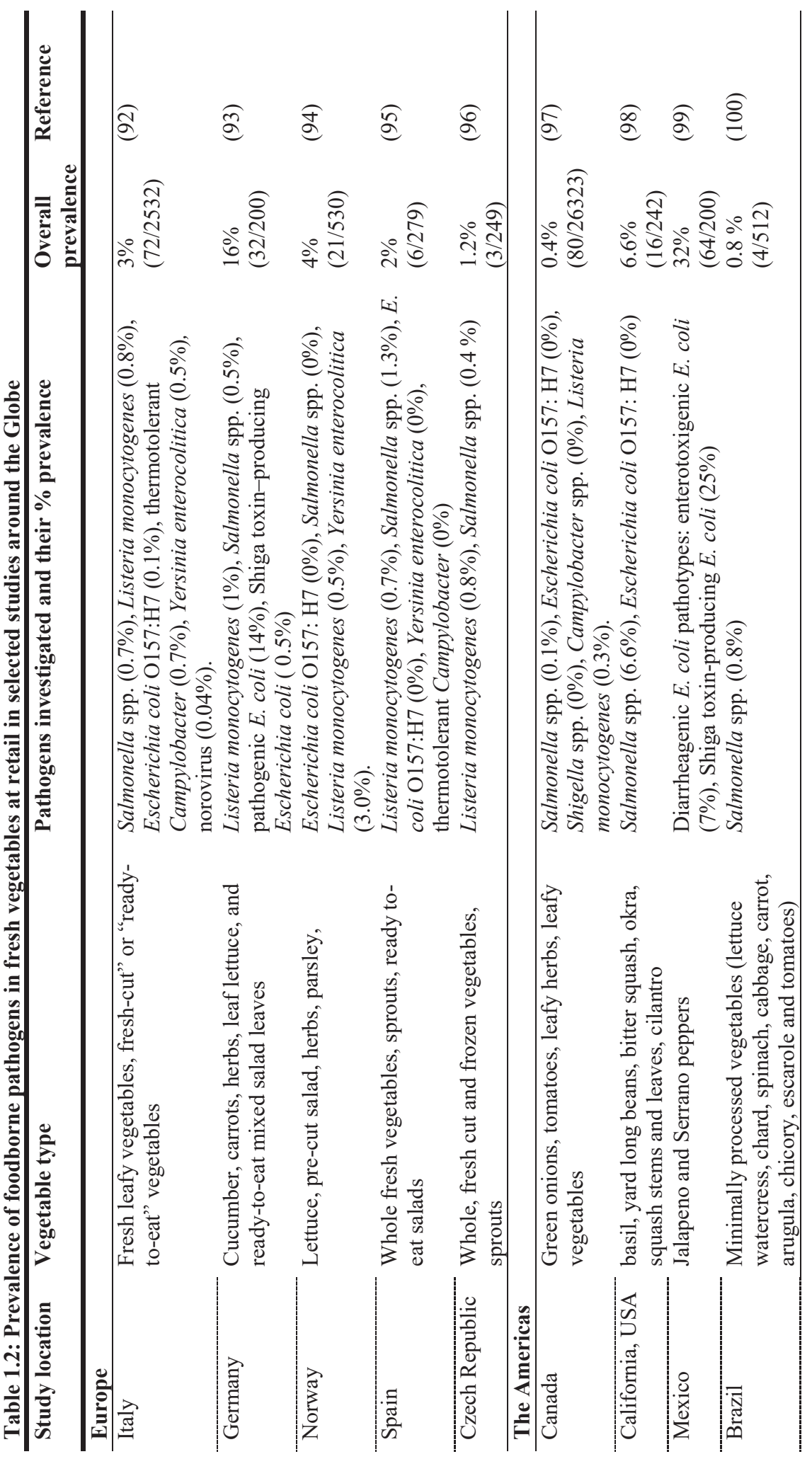




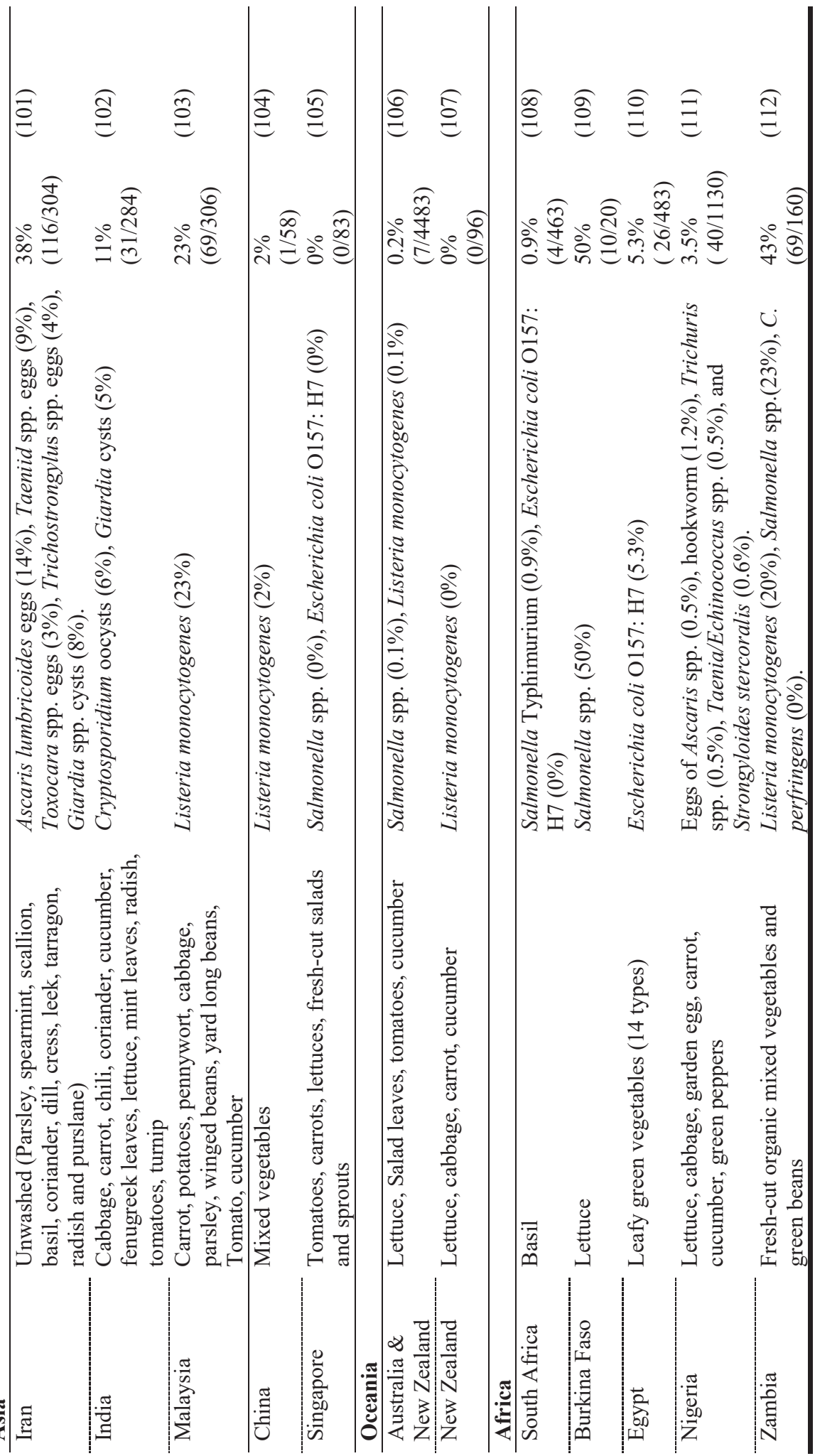




\section{Consumption trends for fresh vegetables}

A diet rich in vegetables has been associated with health benefits like reduced risk to cancers and cardiovascular diseases (113). Consumption of vegetables is increasing year by year (114116) and reports indicate that a large portion of these vegetables are consumed raw (117). Internationally, the WHO has recommended consumption of $400 \mathrm{~g}$ of fruits and vegetables/ day (118) while nationally in Rwanda, the Ministerial Order (No. 002/2008) of the Rwandan Ministry of Agriculture and Animal Resources stipulates that every family in Rwanda must have a backyard garden of vegetables, termed as "akarima k'igikoni". Remarkable growth in trade of fresh vegetables in globalized market settings has been registered (119) and in most countries, agricultural practices to increase the production levels of vegetables have been adopted $(120,121)$.

\section{Pathways for microbial contamination of fresh vegetables along the supply chain}

The prevalence of foodborne pathogens in fresh vegetables varies from one locality to another depending on the conditions and handling practices along the supply chain. Figure 1.5. illustrates the mechanisms and conditions by which fresh vegetables and other foods can become contaminated with pathogenic microorganisms and serve as vehicles of human disease. Food handlers, regulators public health officials and other stake holders have a challenging task to prevent and control microbial contamination of agricultural commodities like fruits and vegetables that are eaten raw (122). This is because pathogens such as L. monocytogenes are naturally present in soil, and their presence on fresh vegetables is not rare (123). Other pathogens like Salmonella spp., C. jejuni, parasites like E. histolytica, and viruses (norovirus) can contaminate fresh vegetables through vehicles such as raw or improperly composted manure, irrigation water containing untreated sewage, or contaminated wash water $(123,124)$. Other probable sources of contamination include contact with domestic and wild animals. Unpasteurized products of animal origin offers another avenue through which pathogens can access vegetables due to cross contamination during food preparation (123). Surfaces, including human hands, which come in contact with whole or cut vegetables, may also become potential points of contamination throughout the "farm to fork" continuum (123).

Generally, to effectively control contamination of vegetables at farm level and along the entire supply chain, it is important to understand the complex interactions between human pathogens and plant structures. Figure 1.6 shows how bacteria can attach and hide in vegetable leaf structures. Studies have highlighted that pathogens can not only attach on the outer surface of plants but can also intrude the inside of fresh vegetables (125-127). Pathogens on the surface of the fresh vegetables can be reduced or eliminated if washed with safe water but on the other hand, transfer of these pathogens in the whole batch can also be aided $(128,129)$. Occurrence of pathogens in the internal parts of vegetables may also render the washing process ineffective (127). Overall, the adhesion of pathogens to surfaces and the internalization of pathogens limits 
the effect of conventional washing and chemical sanitizing methods in preventing transmission from contaminated fresh vegetables (130).

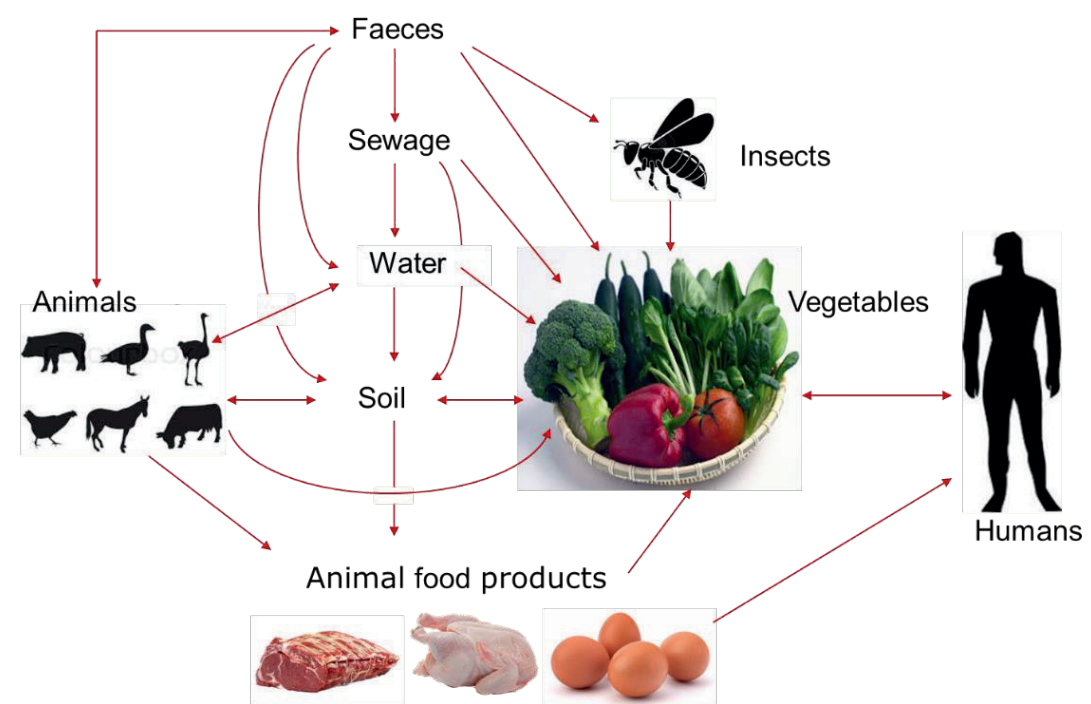

Figure 1.5: Mechanisms by which fresh vegetables and other foods can become contaminated with pathogenic microorganisms and serve as vehicles of human disease. [modified from Beuchat 1996 (131)].

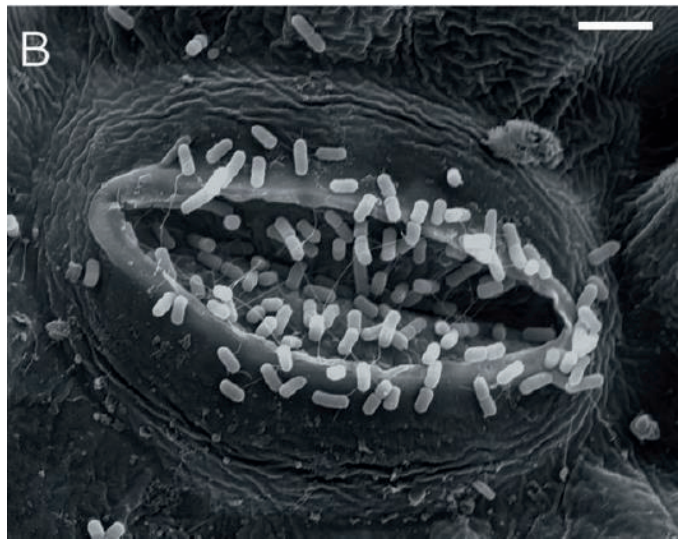

Figure 1.6: Scanning electron micrograph showing binding of pathogenic $E$. coli to exterior and interior of vegetable leaf structure (stomatae).[ source: Berger et al. 2010 (132)].

Overall, it should be noted that if human pathogens are introduced to fresh vegetables along the supply chain, they have the potential to survive and they are also difficult to eliminate prior to consumption. The presence of foodborne pathogens in fresh vegetables is of great public health concern if these vegetables are to be consumed raw. Fortunately, the microbial safety of fresh vegetables is today not a "terra incognita", a lot is now known thanks to the indicative studies that have been conducted in different countries like those in the EU (Veg-I-Trade project) (133135), the USA (123, 136-139), Canada (27, 76, 89, 97, 140), and the Netherlands (74, 141-143), 
to mention a few. Indicatives studies in these countries have been conducted to: (i) identify microbial populations in different farming systems in order to detect emerging and re-emerging pathogens; (ii) better understand the interactions between host, pathogen and environment that contribute to inter-species jumps and adaptation in a new host; (iii) generate more precise information on the infection and transmission behaviour of pathogens under different farming systems and human populations to estimate the burden of disease; (iv) understand the conditions, motives and priorities of farmers and other stakeholders so as to develop interventions that can lead to community based disease control (144). In Rwanda so far, no microbial safety indicative study has been conducted along the vegetable supply chain.

\section{Study objective and outline}

In this study we aim to conduct an indicative study by estimating the burden of foodborne infectious diseases, investigating the current microbial safety status and performing a quantitative microbial risk assessment for fresh vegetables in Rwanda, identifying critical activities and opportunities for improvement, identifying specific food safety roles of the different multidisciplinary stakeholders in the context of the supply chain in Rwanda. Figure 1.7. shows the conceptual approach of this study.

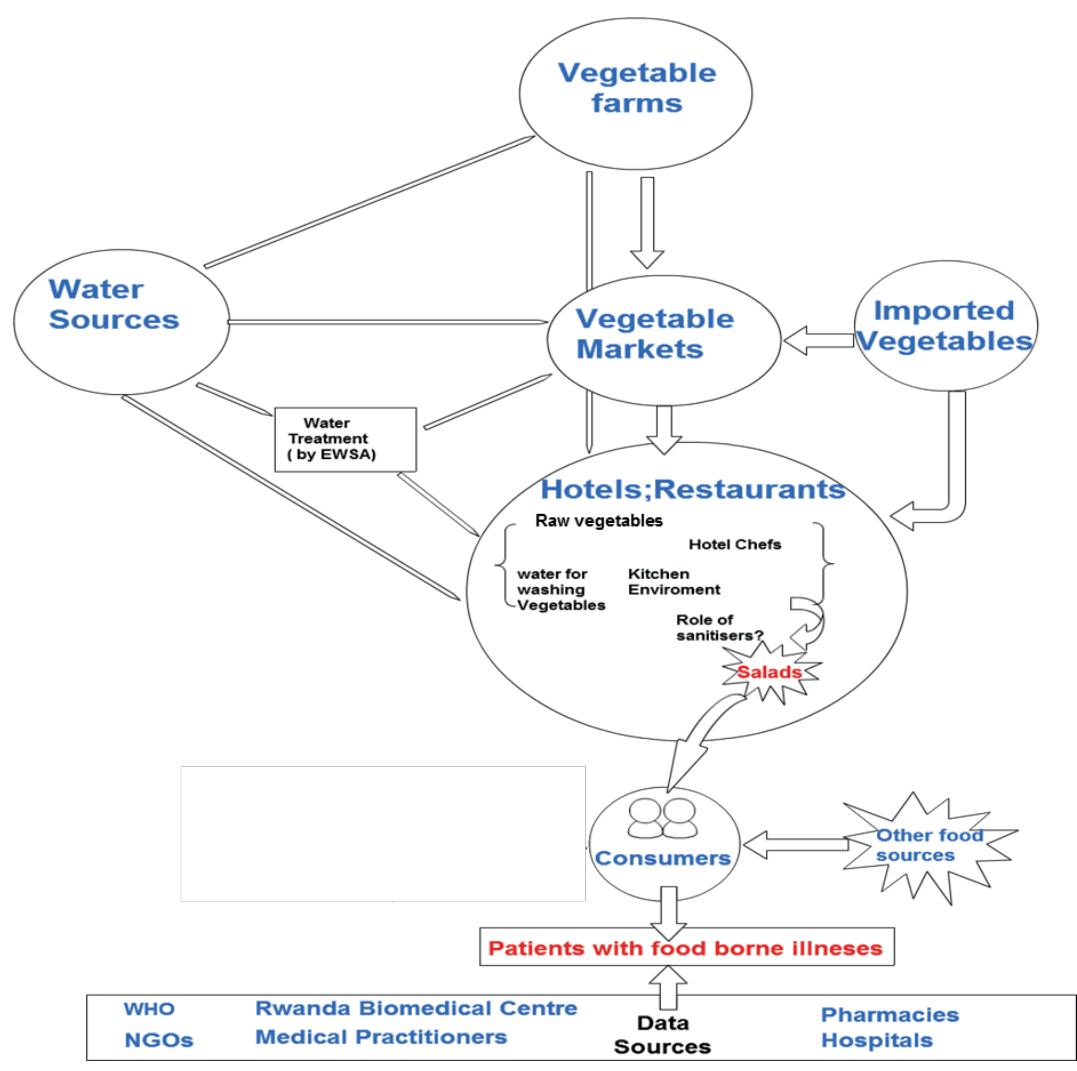

Figure 1.7: Schematic representation of the conceptual approach used in this study. 
This thesis is made up of six chapters. In this chapter (Chapter 1), the background and rationale for the study are presented. Chapter 2 provides the estimates of the burden of food related illnesses in DALYs and also discusses a methodology that can be adopted in resource scarce settings. In chapter $\mathbf{3}$, the levels of indicator microorganisms in fresh vegetable along the supply chain are studied from farms, markets to food service establishments (hotels, restaurants and bars) to obtain an insight into the effect of the current handling practices on the microbial levels and identify areas of priority for interventions. In chapter 4 , the prevalence of foodborne pathogens in farms vegetables and agricultural water is presented in conjunction with their risk exposure factors. Chapter $\mathbf{5}$ discusses the reduction of microbial counts during kitchen scale washing and sanitization of salad vegetables from the food service establishments in Rwanda and laboratory trials to screen the applied vegetable chemical sanitizers and also identify the most effective washing technique(s). Finally in Chapter 6, we present results of a "farm to fork" microbial risk assessment based on the WHO/FAO CODEX alimentarius approach, discuss the study findings in general, make conclusions and recommendations, and present future perspectives. Overall, the findings and discussions in this thesis provide more insight for risk managers in countries especially those at an infant stage of operating an integrated food chain system, a system that is recommended by the WHO (1) and FAO (144) as indispensable in order to detect, control and prevent foodborne illness. 


\section{References}

1. The World Health Organization of the United Nations (WHO). 2012. Manual for integrated foodborne disease surveillence in the WHO Africa Region. Available at:

http://apps.who.int/iris/bitstream/10665/170262/1/foodborne-disease-manual.pdf. $\quad$ Accessed $\quad 02^{\text {nd }}$ September 2016.

2. Food and Drug Administration (FDA) of the United States. 2012. Bad bug book, foodborne pathogenic microorganisms and natural toxins. second edition. Available at:

https://www.fda.gov/downloads/food/foodsafety/foodborneillness/foodborneillnessfoodbornepathoge nsnaturaltoxins/badbugbook/ucm297627.pdf. Accessed $19^{\text {th }}$ May 2017.

3. Lasky T. 2002. Foodborne illness - Old problem, new relevance. Epidemiology 13:593-598.

4. Mughini-Gras L, Schaapveld M, Kramers J, Mooij S, Neefjes-Borst EA, van Pelt W, Neefjes J. 2018. Increased colon cancer risk after severe Salmonella infection. PloS one 13:e0189721.

5. Thomas MK, Murray R, Flockhart L, Pintar K, Pollari F, Fazil A, Nesbitt A, Marshall B. 2013. Estimates of the burden of foodborne illness in Canada for 30 specified pathogens and unspecified agents, Circa 2006. Foodborne Pathogens \& Disease 10:639-648.

6. Michigan State University Extension. 2014. History of food safety in the U.S. - part 1. Available at: http://msue.anr.msu.edu/news/history_of_food_safety_in_the_us_part_1. Accessed $02^{\text {nd }}$ June 2017.

7. Food Safety News. 2011. Bugs through the ages: the foodborne illness fight. Available at: http://www.foodsafetynews.com/2011/01/fbi-through-the-ages/\#.VBrpSxaa8tE. Accessed $08^{\text {th }}$ July 2017.

8. Roberts CA. 2001. The food safety information handbook. Greenwood Publishing Group, Westport, CT, United States, pp 25-28.

9. Havelaar et al. 2015. World Health Organization global estimates and regional comparisons of the burden of foodborne disease in 2010. PLoS Medicine 12:e1001923.

10. Scott E. 2003. Food safety and foodborne disease in the 21st Century. Canadian Journal of Infectious Diseases \& Medical Microbiology 14:277-280.

11. Tauxe RV, Doyle MP, Kuchenmüller T, Schlundt J, Stein CE. 2010. Evolving public health approaches to the global challenge of foodborne infections. International Journal of Food Microbiology 139:S16-S28.

12. Kasowski EJ, Gackstetter GD, Sharp TW. 2002. Foodborne illness: new developments concerning an old problem. Current Gastroenterology Reports 4:308-318.

13. Bavishi C, Dupont H. 2011. Systematic review: the use of proton pump inhibitors and increased susceptibility to enteric infection. Alimentary Pharmacology \& Therapeutics 34:1269-1281.

14. Cobb CA, Curtis GD, Bansi DS, Slade E, Mehal W, Mitchell RG, Chapman RW. 1996. Increased prevalence of Listeria monocytogenes in the faeces of patients receiving long-term H2-antagonists. European Journal of Gastroenterology \& Hepatology 8:1071-1074.

15. Newell DG, Koopmans M, Verhoef L, Duizer E, Aidara-Kane A, Sprong H, Opsteegh M, Langelaar M, Threfall J, Scheutz F, der Giessen JV, Kruse H. 2010. Food-borne diseases - The 
challenges of 20years ago still persist while new ones continue to emerge. International Journal of Food Microbiology 139:S3-S15.

16. Rasko DA, Webster DR, Sahl JW, Bashir A, Boisen N, Scheutz F, Paxinos EE, Sebra R, Chin CS, Iliopoulos D, Klammer A, Peluso P, Lee L, Kislyuk AO, Bullard J, Kasarskis A, Wang S, Eid J, Rank D, Redman JC, Steyert SR, Frimodt-Møller J, Struve C, Petersen AM, Krogfelt KA, Nataro JP, Schadt EE, Waldor MK. 2011. Origins of the E. coli strain causing an outbreak of hemolytic-uremic syndrome in Germany. New England Journal of Medicine 365:709-717.

17. Centers for Disease Control and Prevention (CDC). 2012. Global water, sanitation, \& hygiene (WASH). Pathways to diarrhea. Available at: http://www.cdc.gov/healthywater/global/diarrheapathways.html, Accessed $17^{\text {th }}$ September 2016.

18. Li B, Vellidis G, Liu H, Jay-Russell M, Zhao S, Hu Z, Wright A, Elkins CA. 2014. Diversity and antimicrobial resistance of Salmonella enterica isolates from surface water in southeastern United States. Applied \& Environmental Microbiology 80:6355-6365.

19. Wang G, Qian W, Zhang X, Wang H, Ye K, Bai Y, Zhou G. 2015. Prevalence, genetic diversity and antimicrobial resistance of Listeria monocytogenes isolated from ready-to-eat meat products in Nanjing, China. Food Control 50:202-208.

20. Yang X, Huang J, Wu Q, Zhang J, Liu S, Guo W, Cai S, Yu S. 2015. Prevalence, antimicrobial resistance and genetic diversity of Salmonella isolated from retail ready-to-eat foods in China. Food Control 60:50-56.

21. Zhang S, Wu Q, Zhang J, Lai Z, Zhu X. 2016. Prevalence, genetic diversity, and antibiotic resistance of enterotoxigenic Escherichia coli in retail ready-to-eat foods in China. Food Control 68:236-243.

22. Lamprecht C, Romanis M, Huisamen N, Carinus A, Schoeman N, Sigge GO, Britz TJ. 2014. Escherichia coli with virulence factors and multidrug resistance in the Plankenburg River. South African Journal of Science, 110: 01-06.

23. Olaniran AO, Naicker K, Pillay B. 2009. Antibiotic resistance profiles of Escherichia coli isolates from river sources in Durban, South Africa. World Journal of Microbiology \& Biotechnology 25:17431749.

24. Akinyemi KO, Iwalokun BA, Foli F, Oshodi K, Coker AO. 2011. Prevalence of multiple drug resistance and screening of enterotoxin (stn) gene in Salmonella enterica serovars from water sources in Lagos, Nigeria. Public Health 125: 65-71.

25. Ben Said L, Klibi N, Dziri R, Borgo F, Boudabous A, Ben Slama K, Torres C. 2016. Prevalence, antimicrobial resistance and genetic lineages of Enterococcus spp. from vegetable food, soil and irrigation water in farm environments in Tunisia Journal of the Science of Food \& Agriculture 96: $1627-1633$.

26. Jernberg C, Hjertqvist M, Sundborger C, Castro E, Löfdahl M, Pääjärvi A, Sundqvist L, Löf E. 2015. Outbreak of Salmonella Enteritidis phage type 13a infection in Sweden linked to imported driedvegetable spice mixes, December 2014 to July 2015. Eurosurveillance 20: 21194.

27. Allen KJ, Kovacevic J, Cancarevic A, Wood J, Xu J, Gill B, Allen JK, Mesak LR. 2013. Microbiological survey of imported produce available at retail across Canada. International Journal of Food Microbiology 162:135-142. 
28. Raguenaud ME, Le Hello S, Salah S, Weill FX, Brisabois A, Delmas G, Germonneau P. 2012. Epidemiological and microbiological investigation of a large outbreak of monophasic Salmonella Typhimurium 4,5,12: i: - in schools associated with imported beef in Poitiers, France, October 2010. Euro surveillance 17:20289.

29. Sharapov UM, Wendel AM, Davis JP, Keene WE, Farrar J, Sodha S, Hyytia-Trees E, Leeper M, Gerner-Smidt P, Griffin PM, Braden C. 2016. Multistate outbreak of Escherichia coli O157:H7 infections associated with consumption of fresh spinach: United States, 2006. Journal of Food Protection 79:2024-2030.

30. McCollum JT, Cronquist AB, Silk BJ, Jackson KA, O'Connor KA, Cosgrove S, Gossack JP, Parachini SS, Jain NS, Ettestad P, Ibraheem M, Cantu V, Joshi M, DuVernoy T, Fogg Jr NW, Gorny JR, Mogen KM, Spires C, Teitell P, Joseph LA, Tarr CL, Imanishi M, Neil KP, Tauxe RV, Mahon BE. 2013. Multistate outbreak of listeriosis associated with cantaloupe. New England Journal of Medicine 369:944-953.

31. Neil KP, Biggerstaff G, MacDonald JK, Trees E, Medus C, Musser KA, Stroika SG, Zink D, Sotir MJ. 2012. A novel vehicle for transmission of Escherichia coli O157:H7 to humans: Multistate outbreak of $E$. coli $\mathrm{O} 157: \mathrm{H} 7$ infections associated with consumption of ready-to-bake commercial prepackaged cookie dough-United States, 2009. Clinical Infectious Diseases 54:511-518.

32. Maritschnik S, Kanitz EE, Simons E, Höhne M, Neumann H, Allerberger F, Schmid D, Lederer I. 2013. A food handler-associated, foodborne norovirus GII.4 Sydney 2012-outbreak following a wedding dinner, Austria, October 2012. Food \& Environmental Virology 5:220-225.

33. Nicolay N, McDermott R, Kelly M, Gorby M, Prendergast T, Tuite G, Coughlan S, McKeown P, Sayers G. 2011. Potential role of asymptomatic kitchen food handlers during a food-borne outbreak of norovirus infection, Dublin, Ireland, March 2009. Eurosurveillance 16:3.

34. Angelillo IF, Viggiani NMA, Rizzo L, Bianco A. 2000. Food handlers and foodborne diseases: Knowledge, attitudes, and reported behavior in Italy. Journal of Food Protection 63:381-385.

35. Lo SV, Connolly AM, Palmer SR, Wright D, Thomas PD, Joynson D. 1994. The role of the presymptomatic food handler in a common source outbreak of food-borne SRSV gastroenteritis in a group of hospitals. Epidemiology \& Infection 113:513-521.

36. Figgatt M, Mergen K, Kimelstein D, Mahoney DM, Newman A, Nicholas D, Ricupero K, Cafiero T, Corry D, Ade J, Kurpiel P, Madison-Antenucci S, Anand M. 2017. Giardiasis outbreak associated with asymptomatic food handlers in New York State, 2015. Journal of Food Protection $80: 837-841$.

37. Abdel-Dayem M, Al Zou'bi R, Hani RB, Amr ZS. 2013. Microbiological and parasitological investigation among food handlers in hotels in the Dead Sea area, Jordan Journal of Microbiology, Immunology \& Infection 47: 377-380.

38. Gebreyesus A, Adane K, Negash L, Asmelash T, Belay S, Alemu M, Saravanan M. 2014. Prevalence of Salmonella Typhi and intestinal parasites among food handlers in Mekelle University student cafeteria, Mekelle, Ethiopia. Food Control 44:45-48.

39. Nsubuga P, White ME, Thacker SB, Anderson MA, Blount SB, Broome CV, Chiller TM, Espitia V, Imtiaz R, Sosin D. 2006. Public health surveillance: a tool for targeting and monitoring interventions. Disease Control Priorities in Developing Countries 2:997-1018. 
40. Khera A. 2016. Surveillance systems for foodborne illnesses. Food Safety in the $21^{\text {st }}$ Century: Public Health Perspective. Elsevier Inc. Chapter 4, pp 41-51.

41. The World Health Organization (WHO) of the United Nations. 2017. Global infectious disease surveillance. Available at: http://www.who.int/mediacentre/factsheets/fs200/en/. Accessed $25^{\text {th }}$ July 2017.

42. Rwanda Biomedical Center. 2016. Epidemic surveillance and response (ESR) division. Available at: http://www.rbc.gov.rw/index.php?id=348. Accessed $5^{\text {th }}$ August 2017.

43. European Centre for Disease Prevention and Control (ECDC). 2017. Surveillance and disease data. Available at: https://ecdc.europa.eu/en/surveillance-and-disease-data. Accessed $5^{\text {th }}$ August 2017.

44. Centres for Disease Control and Prevention of the United States (CDC). 2017. Surveillance and disease data. Available at: https://www.cdc.gov/. Accessed 5 ${ }^{\text {th }}$ August 2017.

45. Nkengasong JN, Maiyegun O, Moeti M. 2017. Establishing the Africa Centres for Disease Control and Prevention: responding to Africa's health threats. The Lancet Global Health 5:e246-e247.

46. Centres for Disease Control and Prevention of the United States (CDC). 2016. Modernizing our public health surveillance systems. Available at: https://www.cdc.gov/ophss/csels/dhis/blogs/yoon201611.html. Accessed 5 ${ }^{\text {th }}$ August 2017.

47. The World Health Organization (WHO) of the United Nations. 2006. Communicable disease surveillance and response systems: Guide to monitoring and evaluating. Available at: http://www.who.int/csr/resources/publications/surveillance/WHO_CDS_EPR_LYO_2006_2.pdf.

Accessed $28^{\text {th }}$ July 2017.

48. The World Health Organization (WHO) of the United Nations. 2017. Types of Surveillance. Available at:

http://www.who.int/immunization/monitoring_surveillance/burden/vpd/surveillance type/en/. Accessed $5^{\text {th }}$ August 2017.

49. Murray C, Salomon J, Mathers C. 2002. A critical examination of summary measures of population health. In Murray C, Salomon J, Mathers C, Lopez A (ed.), Summary Measures of Population Health. WHO Press, Geneva.

50. Council NR. 2011. Accounting for health and health care: approaches to measuring the sources and costs of their improvement. National Academies Press.

51. Torgerson PR, Devleesschauwer B, Praet N, Speybroeck N, Willingham AL, Kasuga F, Rokni MB, Zhou XN, Fèvre EM, Sripa B, Gargouri N, Fürst T, Budke CM, Carabin H, Kirk MD, Angulo FJ, Havelaar A, de Silva N. 2015. World Health Organization estimates of the global and regional disease burden of 11 foodborne parasitic diseases, 2010: A Data synthesis. PLoS Medicine 12:e1001920.

52. Gkogka E, Reij MW, Havelaar AH, Zwietering MH, Gorris LGM. 2011. Risk-based estimate of effect of foodborne diseases on public health, Greece. Emerging Infectious Diseases 17:1581-1590.

53. Havelaar AH, Kemmeren JM, Kortbeek LM. 2007. Disease burden of congenital toxoplasmosis. Clinical Infectious Diseases : an Official Publication of the Infectious Diseases Society of America 44:1467-1474. 
54. Murray et al. 2012. Disability-adjusted life years (DALYs) for 291 diseases and injuries in 21 regions, 1990-2010: a systematic analysis for the global burden of disease study 2010. The Lancet 380:21972223.

55. Molla M, Madans JH, Wagener DK, Crimmins EM. 2003. Summary measures of population health: Report of findings on methodologic and data issues. National Center for Health Services, Hyattsville, Maryland.

56. Gold MR, Stevenson D, Fryback DG. 2002. HALYs and QALYs and DALYs, Oh My: similarities and differences in summary measures of population Health. Annual Review of Public Health 23:115134.

57. Devleesschauwer B, Haagsma JA, Angulo FJ, Bellinger DC, Cole D, Döpfer D, Fazil A, Fèvre EM, Gibb HJ, Hald T. 2015. Methodological framework for World Health Organization estimates of the global burden of foodborne disease. PLoS One 10:e0142498.

58. Devleesschauwer B, Havelaar AH, Maertens de Noordhout C, Haagsma JA, Praet N, Dorny P, Duchateau L, Torgerson PR, Van Oyen H, Speybroeck N. 2014. DALY calculation in practice: a stepwise approach. International Journal of Public Health 59: 571-574.

59. Batz MB, Doyle MP, Morris Jr JG, Painter J, Singh R, Tauxe RV, Taylor MR, Wong DMALF. 2005. Attributing illness to food. Emerging Infectious Diseases 11: 993-999.

60. Mangen M-JJ, Bouwknegt M, Friesema IHM, Haagsma JA, Kortbeek LM, Tariq L, Wilson M, van Pelt W, Havelaar AH. 2015. Cost-of-illness and disease burden of food-related pathogens in the Netherlands, 2011. International Journal of Food Microbiology 196:84-93.

61. Herman KM, Hall AJ, Gould LH. 2015. Outbreaks attributed to fresh leafy vegetables, United States, 1973-2012. Epidemiology \& Infection 143:3011-3021.

62. Beatty ME, Shevick G, Shupe-Ricksecker K, Bannister E, Tulu A, Lancaster K, Alexander N, Zellner DE, Lyszkowicz E, Braden CR. 2009. Large Salmonella Enteritidis outbreak with prolonged transmission attributed to an infected food handler, Texas, 2002. Epidemiology \& Infection 137:417427.

63. Painter JA, Hoekstra RM, Ayers T, Tauxe RV, Braden CR, Angulo FJ, Griffin PM. 2013. Attribution of foodborne illnesses, hospitalizations, and deaths to food commodities by using outbreak data, United States, 1998-2008. Emerging Infectious Diseases 19:407-415.

64. Little CL, Pires SM, Gillespie IA, Grant K, Nichols GL. 2010. Attribution of human Listeria monocytogenes infections in England and Wales to ready-to-eat food sources placed on the market: Adaptation of the Hald Salmonella source attribution model. Foodborne Pathogens \& Disease 7:749756.

65. King N, Lake R, Campbell D. 2011. Source attribution of nontyphoid salmonellosis in New Zealand using outbreak surveillance data. Journal of Food Protection 74:438-445.

66. Ranta J, Matjushin D, Virtanen T, Kuusi M, Viljugrein H, Hofshagen M, Hakkinen M. 2011. Bayesian temporal source attribution of foodborne zoonoses: Campylobacter in Finland and Norway. Risk Analysis 31:1156-1171. 
67. Wahlström H, Andersson Y, Plym-Forshell L, Pires SM. 2011. Source attribution of human Salmonella cases in Sweden. Epidemiology \& Infection 139:1246-1253.

68. Boysen L, Rosenquist H, Larsson JT, Nielsen EM, Sorensen G, Nordentoft S, Hald T. 2014. Source attribution of human campylobacteriosis in Denmark. Epidemiology \& Infection 142:15991608 .

69. Havelaar AH, Galindo AV, Kurowicka D, Cooke RM. 2008. Attribution of foodborne pathogens using structured expert elicitation. Foodborne Pathogens \& Disease 5:649-659.

70. Hoffmann S, Devleesschauwer B, Aspinall W, Cooke R, Corrigan T, Havelaar A, Angulo F, Gibb H, Kirk M, Lake R. 2017. Attribution of global foodborne disease to specific foods: Findings from a World Health Organization structured expert elicitation. PLoS One 12:e0183641.

71. Callejon RM, Rodriguez-Naranjo MI, Ubeda C, Hornedo-Ortega R, Garcia-Parrilla MC, Troncoso AM. 2015. Reported foodborne outbreaks due to fresh produce in the United States and European Union: trends and causes. Foodborne Pathogens \& Disease 12:32-38.

72. Frank C, Werber D, Cramer JP, Askar M, Faber M, an der Heiden M, Bernard H, Fruth A, Prager R, Spode A. 2011. Epidemic profile of shiga-toxin-producing Escherichia coli O104:H4 outbreak in Germany. New England Journal of Medicine 365:1771-1780.

73. Sivapalasingam S, Friedman CR, Cohen L, Tauxe RV. 2004. Fresh produce: a growing cause of outbreaks of foodborne illness in the United States, 1973 through 1997. Journal of Food Protection 67:2342-2353.

74. Wijnands LM, Delfgou-van Asch EHM, Beerepoot-Mensink ME, van der Meij-Florijn A, FitzJames I, van Leusden FM, Pielaat A. 2014. Prevalence and concentration of bacterial pathogens in raw produce and minimally processed packaged salads produced in and for The Netherlands. Journal of Food Protection 77:388-394.

75. Loutreul J, Cazeaux C, Levert D, Nicolas A, Vautier S, Le Sauvage AL, Perelle S, Morin T. 2014. Prevalence of human noroviruses in frozen marketed shellfish, red fruits and fresh vegetables. Food \& Environmental Virology 6:157-168.

76. Bohaychuk V, Bradbury R, Dimock R, Fehr M, Gensler G, King R, Rieve R, Barrios PR. 2009. A microbiological survey of selected Alberta-grown fresh produce from farmers' markets in Alberta, Canada. Journal of Food Protection 72:415-420.

77. Centres for Disease Control and Prevention of the United States (CDC). 2016. Multistate outbreak of Salmonella Reading and Salmonella Abony infections linked to alfalfa sprouts (Final Update). Available at: https://www.cdc.gov/salmonella/reading-08-16/index.html. Accessed $27^{\text {th }}$ November 2017.

78. Centres for Disease Control and Prevention of the United States (CDC). 2016. Multistate outbreak of listeriosis linked to packaged salads produced at Springfield, Ohio Dole processing facility (Final Update). Available at: https://www.cdc.gov/listeria/outbreaks/bagged-salads-01-16/index.html. Accessed $27^{\text {th }}$ November 2017.

79. Centres for Disease Control and Prevention of the United States (CDC). 2015. Multistate outbreak of Salmonella Poona infections linked to imported cucumbers (Final Update). Available at: https://www.cdc.gov/salmonella/poona-09-15/index.html. Accessed 27 $7^{\text {th }}$ November 2017. 
80. Knoblauch AM, Bratschi MW, Zuske MK, Althaus D, Stephan R, Hächler H, Baumgartner A, Prager R, Rabsch W, Altpeter E, Jost M, Mäusezahl M, Hatz C, Kiefer S. 2015. Cross-border outbreak of Salmonella Bovismorbificans: Multiple approaches for an outbreak investigation in Germany and Switzerland. Swiss Medical Weekly 145.

81. The Australian Government Department of Health Network for Surveillance of Foodborne Diseases (OZFoodNet). 2017. Quarterly report, 1 October to 31 December 2014. Available at: http://health.gov.au/internet/main/publishing.nsf/Content/cda-cdi4101k.htm. Accessed $29^{\text {th }}$ November 2017.

82. Food and Drug Administration (FDA) of the United States. 2016. FDA Investigates 2013 multistate outbreak of Cyclosporiasis. Available at: https://www.fda.gov/Food/RecallsOutbreaksEmergencies/Outbreaks/ucm361637.htm\#updates. Accessed $29^{\text {th }}$ November 2017.

83. Centres for Disease Control and Prevention of the United States (CDC). 2013. Multistate outbreak of Salmonella Saintpaul infections linked to imported cucumbers (Final Update). Available at: https://www.cdc.gov/salmonella/saintpaul-04-13/index.html. Accessed 27 $7^{\text {th }}$ November 2017.

84. Centres for Disease Control and Prevention of the United States (CDC). 2012. Multistate outbreak of shiga toxin-producing Escherichia coli O157:H7 infections linked to organic spinach and spring mix blend (Final Update). Available at: https:/www.cdc.gov/ecoli/2012/O157H7-11-12/index.html. Accessed $27^{\text {th }}$ November 2017.

85. Centres for Disease Control and Prevention of the United States (CDC). 2012. Multistate outbreak of shiga toxin-producing Escherichia coli O26 infections linked to raw clover sprouts at Jimmy John's restaurants (Final Update). Available at: https://www.cdc.gov/ecoli/2012/o26-02-12/index.html. Accessed $27^{\text {th }}$ November 2017.

86. Guzman-Herrador B, Vold L, Comelli H, MacDonald E, Heier B, Wester A, Stavnes T, Jensvoll L, Aanstad AL, Severinsen G. 2011. Outbreak of Shigella sonnei infection in Norway linked to consumption of fresh basil, October 2011. Eurosurveillance 16:20007.

87. Petrignani M, Harms M, Verhoef L, Van Hunen R, Swaan C, Van Steenbergen J, Boxman I, i Sala RP, Ober H, Vennema H. 2010. Update: a food-borne outbreak of hepatitis A in the Netherlands related to semi-dried tomatoes in oil, January-February 2010. Eurosurveillance 15:19572.

88. Centres for Disease Control and Prevention of the United States (CDC). 2010. Multistate outbreak of human E. coli $\mathrm{O} 145$ infections linked to shredded romaine lettuce from a single processing facility (Final Update). Available at: https://www.cdc.gov/ecoli/2010/shredded-romaine-5-21-10.html. Accessed $27^{\text {th }}$ November 2017.

89. Kozak GK, Macdonald D, Landry L, Farber JM. 2013. Foodborne outbreaks in Canada linked to produce: 2001 through 2009. Journal of Food Protection 76:173-183.

90. Centres for Disease Control and Prevention of the United States (CDC). 2009. Multistate outbreak of Salmonella Saintpaul infections linked to raw alfalfa sprouts (Final Update). Available at: https://www.cdc.gov/salmonella/2009/raw-alfalfa-sprouts-5-8-2009.html. Accessed $27^{\text {th }}$ November 2017.

91. Lynch MF, Tauxe RV, Hedberg CW. 2009. The growing burden of foodborne outbreaks due to contaminated fresh produce: risks and opportunities. Epidemiology \& Infection 137(3), 307-315. 
92. Losio MN, Pavoni E, Bilei S, Bertasi B, Bove D, Capuano F, Farneti S, Blasi G, Comin D, Cardamone C, Decastelli L, Delibato E, De Santis P, Di Pasquale S, Gattuso A, Goffredo E, Fadda A, Pisanu M, De Medici D. 2015. Microbiological survey of raw and ready-to-eat leafy green vegetables marketed in Italy. International Journal of Food Microbiology 210:88-91.

93. Fiedler G, Kabisch J, Böhnlein C, Huch M, Becker B, Cho GS, Franz CMAP. 2017. Presence of human pathogens in produce from retail markets in northern Germany. Foodborne Pathogens \& Disease 14:502-509.

94. Johannessen GS, Loncarevic S, Kruse H. 2002. Bacteriological analysis of fresh produce in Norway. International Journal of Food Microbiology 77:199-204.

95. Abadias M, Usall J, Anguera M, Solsona C, Vinas I. 2008. Microbiological quality of fresh, minimally-processed fruit and vegetables, and sprouts from retail establishments. International Journal of Food Microbiology 123:121-129.

96. Vojkovská H, Myšková P, Gelbíčová T, Skočková A, Koláčková I, Karpíšková R. 2017. Occurrence and characterization of food-borne pathogens isolated from fruit, vegetables and sprouts retailed in the Czech Republic. Food Microbiology 63:147-152.

97. Denis N, Zhang H, Leroux A, Trudel R, Bietlot H. 2016. Prevalence and trends of bacterial contamination in fresh fruits and vegetables sold at retail in Canada. Food Control 67:225-234.

98. Pan F, Li X, Carabez J, Ragosta G, Fernandez KL, Wang E, Thiptara A, Antaki E, Atwill ER. 2015. Cross-sectional survey of indicator and pathogenic bacteria on vegetables sold from Asian vendors at farmers' markets in Northern California. Journal of Food Protection 78:602-608.

99. Cerna-Cortes JF, Gómez-Aldapa CA, Rangel-Vargas E, Torres-Vitela MR, Villarruel-López A, Castro-Rosas J. 2012. Presence of some indicator bacteria and diarrheagenic E. coli pathotypes on jalapeño and serrano peppers from popular markets in Pachuca City, Mexico. Food Microbiology $32: 444-447$.

100.Sant'Ana AS, Landgraf M, Destro MT, Franco BDGM. 2011. Prevalence and counts of Salmonella spp. in minimally processed vegetables in São Paulo, Brazil. Food Microbiology 28:1235-1237.

101.Fallah AA, Pirali-Kheirabadi K, Shirvani F, Saei-Dehkordi SS. 2012. Prevalence of parasitic contamination in vegetables used for raw consumption in Shahrekord, Iran: Influence of season and washing procedure. Food Control 25:617-620.

102.Utaaker KS, Kumar A, Joshi H, Chaudhary S, Robertson LJ. 2017. Checking the detail in retail: Occurrence of Cryptosporidium and Giardia on vegetables sold across different counters in Chandigarh, India. International Journal of Food Microbiology 263:1-8.

103.Ponniah J, Robin T, Paie MS, Radu S, Ghazali FM, Kqueen CY, Nishibuchi M, Nakaguchi Y, Malakar PK. 2010. Listeria monocytogenes in raw salad vegetables sold at retail level in Malaysia. Food Control 21:774-778.

104.Yu T, Jiang X. 2014. Prevalence and characterization of Listeria monocytogenes isolated from retail food in Henan, China. Food Control 37:228-231.

105.Seow J, Ágoston R, Phua L, Yuk H-G. 2012. Microbiological quality of fresh vegetables and fruits sold in Singapore. Food Control 25:39-44. 
106.Food Standards Australia and New Zealand. 2011. Supporting Document 2. Review of foodborne illness associated with selected ready-to-eat fresh produce. Proposal P1015. Primary production \& processing requirements for horticulture. Available at:

https://www.foodstandards.gov.au/code/proposals/documents/P1015\%20Horticulture $\% 20$ PPPS $\% 201$ CFS\%20SD2\%20Illness\%20review.pdf. Accessed 29 ${ }^{\text {th }}$ November 2017.

107.Zhu Q, Gooneratne SR, Hussain M. 2016. Detection of Listeria species in fresh produces samples from different retail shops in Canterbury, New Zealand. Advances in Food Technology \& Nutritional Sciences 2:96-102.

108.De Bruin W, Otto D, Korsten L. 2016. Microbiological status and food safety compliance of commercial basil production systems. Journal of Food Protection 79:43-50.

109.Traoré O, Nyholm O, Siitonen A, Bonkoungou IJO, Traoré AS, Barro N, Haukka K. 2015. Prevalence and diversity of Salmonella enterica in water, fish and lettuce in Ouagadougou, Burkina Faso. BMC Microbiology 15:1-7.

110.Khalil RKS, Gomaa MAE, Khalil MIM. 2015. Detection of shiga-toxin producing E. coli (STEC) in leafy greens sold at local retail markets in Alexandria, Egypt. International Journal of Food Microbiology 197:58-64.

111.Adamu NB, Adamu JY, Mohammed D. 2012. Prevalence of helminth parasites found on vegetables sold in Maiduguri, Northeastern Nigeria. Food Control 25:23-26.

112.Nguz K, Shindano J, Samapundo S, Huyghebaert A. 2005. Microbiological evaluation of fresh-cut organic vegetables produced in Zambia. Food Control 16:623-628.

113. He FJ, Nowson CA, Lucas M, MacGregor GA. 2007. Increased consumption of fruit and vegetables is related to a reduced risk of coronary heart disease: meta-analysis of cohort studies. Journal of Human Hypertension 21:717-728.

114.Jacxsens L, Ibañez IC, Gómez-López VM, Fernandes JA, Allende A, Uyttendaele M, Huybrechts I. 2015. Belgian and Spanish consumption data and consumer handling practices for fresh fruits and vegetables useful for further microbiological and chemical exposure assessment. Journal of Food Protection 78:784-795.

115. Miller V, Mente A, Dehghan M, Rangarajan S, Zhang X, Swaminathan S, Dagenais G, Gupta R, Mohan V, Lear S. 2017. Fruit, vegetable, and legume intake, and cardiovascular disease and deaths in 18 countries (PURE): a prospective cohort study. The Lancet 390:2037-2049.

116.FAO STAT (Food and Agriculture Organization of the United Nations, statistics division). 2015. http://faostat3.fao.org/compare/E. Accessed on 03 ${ }^{\text {rd }}$ May 2016.

117.Cook R. 2011. Tracking demographics and US fruit and vegetable consumption patterns. Department of Agricultural and Resource Economics, University of California, Davis. Available at: https://arefiles.ucdavis.edu//uploads/filer_public/2014/05/19/blueprintseoeconsumptioncookfinaljan2 012figures.pdf. Accessed 30 $0^{\text {th }}$ May 2017.

118. The World Health Organization (WHO) of the United Nations. 2004. Fruit and vegetables for health. Report of a joint FAO/WHO workshop, 1-3 September 2004, Kobe, Japan. Available at: http://www.who.int/dietphysicalactivity/publications/fruit_vegetables_report.pdf. Accessed $02^{\text {th }}$ April 2014. 
119.Johnson R. 2016. US Trade Situation for fruit and vegetable Products. Report prepared for members and committees of US Congress. Available at: https://fas.org/sgp/crs/misc/RL34468.pdf. Accessed $25^{\text {th }}$ June 2017.

120.De la Peña R, Hughes J. 2007. Improving vegetable productivity in a variable and changing climate. Journal of SAT Agricultural Research 4:1-22.

121. Hiroyuki K, Holmer R, Linwattana G, Nath P, Keatinge J. 2013. Growing role of vegetables in food security and nutrition in Asia. SEAVEG 2012 high value vegetables in southeast Asia: production, supply and demand. AVRDC-World Vegetable Center. pp 27.

122.Hedberg C, Angulo F, White K, Langkop C, Schell W, Stobierski M, Schuchat A, Besser J, Dietrich S, Helsel L. 1999. Outbreaks of salmonellosis associated with eating uncooked tomatoes: implications for public health. Epidemiology \& Infection 122:385-393.

123. Beuchat LR, Ryu JH. 1997. Produce handling and processing practices. Emerging Infectious Diseases 3:459-465.

124.Heaton JC, Jones K. 2008. Microbial contamination of fruit and vegetables and the behaviour of enteropathogens in the phyllosphere: A review. Journal of Applied Microbiology 104:613-626.

125.Erickson MC. 2012. Internalization of fresh produce by foodborne pathogens. Annual Review of Food Science and Technology 3:283-310.

126.Ongeng D, Muyanja C, Geeraerd AH, Springael D, Ryckeboer J. 2011. Survival of Escherichia coli O157:H7 and Salmonella enterica serovar Typhimurium in manure and manure-amended soil under tropical climatic conditions in Sub-Saharan Africa. Journal of Applied Microbiology 110:10071022 .

127.Donkor ES, Lanyo R, Kayang BB, Quaye J, Edoh DA. 2010. Internalization of microbes in vegetables: Microbial load of Ghanaian vegetables and the relationship with different water sources of irrigation. Pakistan Journal of Biological Sciences 13:857-861.

128.Palma-Salgado S, Pearlstein AJ, Luo Y, Park HK, Feng H. 2014. Whole-head washing, prior to cutting, provides sanitization advantages for fresh-cut Iceberg lettuce (Latuca sativa L.). International Journal of Food Microbiology 179:18-23.

129.Gil MI, Selma MV, López-Gálvez F, Allende A. 2009. Fresh-cut product sanitation and wash water disinfection: Problems and solutions. International Journal of Food Microbiology 134:37-45.

130.Lynch MF, Tauxe RV, Hedberg CW. 2009. The growing burden of foodborne outbreaks due to contaminated fresh produce: Risks and opportunities. Epidemiology \& Infection 137:307-315.

131.Beuchat LR. 1996. Pathogenic microorganisms associated with fresh produce. Journal of Food Protection 59:204-216.

132.Berger CN, Sodha SV, Shaw RK, Griffin PM, Pink D, Hand P, Frankel G. 2010. Fresh fruit and vegetables as vehicles for the transmission of human pathogens. Environmental Microbiology 12(9), 2385-2397.

133.Holvoet K, Sampers I, Seynnaeve M, Uyttendaele M. Relationships among hygiene indicators and enteric pathogens in irrigation water, soil and lettuce and the impact of climatic conditions on 
contamination in the lettuce primary production. International Journal of Food Microbiology 171: 2131.

134. Kirezieva K, Luning PA, Jacxsens L, Allende A, Johannessen GS, Tondo EC, Rajkovic A, Uyttendaele M, van Boekel MAJS. 2015. Factors affecting the status of food safety management systems in the global fresh produce chain. Food Control 52:85-97.

135. Allende A, Castro-Ibáñez I, Lindqvist R, Gil MI, Uyttendaele M, Jacxsens L. 2017. Quantitative contamination assessment of Escherichia coli in baby spinach primary production in Spain: Effects of weather conditions and agricultural practices. International Journal of Food Microbiology 257:238246.

136. Buck J, Walcott R, Beuchat L. 2003. Recent trends in microbiological safety of fruits and vegetables. Plant Health Progress 10:1094.

137.Nightingale K, Schukken Y, Nightingale C, Fortes E, Ho A, Her Z, Grohn Y, McDonough P, Wiedmann M. 2004. Ecology and transmission of Listeria monocytogenes infecting ruminants and in the farm environment. Applied \& Environmental Microbiology 70:4458-4467.

138. Strawn LK, Fortes ED, Bihn EA, Nightingale KK, Gröhn YT, Worobo RW, Wiedmann M, Bergholz PW. 2013. Landscape and meteorological factors affecting prevalence of three food-borne pathogens in fruit and vegetable farms. Applied \& Environmental Microbiology 79:588-600.

139.Chapin TK, Nightingale KK, Worobo RW, Wiedmann M, Strawn LK. 2014. Geographical and meteorological factors associated with isolation of Listeria species in New York state produce production and natural environments. Journal of Food Protection 77:1919-1928.

140.Falardeau J, Johnson RP, Pagotto F, Wang S. 2017. Occurrence, characterization, and potential predictors of verotoxigenic Escherichia coli, Listeria monocytogenes, and Salmonella in surface water used for produce irrigation in the Lower Mainland of British Columbia, Canada. PLoS One 12: e0185437.

141.Franz E, Semenov AV, Van Bruggen AHC. 2008. Modelling the contamination of lettuce with Escherichia coli $\mathrm{O} 157: \mathrm{H} 7$ from manure-amended soil and the effect of intervention strategies. Journal of Applied Microbiology 105:1569-1584.

142.Franz E, Van Bruggen AHC. 2008. Ecology of E. coli O157:H7 and Salmonella enterica in the primary vegetable production chain. Critical Reviews in Microbiology 34:143-161.

143.Liu C, Hofstra N, Franz E. 2013. Impacts of climate change on the microbial safety of pre-harvest leafy green vegetables as indicated by Escherichia coli $\mathrm{O} 157$ and Salmonella spp. International Journal of Food Microbiology 163:119-128.

144. The Food and Agriculture Organisation of the United Nations (FAO). 2008. Contributing to "One World, One Health". A strategic framework for reducing risks of infectious diseases at the animalhuman-ecosystems Interface. Available at ftp://ftp.fao.org/docrep/fao/011/aj137e/aj137e00.pdf. Accessed $01^{\text {st }}$ October 2013. 



\section{2}

Estimates of the burden of illnesses related to foodborne pathogens as from the syndromic surveillance data of 2013 in Rwanda

James Noah Ssemanda ${ }^{1,2}$, Martine Reij ${ }^{1}$, Mark Cyubahiro Bagabe ${ }^{3}$, Claude Mambo Muvunyi ${ }^{4}$, José Nyamusore ${ }^{5}$, Han Joosten ${ }^{1}$, Marcel H. Zwietering ${ }^{1}$

\section{Published in:}

Microbial Risk Analysis (2018)

https://doi.org/10.1016/j.mran.2018.02.002

\footnotetext{
Affiliations:

${ }^{1}$ Laboratory of Food Microbiology, Wageningen University, P.O. Box 17, 6700 AA Wageningen, The Netherlands

${ }^{2}$ Rwanda Standards Board, KK 15 Rd, 49; P.O. Box: 7099, Kigali-Kicukiro, Rwanda

${ }^{3}$ Rwanda Agriculture Board, KK 18 Ave; P. O. Box 5016, Kigali, Rwanda

${ }^{4}$ College of Medicine and Health Sciences, University of Rwanda, P.O. Box: 3286, Kigali, Rwanda

${ }^{5}$ Epidemic Surveillance and Response Division, Rwanda Biomedical Centre, P.O. Box 83 Kigali, Rwanda
} 


\begin{abstract}
Food related illnesses contribute significantly to the global burden of disease and the estimates of these illnesses are important to develop evidence based food safety policies. However estimating the burden of these illnesses is complex. There is paucity of input data, and developing and sustaining disease surveillance systems that provide the input data is resourceintensive. In most developing countries with relative peace, the initial, faster and cheaper kind of health data is generated through syndromic surveillance. In this study, we estimated the burden of food related clinical features and illnesses (watery diarrhea, bloody diarrhea, suspected cases of cholera and typhoid fever) by making use of various syndromic surveillance data sources in Rwanda. Data sources were the reported cases as by the notifiable surveillance system, an opinion survey with health care providers about the prevalence of clinical features related to foodborne pathogens and over the counter prescription of drugs associated with foodborne illnesses. Study findings indicate that for the year 2013, watery diarrhea occurred all year round as by the surveillance system data, resulting to an estimated 672 (95\% credible interval [CrI] 424 - 932) DALY per million inhabitants, bloody diarrhea was seasonal coinciding with the rainy months and caused an estimated $213(95 \% \mathrm{CrI} 50-475)$ DALY per million, typhoid and cholera cases were sporadic with an estimated 73 (95\% CrI 57 - 91) and 1 (95\% CrI 0 - 2) DALY per million respectively. Our DALY estimates from the different data sources were in the same range for combined cases of watery diarrhea, bloody diarrhea and cholera, but significantly different for typhoid fever. The methodology applied in this study can be adopted in resource-scarce settings where most data is from syndromic surveillance (a common phenomenon in most developing countries) other than the desired integrated food chain and laboratory-based surveillance systems, to pave way for future improved estimates of the burden of foodborne illnesses.
\end{abstract}




\section{Introduction}

Worldwide, foodborne illnesses are a threat to public health and social-economic development. Causes of food borne illnesses include bacteria, parasites, viruses, toxins, metals, and prions (1, 2) but the risk due to microbiological agents is higher due to their ability to emerge, re-emerge and adapt to various niches (3). Foodborne illnesses are usually characterised by acute conditions like gastroenteritis and in some cases by long term sequelae such as hemolytic uremic syndrome (due to shiga toxin-producing Escherichia coli ), Guillain-Barré syndrome (Campylobacter spp.), or central nervous system (CNS) abnormalities (Listeria monocytogenes) (2). Other associated long-term sequelae also include chronic arthritis (Campylobacter spp., Shigella spp. and Salmonella spp. can be involved); mental retardation, seizures, paralysis, blindness, or deafness (L. monocytogenes); the incurable irritable bowel syndrome (IBS) (bacterial pathogens) and mental retardation and crossed eyes in newborns (Toxoplasma gondii) (4). Recently colon cancer has been associated with severe Salmonella spp. infections (5). In addition, foodborne illness may also exacerbate other underlying medical conditions (6).

While infectious diseases like malaria, HIV/AIDS and tuberculosis ("the big three") continue to dominate the agenda of health programmes in most African countries (7), it has been estimated that foodborne illnesses comparably and significantly contribute to the overall burden of disease (2). Estimates from the World Health Organisation (WHO) in 2010 indicate that 31\% of the 33 million Disability Adjusted Life Years (DALYs) lost globally due to 31 foodborne hazards was from sub-Saharan Africa with diarrheal disease agents causing nearly $70 \%$ of this burden (2). Studies on costs of foodborne illnesses from the USA (8-10) reported economic losses estimated at 0.1 to $0.2 \%$ the national gross domestic product(GDP) in 2015 due to productivity and medical care costs (11). Estimated costs due to diarrhea in Rwanda in the year 2000 were in the range of 2.5 to $5 \%$ of the GDP (12).

To implement effective control measures, risk managers need information on the magnitude of the burden of foodborne illnesses in order to prioritise, develop and implement risk based food safety policies (13). However, assessing the burden of foodborne illness is complex. First, disease surveillance systems that provide the data used in these assessments are resourceintensive and to date all countries are still developing their systems (14). Second, a number of acute foodborne illnesses are self-limiting, implying that some patients do not seek medical care and as a consequence, the real burden is underreported (15-17). Third, many pathogens that are usually associated with food can also be transmitted from the environment or from direct contact with animals or infected persons $(18,19)$. Cognizant of this complexity, the WHO through the Foodborne Disease Burden Epidemiology Reference Group (FERG) has encouraged national and international studies to assess the burden of foodborne illness. The FERG and volunteer researchers have since adopted the DALY (disability adjusted life year) concept to summarise and rank diseases. 
The DALY is a measure that combines the Years of Life Lost due to premature death (YLL) and the Years Lost due to Disability (YLD) from a disease or condition, for varying degrees of severity, making time itself the common metric for death and disability (20). Studies on food borne illnesses at a global level $(2,21)$, provide world estimates but with many assumptions due to paucity of data. At country level, most studies come from the developed countries with elaborate disease surveillance systems i.e.. England (22), USA (23), Netherlands (19), Greece (18) and Canada (1). More studies on the burden foodborne illnesses from developing countries are required, however, availability of disease surveillance data to use in these studies is still among the major challenges. Syndromic surveillance data that are collected by using standard case definitions of clinical features like watery diarrhea and suspected cases of illnesses (typhoid fever) without laboratory diagnosis or from surrogate data sources (viz. over-thecounter prescription sales, opinion of health care providers) can provide a cheaper and fast data option $(24,25)$.

In this study, we provided insight into- and estimated DALYs for foodborne illnesses in Rwanda using syndromic surveillance data of 2013 as a reference year, presented a methodology and also identified data gaps to contribute to future improved estimates in Rwanda and other developing countries. Because of the kind of data used this study i.e.. non-laboratory confirmed cases and surrogate health data, the term "foodborne illnesses" should be used with caution and hereafter replaced with "food related illnesses" (further definitions in the glossary, Appendix A).

\section{Methods}

\section{Study Approach}

Figure 2.1 shows the approach used to investigate the burden of food related illnesses in Rwanda. Our study was based on the syndromic surveillance data aspects explained by the WHO manual for integrated foodborne disease surveillance in the WHO Africa Region (24). Data from the opinion survey with health care providers (HCPs), the national notifiable surveillance system, and over the counter (OTC) drug prescriptions were used to show trends and estimates of YLL, YLD and DALY for food related- clinical features and illnesses. 


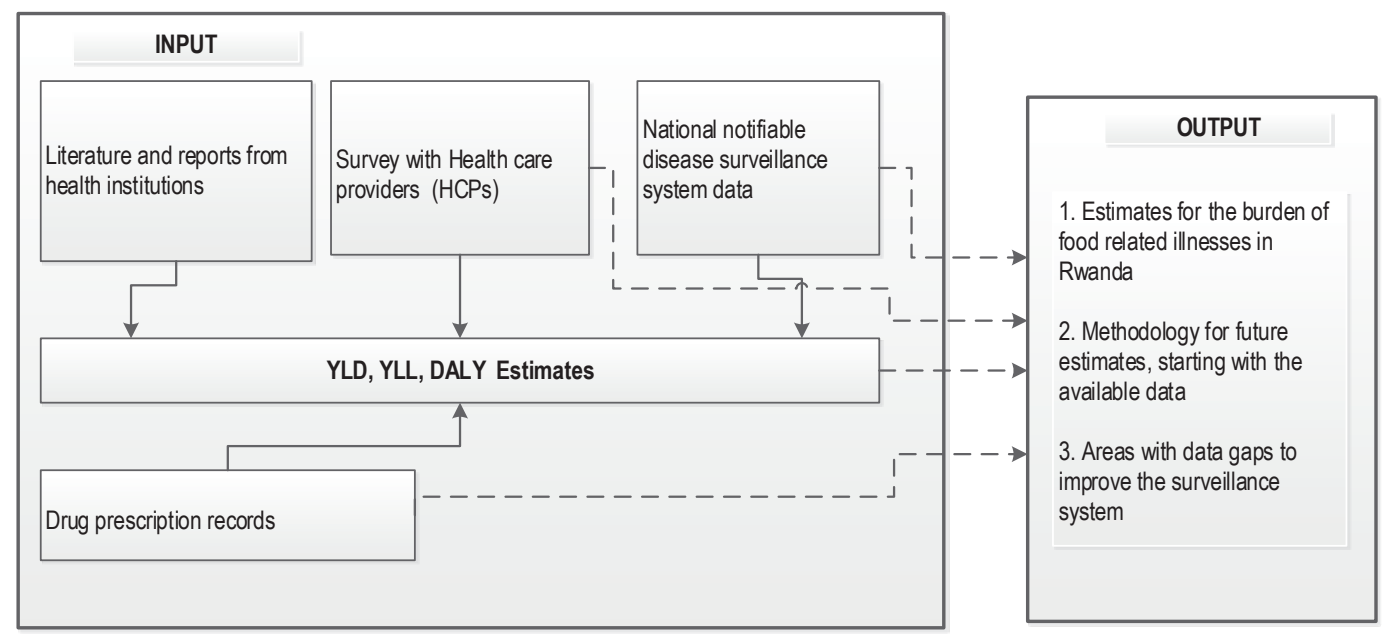

Figure 2.1: Study approach and data sources (inputs) used in this study. YLD, years lived with disability for prevalent cases of illness; YLL, years of life lost due to premature death caused by illness in the population; $\mathrm{DALY}=(\mathrm{YLD}+\mathrm{YLL})$, disability-adjusted life years.

Clinical features (watery diarrhea and bloody diarrhea), and illnesses (cholera and typhoid fever) related to foodborne pathogens were investigated. For cholera and typhoid fever illnesses, this study was based on suspected cases. Standard case definitions of watery diarrhea, bloody diarrhea and suspected cases of cholera and typhoid fever as used in this study are presented in the glossary ( see Technical Appendix A ). We acknowledge that diarrheal diseases are caused by infectious and non-infections agents but because in most developing countries, these diseases are mainly caused by infectious agents (26), we assume in this study that diarrheal cases were all infectious in nature.

\section{Ethical clearance}

This study was approved by both the Rwanda National Health Research Committee (ref: NHRC/2014/PROT/0148) and the Rwanda National Ethics Committee (No. 130/RNEC/2014).

\section{Data collection}

\section{Opinion survey with Health care providers}

Over a period of three months (January to March, 2014), a face to face questionnaire (see online Technical Appendix A, section 6) was administered to 128 HCPs at their respective health facilities (private and public hospitals, clinics and health centres) in the City of Kigali and the other four provinces of Rwanda to investigate about the perceived prevalence of selected clinical features (watery diarrhea and bloody diarrhea) and illness (typhoid fever), commonly related to foodborne pathogens (27). The perceived prevalences were in form of percentage rank categories ie. $0 \%$ (not seen any case in year 2013), between-: 0-1\%, 1-20\%, 20-40\%, 40$60 \%, 60-80 \%$ and $80-100 \%$. We explained the importance of the study to the HCPs and thereafter asked the HCPs to allocate percentage prevalence ranks to the clinical features and typhoid fever illness based on the consultation with patients in the year 2013. HCPs that 
participated in the study were general practising doctors and grade 1 nurses (most likely to handle patients with clinical features in the questionnaire). Percentage (\%) rankings for any clinical feature or illness with less than 10 respondents (HCPs) were considered as outliers and excluded in the incidence calculations for the DALY estimates (Tab. 2A 4, Technical appendix A) because these rank results led to unrealistically large uncertainty.

\section{National notifiable surveillance system data}

The epidemic surveillance and response division of Rwanda Biomedical Centre (RBC) receives and compiles weekly suspected cases of illnesses like cholera, typhoid fever and cases of clinical features; watery and bloody diarrhea from health facilities all over Rwanda based on case definitions as presented in the glossary (Technical Appendix A). In March 2014, with permission from RBC, we retrieved data of reported cases of watery diarrhea, bloody diarrhea, cholera and typhoid fever for the year 2013. In the Rwandan health system, further actions after this syndromic surveillance can involve confirmation of these cases in the National Reference Laboratory but this study focussed on the reported cases of clinical features and suspected cases of the illnesses under investigation.

\section{Over the Counter drugs (OTC) sales}

In two months period (April to May) of year 2014, we collected data on drug prescription from 37 major pharmacies in Rwanda. Rwanda Social Security Board (RSSB), pharmacy division was identified as a one stop centre for drug sales records coupled with prescriptions by medical practitioners. In 2010, the RSSB insurance scheme was estimated to cover $3.7 \%$ (28) of the population in Rwanda of about 10.5 million people (29). Drug sales records as prescribed by the medical practitioners were used to minimise the unrealistic drug sale trends that result from the practice of patients who repetitively buy drugs from individual pharmacies without seeking medical care. With permission from the RSSB management, we accessed the RSSB archive of drug insurance claim forms for RSSB affiliates and their dependants. Data collected covered prescription per pharmacy and age of patient for antibiotics, anthelmintics, antiprotozoal and oral rehydration salts (ORS) for the year 2013.

\section{Estimation of YLD, YLL and DALY for food related illnesses}

In summary, we applied a step wise approach in computing YLD, YLL and DALY as was explained by Devleesschauwer et al. (30). DALY estimates were computed from the following expression (31):

\section{DALY $=$ YLD + YLL}

\section{Where}

YLD $(\mathrm{n} \times D W \times L)$ are computed by multiplying the number of incident cases $(\mathrm{n})$ of a given illness in a population with the disability weight (DW) and the average duration of the case until remission or death ( $\mathrm{L}$ in years).

YLL $\left(\mathrm{n}_{\mathrm{d}} \times L E\right)$ are computed by multiplying the number of deaths $\left(\mathrm{n}_{\mathrm{d}}\right)$ at a given age with the year lost due premature death as compared to the standard life expectancy at that age (LE in years). 
We computed YLD, YLL and DALY for water diarrhea, bloody diarrhea, cholera and typhoid fever. Data sources were the epidemic surveillance and response division of Rwanda Biomedical Centre (RBC), an opinion survey with health care providers (HCPs), prescription records for oral rehydration salts (ORS), Rwanda Ministry of Health reports (MoH), Rwanda National Institute of statistics reports $(28,29)$, the WHO and data in other published literature (Fig. 2.1). Details of the methodology used, are provided in Technical Appendix A of this chapter.

\section{Data analyses}

A bean plot from "R" statistical software (version 3.3.2) was used to visualise data from the HCPs survey (32). DALY estimates were computed in " $\mathrm{R}$ " software environment for statistical computing and graphics using a DALY- calculator (30) set at 20,000 iterations. Data from epidemiology (RBC), survey with HCPs, ORS sales records, health reports and literature were reorganised to suit the inputs parameters of the DALY calculator. Mortality rates and the associated uncertainty were computed using @risk 7.5 software ( Palisade corporation, USA ) at 20,000 iterations (see Technical Appendix A, section 4.8, this Chapter). In IBM SPSS Statistics 22, one way ANOVA followed by Tukey's post hoc tests, was used to determine statistical significance between the number prescriptions/1000 persons/year of drugs among the age groups and drug categories. Statistical significance was set at 0.05.

\section{Results}

\section{Opinion survey with HCPs}

Figure 2.2 , shows the \% prevalence of watery diarrhea, bloody diarrhea, and typhoid fever as perceived by HCPs in the year 2013. Results show perceived prevalence of watery diarrhea with mean perceived prevalence around $40 \%$ and estimates of HCPs divided among all the prevalence categories except for the $0 \%$ category (not seen any case). For bloody diarrhea and typhoid fever the mean perceived prevalence was around $10 \%$ and estimates of most HCPs concentrated around the $0-1 \%$ category. 


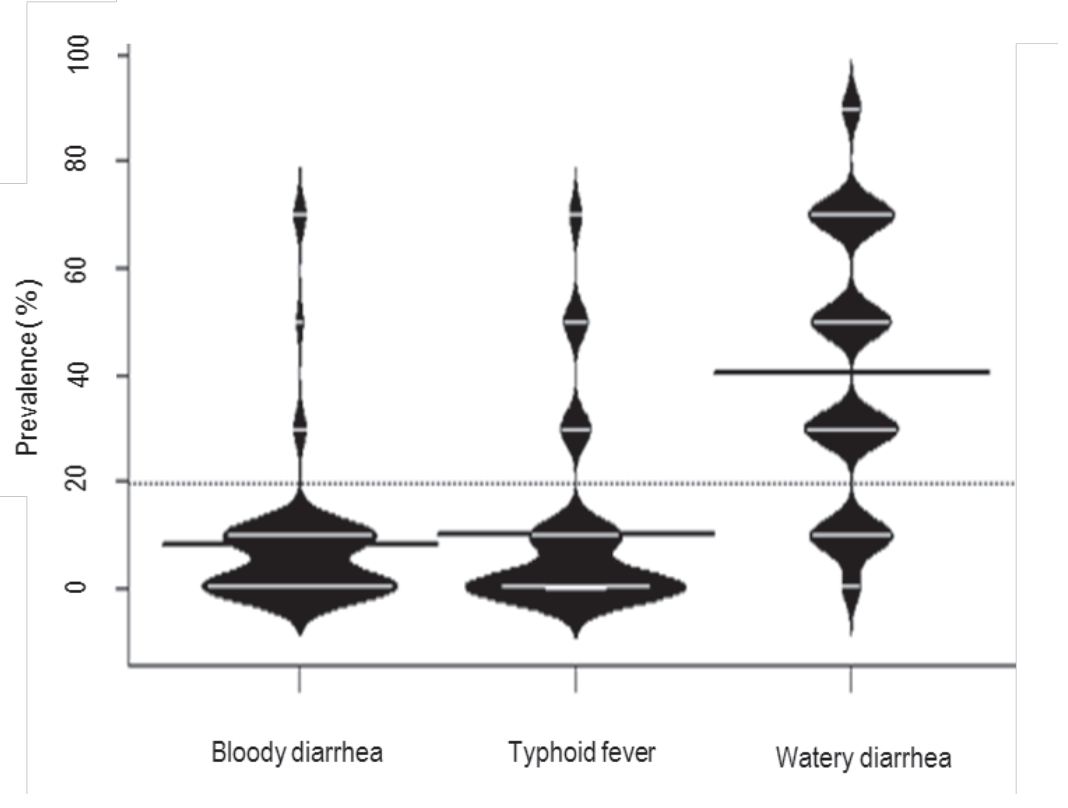

Figure 2.2: Prevalence (\%) of clinical features related to foodborne pathogens as from an opinion survey with health care providers (HCPs, $n=128$ ) in health facilities across Rwanda for the year 2013. The number of "bean pods" show the difference in opinion of HCPs on the \% prevalence of each clinical feature, while the size and shape of the "bean pods" shows the number of HCPs who chose a particular \% prevalence category. White bands in each "bean pods" show the median. Black line crossing "bean pods" is the overall mean $\%$ prevalence for each clinical feature. The dotted line horizontal line, is the overall mean \% prevalence of all the clinical features. Prevalence $=$ estimated number of patients with clinical feature out of the total patients received in 2013 per HCP.

\section{Reported cases of food related illnesses, year 2013}

Figure 2.3 shows the cases for watery diarrhea, bloody diarrhea, cholera and typhoid fever reported in the year 2013 to the national notifiable surveillance system of the epidemic surveillance and response division of RBC from country wide health facilities. 
Watery diarrhea

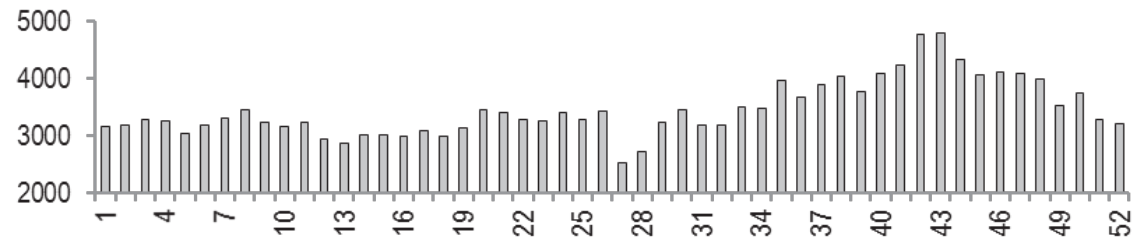

Bloody diarrhea
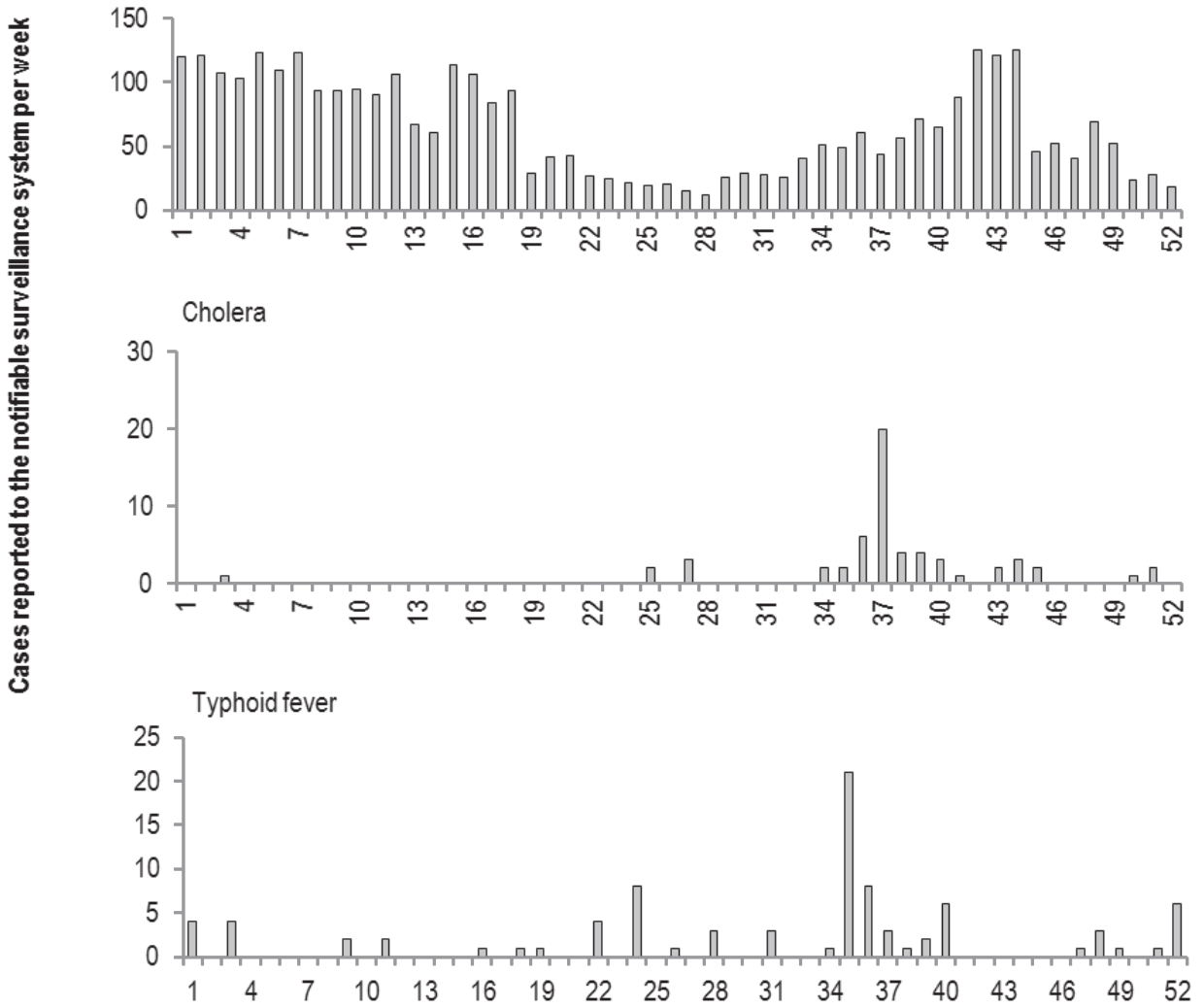

Week of reporting in year 2013

Figure 2.3: Cases of watery diarrhea, bloody diarrhea, cholera and typhoid fever reported weekly by country wide health facilities to the Epidemic Surveillance and Response Division of Rwanda Biomedical Centre (RBC) in the year 2013. 
The reported cases of these illnesses were reported out of the whole population which was estimated to be around 10.5 million inhabitants (29). The annual reported cases for watery diarrhea were 180,121 cases with a weekly reported average of 3464 cases. For bloody diarrhea, annual reported cases were 3395, with a weekly reported average of 65 cases. Cholera and typhoid fever occurred sporadically with an average of 1 case and 2 cases per week respectively, with peaks at the second half of the year.

\section{Trends of drugs prescribed for food related illnesses}

Figure 2.4 shows that antibiotics had the highest monthly prescriptions/pharmacy that peaked in the second half of the year compared to anthelmintic and antiprotozoal drugs that remained relatively stable throughout the year. In Figure 2.5, the number prescriptions/1000persons/year were also significantly higher $(p<0.05)$ for antibiotics compared to antiprotozoal and anthelmintics across all age groups. Although not statistically significant $(p>0.05)$, the age groups of 30 to 39 years registered the highest number of prescriptions/1000persons/year, when all the three drug categories (antibiotics, antiprotozoal and anthelmintics) were combined.

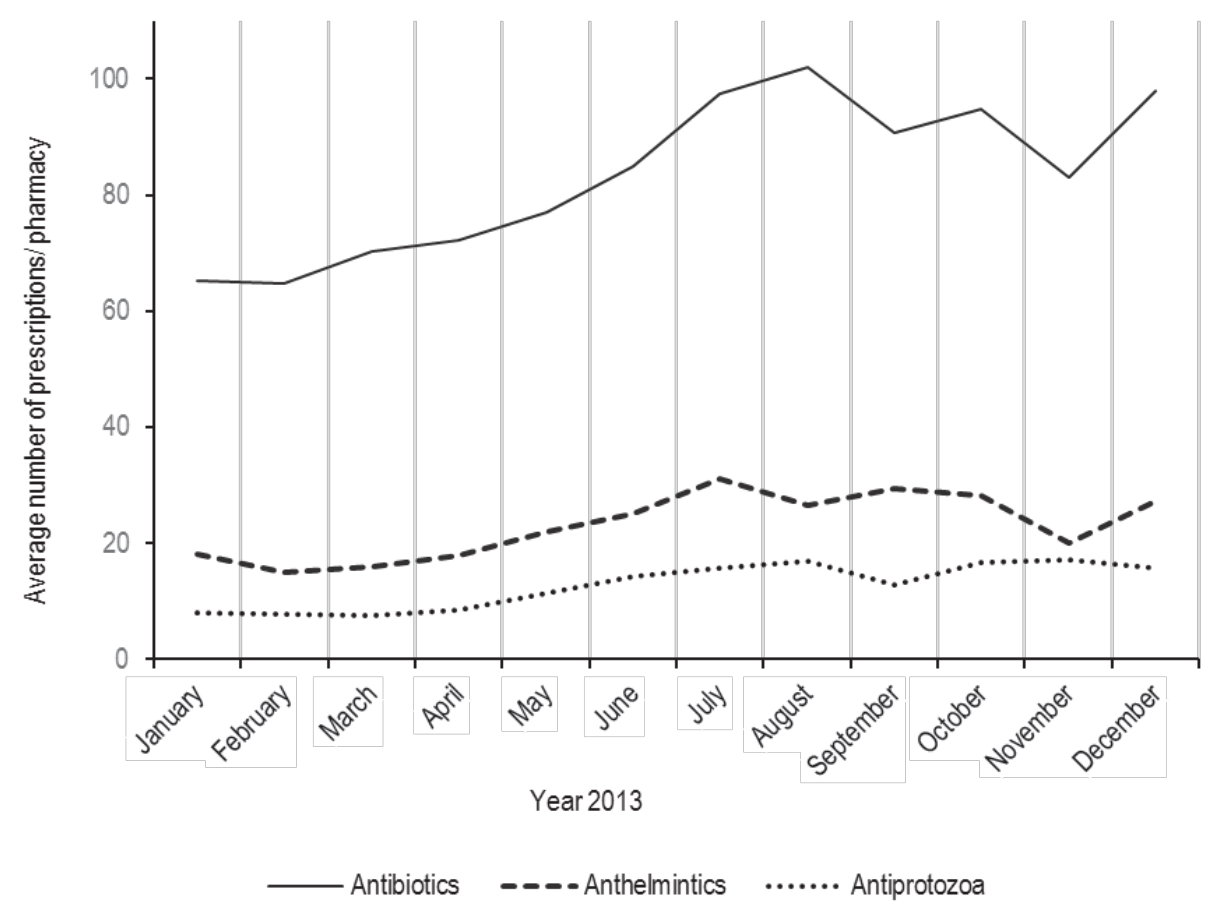

Figure 2.4: Monthly prescription of antibiotics, anthelmintic and antiprotozoal as by insurance claim forms received at Rwanda Social Security Board (RSSB) for the year 2013 from 37 major pharmacies country wide. The RSSB insurance scheme was estimated to cover $3.7 \%$ of the population in Rwanda, year 2010 (28). 


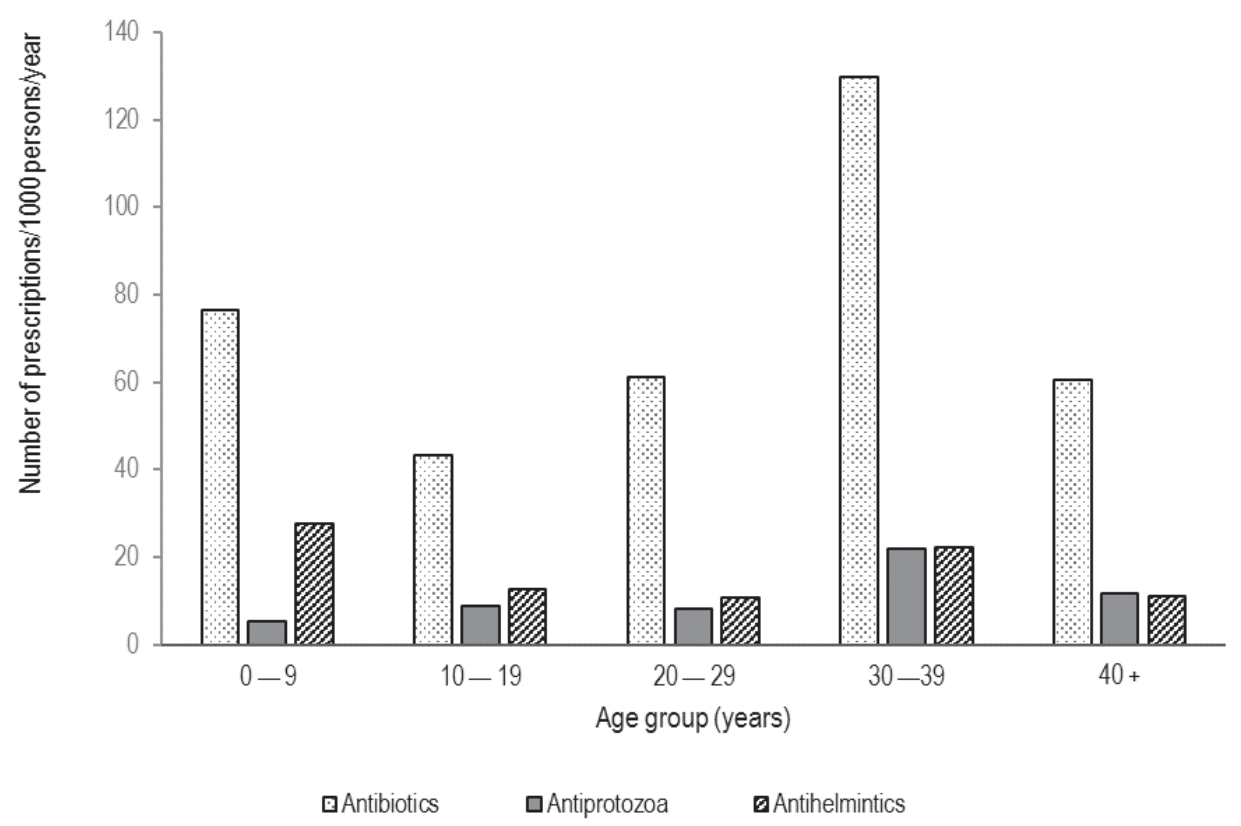

Figure 2.5: Number prescriptions for antibiotics, anthelmintic and antiprotozoal per age group of patients as by insurance claim forms received at Rwanda Social Security Board (RSSB) for the year 2013.

\section{Estimates for YLD, YLL and DALY of food related illnesses}

Table 2.1 shows the details of our estimates for YLD, YLL, DALY and deaths due to watery diarrhea, bloody diarrhea and cholera from RBC, HCPs and ORS prescription data and typhoid fever from RBC, HCPs data. DALY estimates per million inhabitants from RBC data on average were highest for watery diarrhea (672) followed by bloody diarrhea (213), typhoid fever (73) and cholera (1) with the YLL component contributing to over $90 \%$ except for cholera. Table 2.1 also shows that with HCPs data, the YLD component is more pronounced in the DALY estimates compared to RBC (surveillance) data. Cases from ORS prescription data resulted to DALY estimates in the same range (approximately 1.2:1) with the DALY estimates from combined cases of watery diarrhea, bloody diarrhea and cholera from RBC data (Tab. 2.1). Figure 2.6 provides a graphical comparison of the DALY estimates, from RBC, HCPs data for watery diarrhea, bloody diarrhea, typhoid fever. DALY estimates from HCPs survey were in the same range with the DALY from RBC data, while for typhoid fever, HCPs survey DALY estimates were 15 times higher than the DALY from RBC data. 


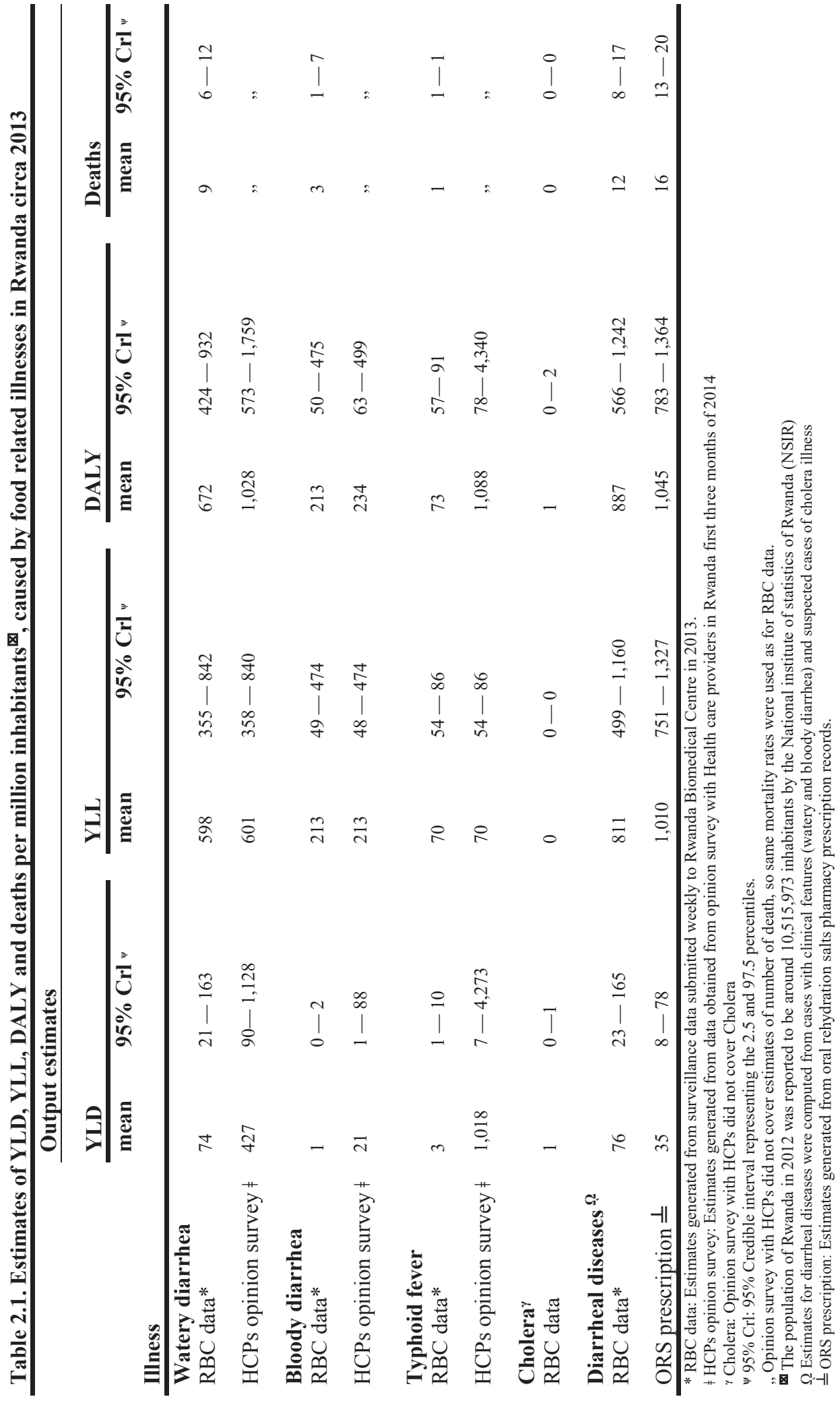




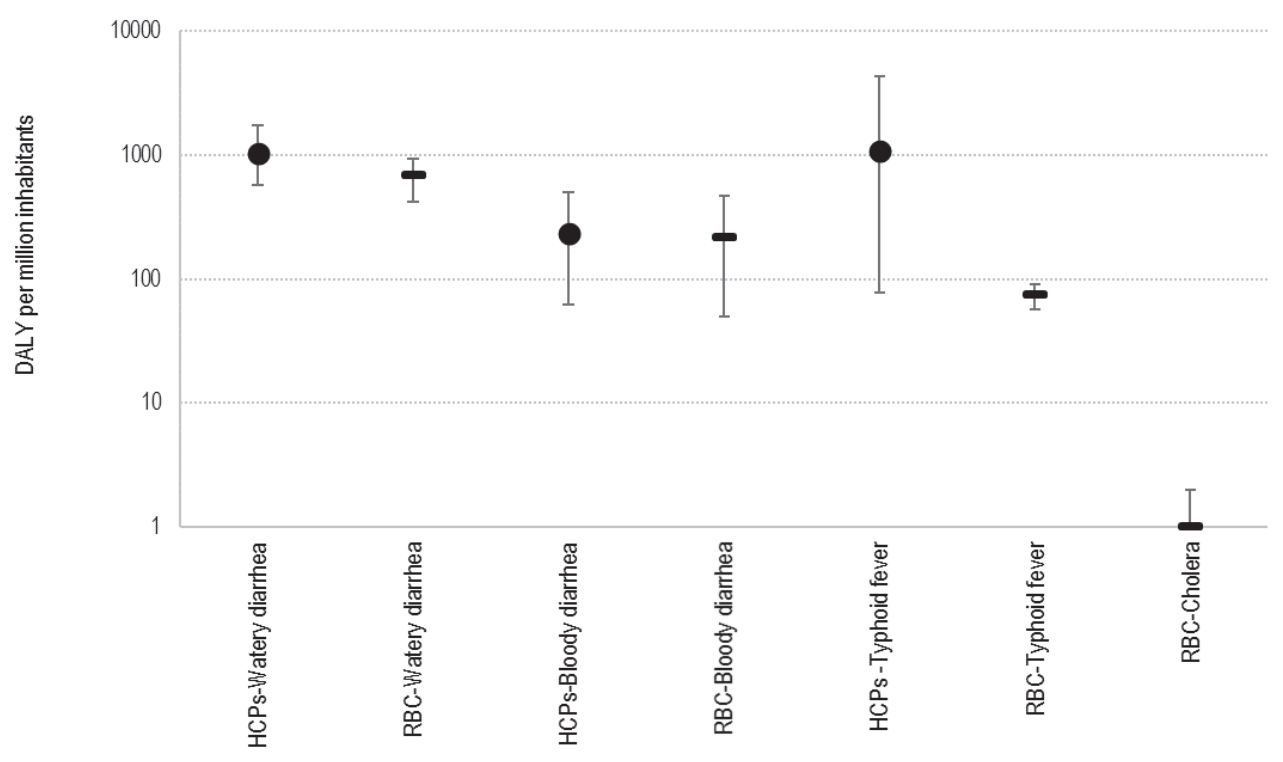

Figure 2.6: Estimates of DALY for clinical features (watery diarrhea and bloody diarrhea) and illnesses (typhoid fever and cholera) related to foodborne pathogens, generated by computing data from both the Epidemic Surveillance and Response Division of Rwanda Biomedical Centre (RBC) and the Opinion survey with health care providers (HCPs) in the year 2013. Estimates are presented on a logarithmic scale on the y-axis. Whiskers represent $95 \%$ credible intervals.

\section{Discussion}

\section{Study findings}

In this study we have presented the reported cases and the opinion of HCPs on the prevalence of selected food related illnesses and estimated YLD, YLL and DALY for watery diarrhea, bloody diarrhea and cholera, ORS prescription cases and typhoid fever for the year 2013. In addition, trends in drug prescription for antibiotics, antiprotozoal and anthelmintics in 2013 have also been presented.

Watery diarrhea had the highest number of cases and occurred all year round. Bloody diarrhea was seasonal coinciding with the rainy season in Rwanda, while cholera and typhoid fever occurred were sporadic. The results of the reported cases seem to be in agreement with the estimates of \% prevalence from our HCPs survey and DALY estimates. Watery diarrhea had the highest mean prevalence (Fig. 2.2) from the HCP survey. The high number of cases and DALY estimates coupled with the year round occurrence of watery diarrhea compared to other studied illnesses may be attributed to the vast range of causative agents (26) with a high prevalence especially in developing countries. In Egypt, one of the most commonly aetiological agents for watery diarrhea, enterotoxigenic E. coli (heat labile toxin strains of ETEC), was reported to be prevalent in similar levels all year round among hospitalized children (33). 
Rotavirus, one of the major causes of profuse watery diarrhea was detected in $39-52 \%$ of hospitalized children in Ghana, Kenya, Uganda and Zambia in 2008 (34). Studies from different countries have reported prevalence of $14.9 \%$ for ETEC in rectal swabs of hospitalized acute diarrhea patients in Indonesia (35) and 9.3\% for non typhoidal Salmonella in faecal samples of diarrhea patients in Chad (36). For bloody diarrhea compared to watery diarrhea, few aetiological agents are commonly reported, i.e.. bacteria (Shigella spp., Enterohemorrhagic E. coli ) (37, 38), parasites (Entamoeba histolytica) (39) and the seasonal trends may be explained by the reported connection of these aetiological to weather seasons (40). Cholera cases peaked in the last quarter of the year (September to December) during the rainy season in Rwanda. Similar trends were reported in Bangladesh (41) and Kenya (42) but differed from the trend reported in Ghana (40). Typhoid fever outbreaks were dispersed over the year but like cholera also peaked in the rainy season of the final quarter of the year similar to findings from India (43) and Zimbabwe (44). The occurrence of these sporadic cases of typhoid and cholera during the rainy season has been linked to the flooding of water sources and increased runoff water in situation were surface water is used for household sores, drinking and food preparation (45-47).

From previous studies, trends of local sales for weekly aggregate OTC drugs were comparable to the outbreak epidemic curves (48). The observed trends in prescription per pharmacy or per age group for antibiotics, antiprotozoal and anthelmintic can therefore also provide a hint about the manifestation of these aetiological agents, although it is not clear whether they are food related or not. OTC drug sales method has been identified as one way in which community health information on illnesses can be obtained even before medical care and notification (48). In this study the peak in prescriptions of antibiotics in the second half of the year coincided with the peak in reported cases for bloody diarrhea, typhoid and cholera. The age of 0-9 and 30-39 year had the highest number of prescriptions for antibiotics. These findings correlate with the incidence of invasive non typhoidal Salmonella spp. reported from other nearby Africa countries (Malawi and South Africa) for these age groups (49).

Reported cases of watery diarrhea were 50 times higher than the cases of bloody diarrhea, but in terms of DALY estimates, watery diarrhea was only greater than bloody diarrhea by a DALY factor of 3. This trend can explain why it is not enough to look at only the number of cases, prevalence or incidence without considering the other aspects of the disease envelope, especially the disease severity. The DALY estimates therefore provide a risk-based perspective of the impact of each illnesses on the population health of a country (18). In prioritizing interventions, policy makers can be advised to address the causes of the studied illnesses in the order of watery diarrhea - bloody diarrhea — typhoid fever — cholera. In most of our DALY estimates, the YLL component was greater than YLD by over $80 \%$. This can be possible because the illnesses in this study were acute with a short duration to influence the YLD component or these illnesses mainly cause death in children resulting to large YLL estimates as it has been reported that children under 5 year old bear a greater burden of foodborne diseases in the Sub Saharan African regions (2).

Our DALY estimates from HCPs survey were in a close range of about 1 to 1.5 fold with the DALY estimates from reported cases (RBC) for watery diarrhea and bloody diarrhea. The same trend was observed for the DALY estimates to combined cases of watery diarrhea, bloody diarrhea and cholera combined) from RBC data compared to the DALY estimates from ORS prescription. This comparison suggests that HCP data can also be used. However, HCP opinion 
survey should be used with caution for illnesses which occur sporadically where some HCPs can finish the whole year without handling a single case. In this study, the sporadic occurrence of typhoid fever (Fig. 2.3) can explain the large 95\% credible interval and the significant difference observed between the DALY estimates for typhoid fever from HCPs and RBC data (Fig. 2.6). Our study has demonstrated that different syndromic surveillance data sources (epidemiology, opinion survey and drug prescriptions) can be used for DALY estimates. This approach can be effective in situations where syndromic data is readily available compared to the desired integrated food chain and laboratory based surveillance data (24).

In Table 2.2, we compared our DALY estimates from notifiable surveillance cases (RBC) with the DALY of comparable illnesses reported in previous studies. In this study, DALY estimates for combined cases of watery diarrhea, bloody diarrhea and cholera were 40 times lower compared to the DALY of diarrhea diseases reported by von Witzke et al. (12) in Rwanda, year 2000 (Tab. 2.2). This decline in DALY estimates for diarrhea over the years is in agreement with what was reported by the Institute for Health Metric and Evaluation (IHME) for the period between 1990 to 2013 (50). Rwanda was also classified among countries in Sub-Saharan Africa that have DALY estimates of diarrheal diseases significantly lower than the mean (50). In addition, our DALY estimates for diarrhea in Rwanda were 20 times lower than the DALY estimates from IHME in 2013 (51). This difference in DALY is justifiable because in the IHME study the deaths estimates used were 10 times more than our study and deaths numbers as observed from this study greatly influences the DALY outcome of short term illnesses. Furthermore, the DALY estimates for typhoid fever in this study were about $15 \%$ of the 2010 estimates from each of the two WHO Africa regions (Tab. 2.2). Considering that there are more than 20 countries in each of these WHO regions (2), these findings support what Havelaar et al. (2) acknowledged that the estimates in their study were conservative and more on the side of underestimation. Comparing DALY estimates across different studies at the moment, should also be done with caution due to the differences in methodology and approach. Nevertheless, continued comparison of DALY estimates can be a basis for setting public health objectives, contribute to the quest to harmonise study approaches and act as a reminder of the gap in estimating the real burden of foodborne illnesses. 


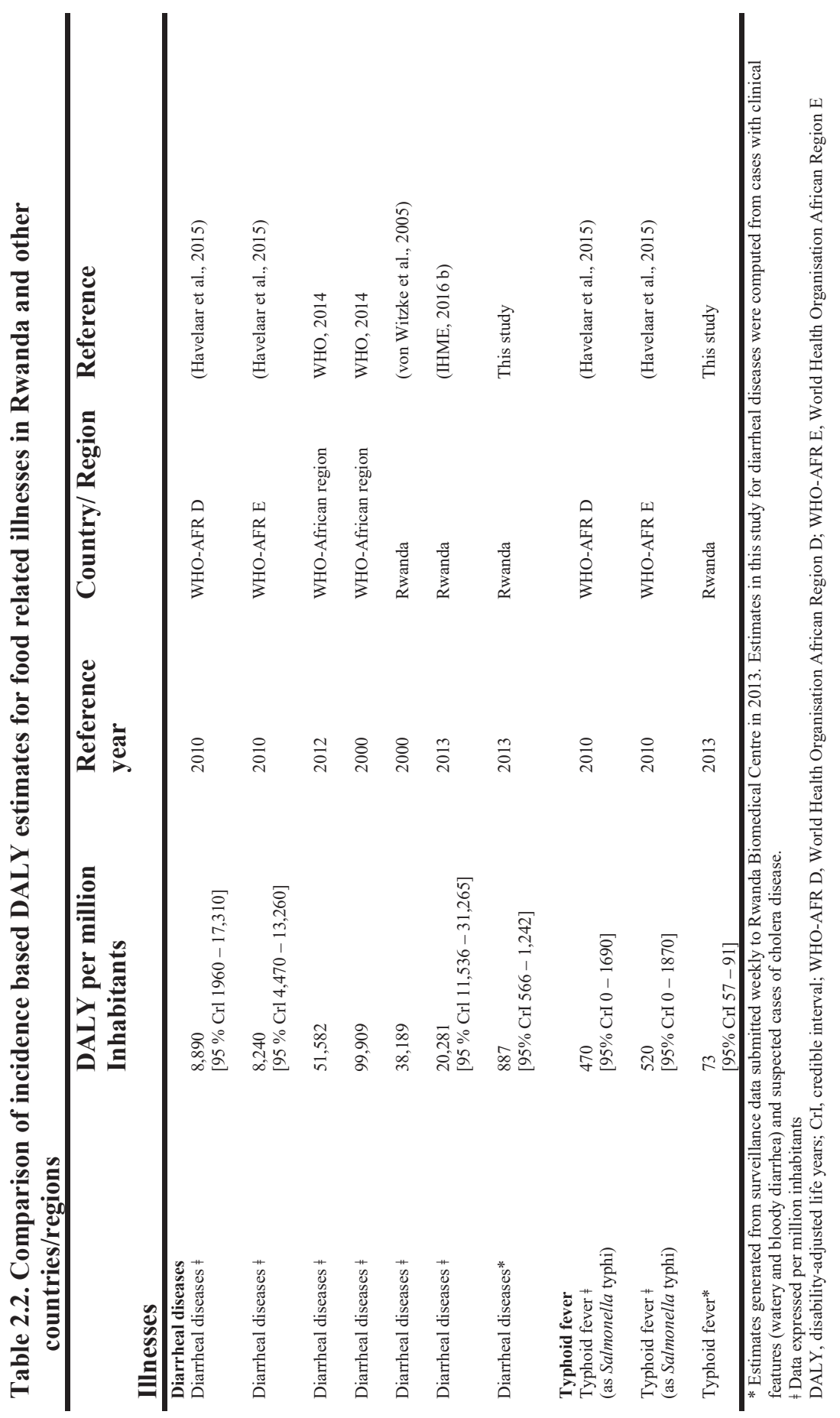




\section{Data gaps and limitation of the study}

For all the reported cases, we assumed that all diarrheal cases are mainly infectious in origin as in most developing countries (26). Even with the assumed infectious nature of these diarrheal cases, it was not possible to underpin and rank from this study the most important foodborne pathogens. Various foodborne pathogens can lead to diarrhea. For example, there is need to investigate the burden of non-typhoidal Salmonella in additional to the already existing surveillance efforts of typhoid fever (targeting Salmonella Typhi). We used population survey studies in USA for the multiplier for underreporting due to medical seeking behaviour and underdiagnosis. Discrepancies may come the fact that multipliers from a developed country were used in this study, this approach may result to underestimation of the burden. DALY estimates in this study would improve if population surveys in Rwanda cover medical seeking behaviours for different illnesses in future. We also assumed that all cases of illnesses registered at health facilities were reported to the notifiable surveillance system at RBC. During this study, the data from the notifiable surveillance system was not stratified by age and sex, so is our DALY estimates. Since diarrheal diseases can also originate from non-food sources such as unhygienic shared sanitation facilities and open defecation (52), attributing cases to sources will provide the clear burden estimates according to sources. For all illnesses, we assumed that all cases in this study were acute and therefore the duration of chronic cases and their related sequelae not considered. We used the WHO deaths estimates per age group (53) to distribute per age group the total deaths reported by the $\mathrm{MoH}$ for each studied illnesses. Registering deaths according to aetiological agents, vehicles and demographics will also lead to improved estimates in future.

For the over the counter (OTC) drug prescription/sales records, the data was paper based and collecting data from individual pharmacies was not possible. We were able to cover the year 2013 in 37 pharmacies for affiliates and dependants (about 3.7\% of population of Rwanda) (28) of the public insurance scheme at Rwanda Social Security Board. Data collection would have been easier and more accurate if all pharmacies had electronic records of sales and prescriptions that are submitted to a one stop centre at a regulated time, but this study shows that even in the absence of an electronic system, pharmacy data can be used to estimate food related illnesses.

In this study we have used data from three syndromic surveillance sources, ie. data from the notifiable surveillance system at RBC, OTC drug prescription and from opinion survey with HCPs to estimates outcome based DALY. Each data source has its advantages and dis advantages. Notifiable surveillance data are easy to retrieve if the electronic reporting system is working (54). However the data from the surveillance system have to be supported by population surveys to determine medical seeking behaviour (55) and in some cases there are under notification and underdiagnosis from health facilities $(15,56)$. Data from drug sales can be more representative and may not require adjusting for medical seeking behaviour especially in situations where patients can access pharmacies with or without HCP's advice. The drawbacks for this data are that it is difficult to collect data from private and public pharmacies, 
and some patients repetitively buy drugs without HCP consultation and this can hype the number of cases and at times misdiagnosis. Opinion survey data requires no pre-existing data collection infrastructure but the data generated is very subjective and greatly influenced by trends, seasons, location for the illnesses understudy. If a survey is conducted in areas where an outbreak has just occurred, the illness understudy may be accorded unrealistic high incidence. In Table A.4 of the Technical appendix A, high and fluctuating incidences of the studied illnesses can be observed.

\section{Conclusion and recommendations}

We have provided trends and estimates for the burden of food related illnesses in Rwanda for the year 2013 based on syndromic surveillance data. We envision that the data gaps identified, and the methodology used in this study will guide future studies on estimating the burden of foodborne illnesses in Rwanda and other developing countries. It is important to note that as developing countries aspire to acquire laboratory based- and integrated food chain disease surveillance systems, the data from the cheaper and available syndromic surveillance data sources can still be used to provide guiding estimates. As recommended by WHO (24), estimating the burden of disease is a step in the right direction towards introducing integrated food chain surveillance systems. Integrated food chain surveillance systems will prepare these countries to address the current and future challenges from foodborne illnesses. This preparedness will involve national multi-task teams (HCPs, food safety experts, academia, agriculturalists) to collect pathogen information from humans, animals and plants. This information will support improved studies to estimate the burden of foodborne diseases based on pathogen identification and ranking, source attribution, acute disease and sequelae ranking, all with aim of supporting evidence based public health policies.

Disclaimer. The findings and conclusions in this study are those of the authors and do not necessarily represent the official position of the institutions where input data were sourced. 


\section{Appendix}




\section{Technical Appendix A}

\section{Outcome based DALY estimates.}

In this appendix, the methodology used to estimate outcome based DALY is presented for watery diarrhea, bloody diarrhea, cholera and typhoid fever in Rwanda, year 2013. Syndromic surveillance data was used in this study. Data sources were the epidemic surveillance and response division of Rwanda Biomedical Centre (RBC), an opinion survey with health care providers (HCPs), prescription records for oral rehydration salts (ORS), Rwanda Ministry of Health reports $(\mathrm{MoH})$, Rwanda National Institute of statistics reports $(28,29)$, the World Health Organisation (WHO) and data in other published literature. DALY estimates were computed using the R-DALY calculator (57).

\section{Glossary}

In the context of this study, the following terms and abbreviations were defined/applied as follows:

Age weighting, refers to a factor which can be used in DALY calculations to carter for the relative value of a year of healthy life lived at different ages (58).

Bloody diarrhea. Case refers to any person with diarrhoea and whose stool contains visible traces of blood.

Case fatality rate (CFR). Proportion of reported cases of a specified disease or condition which are fatal within a specified time. CFR in this study are used in percentage proportions (\% ).

Cholera. Suspected cases, a patient aged 5 years or more develops severe dehydration or dies from acute watery diarrhoea. A case of cholera is confirmed when Vibrio cholerae 01 or 0139 is isolated from any patient with diarrhoea (59). DALY calculations in this study included the 0-4 years age group considering that all age groups can suffer from cholera.

DALY (Disability-Adjusted Life Years), summary metric of population health which measures how many years of healthy life are lost due to premature death and or life lived with the disease and or disability. DALY are the sum of two components: years of life lost due to premature mortality (YLL) and years lived with disability (YLD) (31).

DALY calculator, a DALY package for calculating DALY and performing uncertainty and sensitivity analyses (57).

Disability weight (DW) is a weighing factor that reflects the severity of the disease on a scale from 0 (perfect health) to 1 (equivalent to death). Disability weights are generated through largescale empirical investigation in which judgments about health losses associated with many causes of disease and injury are elicited from the general public in diverse communities (60).

Discounting for time, refers to the inclusion of discount rates in DALY calculations to carter for future health life years lost (61). Discounting for time in DALY calculations is borrowed from economic principles (58).

Duration of disease, refers to the time interval from manifestation of the illness to the time of healing for nonfatal cases or death for fatal cases. 
Food-related pathogens, refers to aetiological agents that can cause human illnesses/diseases through food and other sources.

Food related illnesses, refers to the illnesses that can be caused mainly through food and water notwithstanding other causes. Because non confirmed cases are used in this study, the term "food related illnesses" is used instead of foodborne illnesses.

GBD (Global Burden of Disease) a systematic, scientific effort to quantify the comparative magnitude of health loss due to diseases, injuries, and risk factors by age, sex, and geographies for specific points in time (31).

HCPs: Health care providers, including general practising doctors and grade 1 nurses

Incidence rate, new cases of disease occurring per unit of population, per unit time (number of new cases per 1,000 persons per year).

GBD 2010, life expectancy table. Represents the aspiration for healthy lifespan for all individuals, both female and male (31).

MoH: Ministry of Health of Rwanda (http://www.moh.gov.rw/index.php?id=2).

Mortality, number of deaths due to a specific disease in a population per unit time. (Units in this study were, deaths per 1,000 persons per year)

Multiplier, refers to the multiplication factor used to upscale the reported numbers to carter for the magnitude of underestimation due to medical seeking behaviour (15) and underdiagnosis.

NISR: National Institute of Statistics of Rwanda, a public institution in Rwanda mandated to collect, analyse and disseminate, among others duties, information on population housing census, demographic health survey and population conditions of living (http://www.statistics.gov.rw/).

Onset of disease, age of onset in years is the age at which an individual acquires, develops, or first experiences a condition or symptoms of a disease.

ORS (Oral rehydration salts), a glucose electrolyte solution given to patients by mouth to combat dehydration especially due to diarrhea (62).

Perceived prevalence, in this study perceived prevalence refers to the proportion of individuals in the population, suffering from the illnesses under study in a given period, based on the opinion or experience of health care providers.

PERT distribution (Program Evaluation and Review Technique). A probability distribution which is based on the $\beta$ distributions, originally referring to a project management tool (63). The PERT distribution can be specified either using a minimum, maximum and modal value, or by three percentile points, such as a median value and $95 \%$ credible intervals. As from Kirk et al. (64) we used this distribution widely in our analysis, as it allows for asymmetric distributions. 
RBC (Rwanda Biomedical Centre), a public institution in Rwanda under the Ministry of Health, mandated among others duties to conduct syndromic- and epidemic surveillance and response (http://www.rbc.gov.rw/).

Treatment proportion, the proportion of individuals in the whole population, suffering from the illnesses under study, that seek medical care.

Typhoid fever. Suspected case, any person with gradual onset of steadily increasing and then persistently high fever $\left(38^{\circ} \mathrm{C}\right.$ and above), chills, malaise, headache, sore throat, cough, and, sometimes, abdominal pain and constipation or diarrhoea. Confirmed case: Suspected case confirmed by isolation of Salmonella typhi from blood, bone marrow, bowel fluid or stool (65).

Watery diarrhea. Case refers to a person with three watery stools or more within 24 hours.

WHO, the World Health Organisation of the United Nations.

YLD (Years Lived with Disability) is a component of DALY estimates computed by multiplying the number of incident cases of a given illness in a population with the disability weight (DW) and the average duration of the case until remission or death (years) (31).

YLL (Years of Life Lost due to premature mortality), is a component of DALY estimates, computed by multiplying the number of deaths at a given age with the standard life expectancy at that age (31). 

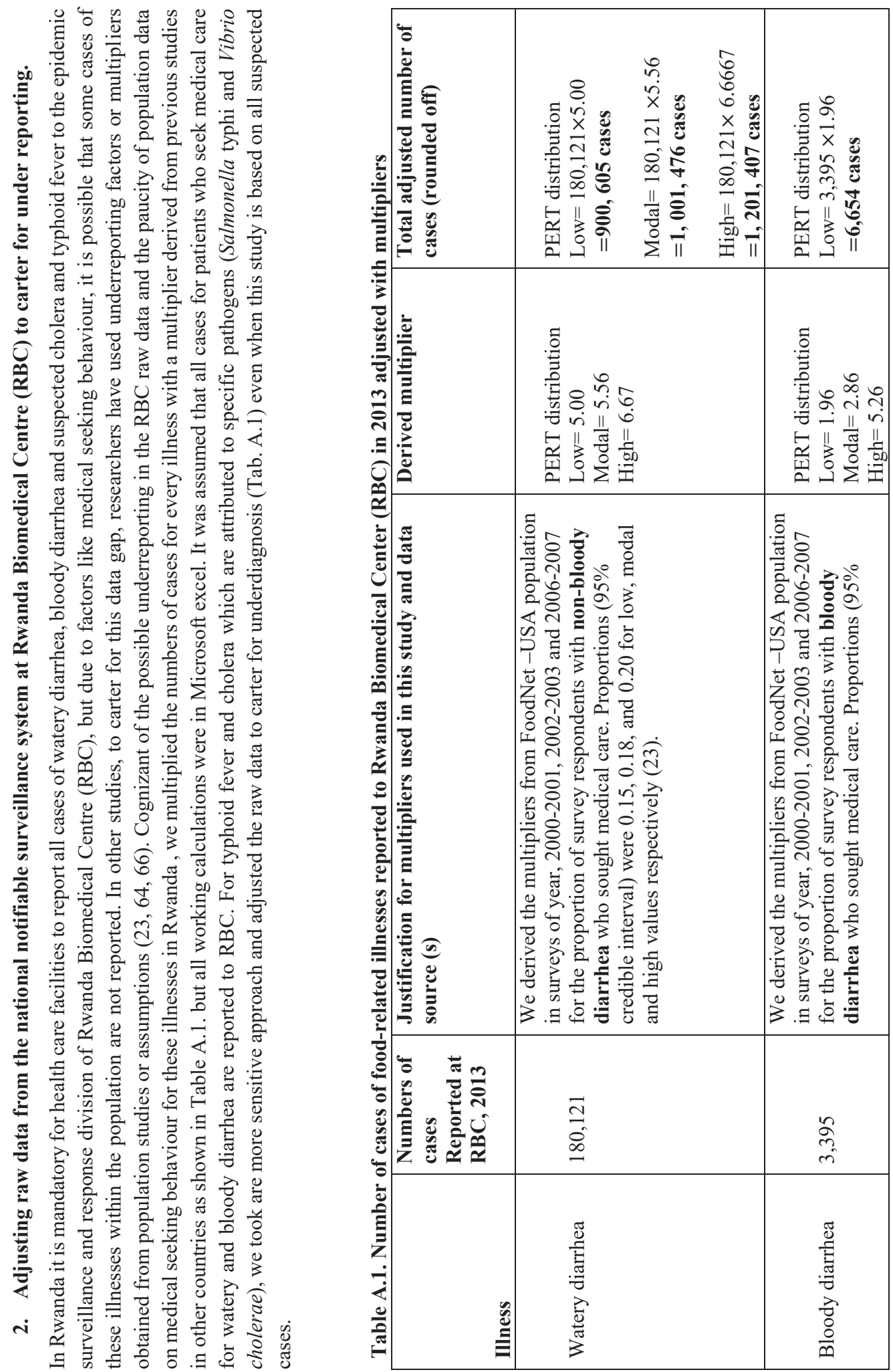


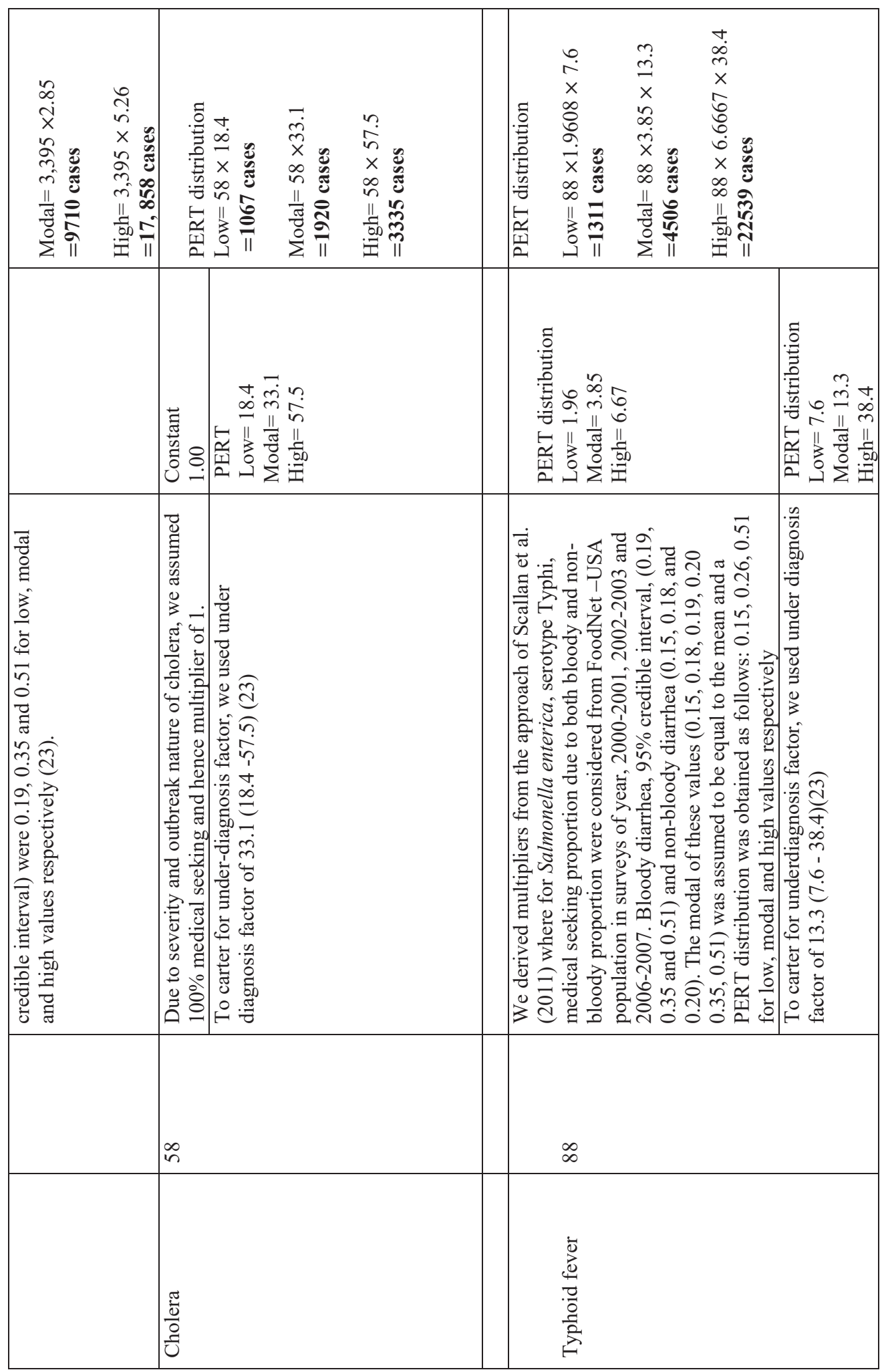




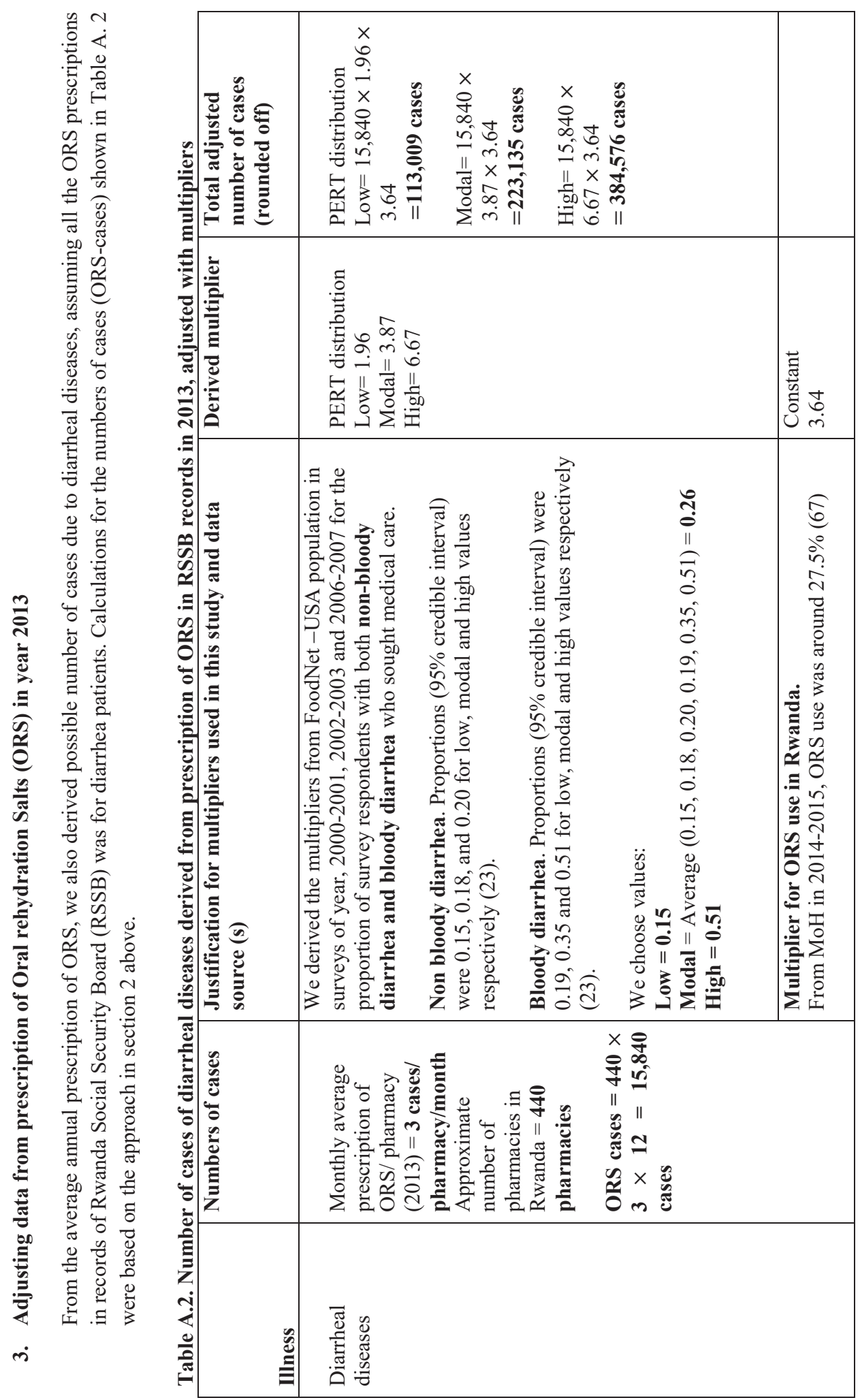




\section{General input parameters for the DALY calculator}

\subsection{Calculation of incidence from RBC data and ORS prescription} (cases/1000persons/year)

We calculated the incidence as follows (Eq. A.1):

\section{Equation A.1}

$$
\text { Incidence }=\frac{\text { Number of cases }}{\text { Population under study }} \div 1 / 1000 \text { persons } \div 1 / \text { year }
$$

The RBC data was not age or gender specific, so in calculating incidence, we chose to consider the whole population of 10,515,973 inhabitants in 2012 (29) without age/gender stratification.

Table A.3. Incidence of food-related illnesses in 2013

\begin{tabular}{|c|c|c|}
\hline & $\begin{array}{l}\text { Total adjusted number of } \\
\text { cases(rounded off) }\end{array}$ & $\begin{array}{l}\text { Incidence } \\
\text { (cases/1000persons/year) }\end{array}$ \\
\hline Illness & & \\
\hline Watery diarrhea & $\begin{array}{l}\text { PERT distribution } \\
\text { Low }=\mathbf{9 0 0 , 6 0 5} \text { cases } \\
\text { Modal }=\mathbf{1 , 0 0 1 , 6 8 0} \text { cases } \\
\text { High }=\mathbf{1}, \mathbf{2 0 0 , 8 1 2} \text { cases }\end{array}$ & $\begin{array}{l}\text { PERT distribution } \\
\text { Low }=85.64 \\
\text { Modal }=95.25 \\
\text { High }=114.19\end{array}$ \\
\hline Bloody diarrhea & $\begin{array}{l}\text { PERT distribution } \\
\text { Low }=\mathbf{6 , 6 5 7} \text { cases } \\
\text { Modal }=\mathbf{9 6 7 0} \text { cases } \\
\text { High }=\mathbf{1 7 , 8 6 9} \text { cases }\end{array}$ & $\begin{array}{l}\text { PERT distribution } \\
\text { Low }=0.633 \\
\text { Modal }=0.922 \\
\text { High }=1.699\end{array}$ \\
\hline Cholera & $\begin{array}{l}\text { PERT distribution } \\
\text { Low }=1067 \text { cases } \\
\text { Modal }=1920 \text { cases } \\
\text { High }==\mathbf{3 3 3 5} \text { cases }\end{array}$ & $\begin{array}{l}\text { PERT distribution } \\
\text { Low }=0.1015 \\
\text { Modal }=0.183 \\
\text { High }=0.317\end{array}$ \\
\hline ORS-diarrhea & $\begin{array}{l}\text { PERT distribution } \\
\text { Low }=\mathbf{1 1 2 , 9 4 8} \text { cases } \\
\text { Modal }=\mathbf{2 2 1 , 5 4 3} \text { cases } \\
\text { High }=\mathbf{3 8 4 , 3 6 1} \text { cases }\end{array}$ & $\begin{array}{l}\text { PERT distribution } \\
\text { Low }=10.74 \\
\text { Modal }=21.08 \\
\text { High }=36.6\end{array}$ \\
\hline Typhoid fever & $\begin{array}{l}\text { PERT distribution } \\
\text { Low }=\mathbf{1 3 1 1} \text { cases } \\
\text { Modal }=\mathbf{4 5 0 2} \text { cases } \\
\text { High }=\mathbf{2 2 5 2 8} \text { cases }\end{array}$ & $\begin{array}{l}\text { PERT distribution } \\
\text { Low }=0.125 \\
\text { Modal }=0.428 \\
\text { High }=2.142\end{array}$ \\
\hline
\end{tabular}




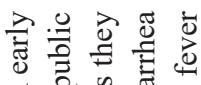

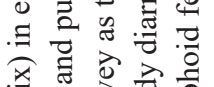

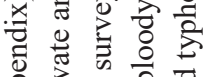

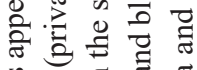

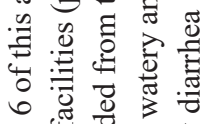

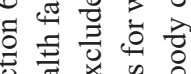

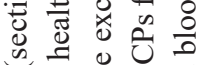

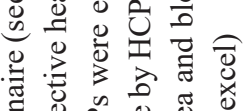

苛论

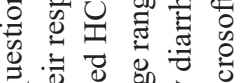

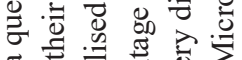

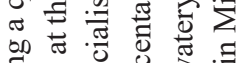

我步

(n)

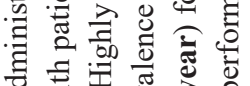

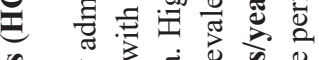

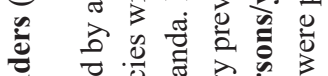

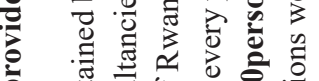

०

ป

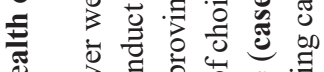

ङ

馬

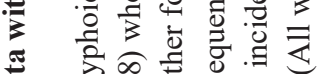

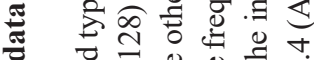

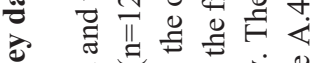

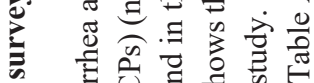

क.

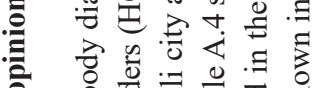

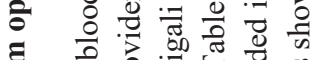

อ อ

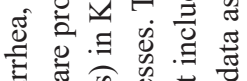

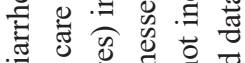

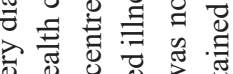
त्य

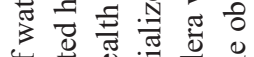

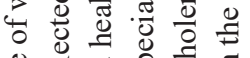
¿ु

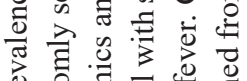

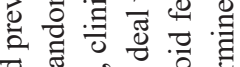

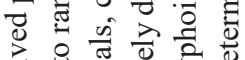

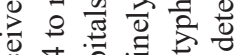

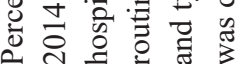

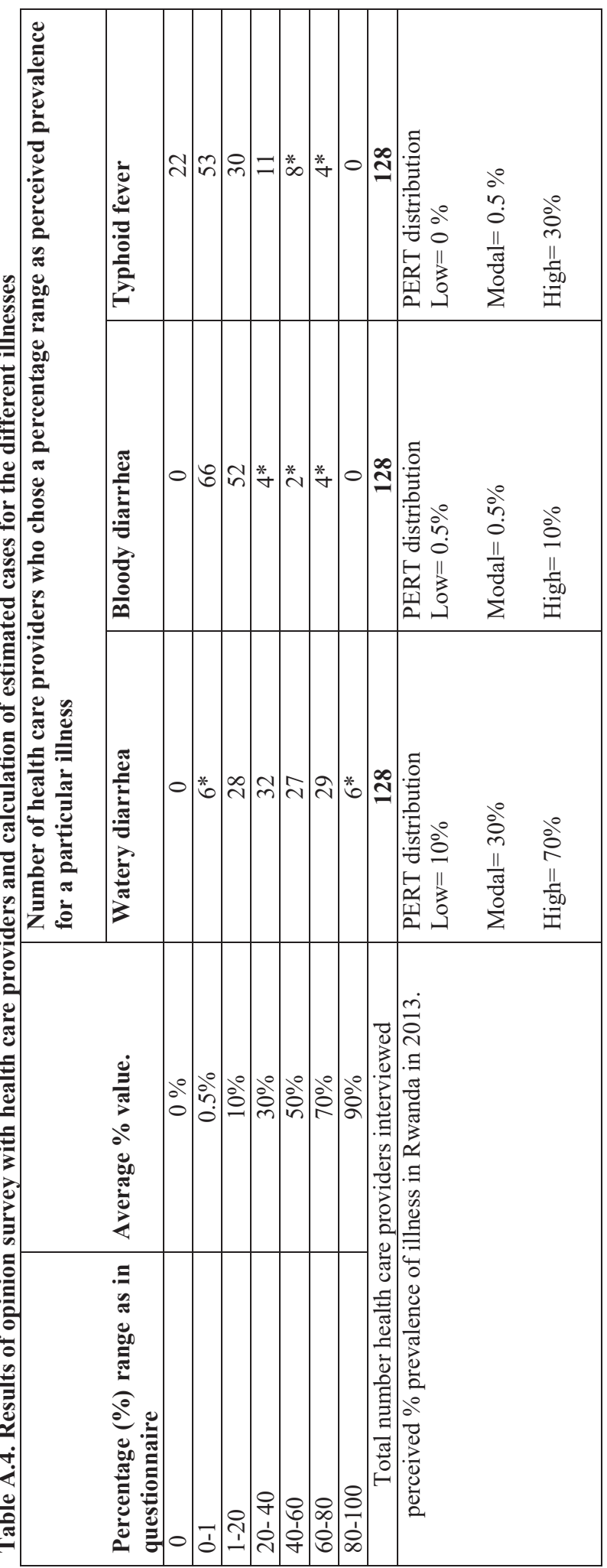




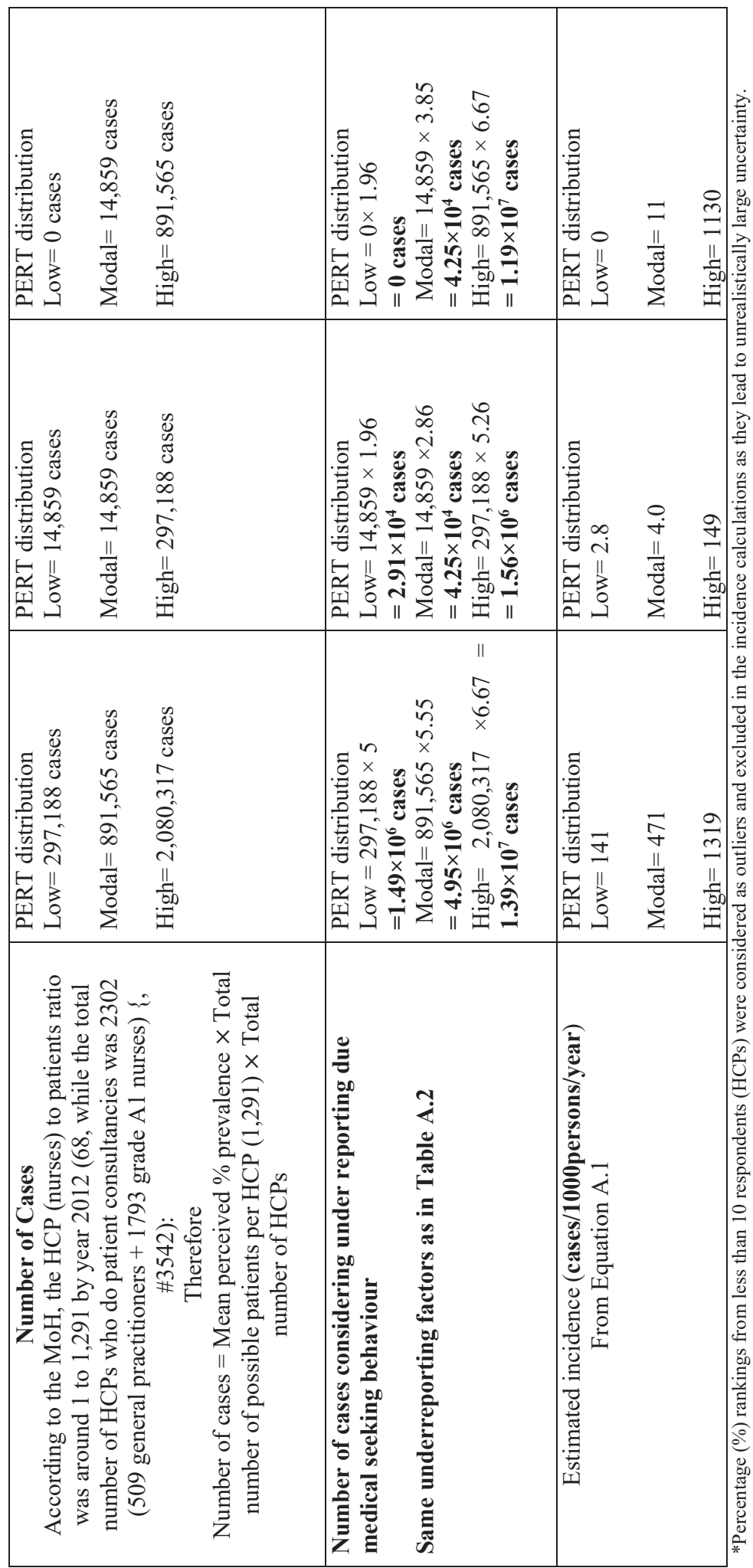




\subsection{Population under study}

Data about the population demographics was obtained from the Rwanda fourth population and housing census conducted by the National Institute of Statistics of Rwanda (29). The data was reorganised to suit the age categories programmed in the R-

DALY calculator (57) as in Table A.5

Table A.5. Population distribution by age in Rwanda 2012

\begin{tabular}{lll}
\hline Age group. & No. of Males & No. of Females \\
\hline $0-4$ & 768,340 & 774,057 \\
$5-14$ & $1,208,114$ & $1,406,385$ \\
$15-44$ & $2,350,514$ & $2,463,900$ \\
$45-59$ & 465,048 & 506,953 \\
$60+$ & 262,853 & 299,811 \\
\hline
\end{tabular}

\subsection{Life expectancy table}

Life expectancy table used in the global burden of disease in 2010 (GBD 2010) for both males and females was adopted (31).

\subsection{Social values}

\subsubsection{Discounting for time}

In this study, a discount rate of $0 \%$ was applied similar to the GBD of 2010 (31).

\subsubsection{Age-weighting}

No age weighting was used in this study.

\subsection{On set age: (in years)}

\subsubsection{Watery diarrhea, bloody diarrhea and cholera}

Even though children (under 5 years) and old people (above 59 years) are more susceptible, diarrheal diseases can lead to morbidity across all age groups (69). The default age groups in R-DALY calculator were arranged in beta PERT distribution and applied in this study, since the onset of acute diarrheal diseases can occur at any age. Average age for each age group was taken as the modal value (Tab A.6).

Table A.6. On set age for diarrhea diseases

\begin{tabular}{l|l|l|l}
\hline \multirow{2}{*}{ Age group } & Age in years & \multicolumn{2}{l}{} \\
\cline { 2 - 4 } & modal & Min & Maximum \\
\hline $0-4$ & 2 & 0 & 4 \\
\hline $5-14$ & 9.5 & 5 & 14 \\
\hline $15-44$ & 29.5 & 15 & 44 \\
\hline $45-59$ & 52 & 45 & 59 \\
\hline $60+$ & 77.5 & 60 & 95 \\
\hline
\end{tabular}




\subsubsection{Typhoid fever}

Default age groups in R-DALY calculator we used in a beta PERT distribution since illness due to typhoid can occur at any age (70) as shown in Tab. A. 6.

\subsection{Disability Weight (DW) of disease: (range [ 0-1])}

\subsubsection{Watery diarrhea, bloody diarrhea and cholera}

The global burden of disease study for the year 2010 (GBD 2010) involved countries like Tanzania in the same region as Rwanda. In the GBD 2010, diarrheal diseases were classified as mild, moderate and severe and awarded disability weights (DW) (60). All reported cases of bloody diarrhea and cholera were assumed to be severe; the GBD 2010 DW for severe diarrhea were, modal $=0.281$ ( low $=0.184-$ high $=0.399$ ) in a beta PERT distribution(60). We also assumed that all reported cases of watery diarrhea had moderate and severe episodes ( DW moderate + DW severe) with the modal as the average $(0.133,0.202,0.299,0.18$, $0.281,0.399)$, leading to a PERT distribution of; modal $=0.250$ ( low $=0.133-$ high $=0.399$ ).

\subsubsection{Typhoid fever}

DW of 0.6 was applied as from a study by Gkogka et al. (18).

\subsection{Mortality: deaths/1000 persons/ year}

\subsubsection{Watery diarrhea, bloody diarrhea and cholera}

We used the deaths (335 deaths) due to diarrheal diseases reported by Ministry of Health of Rwanda for the year 2012 (71) and a pert distribution was obtained as shown in Box 1 to carter for uncertainty under reporting and recording.

Box 1 Deaths due to diarrheal diseases in Rwanda, 2013

\begin{tabular}{|c|c|c|c|}
\hline Symbol & Variable & & Source \\
\hline $\mathrm{dD}$ & Deaths due to diarreal diseases & 335 & MoH, 2013 \\
\hline unD & Deaths due to unknown causes & 5,063 & $\mathrm{MoH}, 2013$ \\
\hline $\mathrm{tD}$ & Total deaths for all causes & 12,172 & $\mathrm{MoH}, 2013$ \\
\hline $\mathrm{kD}$ & Deaths due to known causes = (tD-unD) & 7,109 & Calculated \\
\hline pdD & Proportion of known deaths due to diarhea $=(\mathrm{dD} / \mathrm{kD})$ & 0.0471 & Calculated \\
\hline$x D$ & Deaths due to diarhea not registered $=\left(p d D^{*} u n D\right)$ & 239 & Calculated \\
\hline $\mathrm{mD}$ & Most likely deaths due to diarrhea $=(\mathrm{dD}+\mathrm{xD})$ & 574 & Calculated \\
\hline \multirow[t]{5}{*}{$\mathrm{hD}$} & Highest possible deaths due to diarrhea $=2^{*} \mathrm{mD}$ & 1147 & Assumption \\
\hline & Output: Risk pert distribution & & \\
\hline & low $=335$ deaths & & \\
\hline & modal $=574$ deaths & & \\
\hline & High = 1147 deaths & & \\
\hline
\end{tabular}


To estimate the number of deaths for patients with only watery diarrhea or bloody diarrhea as clinical features, and or cholera disease with respect to the total death burden diarrheal diseases, we used the case fatality rates (CFR) derived from the most suspected respective causative pathogens from literature as in Table A.7. Box 2 shows the methodology used to generate mortality rates and the associated uncertainty were computed using@risk 7.5 software ( Palisade corporation, USA ) at 20,000 iterations.

\begin{tabular}{|c|c|c|c|}
\hline \multicolumn{4}{|c|}{ Bloody diarrhea } \\
\hline & Pathogen & CFR \% & Reference \\
\hline 1 & Shigella spp. & $0.1,1,4,7,15$ & (6) (72) \\
\hline 2 & $\begin{array}{l}\text { Camplylobacter } \\
\text { jejuni }\end{array}$ & $0.1,3,10,0.05$ & $(6,18)$ \\
\hline 3 & $\begin{array}{l}\text { Non typhoidal } \\
\text { Salmonella }\end{array}$ & $0.5,0.14,19,20,25$ & (6),(73-75) \\
\hline 4 & $\begin{array}{l}\text { Entamoeba } \\
\text { histolytica }\end{array}$ & $0.1,0.2,0.3$ & (18) \\
\hline 5 & STEC & $0.8,3,5$ & (6) \\
\hline \multirow[t]{2}{*}{6} & EIEC & Like Shigella spp. & (76) \\
\hline & & & Pert (0.1, 5.7, 25) \\
\hline \multicolumn{4}{|c|}{ Watery diarrhea } \\
\hline 1 & $\begin{array}{l}\text { Norovirus } \\
\text { Rotavirus }\end{array}$ & $0.075,0.1,0.3,0.34,1.6,2.0$ & $(77-80)$ \\
\hline 2 & Giardia lamblia & $0,0.05,0.1$ & (18) \\
\hline 3 & EPEC & 0.01 & $(66,81)$ \\
\hline 4 & ETEC & 0.01 & (66) \\
\hline 5 & $\begin{array}{l}\text { Staphylococcus } \\
\text { aureus and other } \\
\text { food poisoning } \\
\text { bacteria }\end{array}$ & $0,0.025,0.05$ & (18) \\
\hline \multirow[t]{2}{*}{6} & $\begin{array}{l}\text { Cryptosporidium } \\
\text { spp. }\end{array}$ & $0.07,0.6$ & (18) \\
\hline & & & Pert $(0,0.33,2.0))$ \\
\hline \multicolumn{4}{|c|}{ Cholera } \\
\hline & Vibrio cholerae & $\begin{array}{l}\text { From year } 2009 \text { to } 2012 \text {, the WHO data } \\
\text { shows the CFR }=0 \text { in Rwanda. But to } \\
\text { carter for uncertainty due to under } \\
\text { diagnosis especially due to close } \\
\text { resemblance with ETEC, we selected a } \\
\text { CFR between } 0 \% \text { and } 0.01 \% \text {. CFR for } \\
\text { ETEC }=0.01 \%\end{array}$ & $(66,82,83)$ \\
\hline & & & Pert $(0,0.005,0.01)$ \\
\hline
\end{tabular}


From Table A.7, the average CFR was calculated and taken as the modal: watery diarrhea $=\mathbf{0 . 3 3} \%$, bloody diarrhea $=\mathbf{5 . 7 \%}$ and cholera $=\mathbf{0 . 0 0 5} \%$ in the pert distribution.

\section{Calculation of mortality rates}

We computed as in Equation A.2 the mortality rates (deaths/1000 persons/ year), the population of Rwanda (10,515,973 persons) (29) and the number of deaths due to diarrheal diseases.

\section{Equation A.2}

$$
\text { Mortality rate }=\frac{\text { deaths }}{\text { Total population }} \div\left(\frac{1}{1000 \text { persons }} \times \frac{1}{\text { year }}\right)
$$

The minimum, mode and maximum values of mortality rates in the output were selected for further calculations of respective DALY.

To suit the age group settings in the DALY calculator, the deaths proportions (distribution) per age group for watery diarrhea, bloody diarrhea and cholera disease was computed. The deaths estimates (proportions) per age groups from the WHO evidence department (84) were used to distribute the mortality values in Box 2 across different age groups.

\section{Mortality - ORS cases (deaths/1000persons/year)}

To calculate mortality for cases of diarrhea which also received ORS treatment, we multiplied the total diarrhea deaths (consideration underreporting) with the $\%$ (27.5) use of ORS in Rwanda (67) and thereafter computed the mortality as in the formulae above as follows: The same procedure for distribution mortality rate across age groups was followed as mentioned before. 


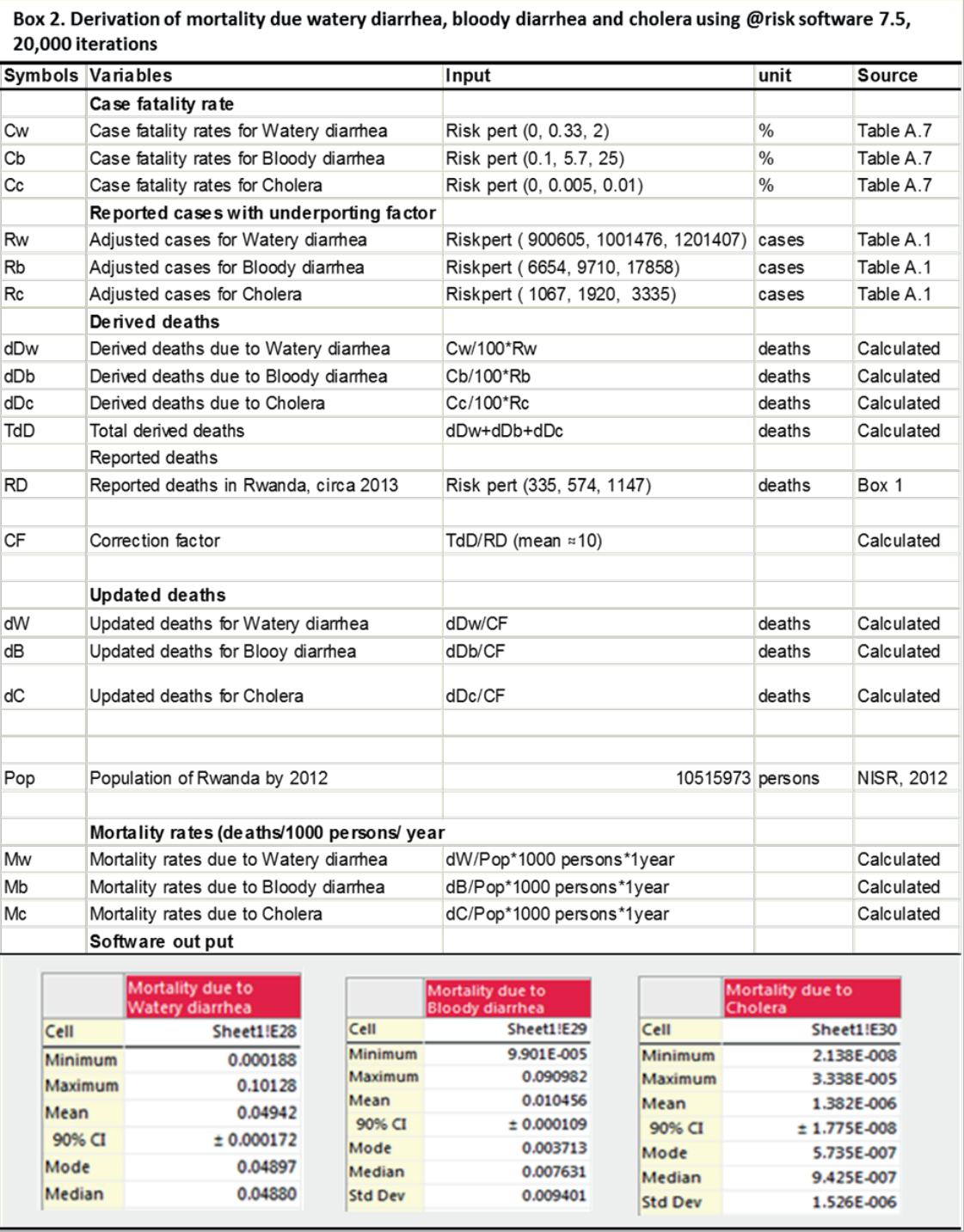

\subsubsection{Typhoid fever}

Due to paucity of data for mortality rates for sub-Saharan Africa in previous studies (85) were used. Buckle et al. (2012) reported, modal $=\mathbf{0 . 0 0 4}$ ( low $=\mathbf{0 . 0 0 2}$, high $=$ 0.007) deaths/1000 persons/ year. Deaths per age groups proportions for infectious agents, WHO GHE code 370 (84) were used to distribute the mortality reported by Buckle et al. (85) to different age groups. 


\subsection{Treatment proportion: (range [ $0-1]$ )}

\subsubsection{Watery diarrhea, bloody diarrhea and cholera}

\section{Watery diarrhea and Bloody diarrhea}

Due to lack of population survey data on medical seeking proportions for watery and bloody diarrhea in Rwanda, we adopted FoodNet -USA population in surveys of year, 2000-2001, 2002-2003 and 2006-2007 for the proportion of survey respondents with non-bloody diarrhea (watery diarrhea) and bloody diarrhea who sought medical care. Proportions (95\% credible interval) were, $\mathbf{0 . 1 5}, \mathbf{0 . 1 8}$, and $\mathbf{0 . 2 0}$ (watery diarrhea) and $\mathbf{0 . 1 9}, 0.35$ and 0.51 (bloody diarrhea) for low, modal and high values respectively (23).

\section{Cholera}

Always an outbreak spark $100 \%$ participation of health care system in Rwanda, therefore treatment proportion assumed to be; 1 (Take A.1).

\subsubsection{Typhoid fever}

We adopted medical seeking proportions used by Scallan et al.(23) for Salmonella enterica, serotype Typhi. Proportions (95\% credible interval) were, $\mathbf{0 . 1 5 , 0 . 2 6}$ and $\mathbf{0 . 5 1}$ for low, modal and high values respectively.

4.10. Duration of disease: (in years)

4.10.1. Watery diarrhea, bloody diarrhea and cholera

We assume that the diarrheal diseases in this study are acute and therefore the duration of chronic diarrhea and their related sequelae are not considered.

\section{Watery diarrhea and bloody diarrhea}

We use the durations published in the World Gastroenterology Organisation (WGO) practice guidelines of 2008 (86).

$3(1-14)$ days $=[\mathbf{0 . 0 0 8 2}(\mathbf{0 . 0 0 2 7}-\mathbf{0 . 0 3 8})]$ years

\section{Cholera}

After infection, the symptoms of cholera can appear from 0.1 to 10 days (87), (88, 89). We therefore adopt the duration of modal $=5$ days, low $=0.1$ and high $=10$ days, [ $0.0137(0.0003-0.0274)]$ years.

\section{ORS Cases}

We used a duration of $3(0.1-14)$ days $=[\mathbf{0 . 0 0 8 2}(\mathbf{0 . 0 0 0 3}-\mathbf{0 . 0 3 8})]$ years for watery diarrhea.

\subsubsection{Typhoid fever}

We take the duration of typhoid fever to be around 14 ( $3-60)$ days $=0.0384$ $(0.0032-0.1644)$ years $(18,65,90))$.

\subsection{Disability Weight (DW) of untreated disease: (range [ 0-1])}

\subsubsection{Watery diarrhea, bloody diarrhea, cholera and ORS cases}


Untreated cases of these diarrheal diseases were assumed to be mild and hence use a DW of $0.061(0.036-0.093)$ used in the 2010 global burden of disease study (60).

\subsubsection{Typhoid fever}

Class 1 DW of $\mathbf{0 . 0 9 6}$ (91) was adopted for uncomplicated typhoid cases (18).

\subsection{Average age at death: age in years}

\subsubsection{Watery diarrhea, bloody diarrhea and cholera}

We use the default age groups in the R-DALY calculator (Tab. A.9) adopted from the 1990 GBD (92). Deaths caused by diarrheal diseases were reported to be more significant for the age groups, $0-4(93)$ and +60 years $(94,95)$ however WHO estimates for sub-Saharan countries (84) indicate significant deaths proportions also in other age groups. Therefore average age at death for diarrheal diseases was adopted as shown in Table A.9

Table A.9. Average age at death for diarrheal diseases.

\begin{tabular}{c|c}
\hline \multirow{2}{*}{ Age group } & Age in years \\
\cline { 2 - 2 } & modal \\
\hline $0-4$ & 2 \\
\hline $5-14$ & 9.5 \\
\hline $15-44$ & 29.5 \\
\hline $45-59$ & 52 \\
\hline+60 & 77.5 \\
\hline
\end{tabular}

\subsubsection{Typhoid fever}

Average age per age groups at death presented in Table A.9 were used. 
5. R-outputs (Estimates for a population of 10,515,973 inhabitants ).

Deaths estimates from different data sources for a given illness are almost equal because of using the same mortality estimates.

DALY Calculator: RBC_Watery diarrhea

$\begin{array}{lrrrr} & \text { Mean } & \text { Median } & 2.5 \% & 97.5 \% \\ \text { DALY } & 7065 & 7056 & 4455 & 9797 \\ \text { YLD } & 778 & 706 & 226 & 1717 \\ \text { YLL } & 6287 & 6279 & 3738 & 8858 \\ \text { cases } & 1016345 & 1012790 & 930438 & 1120283 \\ \text { deaths } & 94 & 94 & 59 & 130\end{array}$

$\mathrm{YLD} / \mathrm{DALY}=11 \%$

YLL/DALY $=89 \%$

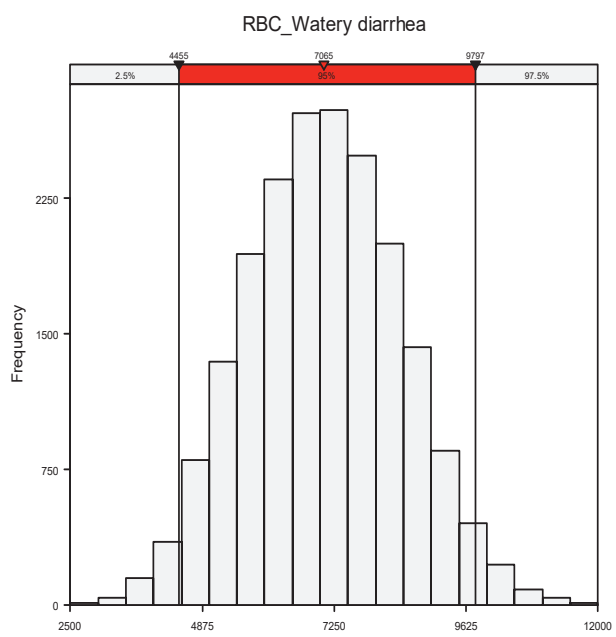

DALY
DALY Calculator: HCPs_Watery diarrhea

$\begin{array}{lrrrr} & \text { Mean } & \text { Median } & 2.5 \% & 97.5 \% \\ \text { DALY } & 10806 & 10271 & 6021 & 18494 \\ \text { YLD } & 4490 & 3789 & 944 & 11865 \\ \text { YLL } & 6317 & 6319 & 3767 & 8838 \\ \text { Cases } & 5839672 & 5668237 & 2427061 & 10242476 \\ \text { deaths } & 95 & 95 & 59 & 130 \\ & & & & \\ \text { YLD/DALY }=39 \% & & & & \\ \text { YLL/DALY }=61 \% & \end{array}$

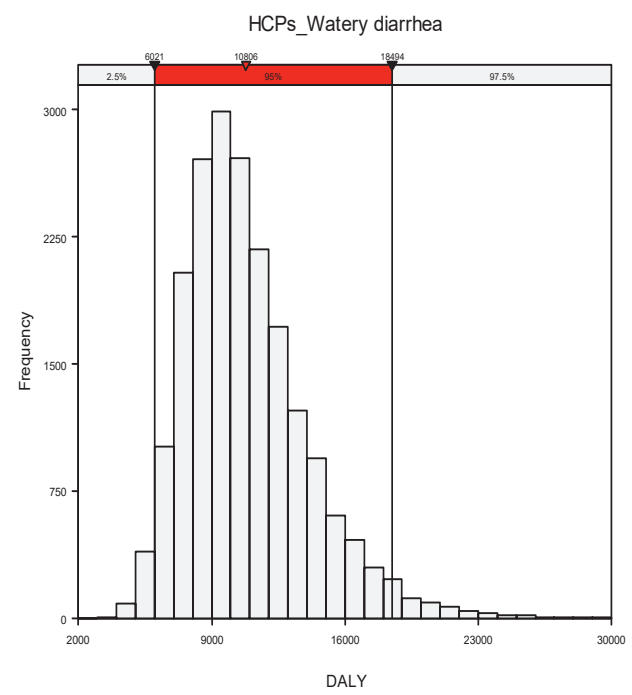


DALY Calculator: RBC_Bloody diarrhea

Mean Median 2.5\% $97.5 \%$

$\begin{array}{lrrrrr}\text { DALY } & 2243 & 2055 & 525 & 4997 \\ \text { YLD } & 8 & 7 & 2 & 19 \\ \text { YLL } & 2235 & 2048 & 516 & 4989 \\ \text { cases } & 10539 & 10380 & 7457 & 14502 \\ \text { deaths } & 34 & 31 & 9 & 70\end{array}$

YLD/DALY $=1 \%$

YLL/DALY $=99 \%$

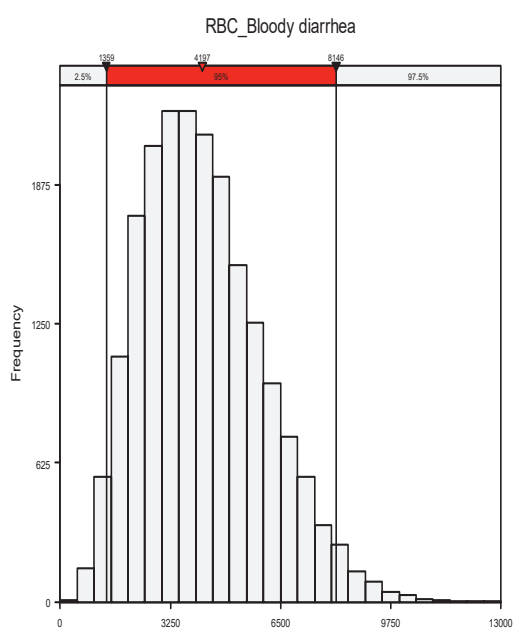

DALY
DALY Calculator: HCPs_Bloody diarrhea

\begin{tabular}{|c|c|c|c|c|}
\hline & Mean & Median & $2.5 \%$ & $97.5 \%$ \\
\hline DALY & 2462 & 2271 & 667 & 5245 \\
\hline YLD & 223 & 136 & 14 & 927 \\
\hline YLL & 2239 & 2051 & 507 & 4982 \\
\hline cases & 290761 & 209560 & 31551 & 953314 \\
\hline deaths & 34 & 31 & 9 & \\
\hline YLD/DAI & $L Y=10$ & & & \\
\hline
\end{tabular}

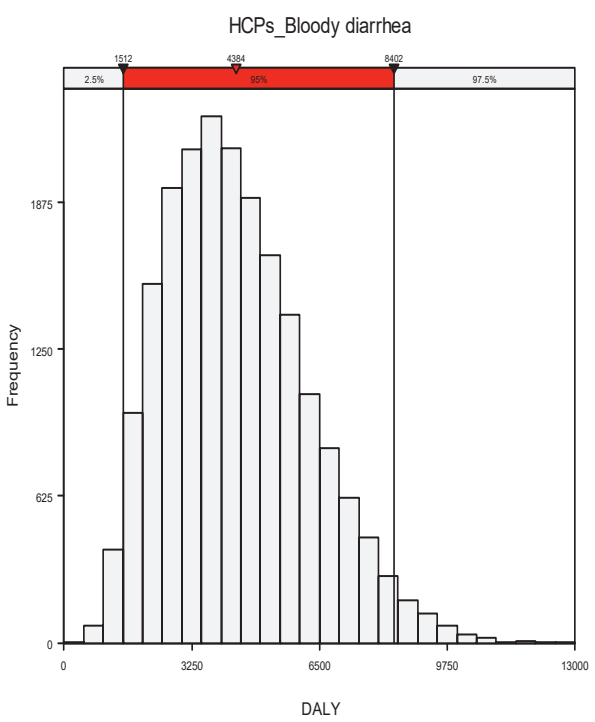


72 | Ch a p t e r 2

DALY Calculator: RBC_Typhoid fever

Mean Median 2.5응 $97.5 \circ$

$\begin{array}{lrrrrr}\text { DALY } & 771 & 770 & 601 & 952 \\ \text { YLD } & 36 & 29 & 6 & 107 \\ \text { YLL } & 735 & 734 & 572 & 905 \\ \text { cases } & 6954 & 6394 & 1887 & 14986\end{array}$

$\begin{array}{lllll}\text { deaths } & 11 & 11 & 8 & 13\end{array}$

$Y L D / D A L Y=5 \%$

YLL/DALY $=95 \%$

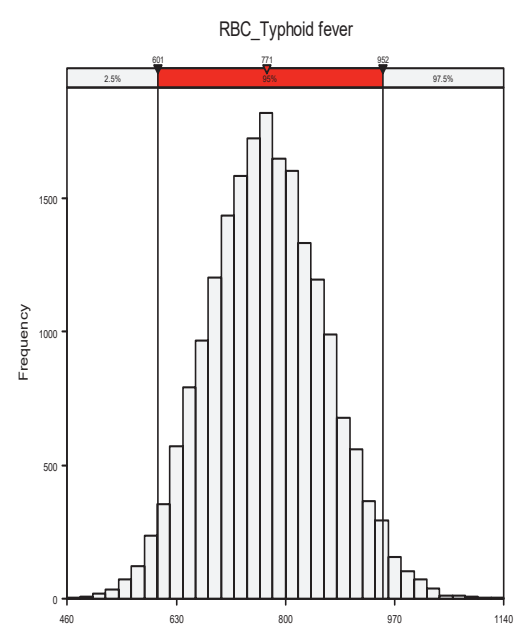

DALY
DALY Calculator: HCPs_Typhoid fever

$\begin{array}{lrrrr} & \text { Mean } & \text { Median } & \mathbf{2 . 5 \%} & \mathbf{9 7 . 5 \%} \\ \text { DALY } & 11437 & 7062 & 815 & 45644 \\ \text { YLD } & 10703 & 6333 & 76 & 44930 \\ \text { YLL } & 734 & 733 & 571 & 906 \\ \text { cases } & 2055633 & 1433517 & 18302 & 7173015 \\ \text { deaths } & 11 & 11 & 8 & 13 \\ & & & & \\ \text { YLD/DALY }=80 \% & & & \\ \text { YLL/DALY }=20 \% & & & & \end{array}$

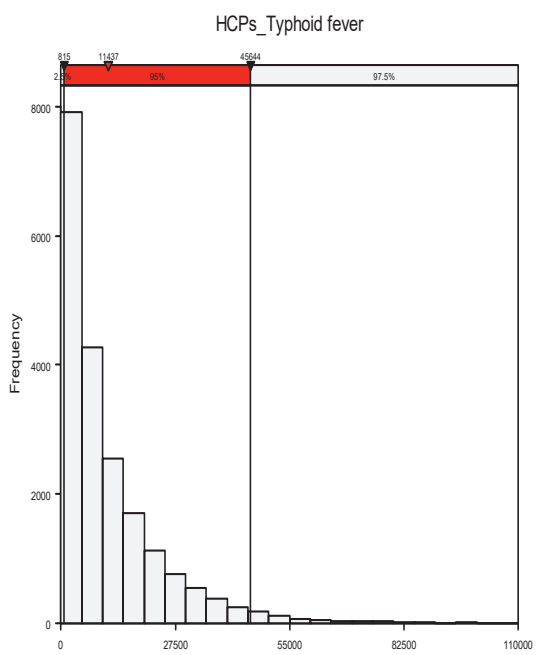

DALY 
DALY Calculator: RBC_Cholera

Mean Median 2.5\% $97.5 \%$

$\begin{array}{lrrrr}\text { DALY } & 8 & 8 & 3 & 16 \\ \text { YLD } & 8 & 8 & 3 & 15 \\ \text { YLL } & 1 & 0 & 0 & 1 \\ \text { cases } & 2017 & 2001 & 1348 & 2771 \\ \text { deaths } & 0 & 0 & 0 & 0\end{array}$

YLD/DALY $=93 \%$

YLL/DALY $=7 \%$

RBC_Cholera

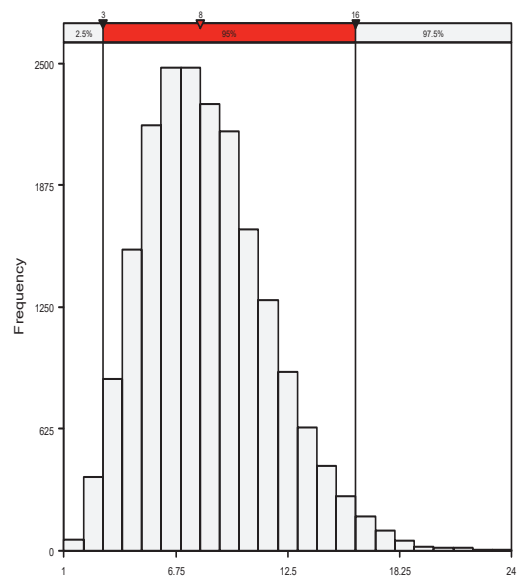

DALY
DALY Calculator: RBC_Diarrheal diseases

(cases of watery diarrhea + bloody disease +suspected cases of cholera)

\begin{tabular}{|c|c|c|c|c|}
\hline & Mean & Median & $2.5 \%$ & $97.5 \%$ \\
\hline DALY & 9324 & 9266 & 5951 & 13063 \\
\hline YLD & 796 & 728 & 244 & 1738 \\
\hline YLL & 8528 & 8486 & 5250 & 12200 \\
\hline cases & 1028839 & 1025790 & 942279 & 1131835 \\
\hline deaths & 128 & 127 & 82 & 178 \\
\hline \multicolumn{5}{|c|}{ YLD $/ D A L Y=9 \%$} \\
\hline YLL/DAL & $L Y=91 \%$ & & & \\
\hline
\end{tabular}

RBC_Diarrheal diseases

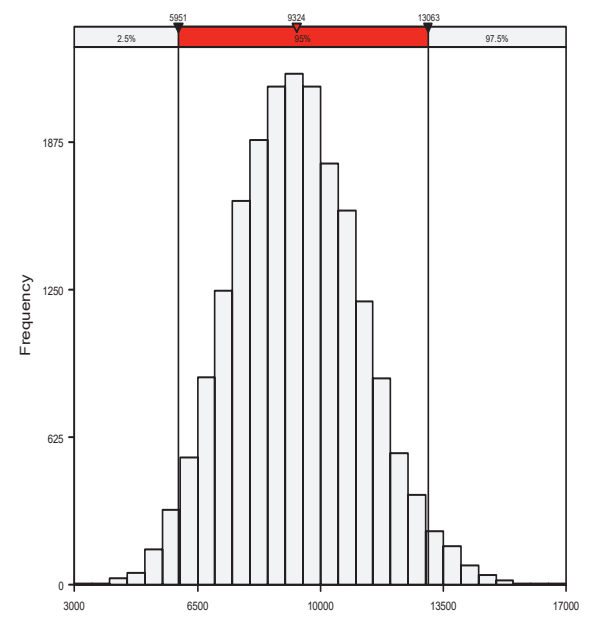

DALY 
$74 \mid \mathrm{C}$ h a p te r 2

DALY Calculator: ORS_Diarrhea

$\begin{array}{lrrrr} & \text { Mean Median } & 2.5 \% & 97.5 \% \\ \text { DALY } & 10990 & 10886 & 8238 & 14339 \\ \text { YLD } & 366 & 337 & 79 & 816 \\ \text { YLL } & 10624 & 10515 & 7894 & 13955 \\ \text { cases } & 230665 & 229470 & 148909 & 320947 \\ \text { deaths } & 170 & 169 & 133 & 212 \\ & & & & \\ \text { YLD/DALY }=3 \% \\ \text { YLL/DALY }=97 \%\end{array}$

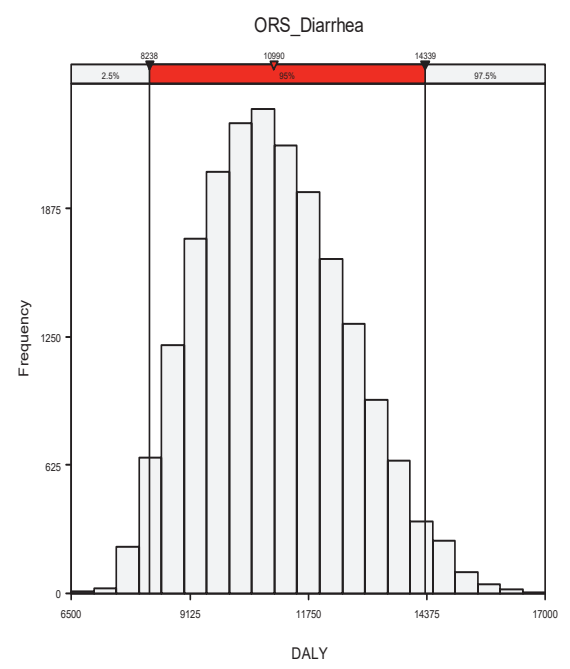




\section{Questionnaire administered to health care providers}

\section{Opinion survey for Medical practitioners about food-related illnesses in 2013}

\section{Symptomatic ranking of food-related illness}

How do you rank the prevalence of the following symptoms/clinical feature depending on your experience with patients in the year 2013. (use the following ranking criteria by ticking $(\sqrt{ })$ where applicable)

Ranking scale

\begin{tabular}{|l|l|l|l|l|l|l|l|}
\hline Category & 1 & 2 & 3 & 4 & 5 & 6 & 7 \\
\hline Percentage (\%) & $\begin{array}{l}\text { Not seen } \\
(0)\end{array}$ & $0-1$ & $1-20$ & $20-40$ & $40-60$ & $60-80$ & $80-100$ \\
\hline
\end{tabular}

Clinical feature

Bloody diarrhoea
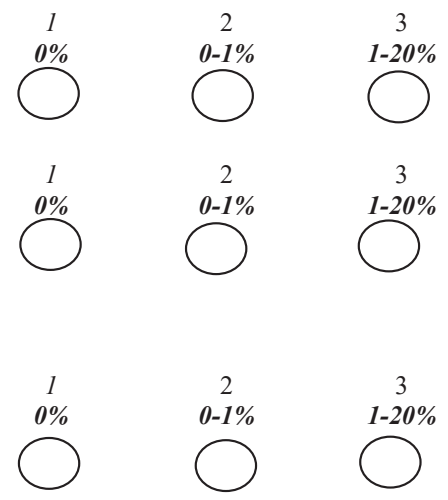

Typhoid fever

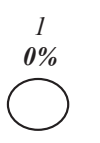

$0-1 \%$
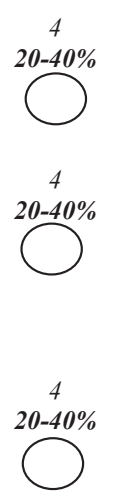

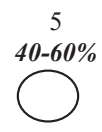

5

$\overbrace{}^{40-60 \%}$

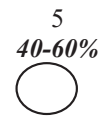

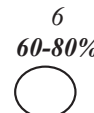

6 60-80\%<smiles>C1CCCCCC1</smiles>
80-100\%<smiles>c1ccc2ccccc2c1</smiles>

7 80-100\%

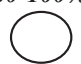

7

$\bigcirc$
6 60-80\%

7

$80-100 \%$ 


\section{References}

1. Thomas MK, Murray R, Flockhart L, Pintar K, Pollari F, Fazil A, Nesbitt A, Marshall B. 2013. Estimates of the burden of foodborne illness in Canada for 30 specified pathogens and unspecified agents, Circa 2006. Foodborne Pathogens \& Disease 10:639-648.

2. Havelaar et al. 2015. World Health Organization global estimates and regional comparisons of the burden of foodborne disease in 2010. PLoS Medicine 12:e1001923.

3. Lasky T. 2002. Foodborne illness - Old problem, new relevance. Epidemiology 13:593-598.

4. Food and Drug Administration (FDA) of the United States. 2012. Bad bug book, foodborne pathogenic microorganisms and natural toxins. second edition. Available at: https://www.fda.gov/downloads/food/foodsafety/foodborneillness/foodborneillnessfoodbornepathogen snaturaltoxins/badbugbook/ucm297627.pdf. Accessed 19 $9^{\text {th }}$ May 2017.

5. Mughini-Gras, L., Schaapveld, M., Kramers, J., Mooij, S., Neefjes-Borst, E. A., van Pelt, W., \& Neefjes, J. (2018). Increased colon cancer risk after severe Salmonella infection. PloS One, 13: e0189721.

6. Barton Behravesh C, Jones TF, Vugia DJ, Long C, Marcus R, Smith K, Thomas S, Zansky S, Fullerton KE, Henao OL, Scallan E, Group FW. 2011. Deaths associated with bacterial pathogens transmitted commonly through food: foodborne diseases active surveillance network (FoodNet), 19962005. Journal of Infectious Diseases 204:263-267.

7. Sidibé M, Piot P, Dybul M. 2012. AIDS is not over. The Lancet 380:2058-2060.

8. Hoffmann S, Maculloch B, Batz M. 2015. Economic burden of major foodborne illnesses acquired in the United States, p. 1-74, Economic cost of foodborne illnesses in the United States. Nova Science Publishers, Inc.

9. Minor T, Lasher A, Klontz K, Brown B, Nardinelli C, Zorn D. 2015. The per case and total annual costs of foodborne Illness in the United States. Risk Analysis 35(6), 1125-1139.

10. Montgomery B. 2015. Economic cost of foodborne illnesses in the U. S. Nova Science Publishers, Inc.

11. Scharff RL. 2012. Economic burden from health losses due to foodborne illness in the united states. Journal of Food Protection 75:123-131.

12. von Witzke H, Kirschke D, Lotze-Campen H, Noleppa S. 2005. The Economics of alternative strategies for the reduction of food-borne diseases in developing countries: The case of diarrhea in Rwanda. (No. 72/2005). Working Paper, Wirtschafts-und Sozialwissenschaften an der Landwirtschaftlich-Gärtnerischen Fakultät, Humboldt-Universität $\mathrm{zu}$ Berlin. Available at: https://www.econstor.eu/bitstream/10419/96474/1/783959796.pdf. Accessed 05 ${ }^{\text {th }}$ September 2013.

13. Wallace RB, Oria M, Council NR. 2010. Adopting a risk-based decision-making approach to food safety. National Research Council (US) Committee on the Review of Food and Drug Administration's Role in Ensuring Safe Food. National Academies Press (US), Washington (DC).

14. Janati A, Hosseiny M, Gouya MM, Moradi G, Ghaderi E. 2015. Communicable disease reporting systems in the world: a systematic review article. Iranian Journal of Public Health 44: 1453. 
15. Gibbons CL, Mangen M-JJ, Plass D, Havelaar AH, Brooke RJ, Kramarz P, Peterson KL, Stuurman AL, Cassini A, Fèvre EM. 2014. Measuring underreporting and under-ascertainment in infectious disease datasets: a comparison of methods. BMC Public Health 14:147.

16. MacDougall L, Majowicz S, Dore K, Flint J, Thomas K, Kovacs S, Sockett P. 2008. Under-reporting of infectious gastrointestinal illness in British Columbia, Canada: who is counted in provincial communicable disease statistics? Epidemiology \& Infection 136:248-256.

17. Majowicz SE, Edge VL, Fazil A, McNab WB, Doré KA, Sockett PN, Flint JA, Middleton D, McEwen SA, Wilson JB. 2005. Estimating the under-reporting rate for infectious gastrointestinal illness in Ontario. Canadian Journal of Public Health 1:178-181.

18. Gkogka E, Reij MW, Havelaar AH, Zwietering MH, Gorris LGM. 2011. Risk-based estimate of effect of foodborne diseases on public health, Greece. Emerging Infectious Diseases 17:1581-1590.

19. Havelaar AH, Haagsma JA, Mangen M-JJ, Kemmeren JM, Verhoef LPB, Vijgen SMC. 2012. Disease burden of foodborne pathogens in the Netherlands, 2009. International Journal of Food Microbiology 156: 231-238.

20. Torgerson PR, Devleesschauwer B, Praet N, Speybroeck N, Willingham AL, Kasuga F, Rokni MB, Zhou XN, Fèvre EM, Sripa B, Gargouri N, Fürst T, Budke CM, Carabin H, Kirk MD, Angulo FJ, Havelaar A, de Silva N. 2015. World Health Organization estimates of the global and regional disease burden of 11 foodborne parasitic diseases, 2010: A data synthesis. PLoS Medicine 12.

21. Murray CJL, Lopez AD. 1997. Global mortality, disability, and the contribution of risk factors: Global Burden of Disease Study. The Lancet 349:1436-1442.

22. Adak G, Long S, O'Brien S. 2002. Trends in indigenous foodborne disease and deaths, England and Wales: 1992 to 2000. Gut 51:832-841.

23. Scallan E, Hoekstra RM, Angulo FJ, Tauxe RV, Widdowson MA, Roy SL, Jones JL, Griffin PM. 2011. Foodborne illness acquired in the United States--major pathogens. Emerging Infectious Diseases 17:7-15.

24. The World Health Organisation of the United Nations. 2012. Manual for integrated foodborne disease surveillance in the WHO Africa Region. Available at:

http://apps.who.int/iris/bitstream/10665/170262/1/foodborne-disease-manual.pdf. Accessed $15^{\text {th }}$ November 2013.

25. Nsubuga P, White ME, Thacker SB, Anderson MA, Blount SB, Broome CV, Chiller TM, Espitia V, Imtiaz R, Sosin D. 2006. Public health surveillance: a tool for targeting and monitoring interventions. Disease Control Priorities in Developing Countries 2:997-1018.

26. Ukey UU, Chitre DS. 2013. The various etiological agents in the causation of gastroenteritis. Annals of Tropical Medicine and Public Health 6:112-116.

27. The World Health Organisation of the United Nations. 2008. Foodborne disease outbreaks: guidelines for investigation and control. Available at: http://www.who.int/foodsafety/publications/foodborne disease/outbreak guidelines.pdf. Accessed $05^{\text {th }}$ September 2013.

28. National Institute of Statistics of Rwanda [Rwanda], Ministry of Health (MOH) [Rwanda], and ICF International. Rwanda Demographic and Health Survey 2010. Calverton, Maryland, USA: NISR, 
$\mathrm{MOH}$, and ICF International. Available at: http://www.statistics.gov.rw/publication/demographic-andhealth-survey-2010-hiv-fact-sheet. Accessed $5^{\text {th }}$ January 2014.

29. National Institute of Statistics of Rwanda, Ministry of finance and economic planning, Rwanda. Rwanda fourth population and housing Census. Thematic report: Data quality assessment . Available at: http://www.statistics.gov.rw/publication/rphc4-final-report-data-quality-assessment. Accessed $05^{\text {th }}$ May 2014.

30. Devleesschauwer B, Havelaar AH, Maertens de Noordhout C, Haagsma JA, Praet N, Dorny P, Duchateau L, Torgerson PR, Oyen H, Speybroeck N. 2014. DALY calculation in practice: a stepwise approach. International Journal of Public Health 59:571-574.

31. Murray et al. 2012. Disability-adjusted life years (DALYs) for 291 diseases and injuries in 21 regions, 1990-2010: a systematic analysis for the Global Burden of Disease Study 2010. The Lancet 380:21972223.

32. Kampstra P. 2008. Beanplot: A boxplot alternative for visual comparison of distributions. Journal of Statistical Software 28:1-9.

33. Rao MR, Abu-Elyazeed R, Savarino SJ, Naficy AB, Wierzba TF, Abdel-Messih I, Shaheen H, Frenck RW, Svennerholm A-M, Clemens JD. 2003. High disease burden of diarrhea due to enterotoxigenic Escherichia coli among rural Egyptian infants and young children. Journal of Clinical Microbiology 41:4862-4864.

34. The World Health Organisation of the United Nations. 2008. Weekly epidemiological record (No. 47, 2008, 83, 421-428). Global networks for surveillance of rotavirus gastroenteritis, 2001-2008. Available at: http://www.who.int/wer/2008/wer8347.pdf?ua=1. Accessed 03 $3^{\text {rd }}$ December 2013.

35. Subekti DS, Lesmana M, Tjaniadi P, Machpud N, Sriwati, Sukarma, Daniel JC, Alexander WK, Campbell JR, Corwin AL, Beecham Iii HJ, Simanjuntak C, Oyofo BA. 2003. Prevalence of enterotoxigenic Escherichia coli (ETEC) in hospitalized acute diarrhea patients in Denpasar, Bali, Indonesia. Diagnostic Microbiology \& Infectious Disease 47:399-405.

36. Tabo D-a, Granier SA, Diguimbaye CD, Marault M, Brisabois A, Mama B, Millemann Y. 2015. Are Salmonella-induced gastroenteritis neglected in developing countries? Feedback from microbiological investigations in N'Djamena hospitals, Chad. PloS one 10:e136153.

37. Pal SC. 1986. Dysentery: an overview. Still problems to resolve. Dialogue on diarrhoea 25, 4

38. Xiao GG, Fan J, Deng JJ, Chen CH, Zhou W, Li XH, He YW, Li H, Hu B, Qiao Y, Chen GH, Wan CM. 2012. A school outbreak of Shigella sonnei infection in China: Clinical features, antibiotic susceptibility and molecular epidemiology. Indian Pediatrics 49:287-290.

39. Nichols GL. 2000. Food-borne protozoa. British Medical Bulletin 56:209-235.

40. Osei-Tutu B, Anto F. 2016. Trends of reported foodborne diseases at the Ridge Hospital, Accra, Ghana: a retrospective review of routine data from 2009-2013. BMC Infectious Diseases 16:1-9.

41. Longini IM, Yunus M, Zaman K, Siddique A, Sack RB, Nizam A. 2002. Epidemic and endemic cholera trends over a 33-year period in Bangladesh. Journal of Infectious Diseases 186:246-251. 
42. Mutonga D, Langat D, Mwangi D, Tonui J, Njeru M, Abade A, Irura Z, Njeru I, Dahlke M. 2013. National surveillance data on the epidemiology of cholera in Kenya, 1997-2010. Journal of Infectious Diseases 208:S55-S61.

43. Banerjee T, Shukla BN, Filgona J, Anupurba S, Sen MR. 2014. Trends of typhoid fever seropositivity over ten years in north India. Indian Journal of Medical Research 140:310.

44. Polonsky JA, Martínez-Pino I, Nackers F, Chonzi P, Manangazira P, Van Herp M, Maes P, Porten K, Luquero FJ. 2014. Descriptive epidemiology of typhoid fever during an epidemic in Harare, Zimbabwe, 2012. PloS one 9:e114702.

45. Oguntoke O, Aboderin OJ, Bankole AM. 2009. Association of water-borne diseases morbidity pattern and water quality in parts of Ibadan City, Nigeria. Tanzania Journal of Health Research 11, 189-195.

46. Kirby MA, Nagel CL, Rosa G, Umupfasoni MM, Iyakaremye L, Thomas EA, Clasen TF. 2017. Use, microbiological effectiveness and health impact of a household water filter intervention in rural Rwanda-A matched cohort study. International Journal of Hygiene \& Environmental Health 220: 10201029.

47. Uwimpuhwe M, Reddy P, Barratt G, Bux F. 2014. The impact of hygiene and localised treatment on the quality of drinking water in Masaka, Rwanda. Journal of Environmental Science \& Health - Part A Toxic/Hazardous Substances \& Environmental Engineering 49:434-440.

48. Edge VL, Pollari F, Lim G, Aramini J, Sockett P, Martin SW, Wilson J, Ellis A. 2004. Syndromic surveillance of gastrointestinal illness using pharmacy over-the-counter sales. A retrospective study of waterborne outbreaks in Saskatchewan and Ontario. Canadian Journal of Public Health 95:446-450.

49. Ao TT, Feasey NA, Gordon MA, Keddy KH, Angulo FJ, Crump JA. 2015. Global burden of invasive nontyphoidal Salmonella disease, 2010. Emerging Infectious Diseases 21: 941-949.

50. IHME, 2016a. Health data for Rwanda. Institute of Health Metrics, Seattle, USA. Available at: http://www.healthdata.org/rwanda, accessed $08^{\text {th }}$ August 2016.

51. IHME, 2016b. Health data for Rwanda. Institute of Health Metrics, Seattle, USA. Available at: http://vizhub.healthdata.org/gbd-compare/, accessed $08^{\text {th }}$ August 2016.

52. Sinharoy SS, Schmidt WP, Cox K, Clemence Z, Mfura L, Wendt R, Boisson S, Crossett E, Grépin KA, Jack W, Condo J, Habyarimana J, Clasen T. 2016. Child diarrhoea and nutritional status in rural Rwanda: a cross-sectional study to explore contributing environmental and demographic factors. Tropical Medicine \& International Health 21:956-964.

53. The World Health Organisation of the United Nations. 2016. Department of information, evidence and research. Global Health Estimates 2015: Deaths by Cause, Age, Sex, by Country and by Region, 2000-2015. Available at:

http://www.who.int/healthinfo/global_burden_disease/estimates/en/index1.html. Accessed 03 ${ }^{\text {rd }}$ April 2017.

54. Nyatani T., Kabeja A., Asiimwe A., Binagwaho A., Koama. J.B., Johnson P., \& Kayumba K. 2014. A National Electronic System for Disease Surveillance in Rwanda (eIDSR): Lessons learned from a successful implementation. Online Journal of Public Health Informatics 6: e118. 
55. Scallan E, Jones TF, Cronquist A, Thomas S, Frenzen P, Hoefer D, Medus C, Angulo FJ, Group FW. 2006. Factors associated with seeking medical care and submitting a stool sample in estimating the burden of foodborne illness. Foodbourne Pathogens \& Disease 3:432-438.

56. Keramarou M, Evans MR. 2012. Completeness of infectious disease notification in the United Kingdom: a systematic review. Journal of Infection 64:555-564.

57. Devleesschauwer B., McDonald S., Haagsma J., Praet N., Havelaar A., Speybroeck N. 2014. DALY: The DALY Calculator - A GUI for stochastic DALY calculation in R. R package version 1.3.0. Available at: http://cran.rproject.org/package=DALY. Accessed $02^{\text {nd }}$ August 2015.

58. Murray C, Acharya A. 1997. Understanding DALYs. Journal of Health Economics 16: 703-730.

59. The World Health Organisation of the United Nations. 2017. Global task force on Cholera control. Prevention and control of cholera outbreaks: WHO policy and recommendations. Available at: http://www.who.int/cholera/technical/prevention/control/en/index1.html . Accessed 22 $2^{\text {th }}$ January 2017.

60. Salomon et al. 2012. Common values in assessing health outcomes from disease and injury: disability weights measurement study for the Global Burden of Disease Study 2010. The Lancet 380:2129-2143.

61. The World Health Organisation of the United Nations. 2013. Methods and data sources for global burden of disease estimates 2000-2011. Available at:

http://www.who.int/healthinfo/statistics/GlobalDALYmethods 2000 2011.pdf?ua=1. Accessed $01^{\text {st }}$ February 2016.

62. The World Health Organisation of the United Nations and United Nations International Children's fund (UNICEF). 2006. Oral rehydration salts. Production of the new ORS. Available at: http://apps.who.int/iris/bitstream/10665/69227/1/WHO FCH_CAH_06.1.pdf?ua=1\&ua=1. Accessed $02^{\text {nd }}$ February 2014.

63. Scallan E, Hoekstra RM, Mahon BE, Jones TF, Griffin PM. 2015. An assessment of the human health impact of seven leading foodborne pathogens in the United States using disability adjusted life years. Epidemiology \& Infection 143: 2795-2804.

64. Kirk M, Ford L, Glass K, Hall G. 2014. Foodborne illness, Australia, Circa 2000 and Circa 2010. Emerging Infectious Diseases 20:1857-1864.

65. The World Health Organisation of the United Nations. 2003. Communicable disease surveillance and response vaccines and biologicals. Background document: The diagnosis, treatment and prevention of typhoid fever. Available at: http://www.who.int/rpc/TFGuideWHO.pdf. Accessed $06^{\text {th }}$ May 2016.

66. Mead PS, Slutsker L, Dietz V, McCaig LF, Bresee JS, Shapiro C, Griffin PM, Tauxe RV. 1999. Food-related illness and death in the United States. Emerging Infectious Diseases 5:607-625.

67. MoH. 2015. Ministry of Health, the Republic of Rwanda and National Institute of Statistics of Rwanda. Demographic and Health Survey (DHS) 2014/2015. Key findings. Available at: http://www.moh.gov.rw/fileadmin/templates/Docs/DHS5_KeyFindings_FINAL_FINAL_12 June 201 5.pdf. Accessed 09 $9^{\text {th }}$ June 2016. 17th February 2015.

68. MoH. 2014. Ministry of Health, the Republic of Rwanda. Monitoring and evaluation plan for the health sector, strategic plan (HSSP III) 2014-2018. Available at: http://www.moh.gov.rw/fileadmin/templates/MOHReports/Final_M E_plan_for_HSSP_III_A..pdf. Accessed $25^{\text {th }}$ January 2017. 
69. Lamberti LM, Fischer Walker CL, Black RE. 2012. Systematic review of diarrhea duration and severity in children and adults in low- and middle-income countries. BMC Public Health 12:276.

70. Dewan AM, Corner R, Hashizume M, Ongee ET. 2013. Typhoid fever and its association with environmental factors in the Dhaka metropolitan area of Bangladesh: a spatial and time-series approach. PLoS Neglected Tropical Diseases 7:e1998.

71. MoH. 2013. Ministry of Health, the Republic of Rwanda, Annual report, 2012-2013. Available at: http://www.moh.gov.rw/fileadmin/templates/Press_release/MoH_Annual_Report_July_2012June_2013.pdf. Accessed $05^{\text {th }}$ June 2015.

72. Bennish ML, Wojtyniak BJ. 1991. Mortality due to shigellosis: community and hospital data. Reviews of Infectious Dseases 13 Suppl 4:S245-251.

73. Uche IV, MacLennan CA, Saul A. 2017. A Systematic review of the incidence, risk factors and case fatality rates of invasive nontyphoidal Salmonella (INTS) disease in Africa (1966 to 2014). PLOS Neglected Tropical Diseases 11:e0005118.

74. Feasey NA, Dougan G, Kingsley RA, Heyderman RS, Gordon MA. 2012. Invasive non-typhoidal Salmonella disease: an emerging and neglected tropical disease in Africa. The Lancet 379:2489-2499.

75. Ao TT, Feasey NA, Gordon MA, Keddy KH, Angulo FJ, Crump JA. 2013. Global burden of invasive nontyphoidal Salmonella disease, 2010. On the Cover 2012:941.

76. van den Beld M, Reubsaet F. 2012. Differentiation between Shigella, enteroinvasive Escherichia coli (EIEC) and noninvasive Escherichia coli. European Journal of Clinical Microbiology \& Infectious Diseases 31:899-904.

77. Lopman BA, Adak GK, Reacher MH, Brown D. 2003. Two epidemiologic patterns of norovirus outbreaks: surveillance in England and Wales, 1992-2000. Emerging Infectious Diseases 9:71-77.

78. Lindsay L, Wolter J, De Coster I, Van Damme P, Verstraeten T. 2015. A decade of norovirus disease risk among older adults in upper-middle and high income countries: a systematic review. BMC Infectious Diseases 15:425.

79. Calderon-Margalit R, Sheffer R, Halperin T, Orr N, Cohen D, Shohat T. 2005. A large-scale gastroenteritis outbreak associated with norovirus in nursing homes. Epidemiology \& Infection 133:3540.

80. Parashar UD, Hummelman EG, Bresee JS, Miller MA, Glass RI. 2003. Global illness and deaths caused by rotavirus disease in children. Emerging Infectious Diseases 9:565-572.

81. Vallance BA, Chan C, Robertson ML, Finlay BB. 2002. Enteropathogenic and enterohemorrhagic Escherichia coli infections: emerging themes in pathogenesis and prevention. Canadian Journal of Gastroenterology \& Hepatology 16:771-778.

82. Nataro JP, Kaper JB. 1998. Diarrheagenic Escherichia coli. Clinical Microbiology Reviews 11:142201.

83. The World Health Organisation of the United Nations. 2013. Weekly epidemiological records. Available at: http://www.who.int/wer/2013/wer8831.pdf. Accessed 21 ${ }^{\text {st }}$ February 2016. 
84. The World Health Organisation of the United Nations. 2016. Department of information, evidence and research. Global Health Estimates 2015: Deaths by Cause, Age, Sex, by Country and by Region, 2000-2015. Geneva, World Health Organization; 2016.. Available at:

http://www.who.int/healthinfo/global_burden_disease/estimates/en/index1.html. Accessed 03 ${ }^{\text {rd }}$ April 2017.

85. Buckle GC, Walker C, Black RE. 2012. Typhoid fever and paratyphoid fever: Systematic review to estimate global morbidity and mortality for 2010. Journal of Global Health 2:10401.

86. World Gastroenterology Organisation (WGO). 2008. Practice guideline: acute diarrhea. Available at : http://doctor-ru.org/main/1100/1101.pdf . Accessed 20 ${ }^{\text {th }}$ February 2015.

87. Azman AS, Rudolph KE, Cummings DA, Lessler J. 2013. The incubation period of cholera: a systematic review. Journal of Infection 66:432-438.

88. The World Health Organisation of the United Nations. 2015. Cholera. Available at: http://www.who.int/mediacentre/factsheets/fs107/en/. Accessed 27 July 2016.

89. Centers for Disease Control and Prevention (CDC). 2014. Cholera. Available at: http://www.cdc.gov/cholera/general/ . Accessed $20^{\text {th }}$ February 2015.

90. Centers for Disease Control and Prevention (CDC). 2014.Typhoid and paratyphoid fever. Available at: $\quad$ http://wwwnc.cdc.gov/travel/yellowbook/2016/infectious-diseases-related-to-travel/typhoidparatyphoid-fever. Accessed on $20^{\text {th }}$ January 2016.

91. Murray CJ. 1994. Quantifying the burden of disease: the technical basis for disability-adjusted life years. Bulletin of the World Health Organization 72:429-445.

92. Murray CJ, Lopez AD. 1996. The global burden of disease and injury series, volume 1: a comprehensive assessment of mortality and disability from diseases, injuries, and risk factors in 1990 and projected to 2020. Cambridge. MA.

93. Boschi-Pinto C, Velebit L, Shibuya K. 2008. Estimating child mortality due to diarrhoea in developing countries. Bulletin of the World Health Organization 86:710-717.

94. Ratnaike R. 1999. Diarrhoea and aging. Journal of Postgraduate Medicine 45:60-66.

95. Holt PR. 2001. Diarrhea and malabsorption in the elderly. Gastroenterology clinics of North America 30:427-444. 


\section{Indicator microorganisms in fresh vegetables from "farm to fork" in Rwanda}

James Noah Ssemanda ${ }^{1,2}$, Martine Reij ${ }^{1 *}$, Mark Cyubahiro Bagabe ${ }^{2}$, Claude Mambo Muvunyi ${ }^{3}$, Han Joosten ${ }^{1}$, Marcel H. Zwietering ${ }^{1}$.

Published in:

Food Control (2017) 75:126-133.

\footnotetext{
Affiliations:

${ }^{1}$ Laboratory of Food Microbiology, Wageningen University, P.O. Box 17, 6700 AA Wageningen, The Netherlands

${ }^{2}$ Rwanda Standards Board, KK 15 Rd, 49; P.O. Box: 7099, Kigali-Kicukiro, Rwanda

${ }^{3}$ College of Medicine and Health Sciences, University of Rwanda, P.O. Box: 3286, Kigali, Rwanda
} 


\begin{abstract}
Microbial safety of ready-to-eat vegetables is currently a global concern. We studied indicator microorganisms in fresh vegetables from "farm to fork" in Rwanda, to identify possible trends in microbial counts along the supply chain in a developing country. A total of 453 samples were taken across the vegetable supply chain (farm, market and food service establishment level) and analyzed for indicator microorganisms; Enterobacteriaceae, Listeria spp., aerobic plate count and coagulase - positive staphylococci. The sampling at farm and market covered 11 types of vegetables commonly eaten raw in salads. Results show that the mean count of Enterobacteriaceae and Listeria spp. in vegetables were respectively 5.8 and $4.6 \mathrm{log} \mathrm{cfu} / \mathrm{g}$ at farm, 6.3 and $4.9 \log \mathrm{cfu} / \mathrm{g}$ at market, 6.0 and $5.1 \mathrm{log} \mathrm{cfu} / \mathrm{g}$ upon arrival at food service establishments, and finally 3.3 and $2.9 \mathrm{log} \mathrm{cfu} / \mathrm{g}$ in ready-to-eat salads. Aerobic plate count and coagulase-positive Staphylococci were on average 6.8 and 4.6 respectively at start of salad preparation and 4.9 and 3.0 in the final product. Unit operations like washing with or without sanitizers, trimming and peeling significantly reduced indicator counts by on average $2.1 \mathrm{log}$ $\mathrm{cfu} / \mathrm{g}$ from start to end of salad preparation. Results also show that $91 \%(51 / 56)$ and $22 \%(12 / 56)$ of ready-to-eat salads prepared by food service establishments met the guidelines for coagulase - positive staphylococci $\left(10^{4} \mathrm{cfu} / \mathrm{g}\right)$ and presumptive Listeria $\mathrm{spp} .\left(10^{2} \mathrm{cfu} / \mathrm{g}\right)$. The high counts of these indicator microorganisms along the vegetable supply chain, raises concern about the potential presence of foodborne pathogens. This study calls for improved adherence to GAPs and GHPs in the fresh vegetable supply chain so as to minimize the potential risk from foodborne pathogens.
\end{abstract}




\section{Introduction}

Global production and consumption of fresh vegetables has been increasing for the last three decades (1), concurrently, the reported foodborne outbreaks linked to fresh vegetables have surged (2-5). Pathogens most implicated in these vegetable related outbreaks include Norovirus, Salmonella spp., Escherichia coli and Shigella spp. $(2,6)$. To minimize the number of these outbreaks internationally, guidelines such as those from the World Health Organization (WHO) and the Food and Agriculture Organization (FAO) (7) have been developed to prevent or control the conditions or factors leading to microbial contamination, survival or growth along the "farm to fork" continuum. To investigate the effectiveness of the control measures in these guidelines, researchers from mainly developed countries have continued to study foodborne pathogens and indicator microorganism (IMOs) at different stages of the vegetable supply chain (8-10). Because pathogens are usually prevalent in low numbers, appear sporadically or absent at times, IMOs like aerobic plate count (APC), faecal coliforms, Enterobacteriaceae, Listeria spp. can provide more information to the detect the changes in control or preventive measures (11). Indicator microorganisms have been defined as a species of microorganisms or a group of microorganisms that indicate if food has been exposed to conditions that pose an increased risk to be contaminated with a pathogen or has been held under conditions that would allow pathogen proliferation (11). Although researchers (8-10) have used IMOs to investigate the extent of contamination of vegetables, most studies do not cover the whole vegetable supply chain (VSC) i.e.. the "farm to fork" continuum. A full overview of microbial levels across the entire supply chain may be of more practical use in preventing foodborne outbreaks at food service level.

In this study, we examined IMOs in the VSC in Rwanda from "farm to fork" to identify possible trends in microbial counts (growth or contamination, inactivation, survival) along the VSC. By investigating the microbial counts of IMOs across the entire VSC, we aim to contribute to practical approaches and information for risk managers in implementing microbial safety guidelines. Three major stages of the VSC were selected for investigation, farm, market and food service establishments (FSEs). To represent the final stage of the VSC, we chose FSEs over households, because in Rwanda, preparation and consumption of raw vegetables salads is more common in FSEs than in households (most people in homes consume cooked vegetables). Four specific objectives were set, (i) determining the difference between counts of IMOs in vegetables at farm and market, (ii) investigating the ability of the different FSEs to eliminate or reduce IMOs counts from start to the end of salad preparation, (iii) benchmarking of the microbial counts in FSE-RTE salads with existing guidelines or regulatory requirements and (iv) comparing the relation between the counts of IMOs at start of salad preparation at FSEs with the counts in the ready-to eat (RTE) salads. Enterobacteriaceae and Listeria spp. were selected as IMOs along the supply chain based on the expected vast abundance in farm vegetables $(12,13)$ and hence the ability to provide observable trends (increase or decrease) across the VSC. At FSEs, we included other IMOs viz. aerobic plate count (APC) and coagulase - positive staphylococci (CP. staphylococci) the former, to indicate the exposure of the vegetables to contamination and proliferation of microorganisms in general (14) and the latter to indicate personnel hygiene behaviors (15) during salad preparation. 


\section{Materials and Methods}

\section{Study design, sampling points and area}

Selected IMOs were analyzed from 453 samples taken along the vegetable supply chain (three major stages: farm, market and FSE) in Rwanda from February to October 2015. The samples at farm and market covered 11 types of vegetables commonly eaten raw, viz.; beet root, cabbage, carrot, celery, cucumber, garlic, green pepper, lettuce, onion, parsley and tomato (each vegetable type sampled nine times). At farm, the study concentrated on the vegetable growing regions of Rwanda. Based on availability and the "one farm one sample" approach, we took 30, 26, 21, 16 and 6 samples from the Western, Southern, Northern and Eastern provinces and the peripherals of the City of Kigali respectively. Markets were selected based on the availability of the 11 chosen vegetables sold in built-open markets and supermarkets in the City of Kigali [15], the Southern [3],Western [2], Northern [1] and Eastern [1] provinces of Rwanda. Sampling in FSEs (hotels, restaurants and bars) was done in two cities of Rwanda (Kigali [51] and Musanze [5]). Food service establishments buy whole vegetables from either from markets or from the farms directly and during salad preparation, different vegetables are mixed, washed and cut. One FSE can buy different vegetables from different markets or growing regions depending on the price or availability and no fresh cut vegetables are available before the food service level. The selection of each FSE was based on the maximum transit time of two hours between the FSEs and the laboratory to minimize holding time of prepared salad before analysis. The samples were stored in cooling boxes during transportation. To prepare the FSEs for the study, we organized a consent meeting in which managers of FSEs were briefed about the study and its importance in improving food safety. Out of 280 FSEs invited, 168 FSE managers showed interest to participate in the study and were provided with consent forms to register. To investigate the ability of FSEs to decrease microbial load during salad preparation, a sample was taken at the start and at the end of salad preparation. The samples were provided for free and after the laboratory analysis, we shared the test report and feedback with each individual FSE.

\section{Sample collection}

\section{Farms}

Each of the 11 types of vegetables was sampled 9 times leading to total of 99 vegetable samples which were purchased randomly from 99 farms. The sampling procedure slightly differed for the three categories of vegetables (fruit, subterranean, leafy). Fruit vegetables (i.e. cucumber, green pepper, tomato) were picked at maturity from the plant. Subterranean vegetables like carrot, beet root, garlic and onion, the vegetable roots, tubers or bulbs were uprooted, hand shaken to remove the attached soil and the aerial part cut off and discarded. Leafy vegetables such as lettuce, cabbage, celery and parsley, the samples consisted of only aerial parts which were cut from the root base. For cabbage, ten heads were collected from each farm. For other farm vegetables, a pooled farm sample $(\sim 2 \mathrm{~kg})$ was collected as far apart as possible depending on the farm size. Farm size ranged from around $6 \mathrm{~m}^{2}$ to over $4000 \mathrm{~m}^{2}$ and several of these farm units conglomerate to form a vegetable farming area and in each farm one type of vegetable is 
grown. Sterile materials such as gloves and knives were used throughout the sampling process and changed between each farm sample.

\section{Markets}

Twenty two markets were visited and in each market 11 types of vegetables were purchased leading to a total of 242 samples. To obtain a representative sample for a given market, we randomly purchased small units of vegetables from 6 to 10 vendors to get a pooled sample of about $2 \mathrm{~kg}$ for each type of vegetable in retail markets. In supermarkets (single vendors), packaged units were sampled from the shelves of each vegetable type. For cabbage, ten heads were purchased from each market.

\section{Food Service establishments (FSEs)}

A total of 56 FSEs (43 hotels and 13 restaurant/bars) were randomly selected and sampled. Each FSE provided 2 samples, one of whole mixed vegetables (FSE-WMV) at start of salad preparation (about 1-2 kg) and another of ready-to- eat (FSE-RTE) vegetables (about 0.5-1 kg). For the 56 FSEs, a total of $112(56 \times 2)$ vegetables samples were collected. About $70 \%(39 / 56)$ of the visited FSEs washed vegetables with sanitizers, while others did not use any sanitizer but rinsed vegetables with either boiled water or containerized drinking water. Different sanitizers were used; $2 \%$ of FSEs used sodium troclosene (25-75 ppm), 12\% used sodium hypochlorite ( $\approx 25 \mathrm{ppm}$ ), 21\% used scouring powder (polyphosphate, sodium hydrogen carbonate, active chlorine; $4 \mathrm{~g} / \mathrm{l}$ ) and $65 \%$ used potassium permanganate (0.001-0.003\%). Contact time of sanitizers was according to manufacturer instructions but varied between 1 and $10 \mathrm{~min}$, sanitization method was by dipping and all FSEs use tap water to acquire the aqueous sanitizing solution. Food handlers had no specific information on the quantity of vegetables that can sanitized for a given concentration of sanitizer solution.

\section{Sample storage and transportation}

After sampling, all samples were placed in sterile zipped polyethylene bags and immediately stored in cooling boxes with ice packs and transported to the laboratory. The transit time was 1-3 h. The samples from farms and markets were analyzed within $24 \mathrm{~h}$ while samples from FSEs were analyzed immediately upon reaching the laboratory.

\section{Microbiological analyses}

Whole vegetable samples from farm, market and FSEs were first sliced /cut into small pieces (16) on a sterile stainless steel tray using sterilized knives and gloves for each sample, mixed and followed by weighing of the 25 ganalytical unit to make the 1:10 dilution with $225 \mathrm{ml}$ of diluent. For the cut RTE vegetables, the samples were hand mixed while still in the field sampling bags and thereafter the $25 \mathrm{~g}$ sample was measured into a stomacher bag using sterile tweezers. The culture media and consumables used were from Oxoid (Oxoid Ltd., Basingstoke, UK). The samples were stomached (Model 400 Circulator, Seward, UK) in $225 \mathrm{ml}$ of maximum recovery diluent (MRD) for $1 \mathrm{~min}$ and this was followed by tenfold serial dilutions of the initial suspension using the same diluent for the enumeration of Enterobacteriaceae, APC, and coagulase - positive staphylococci (CP. staphylococci); while for Listeria spp. buffered peptone was used as a diluent. The IMOs were enumerated according to ISO methods i.e..; 
Enterobacteriaceae [ISO 21528-2: 2004] (17), APC [ISO 4833-1: 2013] (18), coagulase positive Staphylococci (CP. staphylococci) [ISO 6888-2: 1999] (19), Listeria spp. [ISO 11290 2: 1998/Amd 1: 2004] (20)at $37^{\circ} \mathrm{C}$ for $48 \mathrm{~h}$ (presumptive, typical, blue or blue-green colonies with or without halo were counted as Listeria spp.). Selected presumptive Listeria strains ( $\mathrm{n}=$ 99) isolated from farm vegetables were confirmed with API Listeria (Biomerieux, France). For quality control of the media and positive controls of the experiments, strains of E. coli (LMG 8063) for Enterobacteriaceae, Listeria monocytogenes (LMG 16783) for Listeria spp. and S. aureus (LMG 8224) for CP. staphylococci from BCCM (Belgian Coordinated Collection of Microorganisms) were used.

\section{Data analyses}

Changes in microbial load from start to end of salad preparation were calculated by subtracting $\log$ transformed counts of each IMO in salads (FSE-RTE) from counts in mixed whole vegetables at start of salad preparation process for every FSE. Statistical analyses were performed using IBM SPSS Statistics 22. Pearson's correlation $(r)$ was used to determine the relation between the initial counts of IMOs at start of salad preparation and the counts in ready to eat salads. Paired sample $\mathrm{t}$ - tests were used to compare the counts of Enterobacteriaceae and Listeria spp. in farm and market vegetables, counts of IMOs in vegetables at start of salad preparation and the counts in FSE-RTE. One way ANOVA followed by Tukey's post hoc test, was used to compare the variation in counts between the IMOs during salad preparation. Statistical significance was set at $<0.05$.

\section{Results and Discussion}

\section{Counts of Indicator microorganisms in farm and market vegetables}

Fig. 3.1 and Table 3A.1 (see Appendix) show that from one vegetable to another, mean Enterobacteriaceae counts ranged from 4.7 to $7.2 \mathrm{log} \mathrm{cfu} / \mathrm{g}$ at farm and 5.6 to $6.9 \mathrm{log} \mathrm{cfu} / \mathrm{g}$ at market while the mean Listeria spp. counts ranged from 3.0 to 5.8 and 3.5 to $6.1 \mathrm{log} \mathrm{cfu} / \mathrm{g}$ at farm and market respectively. For most vegetables (Fig. 1), mean Enterobacteriaceae and Listeria spp. counts were on average higher by $0.9 \log \mathrm{cfu} / \mathrm{g}(p=0.01)$ and by $0.5 \mathrm{log} \mathrm{cfu} / \mathrm{g}(p$ $=0.18$ ) respectively at market compared to farm. However, for garlic and onion, the mean Enterobacteriaceae and Listeria spp. counts were lower in market samples by 0.6 and $0.8 \log$ $\mathrm{cfu} / \mathrm{g}$ respectively compared to farm samples.

Current guidelines on microbial safety and quality of fresh vegetables do not provide standard limits for counts of Enterobacteriaceae and Listeria spp. at farm level. In previous studies, Listeria spp. have been reported in vegetable agricultural environment (21) and in retail vegetables. Prevalence can range $0-100 \%(13,22)$. Our mean counts Listeria spp. at farm and market (retail) were higher than most of the counts reported from different countries, Spain (23), Japan (24), UK $(25,26)$ but comparable to the counts reported in New Zealand (27). For Enterobacteriaceae, counts higher than the counts reported in this study have reported in fresh vegetables $(12,28)$. Nevertheless, in line with our main objective of identifying trends in microbial counts along the VSC, we observed that the counts of these IMOs increased from farm to market, indicating that between farm and market, vegetables are either contaminated or 
that there are conditions that allow growth of microorganisms. The results in this study are in agreement with what has been reported elsewhere in developing countries. Studies by Shenge et al. (29) in Nigeria indicated that contamination of tomato fruits with total coliforms and $E$. coli, increased from farm to market. In Jordan, the same trend was observed in fresh vegetables (parsley, lettuce, radish), E. coli counts increased by $1 \mathrm{log} \mathrm{cfu} / \mathrm{g}$ from farm to market (30).

Previous studies have attributed this microbial contamination and or proliferation at farm and market to the pre-and post-harvest factors including soil, irrigation water, green or inadequately composted manure, air (dust), weather conditions, wild and domestic animals, insects, feces, wash water, human handling, among others (30-33). For garlic and onion, the mean counts of Enterobacteriaceae and Listeria spp. at market were lower compared to the farm level. This trend in microbial counts may be attributed to the reported antimicrobial activity of the organosulphur compounds in these vegetables (34) but also to the practices between farm and market or at market level. In practice, garlic and onion are be kept for longer time at market (more than one week), the outer covers (layers) dry out and keep peeling off, yet the inside fresh parts with nutrients may be undesirable to microorganisms due to the reported antimicrobial compounds. Therefore fresh garlic and onion in open field farms are most likely to have higher microbial counts than the counts from the drying garlic and onion at market level. Further research is needed to investigate the downward trend in microbial counts from farm to market for onion and garlic. If the research outcome points to the reported antimicrobial activity of compounds in onion and garlic, extracts of these compounds may be used in future as antimicrobial ingredients in vegetable salads. 
90 | Ch a p ter 3
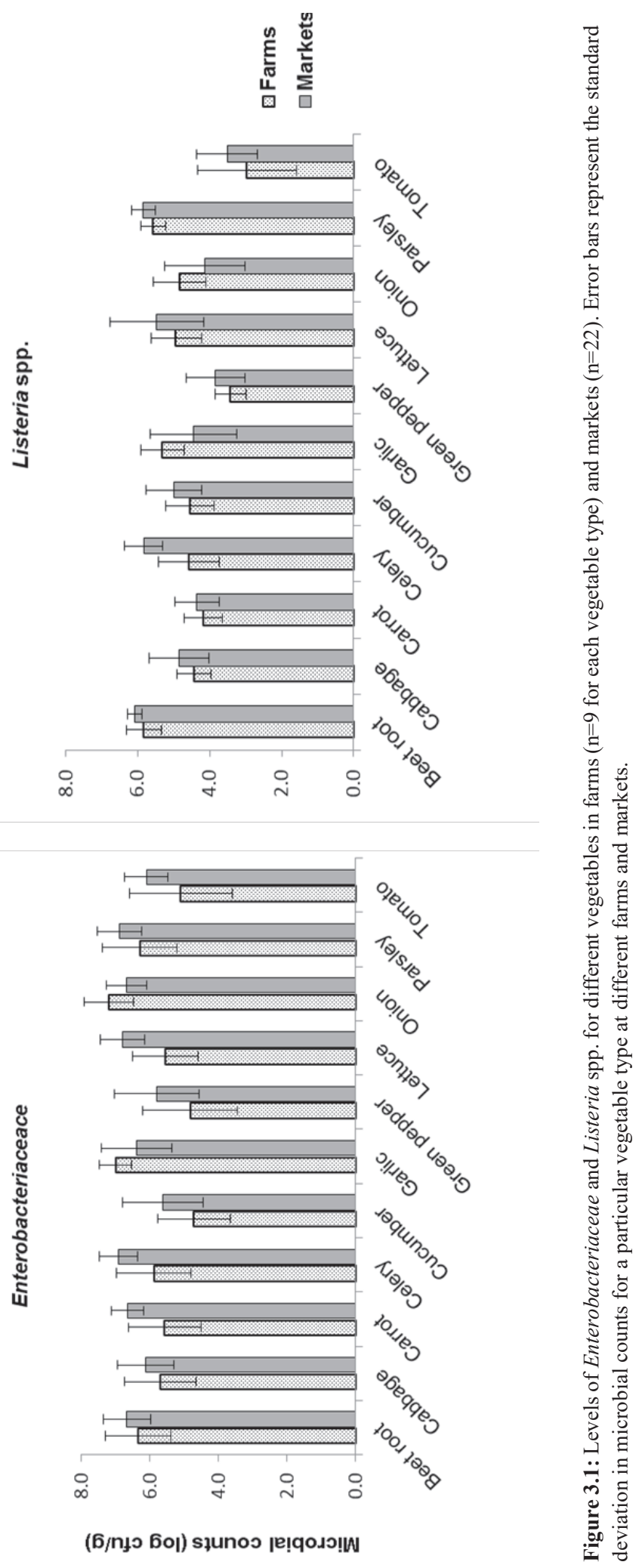


\section{Counts of indicator microorganisms during salad preparation at FSEs}

Fig. 3.2 shows respective pooled mean counts for Enterobacteriaceae and Listeria spp. in vegetables at farm (5.8 and $4.6 \mathrm{log} \mathrm{cfu} / \mathrm{g}$ ) and at market (6.3 and $4.9 \mathrm{log} \mathrm{cfu} / \mathrm{g}$ ) in addition to mean counts for these IMOs in whole mixed vegetables at FSE level (6.0 and $5.1 \mathrm{log} \mathrm{cfu} / \mathrm{g}$ respectively). Fig. 3.2 also shows that from start to end of salad preparation, mean counts for Enterobacteriaceae and Listeria spp. were significantly reduced $(\mathrm{p}<0.001)$ on average by 2.5 $\log \mathrm{cfu} / \mathrm{g}$.

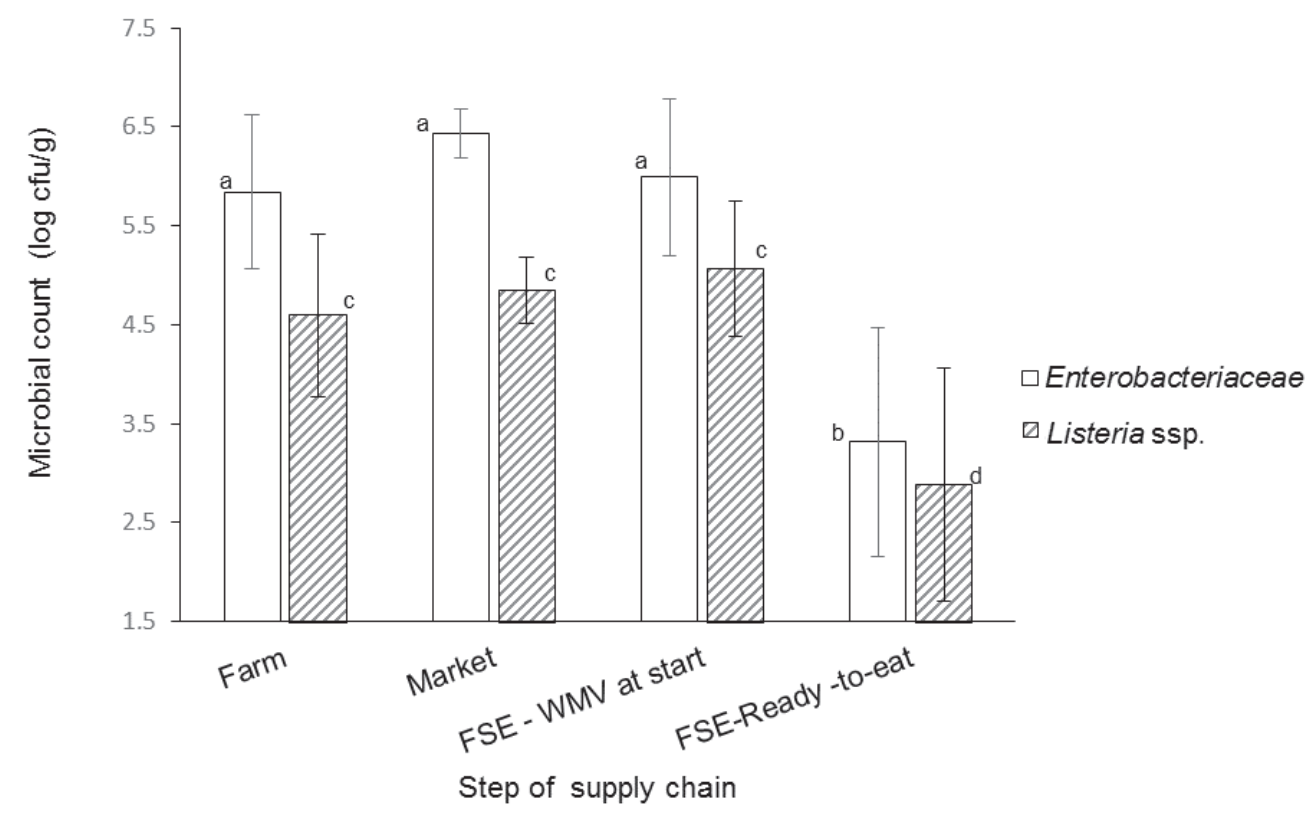

Figure 3.2: Average counts of Enterobacteriaceae and Listeria spp. at various points of the vegetable supply chain, represented as the mean from different vegetables used for salad preparation. WMV-FSE at start $=$ whole mixed vegetables at start of salad preparation and FSE- Ready-to-eat = garnished ready-to-eat salads at FSEs. Error bars represent the standard deviation in microbial counts at the different stages of the vegetable supply chain. Bars without a common letter show mean microbial counts that differ significantly.

In other results, mean count for aerobic plate count and CP. staphylococci were 6.8 , and $4.6 \log$ $\mathrm{cfu} / \mathrm{g}$ in whole mixed vegetables before salad preparation (FSE-WMV) and 4.9 and 3.0 in readyto-eat salads (FSE-RTE) respectively. Overall, with all the four IMOs combined, average microbial load reduction was $2.1 \mathrm{log} \mathrm{cfu} / \mathrm{g}$ from start to end of salad preparation in FSEs. The salad preparation process at FSEs is done manually by food handlers. Salad contact surfaces include knives, shredders, chopping boards, washing and or sanitization sinks. Furthermore Fig. 3.3 shows the changes in counts of different IMOs during salad preparation form one FSE to the other. We observed decreases and few increases in counts of different IMOs separated by the "zero change line" (line for no increase or decrease in IMO counts) at individual FSEs during salad preparation. It can be seen that $88 \%$ (49/56) of FSEs show a decrease for all the four IMOs (Enterobacteriaceae, Listeria spp., APC and CP. staphylococci) during salad preparation. Among the 7 FSEs that were above the "zero change line"; 4/7 of FSEs had 
increased counts in CP. staphylococci; 1/7 in APC; 1/7 in Listeria spp. and 1/7 in Enterobacteriaceae. Using Tukey's method with post hoc tests to compare the ability of FSEs to reduce counts between IMOs, our results indicate that Enterobacteriaceae counts were most reduced compared to CP. staphylococci $(\mathrm{p}<0.001)$, APC $(p=0.006)$ and Listeria $\mathrm{spp}$. $(p=$ $0.085)$.

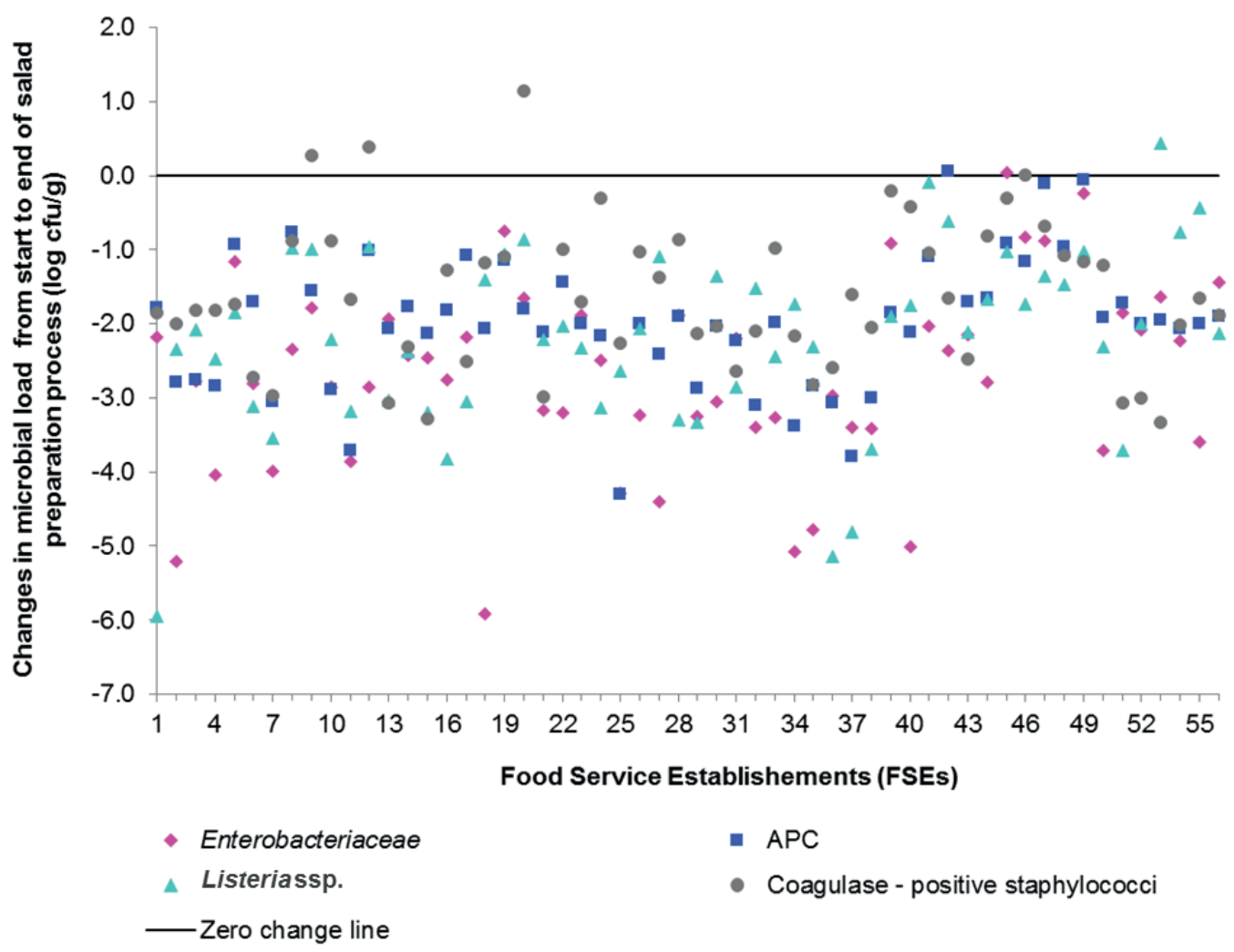

Figure 3.3: Changes of IMOs during salad preparation by 56 Food Service Establishments with average reductions ( \pm standard deviations) of 2.7 ( \pm 1.3$) \mathrm{log} \mathrm{cfu} / \mathrm{g}$ for Enterobacteriaceae; $2.0( \pm 0.9)$ APC; $2.2( \pm 1.2)$ of Listeria ssp. and $1.6( \pm 1.0)$ of Coagulase-positive staphylococci.

The significant reduction in microbial counts at FSEs (Fig. 3.2) suggests that in the entire VSC in Rwanda, the burden of cleaning vegetables is targeted only at FSEs. This reduction can be attributed to process operations like washing and sanitization, trimming, peeling and cutting that occur at FSEs. However these very process operations such as washing, have also been pointed out as a potential source of contamination if mismanaged $(35,36)$. In this study, evidence of infrequent contamination is demonstrated by the increase in microbial count during salad preparation shown in Fig. 3.3. These results also show that the ability of FSEs to reduce the microbial load differs among microorganisms indicating that the efficacy of the washing and sanitization process depends on nature of microorganisms present in the vegetables, but also on the effectiveness of the sanitation process. Effectivity of the sanitization process could be improved by selecting and advising reliable sanitation techniques aiming at a lower mean concentration in the final product. In addition the large standard deviation of the counts might 
be a target for improved hygienic practices during the salad sanitation and preparation processes. Among the used IMOs, CP. staphylococci increased more dominantly during salad preparation than the other studied IMOs and this contamination may be from food handlers. The observed differences in microbial counts for various vegetable types (Fig. 3.1), the reported high microbial counts in vegetables at start of salad preparation, and the observed possibility of food handlers to contaminate salads during preparation, illustrates the complexity of controlling microbial safety of ready-to eat vegetables.

\section{Benchmarking of microbial counts in salads with regulatory requirements}

The ability to reduce the microbial load of incoming vegetables by the majority of FSEs (88\%) is encouraging but regulatory requirements may still not be achieved. In Rwanda, guidelines or regulatory requirements for ready-to-eat vegetables are yet to be determined, so we compared our results with the guidelines from the United Kingdom (37). The Health Protection Agency (UK-HPA) classifies total Listeria spp. as hygiene indicator with a maximum number of $10^{2}$ cfu/g and CP. staphylococci as pathogen (S. aureus) at $10^{4} \mathrm{cfu} / \mathrm{g}$. Enterobacteriaceae and APC have no set limits since these IMOs are considered to be part of the normal micro flora of vegetables (37). Fig. 3.4 shows that $91 \%(51 / 56)$ and $22 \%(12 / 56)$ of FSEs fulfill the guidelines for $S$. aureus and Listeria spp. respectively.

Whereas Listeria spp. have been commonly associated with agricultural and produce production environments $(21,31)$, the possibility of pathogenic Listeria spp. (Listeria monocytogenes) being present cannot be ignored. Indeed confirmation of selected presumptive Listeria strains isolated from farm vegetables (data not shown) revealed that 4 out of 99 isolates were L. monocytogenes. Chapin et al. (21) reported that half of the samples where Listeria spp. was isolated from produce production environment had L. monocytogenes and in some cases (6\%) all Listeria spp. were L. monocytogenes. On the other hand, not all presumptive Listeria spp. isolates may be truly Listeria spp., as Angelidis et al. (38) have reported non Listeria spp. bacteria growing with closely similar colonies (bluish green) on the agar we used (Agar Listeria according to Ottaviani and Agosti). Nevertheless, the high counts of presumptive Listeria spp. reported in this study may indicate exposure to L. monocytogenes and risk of listeriosis to consumers of vegetable salads especially the young, old, pregnant and immuno-compromised individuals. 


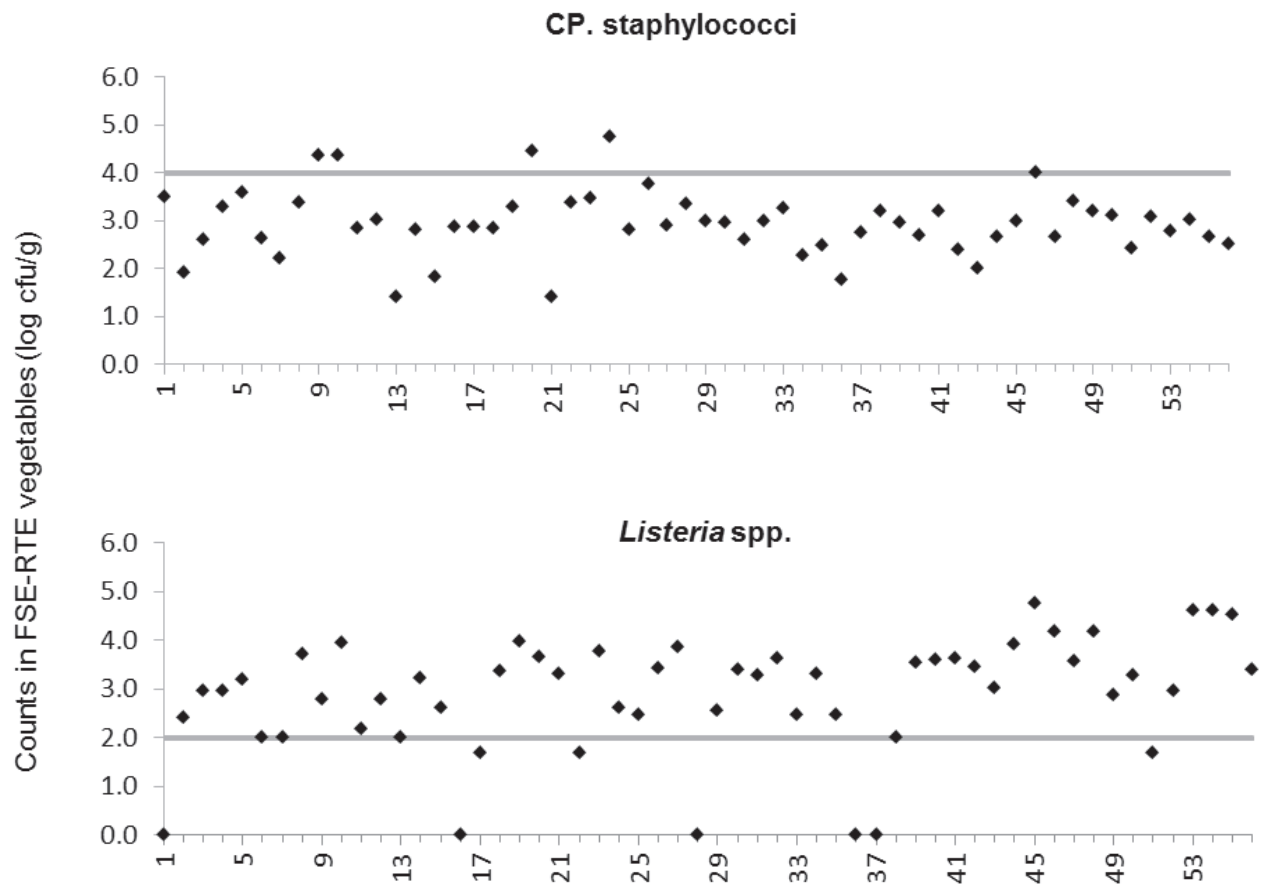

Food Service Establishments (FSEs)

Figure 3.4: Comparison of microbial levels in Ready-to-eat salads prepared in 56 food service establishments in Rwanda with the requirements of the UK-Health Protection Agency for ready-to-eat vegetables: Listeria spp. less than $10^{2} \mathrm{cfu} / \mathrm{g}$ and coagulase-positive staphylococci (CP. staphylococci) less than $10^{4} \mathrm{cfu} / \mathrm{g}$. Points on the $\mathrm{x}$ - axis were bellow detection limit.

Correlation between microbial counts in vegetables at start and at the end of salad preparation.

In this study we also focused on the microbial load of the vegetables at the start of salad preparation and how it can influence the microbial load in the final product (FSE - RTE). Fig. 3.5 shows the relationship between the initial microbial counts of IMOs in mixed vegetables at the start of salad preparation (FSE-WMV) and the microbial counts in ready- to-eat salads for each FSE. The plots show that almost all points were below the line $\mathrm{y}=\mathrm{x}-\mathrm{axis}$ and no significant correlation $(r)$ between the FSE-WMV and FSE - RTE for all the four IMOs, ie. CP. staphylococci $(r=0.04, p=0.974)$; APC $(r=0.086, p=0.528)$; Enterobacteriaceae $(r=0.203$, $p=0.134)$ and Listeria spp. $(r=0.245, p=0.073)$.

Researchers have highlighted a close relationship between the total mesophilic aerobic counts on lettuce raw material and those on finished shredded lettuce product (39). However, in our study the correlations between counts of in-coming vegetables and the counts of ready-to-eat 
were insignificant, suggesting that the quality of washing and sanitization plays an important role in changing the microbial levels of ready-to-eat salads.
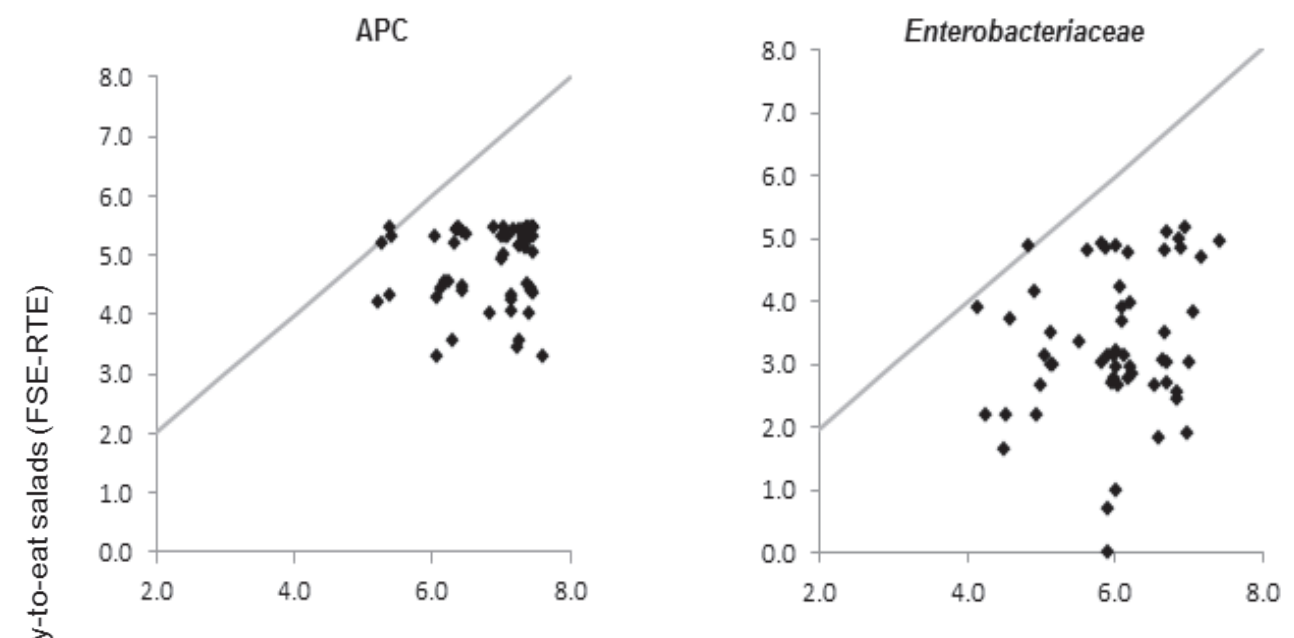

Listeria spp.

CP. staphylococci
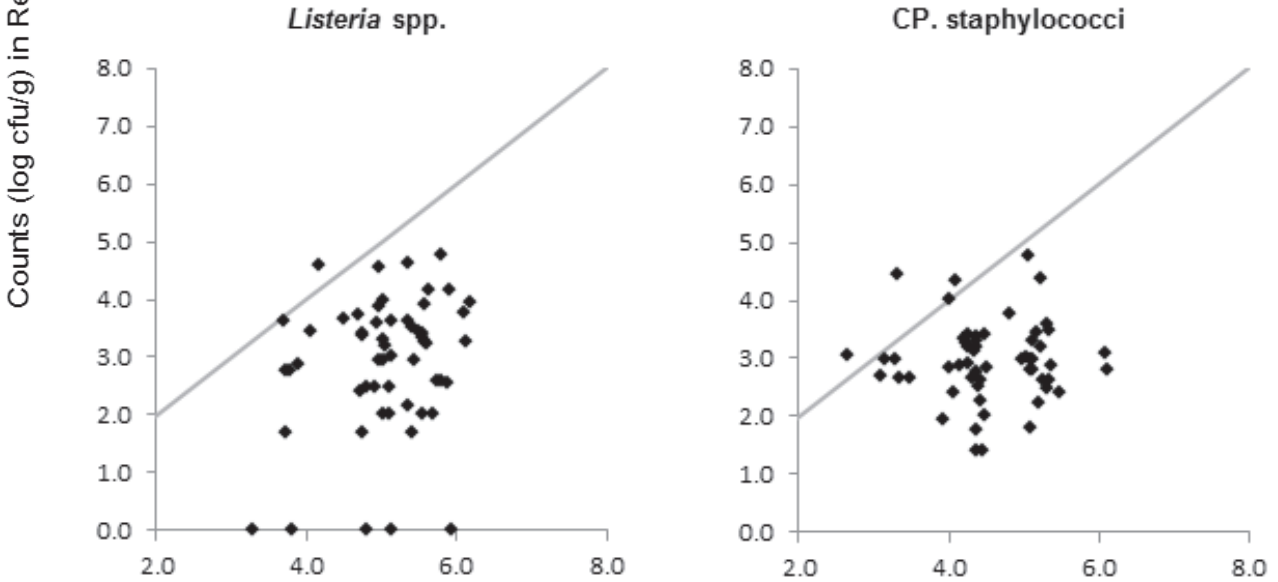

Counts (log cfu/g) in vegetables at start of salad preparation (FSE-WMV)

Figure 3.5: Comparison of the initial microbial counts of IMOs in mixed vegetables at the start of salad preparation (FSE-WMV) and the microbial counts in Ready to eat salads (FSE-RTE) for 56 FSEs. The plotted line represents $\mathrm{y}=\mathrm{x}$. Points on the $\mathrm{x}$-axis were bellow detection limit. 


\section{Conclusion}

In this study, we have investigated the trends in counts of IMOs along the VSC (farm, market and FSE) in Rwanda. We have shown that the IMOs counts increased from farm to market vegetables and that IMOs counts did not significantly change from market to FSEs (vegetable before salad preparation). Overall at food service establishments, microbial counts were significantly reduced by unit operations like washing with or without sanitizers, trimming/peeling, with an average reduction of $2.1 \mathrm{log} \mathrm{cfu} / \mathrm{g}$ from start to end of salad preparation. We have also observed that counts of presumptive Listeria spp. and CP. staphylococci in ready-to-eat salads from $78 \%$ and $9 \%$ of FSEs respectively, exceeded the guideline established by the UK-HPA (37). We acknowledge that exceeding the guideline for counts of these IMOs in ready-to-eat vegetables may not necessarily mean these vegetables are unsafe for consumption. However, the trends in microbial counts presented in this study, should alert the concerned stakeholders, risk managers, and policy makers about the importance of microbial safety in this VSC. Consequently, it would be important in future to study and understand the pre- and post-harvest practices, the mechanisms of contamination and the major pathogens in the context of this VSC. 
Indicator microorganisms from “farm to fork" 97

Appendix 


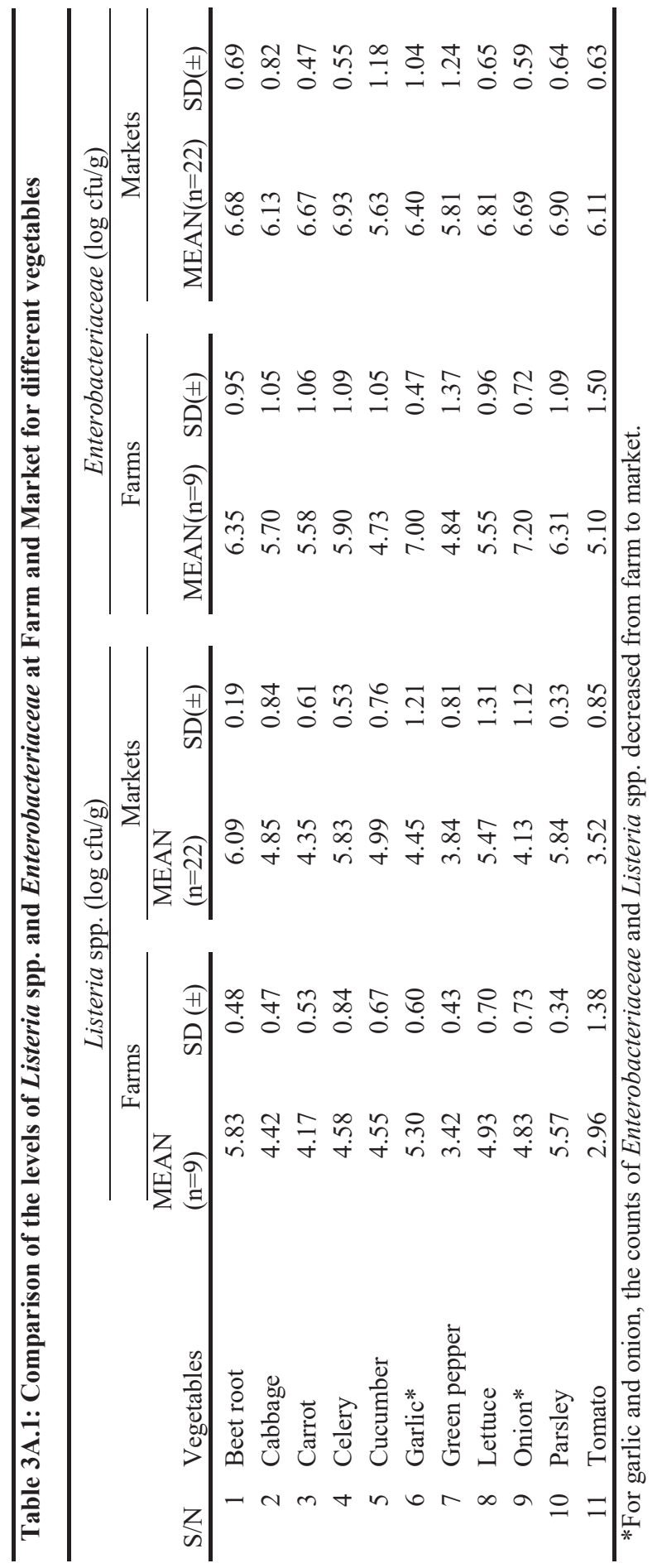




\section{References}

1. FAO STAT (Food and Agriculture Organization of the United Nations, statistics division). 2015. http://faostat3.fao.org/compare/E. Accessed on 03 ${ }^{\text {rd }}$ May 2016.

2. Callejon RM, Rodriguez-Naranjo MI, Ubeda C, Hornedo-Ortega R, Garcia-Parrilla MC, Troncoso AM. 2015. Reported foodborne outbreaks due to fresh produce in the United States and European Union: trends and causes. Foodborne Pathogens \& Disease 12:32-38.

3. Herman KM, Hall AJ, Gould LH. 2015. Outbreaks attributed to fresh leafy vegetables, United States, 1973-2012. Epidemiology \& Infection 143:3011-3021.

4. Painter JA, Hoekstra RM, Ayers T, Tauxe RV, Braden CR, Angulo FJ, Griffin PM. 2013. Attribution of foodborne illnesses, hospitalizations, and deaths to food commodities by using outbreak data, United States, 1998-2008. Emerging Infectious Diseases 19:407-415.

5. Lynch MF, Tauxe RV, Hedberg CW. 2009. The growing burden of foodborne outbreaks due to contaminated fresh produce: Risks and opportunities. Epidemiology \& Infection 137:307-315.

6. Kozak GK, Macdonald D, Landry L, Farber JM. 2013. Foodborne outbreaks in Canada linked to produce: 2001 through 2009. Journal of Food Protection 76:173-183.

7. CAC/RCP 53. 2003. Code of hygienic practice for fresh fruits and vegetables. Codex Alimentarius Commision. http://www.fao.org/ag/agn/CDfruits_en/others/docs/alinorm03a.pdf. Accessed $06^{\text {th }}$ January 2016.

8. Holvoet K, Sampers I, Seynnaeve M, Uyttendaele M. 2014. Relationships among hygiene indicators and enteric pathogens in irrigation water, soil and lettuce and the impact of climatic conditions on contamination in the lettuce primary production. International Journal of Food Microbiology 171:2131.

9. Schwaiger K, Helmke K, Hölzel CS, Bauer J. 2011. Comparative analysis of the bacterial flora of vegetables collected directly from farms and from supermarkets in Germany. International Journal of Environmental Health Research 21:161-172.

10. Ward M, Dhingra R, Remais JV, Chang HH, Johnston LM, Jaykus L-A, Leon J. 2015. Associations between Weather and Microbial Load on Fresh Produce Prior to Harvest. Journal of Food Protection 78:849-854.

11. Buchanan RL, Oni R. 2012. Use of microbiological indicators for assessing hygiene controls for the manufacture of powdered infant formula. Journal of Food Protection 75:989-997.

12. Little C, Roberts D, Youngs E, De Louvois J. 1999. Microbiological quality of retail imported unprepared whole lettuces: A PHLS food working group study. Journal of Food Protection 62:325-328.

13. Zhu Q, Hussain MA. 2015. Prevalence of Listeria species in Fresh Salad Vegetables and Ready-to-Eat Foods Containing Fresh Produce Marketed in Canterbury, New Zealand. Advanced in Food Technology and Nutritional Sciences - Open Journal 1:5-9.

14. Aycicek H, Oguz U, Karci K. 2006. Determination of total aerobic and indicator bacteria on some raw eaten vegetables from wholesalers in Ankara, Turkey. International Journal of Hygiene \& Environmental Health 209:197-201.

15. Balzaretti CM, Marzano MA. 2013. Prevention of travel-related foodborne diseases: Microbiological risk assessment of food handlers and ready-to-eat foods in northern Italy airport restaurants. Food Control 29:202-207. 
16. Mukherjee A, Speh D, Diez-Gonzalez F. 2007. Association of farm management practices with risk of Escherichia coli contamination in pre-harvest produce grown in Minnesota and Wisconsin. International Journal of Food Microbiology 120:296-302.

17. ISO 21528-2. 2004. Microbiology of food and animal feeding stuffs -- Horizontal methods for the detection and enumeration of Enterobacteriaceae -- Part 2: Colony-count method.

18. ISO 4833-1. 2013. Microbiology of the food chain -- Horizontal method for the enumeration of microorganisms -- Part 1: Colony count at 30 degrees $\mathrm{C}$ by the pour plate technique.

19. ISO 6888-2. 1999. Microbiology of food and animal feeding stuffs -- Horizontal method for the enumeration of coagulase-positive staphylococci (Staphylococcus aureus and other species) -- Part 2: Technique using rabbit plasma fibrinogen agar medium.

20. ISO 11290-2:1998/Amd 1. 2004. Microbiology of food and animal feeding stuffs — Horizontal method for the detection and enumeration of Listeria monocytogenes - Part 2: Enumeration method AMENDMENT 1: Modification of the enumeration medium.

21. Chapin TK, Nightingale KK, Worobo RW, Wiedmann M, Strawn LK. 2014. Geographical and meteorological factors associated with isolation of Listeria species in New York state produce production and natural environments. Journal of Food Protection 77:1919-1928.

22. McMahon MAS, Wilson IG. 2001. The occurrence of enteric pathogens and Aeromonas species in organic vegetables. International Journal of Food Microbiology 70:155-162.

23. Selma MV, Allende A, López-Gálvez F, Elizaquível P, Aznar R, Gil MI. 2007. Potential microbial risk factors related to soil amendments and irrigation water of potato crops. Journal of Applied Microbiology 103:2542-2549.

24. Kaneko KI, Hayashidani H, Ohtomo Y, Kosuge J, Kato M, Takahashi K, Shiraki Y, Ogawa M. 1999. Bacterial contamination of ready-to-eat foods and fresh products in retail shops and food factories. Journal of Food Protection 62:644-649.

25. Little CL, Mitchell RT. 2004. Microbiological quality of pre-cut fruit, sprouted seeds, and unpasteurised fruit and vegetable juices from retail and production premises in the UK, and the application of HACCP. Communicable Disease and Public Health / PHLS 7:184-190.

26. Sagoo SK, Little CL, Mitchell RT. 2001. The microbiological examination of ready-to-eat organic vegetables from retail establishments in the United Kingdom. Letters in Applied Microbiology 33:434439 .

27. Zhu, Qi. 2015. Assessment of Listeria species in fresh produce grown and sold in Canterbury, New Zealand. https://researcharchive.lincoln.ac.nz/handle/10182/6671?show=full. Accessed 30 ${ }^{\text {th }}$ August 2015.

28. Oliveira M, Usall J, Vinas I, Anguera M, Gatius F, Abadias M. 2010. Microbiological quality of fresh lettuce from organic and conventional production. Food Microbiology 27:679-684.

29. Shenge KC, Whong CMZ, Yakubu LL, Omolehin RA, Erbaugh JM, Miller SA, LeJeune JT. 2015. Contamination of tomatoes with coliforms and Escherichia coli on farms and in markets of Northwest Nigeria. Journal of Food Protection 78:57-64.

30. Faour-Klingbeil D, Murtada M, Kuri V, Todd ECD. 2016. Understanding the routes of contamination of ready-to-eat vegetables in the Middle East. Food Control 62:125-133.

31. Beuchat LR, Ryu JH. 1997. Produce Handling and Processing Practices. Emerging Infectious Diseases 3:459-465. 
32. Gil MI, Selma MV, Suslow T, Jacxsens L, Uyttendaele M, Allende A. 2015. Pre- and postharvest preventive measures and intervention strategies to control microbial food safety hazards of fresh leafy vegetables. Critical Reviews in Food Science and Nutrition 55:453-468.

33. Marvasi M, Hochmuth GJ, Giurcanu MC, George AS, Noel JT, Bartz J, Teplitski M. 2013. Factors that affect proliferation of Salmonella in tomatoes post-harvest: The roles of seasonal effects, irrigation regime, crop and pathogen genotype. PLOS ONE 8.

34. Wilson EA, Demmig-Adams B. 2007. Antioxidant, anti-inflammatory, and antimicrobial properties of garlic and onions. Nutrition \& Food Science 37:178-183.

35. Gil MI, Selma MV, López-Gálvez F, Allende A. 2009. Fresh-cut product sanitation and wash water disinfection: Problems and solutions. International Journal of Food Microbiology 134:37-45.

36. Holvoet K, De Keuckelaere A, Sampers I, Van Haute S, Stals A, Uyttendaele M. 2014. Quantitative study of cross-contamination with Escherichia coli, E. coli O157, MS2 phage and murine norovirus in a simulated fresh-cut lettuce wash process. Food Control 37:218-227.

37. HPA-UK. 2009. Health Protection Agency. Guidelines for Assessing the microbiological safety of ready-to-Eat foods. London: UK, Health Protection Agency.

https://www.gov.uk/government/uploads/system/uploads/attachment_data/file/363146/Guidelines_for assessing the microbiological_safety_of ready-to-eat foods_on the market.pdf. Accessed $15^{\text {th }}$ November 2015.

38. Angelidis AS, Kalamaki MS, Georgiadou SS. 2015. Identification of non-Listeria spp. bacterial isolates yielding a $\beta$-d-glucosidase-positive phenotype on Agar Listeria according to Ottaviani and Agosti (ALOA). International Journal of Food Microbiology 193:114-129.

39. Barth M, Hankinson TR, Zhuang H, Breidt F. 2009. Microbiological spoilage of fruits and vegetables, p. 135-183. In Sperber HW, Doyle PM (ed.), Compendium of the Microbiological Spoilage of Foods and Beverages. Springer New York, New York, NY. 



\title{
4
}

\section{Foodborne pathogens and their risk exposure factors associated with farm vegetables in Rwanda}

\author{
James Noah Ssemanda ${ }^{1,2}$, Martine Reij ${ }^{1 *}$, Gerrieke van Middendorp ${ }^{1}$, \\ El Bouw ${ }^{3}$, Rozemarijn van der Plaats ${ }^{3}$, Eelco Franz ${ }^{3}$, \\ Claude Mambo Muvunyi ${ }^{4}$, Mark Cyubahiro Bagabe ${ }^{5}$, \\ Marcel H. Zwietering ${ }^{1}$, Han Joosten ${ }^{1}$.
}

Published in:

Food Control (2018) 89: 86 - 96

Affiliations:

${ }^{1}$ Laboratory of Food Microbiology, Wageningen University and Research, P.O. Box 17, 6700 AA

Wageningen, The Netherlands.

${ }^{2}$ Rwanda Standards Board, KK 15 Rd 49; P.O. Box 7099, Kigali-Kicukiro, Rwanda.

${ }^{3}$ Laboratory for Zoonoses and Environmental Microbiology, Centre for Infectious Disease Control, National Institute for Public Health and the Environment, P.O. Box 1, 3720BA Bilthoven, The Netherlands.

${ }^{4}$ College of Medicine and Health Sciences, University of Rwanda, P.O. Box: 3286, Kigali, Rwanda.

${ }^{5}$ Rwanda Agriculture Board, KK 18 Ave; P. O. Box 5016, Kigali, Rwanda. 


\begin{abstract}
In this study, we tested farm vegetables and agricultural water for the presence of foodborne pathogens, and evaluated farming practices of vegetable farms in Rwanda. Farm vegetable samples were found to be contaminated with food borne pathogens at considerably high rate (overall 15/99=15\%). Specifically, the prevalence of pathogens in farm vegetables varied from 1.0\% (1/99) for Listeria monocytogenes, 3.0\% (3/99) for thermo-tolerant Campylobacter spp., $5.1 \%$ (5/99) for Salmonella spp. to 6.1\% (6/99) pathogenic Escherichia coli. In agricultural water from rivers, lakes, lagoons, ground and marshlands, prevalence of DNA from pathogens varied from $3.3 \%$ (1/30) for Enteroinvasive E. coli (EIEC); 6.7\% (2/30) for Enteroaggregative E. coli (EAEC); 13.3\% (4/30) for Enterotoxigenic E. coli. (ETEC) and Vibrio cholera; $20.0 \%$ (6/30) for Yersinia pestis; 26.7\% (8/30) for Francisella tularensis; 40\% (12/30) for Cyclospora to $86.7 \%$ (26/30) for thermo-tolerant Campylobacter spp. DNA of the following pathogens was not detected in water: entero pathogenic E. coli (EPEC), shiga toxin producing E.coli (STEC), Salmonella spp., L. monocytogenes, Burkholderia, Rickettsia, Toxoplasma gondii, Giardia lamblia, Cryptosporidium, Entamoeba histolytica and Hepatitis E. About farming practices, $60 \%$ of the visited vegetable farms practiced irrigation and all the water used was from unprotected sources (from marshlands [70\%], rivers [18\%], lakes [7\%], runoff lagoons [5\%]). Over $80 \%$ of the farms applied overhead irrigation methods and none of the farms had implemented measures to restrict to access of domestic and wild animals, while $50 \%$ of the farms used untreated manure. The high detection rate of foodborne pathogens in agricultural water in combination with the observed several risky farming practices forms a likely explanation for the observed prevalence of pathogens in farm vegetables as reported in this study and is of important public health concern if these vegetables are to be consumed raw.
\end{abstract}




\section{Introduction}

Foodborne illnesses caused by microbial hazards contribute significantly to the global burden of disease (1). In attribution studies, fresh vegetables have been reported among the major food vehicles of foodborne microbial hazards or pathogens $(2,3)$. Fresh vegetables are known to harbor significant numbers of epiphytic microorganisms, mostly nonpathogenic. However during the "farm to fork" continuum especially in the open field cultivation, fresh vegetables are exposed to environmental conditions or factors that can introduce all kinds of pathogenic microorganisms; bacteria (4), parasites (5) and viruses (6). Once introduced to vegetable plant structures, pathogens can become part of the resident microflora through attachment (7) and internalization (8). With growing popularity of vegetables eaten raw, early detection, control and prevention of factors that contaminate fresh vegetables along the supply chain is paramount.

Beuchat and Rhu (9) classified the sources of contamination for fresh vegetables into pre- and postharvest factors. Pre-harvest factors include: irrigation water, soil, inadequately composted manure, domestic and wild animals, among others, while postharvest factors mostly include: human handling, equipment, containers, wash and rinse water, flying insects to mention a few. In order to reduce the burden of foodborne illnesses due to fresh vegetables, it is important to adopt preventive measures that have shown to be effective. Cognizant of this need, several countries and international organizations like the World Health Organization (WHO) and the Food and Agricultural Organization (FAO) have since developed codes of practice, guidelines and regulations (10-15) with measures that can be used to prevent and control microbial hazards along the fresh vegetable supply chain. While these preventive measures have been documented, the levels of implementation varies from region to region and country to country.

In this study, we investigated the farming practices, prevalence of foodborne pathogens in farms vegetables and agricultural water in Rwanda. First, in vegetable farms, we observed farming practices and also detected foodborne pathogens commonly implicated in outbreaks associated with fresh vegetables (16) and Listeria monocytogenes, considered ubiquitous in plant vegetation (17) and having high case fatality rate (18). Second, we analyzed agriculture water for presence of DNA of 19 foodborne pathogens since water has been pointed out as a potential major source of microbial contamination for fresh vegetables through irrigation, washing and flooding $(19,20)$. The microbial profile of water from surrounding rivers, lakes, ponds/lagoons and marshlands was also used to reflect on the associated environmental activities by humans, livestock and wild life within the vicinity of vegetables fields.

\section{Materials and methods}

\section{Study setup}

Figure 4.1 shows an overview of the study location. Vegetable samples from Rwandan farms were purchased and investigated for the presence of Salmonella spp., L. monocytogenes, Campylobacter jejuni and pathogenic E. coli from February to October 2015. Sampling of farm vegetables was done simultaneously with observation of farming practices with impact on 
microbial safety of fresh vegetables. In the second part, we extracted DNA from agricultural water (i.e.. irrigation and on-farm postharvest wash water) and investigated the presence of DNA originating from pathogenic microorganisms.

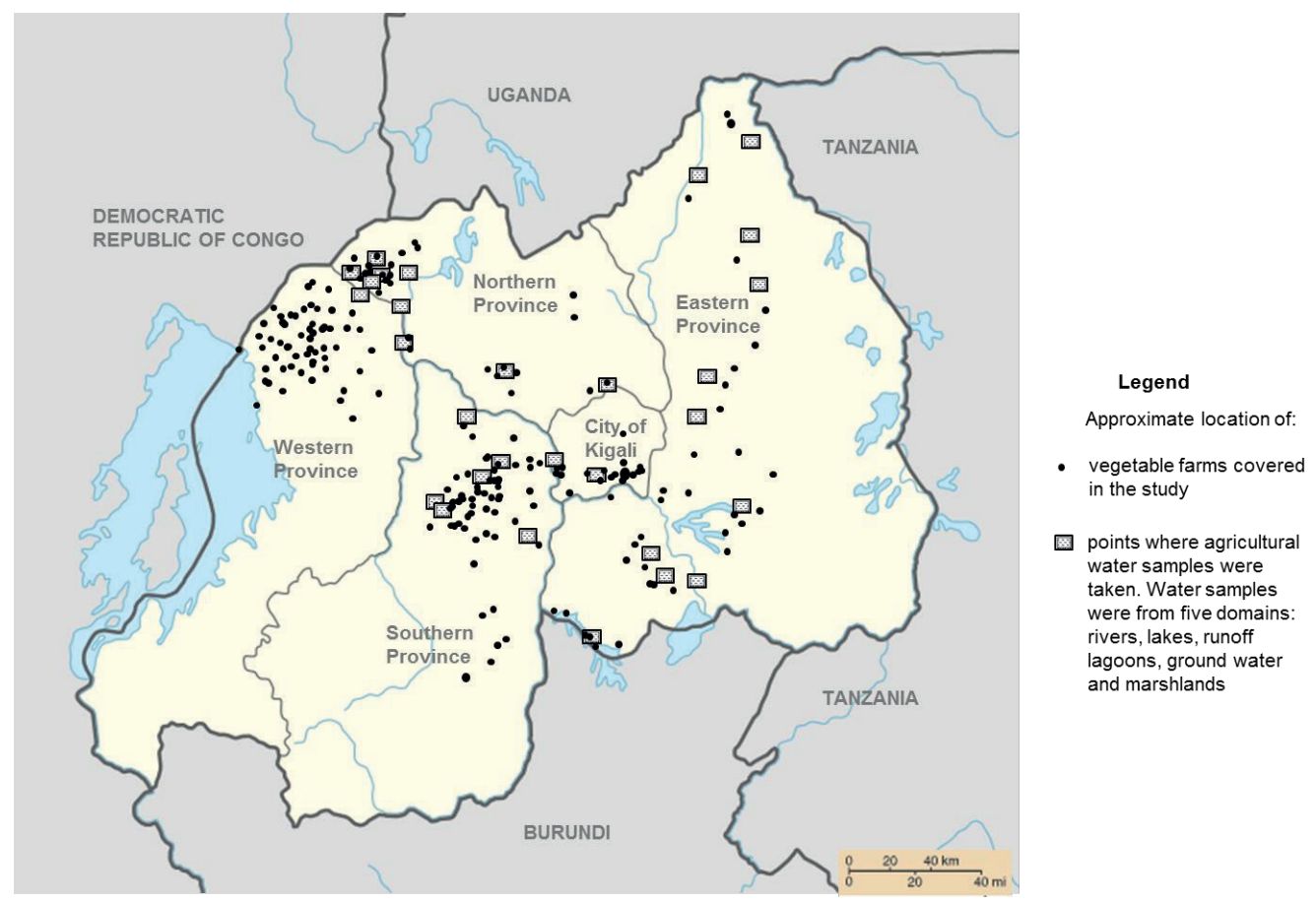

Figure 4.1: Map of Rwanda showing study points in the four provinces and the City of Kigali [Source:

Adapted from Wikipedia (21) ]

\section{Observation study of farming practices and field conditions}

From February to October 2015, a farm review consisting of on-site observations and face to face interviews with vegetable farmers was conducted in Rwanda (Fig. 4.1). The farm review was based on the USA department of Agricultural (USDA) checklist for Good Agricultural Practices (GAPs) and Good Handling Practices ( using part1 - farm review section, Tab.3) (11). Special focus was accorded to irrigation water, animal and human activity and compost manure as part of the WHO - five keys to growing safer fruits and vegetables (12) and the \% number of farms falling in the "yes", "no" or not applicable (NA) answers options was recorded. A total of 198 farms were covered in the study, 29 farms in the Northern province, 59 in the Western province , 34 in the Eastern province , 57 in the Southern province and 19 farms in peripherals of the City of Kigali (Fig. 4.1). Selection of farms for the study was based on the availability of vegetables in farms and one vegetable type was sampled per farm using the same approach as in our previous related study (22). Vegetables understudy were, fruit (i.e.. cucumber, green pepper and tomato); subterranean (carrots, beet root, garlic and onion) and leafy vegetables (lettuce, cabbage, celery and parsley). 


\section{Sampling of farm vegetables}

Each of the 11 types of vegetables were sampled 9 times leading to a total of 99 vegetable samples which were purchased randomly from 99 farms. Sampling of farm vegetables was done in line with the methodology employed in a previous related study (22). Briefly, for subterranean vegetables like carrot, beet root, garlic and onion, the vegetable roots, tubers or bulbs were uprooted, hand shaken to remove the attached soil and the aerial part cut off and discarded. The samples of leafy vegetables such as lettuce, cabbage, celery and parsley consisted of only aerial parts which were cut from the root base. For cabbage, ten heads were collected from each farm. For the other farm vegetables, a pooled farm sample $(\sim 2 \mathrm{~kg})$ was collected as far apart as possible. Sterile materials such as gloves and knives were used throughout the sampling process and changed between each farm sample.

\section{Sampling of agriculture water}

A total of 30 samples of agricultural water (Fig. 4.1) i.e.., irrigation and on-farm postharvest wash water were taken, i.e.. 6 samples from each of the 5 irrigation water domains as listed in the Rwanda irrigation master plan (lakes, rivers, marshlands, ground water, runoff - reservoirs) (23). Water sources or area for each irrigation domain were: Lakes; Muhazi, Mugesera, Cyohoha, Mirayi, Rumira and Birira. Rivers; Mukungwa, Base, Nyabarongo, Akagera, Muvumba and Akanyaru. Marshlands/valleys at; Yanze, Kajevuba, Jenda, Ruhengeri, Kamonyi and Kajeke. Ground water sources (water from natural sand and rocks filtration collected from boreholes and protected wells) at; Mukamira, Nyabihu, Gihinga, Kamonyi, Kigali and Kiramuruzi. Runoff - reservoirs at; Kajevuba, Cyamabuye, Kabgwayi 1, Kabgwayi 2, Kabarore and Rwagitima. Sampling of water was done according to ISO 19458 : 2006 (24) in sterilized Schott glass bottle (DURAN®, Germany) and for each water source, 1L sample was taken.

\section{Handling and transport of samples}

All vegetables and water samples were immediately stored in cooling boxes with ice packs and transported for 1-3 h to the laboratory and analyzed within $1 \mathrm{~h}$.

\section{Isolation and confirmation of foodborne pathogens from farm vegetables}

Preparation of laboratory samples from farm vegetables was done according to the methodology used by Mukherjee et al. (25) with slight modifications. The $\sim 2 \mathrm{~kg}$ field vegetable samples were first sliced/cut into small pieces on a sterile stainless steel tray using sterilized knives, gloves and thereafter mixed and quartered. Each quarter provided a sample for detecting one of the four pathogens understudy (Salmonella spp., L. monocytogenes, thermo-tolerant Campylobacter spp. and pathogenic E. coli ). These pathogens were isolated according to ISO methods except for the modification where each vegetable analytical unit was weighed and diluted in a 1:1 weight by volume $(\mathrm{w} / \mathrm{v})$ ratio with the enrichment broth/diluent (26) homogenized by hand rubbing for $2 \mathrm{~min}$ and incubated at room temperature for $1 \mathrm{~h}$. Unless stated otherwise, all culture media and consumables used were from Oxoid (Basingstoke, UK).

\section{Salmonella spp.}

Salmonella spp. was isolated from vegetable samples according to ISO 6579:2002 Amd 2007 (27) and confirmation reactions were applied by using the Oxoid Microbact GNB 24E 
biochemical identification kit for Gram-negative bacteria (Oxoid Ltd., Basingstoke, UK). Positive controls were performed using Salmonella Typhimurium (LMG 14933).

\section{L. monocytogenes}

L. monocytogenes was isolated from vegetable samples according to ISO 11290-1: 1998/Amd 1: 2004 (28). Typical blue green colonies, with or without halo were harvested from Listeria Agar according to Ottaviani \& Agosti (ALOA). DNA was extracted from the blue green colonies using the 'Wizard genomic DNA purification kit' (Promega Corporation, Madison, U.S.A.) following the manufacturer's instructions for isolation of genomic DNA from Grampositive bacteria. For confirmation, real-time polymerase chain reaction (qPCR) targeting $L$. monocytogenes characteristic genes was performed. Details of the primers, probes and cycling parameters are listed in Table 4.1.

\section{Thermo-tolerant Campylobacter spp.}

Detection and confirmation of thermo-tolerant Campylobacter spp. from vegetable samples was done according to ISO 10272-1: 2017 (29), except that Bolton broth was replaced with Preston broth (higher sensitivity in presence of contaminants). For confirmation, suspected greyish colonies on modified charcoal cefoperazone deoxycholate (mCCD) agar were picked, streaked on Columbia+ horse blood agar (CAB) and incubated micro-aerobically at $41.5{ }^{\circ} \mathrm{C}$ for $48 \mathrm{~h}$. Thereafter, five colonies (each sample) were further streaked on Rapid Campylobacter agar (Bio-rad, Netherlands) and incubated micro-aerobically at $41.5{ }^{\circ} \mathrm{C}$ for $48 \mathrm{~h}$. Typical brick red colonies were picked and grown on $\mathrm{CAB}$ for confirmation tests that consisted of microscopic observation of morphology and motility test in combination with test for micro-aerobic growth at $25^{\circ} \mathrm{C}$, aerobic growth at $41.5^{\circ} \mathrm{C}$, oxidase and catalase test as described in the ISO10272-1: 2006 (29). Positive controls were performed simultaneously using C. jejuni C356 strains (chicken faeces; ASG-WUR, Lelystad, the Netherlands). 


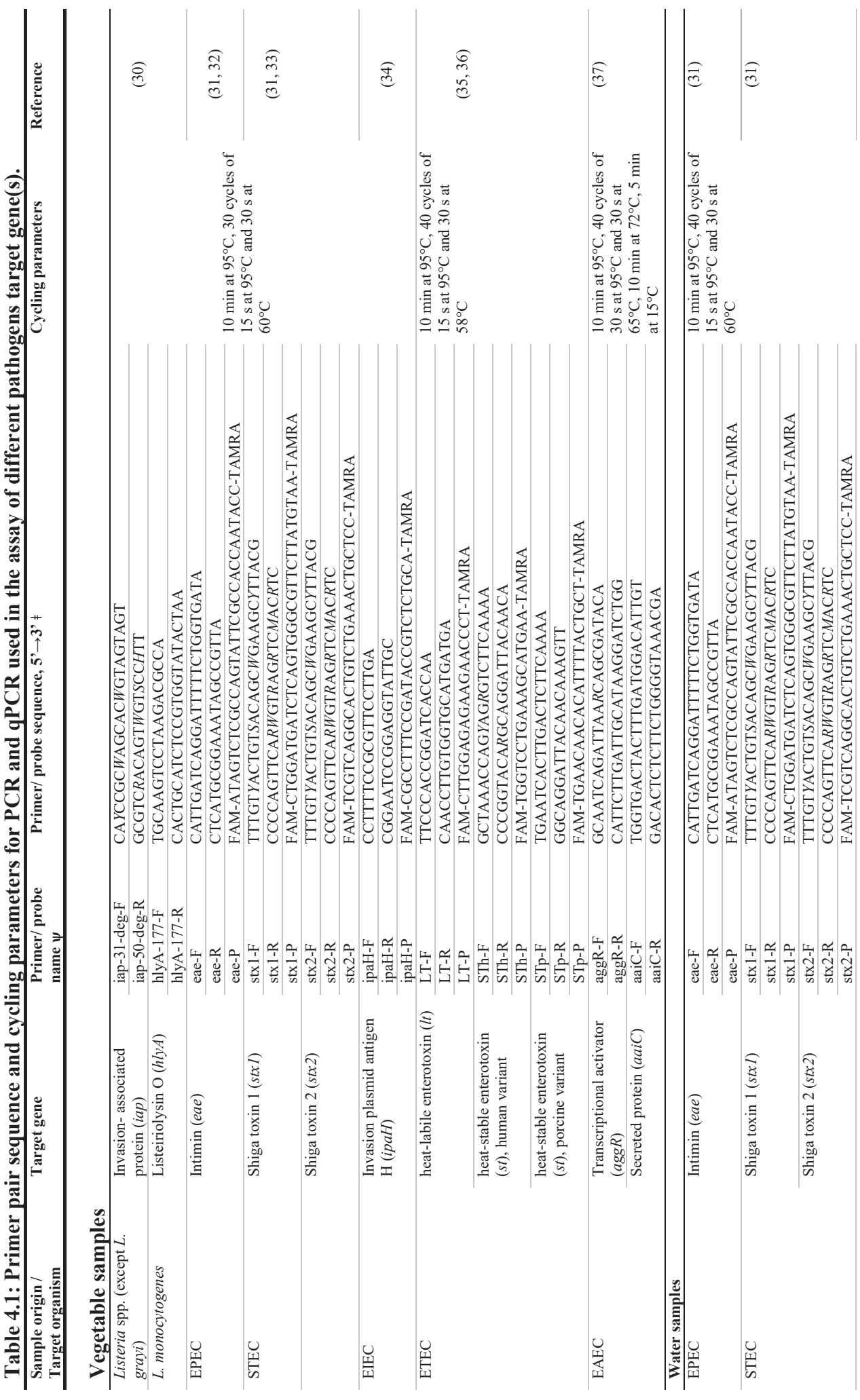




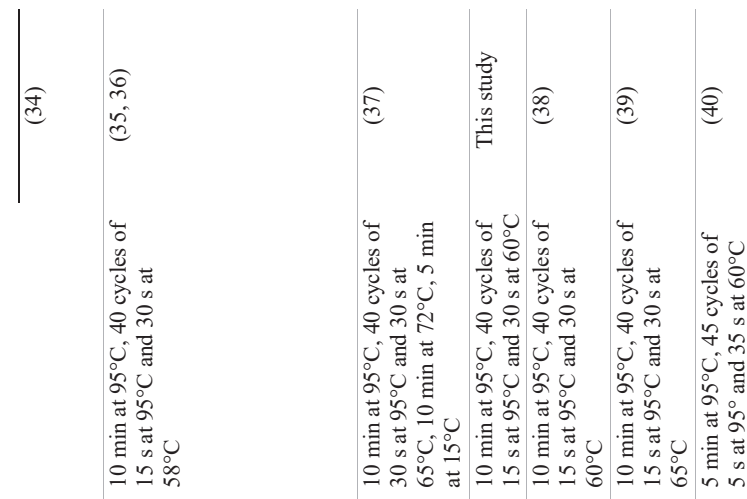

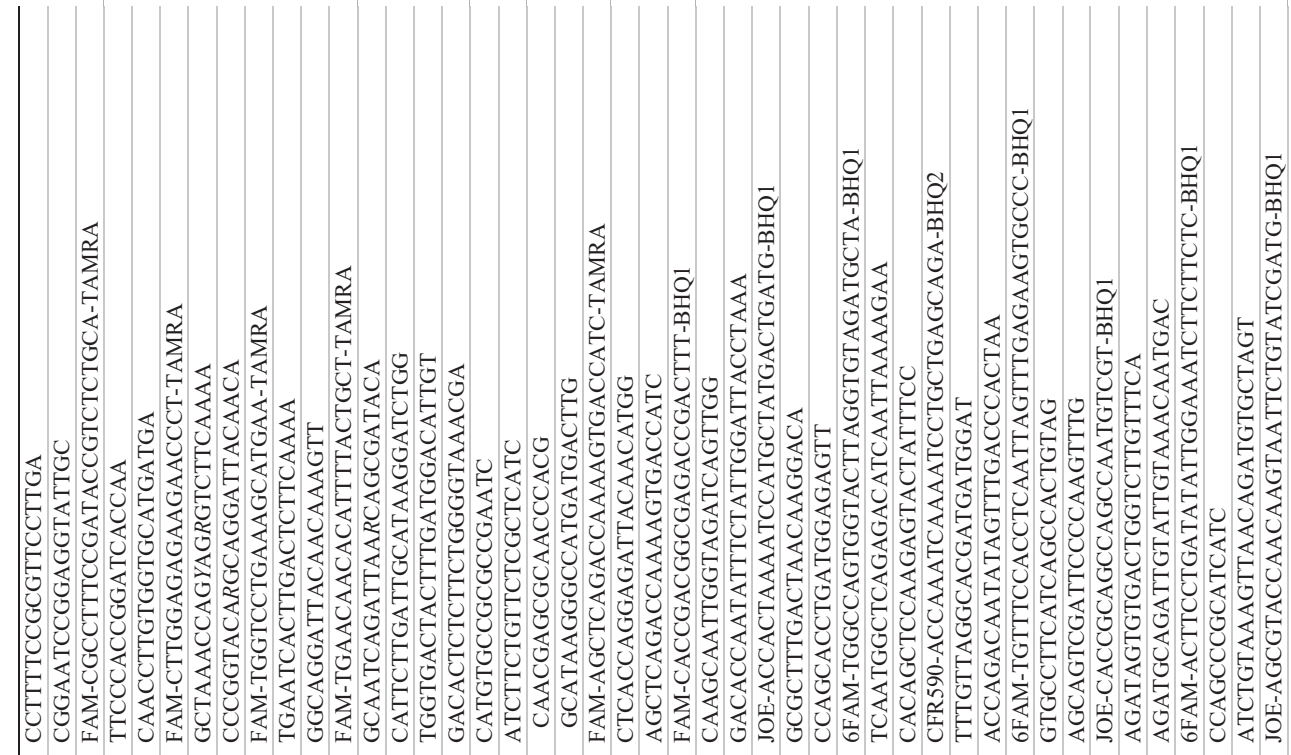
药

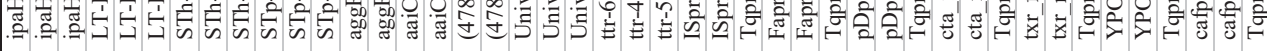

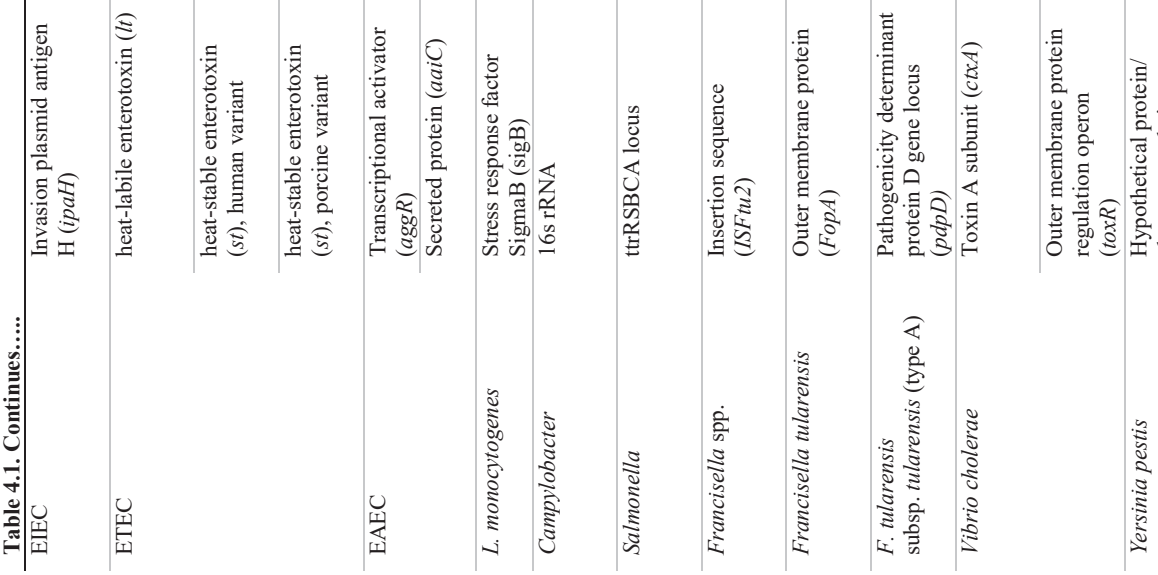



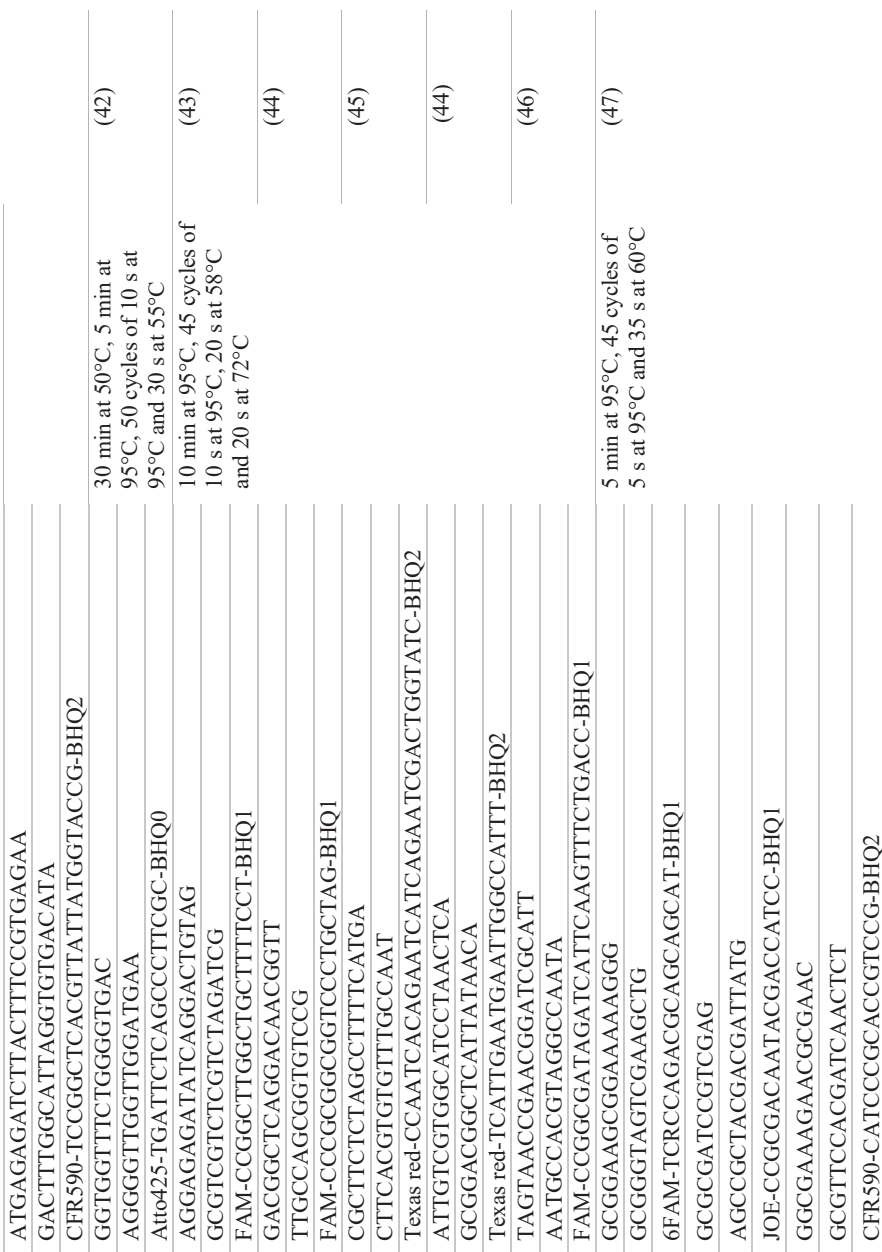

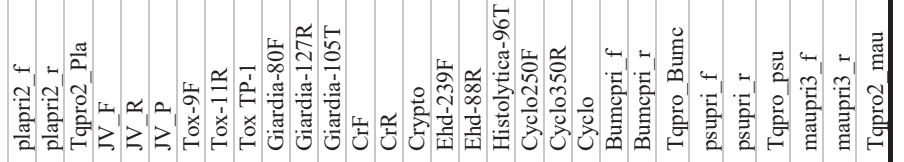

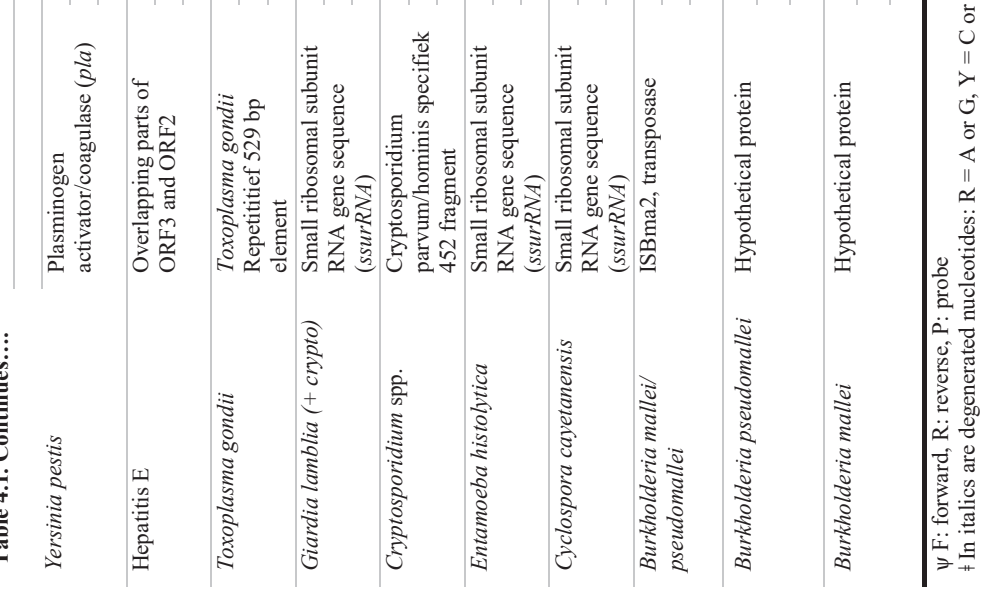




\section{Pathogenic E. coli}

Escherichia coli were isolated from farm vegetables as blue green colonies on tryptone-bileglucuronide agar (TBX) based on ISO 16649-2: 2001 (48). The isolated colonies were further tested for pathogenic E. coli; entero pathogenic E. coli (EPEC), shiga toxin-producing E. coli (STEC), enteroinvasive E. coli (EIEC), enterotoxigenic E. coli (ETEC), enteroaggregative $E$. coli (EAEC) using PCR based methods. STEC was specifically examined according to ISO/TS 13136:2012 (31). Details of the PCR methodology are presented in Table 4.1.

\section{DNA extraction and detection of pathogens from agricultural water}

DNA was extracted from agricultural water using the Power Water DNA isolation kit (MO BIO Laboratories/QIAGEN Company, Carlsbad, CA, USA) following the manufacturer's instructions. Controls of sterile deionized water $(1 \mathrm{~L})$ and sterile deionized water $(1 \mathrm{~L})$ inoculated with $1 \mathrm{~mL}$ of $E$. coli (LMG 8063) were included to evaluate the effectiveness of the DNA isolation procedure. Using PCR based methods, the extracted DNA samples were investigated for target genes of pathogenic E. coli (EPEC, STEC, EIEC, EAEC and ETEC), Salmonella spp., thermo-tolerant Campylobacter spp., L. monocytogenes, Burkholderia, Francisella spp. and Francisella tularensis, Vibrio cholera, Yersinia pestis, Hepatitis E, Rickettsia, Toxoplasma gondii, Giardia lamblia, Cryptosporidium, Entamoeba histolytica and Cyclospora. Details of the PCR methodology are presented in Table 1.

\section{Results and discussion}

\section{Foodborne pathogens in farm vegetables}

Table 4.2 shows detailed results for the tested pathogens in different farm vegetables. Out of 99 farm vegetables samples, $L$. monocytogenes was detected in 1.0\% (1/99) of the samples, thermo-tolerant Campylobacter spp., in 3.0\% (3/99), Salmonella spp. in 5.1\% (5/99) E. coli pathotypes detected in $6.1 \%(6 / 99)$ of the samples. Generally one pathogen was isolated per farm except for two farms where two pathogens were detected in each ie. Salmonella spp. and thermo-tolerant Campylobacter spp. together in a lettuce farm from the southern province (Fig. 4.1) and another farm of parsley with Shiga toxin-producing E. coli (STEC) thermo-tolerant Campylobacter spp. in the Northern province. Furthermore, generic E. coli as an indicator of pathogenic microorganisms was isolated in vegetable samples from 76 out of 99 farms.

In farm vegetables, various researchers have reported differing prevalence for these pathogens. Microbial risk differs from one locality (region or country), season to another and also greatly influenced by level of implementation of GAPs in vegetable farms. For example, pathogenic $E$. coli, serotype O157:H7 was reported at 0\% [0/605] in USA (49) and [0/36] in Brazil (50) and $5 \%$ [3/60] in Greece (51). Salmonella spp. was at 2.7\% [1/36] in Brazil (50), 15\% [35/238] in Nigeria (52), 50\% [10/20] in Burkina Faso (53). Thermo-tolerant Campylobacter spp. were reported at 3.0 [1/33] and $19 \%$ [3/16] (54), 35\% [90/255] in Malaysia (55). L. monocytogenes in farm vegetables was reported at $0 \%[0 / 33]$ in Canada (56) and $14 \%[16 / 118]$ in Korea (57, 58). 


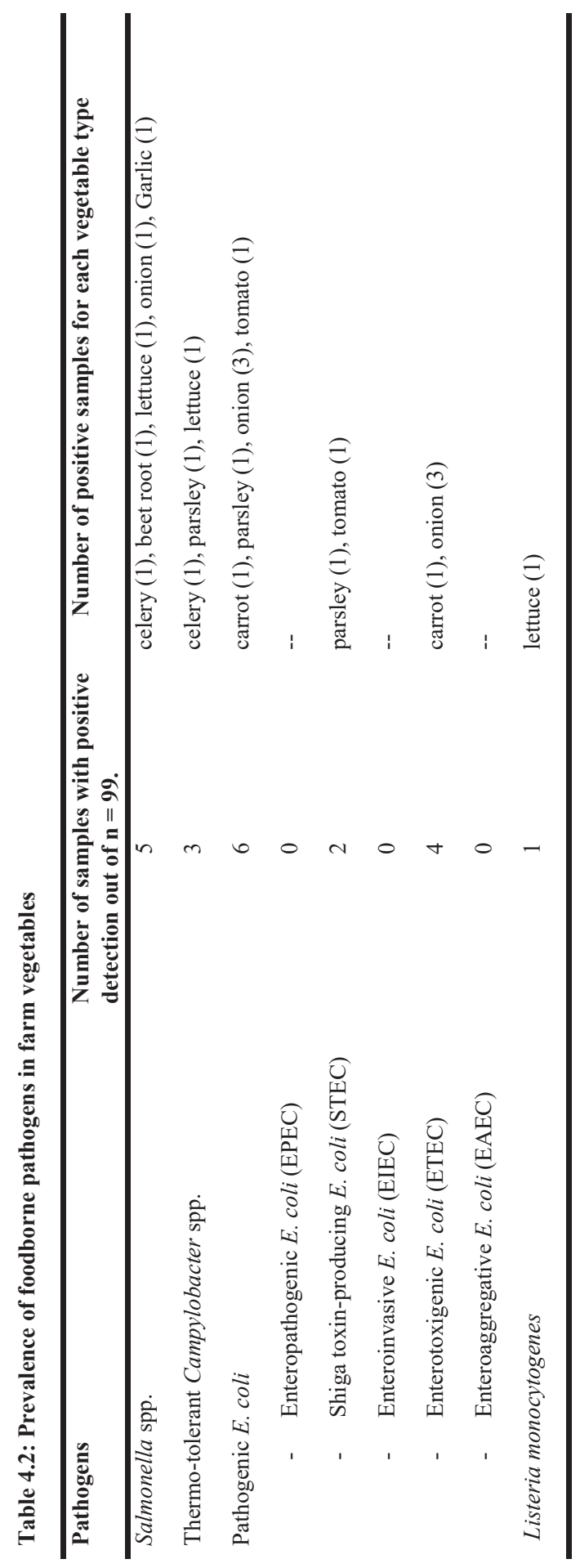




\section{Pre-harvest factors and risk exposure assessment}

Several pre-harvest factors have been reported to affect the microbial safety of fresh vegetables in farms $(9,15)$. In this study, it also observed that the vegetable farming practices, settings and conditions were closely similar (over $50 \%$ score as shown in Table 4.3) throughout the studied area and hence it was difficult to conclude from this study the exact contributing factor(s) of the pathogens isolated in some farms. Further studies will be required to establish causal relationship between the prevalence and trends of specific pathogens isolated in fresh vegetables along the supply chain and their predisposing factors. Nevertheless, the high detection of generic $E$. coli in vegetable samples from $77 \%$ of farms can already be an indication of the significant contribution of zoonotic sources where vegetables in farms can be contaminated via water usage, human activities, livestock and wild life, and compost manure application as further discussed in our qualitative assessment in the following sections.

\section{Water usage}

Vegetables are commonly grown in marshlands and valleys to make use of the entrapped water for irrigation and the available arable land since Rwanda is a high altitude country with the lowest point at $950 \mathrm{~m}$ above sea level (59). About $60 \%$ of the visited farmers irrigated their vegetables during the dry season, while the rest entirely relied on rainfall. Irrigation water was sourced directly from marshlands (70\%), rivers (18\%), lakes (7\%), runoff lagoons (5\%) without any further treatment. No farmer irrigated with ground water. Farm vegetables are mainly irrigated by a combination of furrow and manual watering cans (62\% [ 78/125] of the famers who irrigate) while in $11 \%$ and $27 \%$ of farms, only furrow and manual watering cans was singly used. The climate in Rwanda is temperate tropical with a temperature range of $12^{\circ} \mathrm{C}$ to $27^{\circ} \mathrm{C}$, two rainy seasons from February to May and September to December and a dry season from June to September (23). Figure 4.1 a shows the prevalence of pathogen DNA in irrigation water samples for the different water sources. Prevalence for EIEC was $3.3 \%$ (1/30); 6.7\% $(2 / 30)$ for EAEC; $13.3 \%$ (4/30) for ETEC and Vibrio cholera; $20.0 \%(6 / 30)$ for Yersinia pestis; 26.7\% (8/30) for Francisella tularensis; 40\% (12/30) for Cyclospora and 86.7\% (26/30) for thermo-tolerant Campylobacter spp. Figure $4.2 \mathrm{~b}$ shows that overall prevalence of pathogens DNA (number of positive samples) was highest for water from rivers $(28 \%)$ followed by marshland and run off/ lagoons $(22 \%)$ and lowest in ground water $(10 \%)$. The following pathogens were not detected in any of the 30 water samples: EPEC, STEC, Salmonella spp., L. monocytogenes, Burkholderia, Rickettsia, T. gondii, G. lamblia, Cryptosporidium, E. histolytica and Hepatitis E. Comparing the results of this study to other studies in the African region (although different test methods were used), Salmonella spp. was 19\% (37/200) in well, piped and sachet water in Nigeria (60). In South Africa, Ijabadeyini (61) reported 53\% for Listeria monocytogenes, and $42 \%$ for Salmonella spp. from 36 samples taken 3 rivers/canal. This study did not focus on the comparison of pathogens in farm vegetables and the nearby agricultural water because only a few (four) pathogens were investigated in farm vegetables compared to the 19 pathogens studied agricultural water. However in the Northern province, ETEC was isolated in onion and carrot samples which corresponded with the ETEC DNA detected in the nearby water sources. 
Table 4.3: Farms review checklist for good agricultural practices (GAPs) and good handling practices for fresh vegetables. Number farms surveyed $(n)=198$.

\begin{tabular}{|c|c|c|c|c|}
\hline \multirow[t]{2}{*}{$\begin{array}{l}\text { Question } \\
\text { No. }\end{array}$} & \multirow[t]{2}{*}{ Farm aspect//GAP/Activity question } & \multicolumn{3}{|c|}{$\begin{array}{l}\text { \% number of farms } \\
\text { under each answer } \\
\text { category }\end{array}$} \\
\hline & & Yes & No & NA \\
\hline & Water usage & & & \\
\hline 1. & $\begin{array}{l}\text { A water quality assessment has been performed to determine the } \\
\text { quality of water used for irrigation purpose on the crop(s) being } \\
\text { applied. }\end{array}$ & $0 \%$ & $63 \%$ & $37 \%$ \\
\hline 2. & $\begin{array}{l}\text { A water quality assessment has been performed to determine the } \\
\text { quality of water use for chemical application or fertigation method. }\end{array}$ & $0 \%$ & $63 \%$ & $37 \%$ \\
\hline 3. & $\begin{array}{l}\text { If necessary, steps are taken to protect irrigation water from potential } \\
\text { direct and nonpoint source contamination. }\end{array}$ & $0 \%$ & $63 \%$ & $37 \%$ \\
\hline & Sewage Treatment & & & \\
\hline 4. & $\begin{array}{l}\text { The farm sewage treatment system/septic system is functioning } \\
\text { properly and there is no evidence of leaking or runoff. }\end{array}$ & $0 \%$ & $0 \%$ & $100 \%$ \\
\hline 5. & $\begin{array}{l}\text { There is no municipal/commercial sewage treatment facility or waste } \\
\text { material landfill adjacent to the farm. }\end{array}$ & $0 \%$ & $0 \%$ & $100 \%$ \\
\hline & Animals/Wildlife/Livestock & & & \\
\hline 6. & $\begin{array}{l}\text { Crop production areas are not located near or adjacent to dairy, } \\
\text { livestock, or fowl production facilities unless adequate barriers exist. }\end{array}$ & $70 \%$ & $30 \%$ & $0 \%$ \\
\hline 9. & $\begin{array}{l}\text { Manure lagoons located near or adjacent to crop production areas are } \\
\text { maintained to prevent leaking/overflowing, or measures have been } \\
\text { taken to stop runoff from contaminating the crop production areas. }\end{array}$ & $0 \%$ & $0 \%$ & $100 \%$ \\
\hline 7. & $\begin{array}{l}\text { Manure stored near or adjacent to crop production areas is contained } \\
\text { to prevent contamination of crops. }\end{array}$ & $0 \%$ & $7 \%$ & $93 \%$ \\
\hline 8. & $\begin{array}{l}\text { Measures are taken to restrict access of livestock to the source or } \\
\text { delivery system of crop irrigation water. }\end{array}$ & $0 \%$ & $\begin{array}{l}100 \\
\%\end{array}$ & $0 \%$ \\
\hline 9. & $\begin{array}{l}\text { Crop production areas are monitored for the presence or signs of wild } \\
\text { or domestic animals the entering the land. }\end{array}$ & $0 \%$ & $\begin{array}{l}100 \\
\%\end{array}$ & $0 \%$ \\
\hline 10. & $\begin{array}{l}\text { Measures are taken to reduce the opportunity for wild and/or } \\
\text { domestic animals from entering crop production areas. }\end{array}$ & $0 \%$ & $\begin{array}{l}100 \\
\%\end{array}$ & $0 \%$ \\
\hline
\end{tabular}

\section{Manure and Municipal Biosolids}

Option A: Raw Manure

\begin{tabular}{|c|c|c|c|c|}
\hline 11. & $\begin{array}{l}\text { When raw manure is applied, it is incorporated at least } 2 \text { weeks prior } \\
\text { to planting or a minimum of } 120 \text { days prior to harvest. }\end{array}$ & $62 \%$ & $0 \%$ & $38 \%$ \\
\hline 12. & $\begin{array}{l}\text { Raw manure is not used on commodities that are harvested within } \\
120 \text { days of planting. }\end{array}$ & $62 \%$ & $0 \%$ & $38 \%$ \\
\hline 13. & $\begin{array}{l}\text { If both raw and treated manure are used, the treated manure is } \\
\text { properly treated, composted or exposed to reduce the expected levels } \\
\text { of pathogens. }\end{array}$ & $10 \%$ & $53 \%$ & $38 \%$ \\
\hline 14. & Manure is properly stored prior to use. & $7 \%$ & $56 \%$ & $38 \%$ \\
\hline
\end{tabular}


Table 4.3 Continues...

\begin{tabular}{|c|c|c|c|c|}
\hline & $\begin{array}{l}\text { Manure and Municipal Biosolids } \\
\text { Option B: Composted Manure }\end{array}$ & & & \\
\hline 15. & Only composted manure are used as a soil amendment. & $28 \%$ & $34 \%$ & $38 \%$ \\
\hline 16. & $\begin{array}{l}\text { Composted manure are properly treated, composted, or exposed to } \\
\text { environmental conditions that would lower the expected level of } \\
\text { pathogens. }\end{array}$ & $4 \%$ & $24 \%$ & $38 \%$ \\
\hline 17. & $\begin{array}{l}\text { Composted manure are properly stored and are protected to minimize } \\
\text { recontamination. }\end{array}$ & $0 \%$ & $28 \%$ & $38 \%$ \\
\hline \multirow[t]{2}{*}{18.} & $\begin{array}{l}\text { Analysis reports are available for composted manure/treated } \\
\text { biosolids. }\end{array}$ & $0 \%$ & $62 \%$ & $38 \%$ \\
\hline & $\begin{array}{l}\text { Manure and Municipal Biosolids } \\
\text { Option C: No Manure/Biosolids Used }\end{array}$ & & & \\
\hline \multirow[t]{2}{*}{19.} & No animal manure are used. & $38 \%$ & $62 \%$ & $0 \%$ \\
\hline & Soils & & & \\
\hline 20. & A previous land use risk assessment has been performed. & $0 \%$ & $\begin{array}{l}100 \\
\%\end{array}$ & $0 \%$ \\
\hline 21. & $\begin{array}{l}\text { When previous land use history indicates a Soils Questions } \\
\text { possibility of contamination, preventative measures have been taken } \\
\text { to mitigate the known risks and soils have been tested for } \\
\text { contaminants and the land use is commensurate with test results. }\end{array}$ & $0 \%$ & $\begin{array}{l}100 \\
\%\end{array}$ & $0 \%$ \\
\hline \multirow[t]{2}{*}{22.} & $\begin{array}{l}\text { Crop production areas that have been subjected to flooding are tested } \\
\text { for potential microbial hazards. }\end{array}$ & $0 \%$ & $\begin{array}{l}100 \\
\%\end{array}$ & $0 \%$ \\
\hline & Traceability & & & \\
\hline 24. & $\begin{array}{l}\text { Each production area is identified or coded to enable traceability in } \\
\text { the event of a recall. }\end{array}$ & $0 \%$ & $\begin{array}{l}100 \\
\%\end{array}$ & $0 \%$ \\
\hline
\end{tabular}

NA, response denotes those GAPs or GHPs that are not applicable or practical to the farm situation in Rwanda

DNA detection in agricultural water (irrigation and on-farm washing water) has revealed strikingly high prevalence of thermo-tolerant Campylobacter spp. (86.7\%). In other studies, the prevalence of thermo-tolerant Campylobacter spp. in environmental water sources was reported at $19.3 \%$ [50/260] in USA (62), 30.9\% [37/120] in Belgium (63) and 55.3\% [162/293] in New Zealand (64). Detecting DNA from Campylobacter and other pathogens may not necessarily represent the presence of their living cells, but these results indicate a high risk of microbial contamination and using this water to irrigate and or wash vegetables after harvesting may present a major risk of microbial hazards.

This study revealed that rivers and marshlands had the highest prevalence of pathogen DNA, implying that if this water is used for overhead irrigation of leafy vegetables (10), contamination of the edible part of the vegetables may occur. Ground water had the lowest prevalence of pathogens DNA, but this water is hardly used for irrigation in most developing countries. Instead it is mainly targeted for household use (65). 


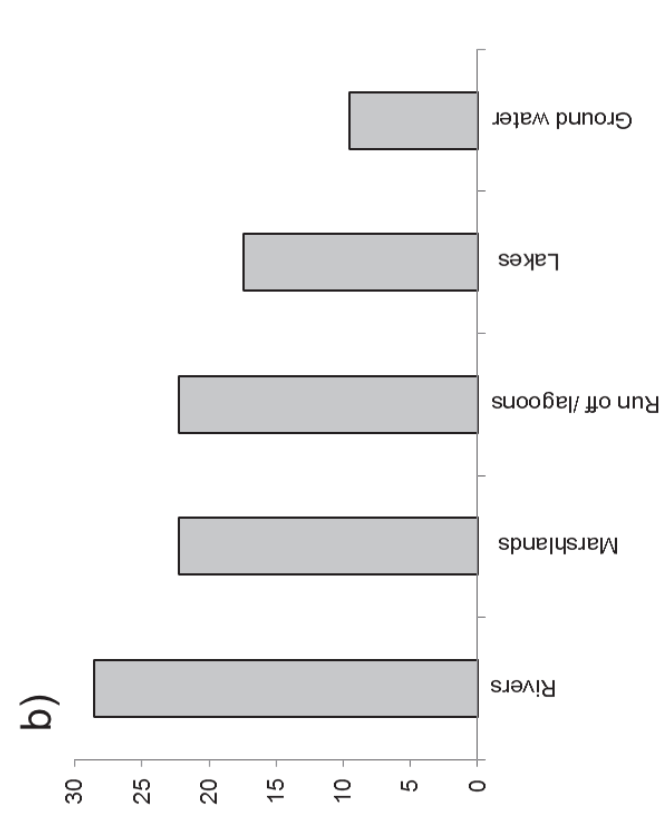

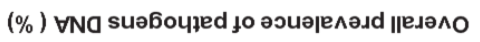

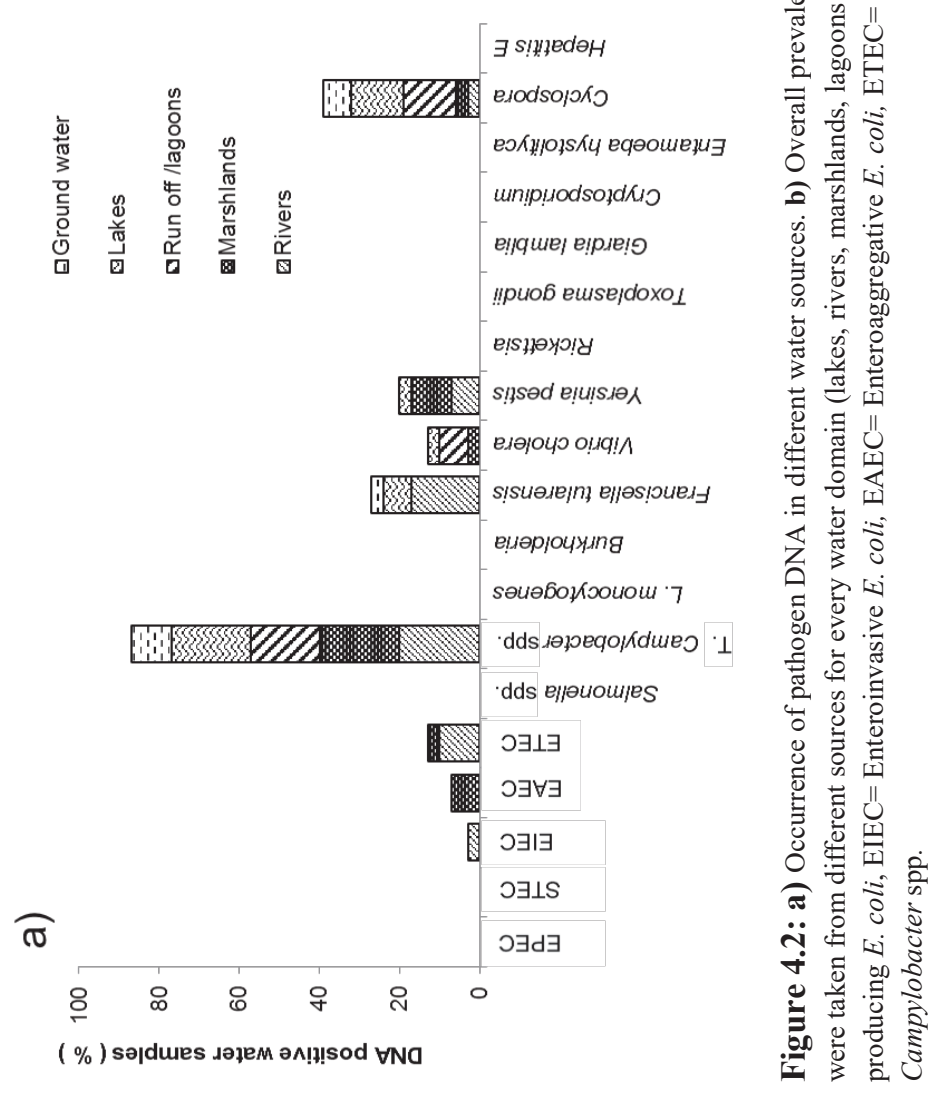




\section{Human activity, livestock and wildlife}

Population density is characteristically high in the farming areas, i.e.. in the main vegetable growing areas of Musanze and Rubavu, it was reported in the national census in 2012 that there were 694 and 1,039 inhabitants per sq.km (66). Mixed farming is common; domestic animals (goats, sheep and cattle) were observed in the vegetable growing areas. We observed that measures to restrict domestic and wild animals (15) from accessing crop production areas and irrigation water were not implemented. In other countries, unrestricted animal access to vegetable farms was observed in $60 \%$ [6/10] of the vegetable farms in Nigeria (67) and $23 \%$ [57/246] in USA (68).

The presence of zoonotic pathogens in environmental water indicates the possibility of human, livestock and wildlife activities to introduce zoonotic pathogens either directly or indirectly through runoff and erosion of land surfaces after precipitation (69). The high prevalence of Campylobacter spp. in the studied agricultural water may be linked to the reported high population (66) and livestock density per $\mathrm{km}^{2}$ (70) but also due to the un controlled roaming of livestock and wild animals in the environment (71), especially since this bacterium has been detected frequently in fecal droppings (72). In addition, the pathogens detected in farm vegetables (section 3.1) can also be attributed to humans and animals in vegetable growing areas.

\section{Compost manure application}

With the increasing amount of livestock (70), the use of animal manure is popular in Rwanda. Compost and or raw manure application was used in $60 \%$ of the visited vegetable farms while recommended storage (12) and treatment (15) of this manure was not yet implemented by over $50 \%$ of the farmers. Similar findings were observed in Nigeria (67) whereas only $2 \%$ of the farmers in Minnesota applied raw manure, USA (68). Improperly treated animal manure has been reported to harbor human pathogens (73), and in order to minimize these microbial hazards in compost manure, measures such as active and passive treatment of manure have been recommended (15).

\section{Conclusion}

Like in studies from countries with settings similar to Rwanda, i.e.. Nigeria (74), the Middle East (75), farming practices that can expose fresh vegetables to a high microbial contamination (15) have been observed in this study. With the growing population and the increasing amount of livestock and production of fresh vegetables, risk managers will have to adopt sustainable approaches (76) (77) to prevent or control the spread of pathogens in the human-plant-animal interface. Efforts to address the challenges of microbial safety in farm vegetables will require strict adherence to GAPs and GHPs. Farming practices are critical to control and prevention of microbial hazards and in this study, serious gaps have been observed. Farmers will have to be trained and or provided with an economic incentive/ legislation to impact behavior change and improve on hygienic farming. In Nigeria, it was reported that farmers were generally unware of the link between food safety practices and microbial contamination of fresh vegetables (74) and their findings seem to be in line with the current study. Recommendations from organization like the FAO $(13,15)$ and the WHO (12) of the United Nations should be adopted 
to guide practices on water use, compost manure, handling domestic and wild animals, human activities and general environmental hygiene in vegetable farms. 


\section{References}

1. Havelaar et al. 2015. World Health Organization global estimates and regional comparisons of the burden of foodborne disease in 2010. PLoS Medicine 12:e1001923.

2. Batz MB. 2013. The foods most often associated with major foodborne pathogens: attributing illnesses to food sources and ranking pathogen/food combinations. In Morris G. J., Potter M. (4th Edn). Foodborne Infections \& Intoxications (pp 19-35). London: Academic Press.

3. Painter JA, Hoekstra RM, Ayers T, Tauxe RV, Braden CR, Angulo FJ, Griffin PM. 2013. Attribution of foodborne illnesses, hospitalizations, and deaths to food commodities by using outbreak data, United States, 1998-2008. Emerging Infectious Diseases 19:407-415.

4. Holvoet K, Sampers I, Callens B, Dewulf J, Uyttendaele M. 2013. Moderate prevalence of antimicrobial resistance in Escherichia coli isolates from lettuce, irrigation water, and soil. Applied \& Environmental Microbiology 79:6677-6683.

5. Adamu NB, Adamu JY, Mohammed D. 2012. Prevalence of helminth parasites found on vegetables sold in Maiduguri, Northeastern Nigeria. Food Control 25:23-26.

6. Aw TG, Wengert S, Rose JB. 2016. Metagenomic analysis of viruses associated with field-grown and retail lettuce identifies human and animal viruses. International Journal of Food Microbiology 223:50-56.

7. Gorski L, Palumbo JD, Nguyen KD. 2004. Strain-specific differences in the attachment of Listeria monocytogenes to alfalfa sprouts. Journal of Food Protection 67:2488-2495.

8. Macarisin D, Patel J, Sharma VK. 2014. Role of curli and plant cultivation conditions on Escherichia coli $\mathrm{O} 157: \mathrm{H7}$ internalization into spinach grown on hydroponics and in soil. International Journal of Food Microbiology 173:48-53.

9. Beuchat LR, Ryu JH. 1997. Produce handling and processing practices. Emerging Infectious Diseases 3:459-465.

10. Gil MI, Selma MV, Suslow T, Jacxsens L, Uyttendaele M, Allende A. 2015. Pre- and postharvest preventive measures and intervention strategies to control microbial food safety hazards of fresh leafy vegetables. Critical Reviews in Food Science \& Nutrition 55:453-468.

11. USDA. 2014. United States department of agriculture. Good Agricultural Practices, Good Handling Practice audit verification checklist. Available at:

https://www.ams.usda.gov/sites/default/files/media/GAPGHP_Checklist_no_spell_Checklist_Enable d\%5B1\%5D.pdf. Accessed 15 ${ }^{\text {th }}$ November 2014.

12. WHO. 2012. World Health Organization of the United Nations. Five keys to growing safer fruits and vegetables. Promoting health by decreasing microbial contamination. Available at: http://apps.who.int//iris/bitstream/10665/75196/1/9789241504003_eng.pdf?ua=1. Accessed $15^{\text {th }}$ November 2014.

13. FAO. 2012. Food and Agriculture Organization of the United Nations. On-farm practices for the safe use of wastewater in urban and peri-urban horticulture. A training handbook for farmer field schools. Available at: http://www.fao.org/docrep/016/i3041e/i3041e.pdf. Accessed 17 July 2013.

14. FAO. 2008a. Food and Agriculture Organisation (FAO) of the United Nations. Contributing to "One World, One Health". A strategic framework for reducing risks of infectious diseases at the animal- 
human-ecosystems interface. Available at $\mathrm{ftp} / / \mathrm{ftp}$. fao.org/docrep/fao/011/aj137e/aj137e00.pdf. Accessed $01^{\text {st }}$ October 2016.

15. FAO. 2008b. Food and Agriculture Organization and the World Health Organization (WHO) of the United Nations. Microbiological hazards in fresh leafy vegetables and herbs. Meeting report. Available at : http://www.fao.org/3/a-i0452e.pdf. Accessed 15 $5^{\text {th }}$ November 2015.

16. Callejon RM, Rodriguez-Naranjo MI, Ubeda C, Hornedo-Ortega R, Garcia-Parrilla MC, Troncoso AM. 2015. Reported foodborne outbreaks due to fresh produce in the United States and European Union: trends and causes. Foodborne Pathogens \& Disease 12:32-38.

17. Beuchat LR. 1996. Listeria monocytogenes: incidence on vegetables. Food Control 7:223-228.

18. Mead PS, Slutsker L, Dietz V, McCaig LF, Bresee JS, Shapiro C, Griffin PM, Tauxe RV. 1999. Food-related illness and death in the United States. Emerging Infectious Diseases 5:607-625.

19. Beuchat LR. 2006. Vectors and conditions for preharvest contamination of fruits and vegetables with pathogens capable of causing enteric diseases. British Food Journal 108:38-53.

20. Uyttendaele M, Jaykus L-A, Amoah P, Chiodini A, Cunliffe D, Jacxsens L, Holvoet K, Korsten L, Lau M, McClure P, Medema G, Sampers I, Rao Jasti P. 2015. Microbial hazards in irrigation water: standards, norms, and testing to manage use of water in fresh produce primary production. Comprehensive Reviews in Food Science \& Food Safety 14:336-356.

21. Wikipedia. 2016. Template: Location map of Rwanda. Available at: https://en.wikipedia.org/wiki/Template:Location_map_Rwanda. Accessed $12^{\text {th }}$ December 2017.

22. Ssemanda JN, Reij M, Bagabe MC, Muvunyi CM, Joosten H, Zwietering MH. 2017. Indicator microorganisms in fresh vegetables from "farm to fork" in Rwanda. Food Control 75:126-133.

23. Malesu MM, Oduor A, Chrogony K, Nyolei D, Gachene C, Biamah E, O'Neil M, Ilyama M, Mogoi J. 2010. Rwanda irrigation master plan. Nairobi, Kenya: The Government of Rwanda, Ministry of agriculture and animal resources, Ebony Company Limited \& World Agro-forestry Centre (ICRAF).

24. ISO 19458: 2006. Water quality -- Sampling for microbiological analysis. International Organization for Standardization (ISO), Geneva, Switzerland.

25. Mukherjee A, Speh D, Diez-Gonzalez F. 2007. Association of farm management practices with risk of Escherichia coli contamination in pre-harvest produce grown in Minnesota and Wisconsin. International Journal of Food Microbiology 120:296-302.

26. Pagadala S, Marine SC, Micallef SA, Wang F, Pahl DM, Melendez MV, Kline WL, Oni RA, Walsh CS, Everts KL, Buchanan RL. 2015. Assessment of region, farming system, irrigation source and sampling time as food safety risk factors for tomatoes. International Journal of Food Microbiology 196:98-108.

27. ISO 6579: 2002/Amd 1: 2007. Microbiology of food and animal feeding stuffs -- Horizontal method for the detection of Salmonella spp. Annex D: Detection of Salmonella spp. in animal faeces and in environmental samples from the primary production stage. International Organization for Standardization, Geneva, Switzerland.

28. ISO 11290-1:1996/Amd 1:2004. Microbiology of food and animal feeding stuffs -- Horizontal method for the detection and enumeration of Listeria monocytogenes -- Part 1: Detection method. Amendments: Modification of the isolation media and the haemolysis test, and inclusion of precision data. International Organization for Standardization, Geneva, Switzerland. 
29. ISO 10272-1: 2017. Microbiology of food and animal feeding stuffs -- Horizontal method for detection and enumeration of Campylobacter spp. -- Part 1: Detection method. International Organization for Standardization, Geneva, Switzerland.

30. Barbau-Piednoir E, Botteldoorn N, Yde M, Mahillon J, Roosens NH. 2013. Development and validation of qualitative SYBR ${ }^{\circledR}$ Green real-time PCR for detection and discrimination of Listeria spp. and Listeria monocytogenes. Applied Microbiology \& Biotechnology 97:4021-4037.

31. ISO/TS 13136: 2012. Microbiology of food and animal feed -- Real-time polymerase chain reaction (PCR)-based method for the detection of food-borne pathogens -- Horizontal method for the detection of Shiga toxin-producing Escherichia coli (STEC) and the determination of O157, O111, O26, O103 and O145 serogroups. International Organization for Standardization, Geneva, Switzerland.

32. Nielsen EM, Andersen MT. 2003. Detection and characterization of verocytotoxin-producing Escherichia coli by automated 5' nuclease PCR assay. Journal of Clinical Microbiology 41:2884-2893.

33. Perelle S, Dilasser F, Grout J, Fach P. 2004. Detection by 5'-nuclease PCR of Shiga-toxin producing Escherichia coli $\mathrm{O} 26, \mathrm{O} 55, \mathrm{O} 91, \mathrm{O} 103, \mathrm{O} 111, \mathrm{O} 113, \mathrm{O} 145$ and O157: H7, associated with the world's most frequent clinical cases. Molecular and Cellular Probes 18:185-192.

34. Thiem VD, Sethabutr O, von Seidlein L, Van Tung T, Chien BT, Lee H, Houng H-S, Hale TL, Clemens JD, Mason C. 2004. Detection of Shigella by a PCR assay targeting the ipaH gene suggests increased prevalence of shigellosis in Nha Trang, Vietnam. Journal of Clinical Microbiology 42:20312035.

35. EU. 2013. European Union reference laboratory for E. coli. Detection of Enterotoxigenic Escherichia coli in food by Real Time PCR amplification of the lt, sth, and stp genes, encoding the heat-labile and heat-stable enterotoxins. Department of veterinary public health and food safety, unit of foodborne zoonoses, (Istituto Superiore di Sanità). Available at:

http://www.iss.it/binary/vtec/cont/EU_RL_VTEC_Method_08_Rev_0.pdf. Accessed 04 ${ }^{\text {th }}$ June 2015.

36. Liu J, Gratz J, Amour C, Kibiki G, Becker S, Janaki L, Verweij JJ, Taniuchi M, Sobuz SU, Haque R. 2013. A laboratory-developed TaqMan Array Card for simultaneous detection of 19 enteropathogens. Journal of Clinical Microbiology 51:472-480.

37. Boisen N, Scheutz F, Rasko DA, Redman JC, Persson S, Simon J, Kotloff KL, Levine MM, Sow S, Tamboura B. 2012. Genomic characterization of enteroaggregative Escherichia coli from children in Mali. Journal of Infectious Diseases 205:431-444.

38. Keramas G, Bang DD, Lund M, Madsen M, Rasmussen SE, Bunkenborg H, Telleman P, Christensen CBV. 2003. Development of a sensitive DNA microarray suitable for rapid detection of Campylobacter spp. Molecular \& Cellular Probes 17:187-196.

39. Malorny B, Paccassoni E, Fach P, Bunge C, Martin A, Helmuth R. 2004. Diagnostic real-time PCR for detection of Salmonella in food. Applied \& Environmental Microbiology 70:7046-7052.

40. Janse I, Hamidjaja RA, Bok JM, van Rotterdam BJ. 2010. Reliable detection of Bacillus anthracis, Francisella tularensis and Yersinia pestis by using multiplex qPCR including internal controls for nucleic acid extraction and amplification. BMC Microbiology 10:314.

41. Schets F, Van den Berg H, Marchese A, Garbom S, de Roda Husman A. 2011. Potentially human pathogenic vibrios in marine and fresh bathing waters related to environmental conditions and disease outcome. International Journal of Hygiene \& Environmental Health 214:399-406. 
42. Vasickova P, Kralik P, Slana I, Pavlik I. 2012. Optimisation of a triplex real time RT-PCR for detection of hepatitis E virus RNA and validation on biological samples. Journal of Virological Methods 180:38-42.

43. Reischl U, Bretagne S, Krüger D, Ernault P, Costa J-M. 2003. Comparison of two DNA targets for the diagnosis of Toxoplasmosis by real-time PCR using fluorescence resonance energy transfer hybridization probes. BMC Infectious Diseases 3:7.

44. Verweij JJ, Blangé RA, Templeton K, Schinkel J, Brienen EA, van Rooyen MA, van Lieshout L, Polderman AM. 2004. Simultaneous detection of Entamoeba histolytica, Giardia lamblia, and Cryptosporidium parvum in fecal samples by using multiplex real-time PCR. Journal of Clinical Microbiology 42:1220-1223.

45. Fontaine M, Guillot E. 2002. Development of a TaqMan quantitative PCR assay specific for Cryptosporidium parvum. FEMS Microbiology Letters 214:13-17.

46. Verweij JJ, Laeijendecker D, Brienen EA, van Lieshout L, Polderman AM. 2003. Detection of Cyclospora cayetanensis in travellers returning from the tropics and subtropics using microscopy and real-time PCR. International Journal of Medical Microbiology 293:199-202.

47. Janse I, Hamidjaja RA, Hendriks AC, van Rotterdam BJ. 2013. Multiplex qPCR for reliable detection and differentiation of Burkholderia mallei and Burkholderia pseudomallei. BMC Infectious Diseases 13:86.

48. ISO 16649-2:2001. Microbiology of food and animal feeding stuffs -- Horizontal method for the enumeration of beta-glucuronidase-positive Escherichia coli -- Part 2: Colony-count technique at 44 degrees C using 5-bromo-4-chloro-3-indolyl beta-D-glucuronide. International Organization for Standardization, Geneva, Switzerland.

49. Mukherjee A, Speh D, Dyck E, Diez-Gonzalez F. 2004. Preharvest evaluation of coliforms, Escherichia coli, Salmonella, and Escherichia coli O157: H7 in organic and conventional produce grown by Minnesota farmers. Journal of Food Protection 67:894-900.

50. de Quadros Rodrigues R, Loiko MR, Minéia Daniel de Paula C, Hessel CT, Jacxsens L, Uyttendaele M, Bender RJ, Tondo EC. 2014. Microbiological contamination linked to implementation of good agricultural practices in the production of organic lettuce in Southern Brazil. Food Control 42:152-164.

51. Pinaka O, Pournaras S, Mouchtouri V, Plakokefalos E, Katsiaflaka A, Kolokythopoulou F, Barboutsi E, Bitsolas N, Hadjichristodoulou C. 2013. Shiga toxin-producing Escherichia coli in Central Greece: Prevalence and virulence genes of O157:H7 and non-O157 in animal feces, vegetables, and humans. European Journal of Clinical Microbiology \& Infectious Diseases 32:1401-1408.

52. Abakpa GO, Umoh VJ, Ameh JB, Yakubu SE, Kwaga JKP, Kamaruzaman S. 2015. Diversity and antimicrobial resistance of Salmonella enterica isolated from fresh produce and environmental samples. Environmental Nanotechnology, Monitoring \& Management 3:38-46

53. Traoré O, Nyholm O, Siitonen A, Bonkoungou IJO, Traoré AS, Barro N, Haukka K. 2015. Prevalence and diversity of Salmonella enterica in water, fish and lettuce in Ouagadougou, Burkina Faso. BMC Microbiology 15:1-7.

54. Chai LC, Ghazali FM, Bakar FA, Lee HY, Suhaimi LRA, Talib SA, Nakaguchi Y, Nishibuchi M, Radu S. 2009. Occurrence of thermophilic Campylobacter spp. contamination on vegetable farms in Malaysia. Journal of Microbiology and Biotechnology 19:1415-1420. 
55. Khalid MI, Tang JYH, Baharuddin NH, Rahman NS, Rahimi NF, Radu S. 2015. Prevalence, Antibiogram, and cdt Genes of Toxigenic Campylobacter jejuni in Salad Style Vegetables (Ulam) at farms and retail outlets in Terengganu. Journal of Food Protection 78:65-71.

56. Dallaire R, LeBlanc DI, Tranchant CC, Vasseur L, Delaquis P, Beaulieu C. 2006. Monitoring the microbial populations and temperatures of fresh broccoli from harvest to retail display. Journal of Food Protection 69:1118-1125.

57. Tango CN, Choi NJ, Chung MS, Oh DH. 2014. Bacteriological quality of vegetables from organic and conventional production in different areas of Korea. Journal of Food Protection 77:1411-1417.

58. Thapa SP, Kim SS, Hong SS, Park DS, Lim CK, Hur JH. 2008. Monitoring of bacterial pathogens in agricultural products and environments at farms in Korea. Journal of Applied Biological Chemistry 51:128-135.

59. MINAFFET. 2017. Ministry of foreign affairs and cooperation of the Republic of Rwanda. Geography. Available at: http://www.minaffet.gov.rw/rwanda/geography/. Accessed $02^{\text {nd }}$ February 2017.

60. Akinyemi KO, Iwalokun BA, Foli F, Oshodi K, Coker AO. 2011. Prevalence of multiple drug resistance and screening of enterotoxin (stn) gene in Salmonella enterica serovars from water sources in Lagos, Nigeria. Public Health 125: 65-71

61. Ijabadeniyi OA, Debusho LK, Vanderlinde M, Buys EM. 2011. Irrigation water as a potential preharvest source of bacterial contamination of vegetables. Journal of Food Safety 31:452-461.

62. Gu G, Luo Z, Cevallos-Cevallos JM, Adams P, Vellidis G, Wright A, van Bruggen AHC. 2013. Occurrence and population density of Campylobacter jejuni in irrigation ponds on produce farms in the Suwannee River watershed. Canadian Journal of Microbiology 59:339-346.

63. Holvoet K, Sampers I, Seynnaeve M, Uyttendaele M. 2014. Relationships among hygiene indicators and enteric pathogens in irrigation water, soil and lettuce and the impact of climatic conditions on contamination in the lettuce primary production. International Journal of Food Microbiology 171:2131.

64. Devane M, Nicol C, Ball A, Klena J, Scholes P, Hudson J, Baker M, Gilpin B, Garrett N, Savill M. 2005. The occurrence of Campylobacter subtypes in environmental reservoirs and potential transmission routes. Journal of Applied Microbiology 98:980-990.

65. Jimmy DH, Sundufu AJ, Malanoski AP, Jacobsen KH, Ansumana R, Leski TA, Bangura U, Bockarie AS, Tejan E, Lin B, Stenger DA. 2013. Water quality associated public health risk in Bo, Sierra Leone. Environmental Monitoring \& Assessment 185:241-251.

66. NISR. 2012. National Institute of Statistics of Rwanda, Ministry of Finance and Economic Planning, Rwanda. Rwanda fourth population and housing census. Thematic Report: Data quality assessment . Available at: http://www.statistics.gov.rw/publication/rphc4-final-report-data-quality-assessment. Accessed $05^{\text {th }}$ February 2015.

67. Oyinlola LA, Obadina AO, Omemu AM, Oyewole OB. 2017. Prevention of microbial hazard on fresh-cut lettuce through adoption of food safety and hygienic practices by lettuce farmers. Food Science \& Nutrition 5:67-75.

68. Hultberg A, Schermann M, Tong C. 2012. Results from a mail survey to assess Minnesota vegetable growers' adherence to good agricultural practices. HortTechnology 22:83-88. 
69. Cooley M, Quiñones B, Oryang D, Mandrell R, Gorski L. 2014. Prevalence of shiga toxin producing Escherichia coli, Salmonella enterica, and Listeria monocytogenes at public access watershed sites in a California Central Coast agricultural region. Frontiers in Cellular \& Infection Microbiology 4:3043

70. MINAGRI. 2012. Ministry of Agriculture and Animal Resources. Republic of Rwanda. Strategic and investment plan to strengthen meat industry in Rwanda. Final report, July, 2012. Available at: http://www.minagri.gov.rw/fileadmin/user_upload/documents/STRAT.PLC/Final_report_Rwanda Meat industry final.pdf. Accessed $04^{\text {th }}$ January 2017.

71. Chatikobo P, Manzi M, Kagarama J, Rwemarika J, Umunezero O. 2009. Benchmark study on husbandry factors affecting reproductive performance of smallholder dairy cows in the Eastern Province of Rwanda. Livestock Research for Rural Development 21:83.

72. Ogden ID, Dallas JF, MacRae M, Rotariu O, Reay KW, Leitch M, Thomson AP, Sheppard SK, Maiden M, Forbes KJ, Strachan NJC. 2009. Campylobacter excreted into the environment by animal sources: Prevalence, concentration shed, and host association. Foodborne Pathogens \& Disease 6:1161-1170.

73. Strawn LK, Gröhn YT, Warchocki S, Worobo RW, Bihn EA, Wiedmann M. 2013. Risk factors associated with Salmonella and Listeria monocytogenes contamination of produce fields. Applied \& Environmental Microbiology 79:7618-7627.

74. Shenge KC, Whong CMZ, Yakubu LL, Omolehin RA, Erbaugh JM, Miller SA, LeJeune JT. 2015. Contamination of tomatoes with coliforms and Escherichia coli on farms and in markets of Northwest Nigeria. Journal of Food Protection 78:57-64.

75. Faour-Klingbeil D, Murtada M, Kuri V, Todd ECD. 2016. Understanding the routes of contamination of ready-to-eat vegetables in the Middle East. Food Control 62:125-133.

76. Nyatanyi T, Wilkes M, McDermott H, Nzietchueng S, Gafarasi I, Mudakikwa A, Kinani JF, Rukelibuga J, Omolo J, Mupfasoni D. 2017. Implementing One Health as an integrated approach to health in Rwanda. BMJ Global Health 2:e00121.

77. Fresco, L.O., Bouwstra, R.J., de Jong, M.C.M., van der Poel, W.H.M., Scholten, M.C.T., Takken, W. and the global one health task force of Wageningen University and Research Centre. 2015. Global one health - a new integrated approach Available at:

http://www.wur.nl/upload_mm/e/a/c/d734f322-b66d-4ec0-aa5b

3ceb31001fe0_GOH_Final_20150602.pdf. Accessed 20 $0^{\text {th }}$ September 2016. 



\title{
Reduction of microbial counts during kitchen scale washing and sanitization of salad vegetables
}

\author{
James Noah Ssemanda ${ }^{\mathbf{1}, \mathbf{2}}$, Han Joosten ${ }^{\mathbf{1}}$, Mark Cyubahiro Bagabe ${ }^{\mathbf{3}}$, \\ Marcel H. Zwietering ${ }^{1}$, Martine W. Reij ${ }^{1 *}$.
}

Published in:

Food Control (2018) 85:495-503

\author{
Affiliations: \\ ${ }^{1}$ Laboratory of Food Microbiology, Wageningen University, P.O. Box 17, 6700 AA Wageningen, The \\ Netherlands \\ ${ }^{2}$ Rwanda Standards Board, KK 15 Rd, 49; P.O. Box: 7099, Kigali-Kicukiro, Rwanda \\ ${ }^{3}$ Rwanda Agriculture Board, KK 18 Ave; P. O. Box 5016, Kigali, Rwanda
}




\begin{abstract}
Washing with or without sanitizers is one of the important steps designated to reduce or eliminate microbial hazards in fresh vegetables but the settings, conditions and effectiveness of this step remain contentious. In this study, we investigated kitchen scale salad preparation practices in a field study in Rwandan food service establishments (FSEs) and conducted laboratory trials to identify treatments that can improve reduction of microbial counts during washing and sanitization. In the field study, vegetable samples $(n=112)$ were taken from 56 FSEs before and after washing with or without sanitizer(s) to determine reduction of counts of Enterobacteriaceae, Listeria spp., and coagulase positive (CP)-staphylococci coupled with observation of the salad preparation practices from start to end. Based on the results obtained during the field study, 8 sanitizers were evaluated in the laboratory to optimize the efficacy of washing of leafy vegetables (corn salad, Valerianella locusta). Findings in the field study revealed that about $61 \%$ of the visited FSEs used sanitizers during washing of fresh vegetables, in particular, potassium permanganate $\left(\mathrm{KMnO}_{4}\right)$ in $39 \%$ of FSEs, sanitizing powder (a mixture of polyphosphate, sodium hydrogen carbonate and active chlorine), 13\%; sodium hypochlorite $(\mathrm{NaClO}), 7 \%$; and sodium dichloroisocyanurate $(\mathrm{NaDCC})$ in $2 \%$. Average inactivation ranged from $1.0 \log \left(\mathrm{KMnO}_{4}\right)$ to $3.1 \log (\mathrm{NaDCC})$. In the laboratory study, average inactivation observed with Listeria spp., Escherichia coli and Aerobic plate count (APC) ranged from $0.7 \log$ (water alone) to $3.0 \log (\mathrm{NaDCC})$. Out of the 8 sanitizers that were evaluated, 5 sanitizers ( $\mathrm{NaDCC}$ [90 ppm], $\mathrm{NaClO}$ [200 ppm], lemon juice [98\%], acetic acid [2\%] and sanitizing powder [4 g/L]) resulted in significantly higher inactivation compared to water alone. A contact time of $5 \mathrm{~min}$ and salad-sanitizer ratio of 1: 20 were considered optimal for kitchen based washing of the studied leafy vegetables with NaDCC and $\mathrm{NaClO}$ sanitizers.
\end{abstract}




\section{Introduction}

A diet rich in vegetables has been associated with health benefits like reduced risk to cancers and cardiovascular diseases (1). Consumption of fresh vegetables is increasing year by year (2) and reports indicate that a large portion of these vegetables are consumed raw (3). At the same time, the number of reported foodborne illnesses linked to fresh vegetables has been increasing. In the United States between 1998 and 2008, produce (fresh vegetables and nuts) accounted for $46 \%$ of foodborne illness (4) while a high number of outbreaks has also been reported in the European Union (5). Etiological agents range from pathogenic bacteria (5) (6) to parasites (7) and viruses $(5,8)$.

Washing with water is a crucial postharvest step designated to reduce or eliminate field dirt and their associated microorganisms from fresh vegetables but this step also increases the chances for microbial hazards to spread in the entire batch $(9,10)$. Chemical sanitizers can be added to increase the efficacy i.e.. by preventing cross contamination (11), but maximum reduction rates are typically around $3 \operatorname{logs}(10)$. To date, efforts to further improve washing and sanitization of fresh vegetables are ongoing especially in countries with a developed commercial fresh cut industry (12-15). Such efforts include pilot and laboratory studies to evaluate the efficacy of different vegetable sanitizers and washing techniques. In countries with limited fresh cut industry, the washing and sanitization of fresh vegetables is mainly done in kitchens of food service establishments (FSEs) and households during salad preparation. However, it has been acknowledged that commercial washing and sanitization conditions are not suitable for food service or home use, because the users lack technical skills, knowledge, and equipment to apply treatments safely and effectively (9). So far few studies (16-18) have targeted kitchen based washing and sanitization of fresh vegetables, but also do not compare microbial inactivation in the field (FSEs or households) and in the laboratory.

In this study, we seek to identify sanitizers, conditions, treatments and techniques that enable targeted microbial reduction during washing and sanitization of fresh vegetables to propose guidelines for FSEs and households. Our study consisted of a field study in which practices for preparing vegetable salads were investigated with a focus on microbial inactivation and a laboratory simulation of the washing and sanitization of vegetables in FSEs based on the results from the field study to identify alternatives for improvement. The field study was conducted in Rwanda, a country where vegetable washing and sanitization is mainly done in FSEs and household level (19). 


\section{Materials and methods}

Field study

\section{Study description and sampling}

The field study was conducted in food service establishments (FSEs) in Rwanda from February to October 2015. We interacted face to face with managers and food handlers in FSEs during salad vegetable preparations, observed the unit operations (especially washing and sanitization steps) and took samples of vegetables for microbiological analysis. Efficacy of washing and sanitization of fresh vegetables in FSEs was evaluated based on the changes in counts of indicator microorganisms; APC (aerobic plate count), Enterobacteriaceae, Listeria spp. and coagulase positive staphylococci (CP. staphylococci).

FSEs were prepared for the study in a way reported in our previous related study (Ssemanda et al., 2017). In summary, out of the 280 FSEs managers invited, 168 showed interest and we were able to cover 56 of these FSEs in this study. Each FSE provided 2 samples, one sample (1 - $2 \mathrm{~kg}$ ) of whole mixed vegetables was taken before washing and another sample $(0.5-1 \mathrm{~kg})$ after washing treatment, before cutting. Vegetables commonly used for salad making were beet root, cabbage, carrot, celery, cucumber, garlic, green pepper, lettuce, onion, parsley and tomato. Using sterile hand gloves, the 2 samples were placed and closed in sterile plastic zip bags and thereafter, all samples were stored in cooling boxes with ice packs and transported for 1-3 $\mathrm{h}$ to the laboratory and analyzed immediately.

\section{Microbiological analysis}

The 1-2 kg whole vegetable samples from FSEs as described in section 2.1.1 of different types were sliced /cut into small pieces (20) on a sterile stainless steel tray using sterilized knives and gloves for each sample and thereafter mixed. Then $25 \mathrm{~g}$ of analytical unit of these samples were thereafter stomached (Model 400 Circulator, Seward, UK) in $225 \mathrm{~mL}$ of maximum recovery diluent (MRD) for $1 \mathrm{~min}$. Thereafter, tenfold serial dilutions were prepared using MRD for the enumeration of Enterobacteriaceae, APC and CP. staphylococci and buffered peptone for Listeria spp. The culture media and consumables used were from Oxoid (Oxoid Ltd., Basingstoke, UK). The enumeration was conducted according to ISO methods i.e..; Enterobacteriaceae, ISO 21528-2:2004 (21); APC, ISO 4833-1:2013 (22) ; CP. staphylococci, ISO 6888-2:1999 (23); and Listeria spp., ISO 11290-2:1998/Amd 1:2004 (24). For quality control of the media and positive controls of the experiments in the field study, the following strains from the Belgian Coordinated Collection of Microorganisms were used: i.e.. E. coli (LMG 8063) for Enterobacteriaceae, Listeria monocytogenes (LMG 16783) for Listeria spp. and Staphylococcus aureus (LMG 8224) for CP. staphylococci.

\section{Laboratory study}

\section{Preparing vegetables for the laboratory study.}

Corn salad (Valerianella locusta) was selected in this study because leafy vegetables are known for their high microbial attachment (25) and because they are eaten raw, easy to 
handle (require no cutting during washing) and available year round. For every experimental set up, prewashed, ready to eat corn salads in unit plastic packages of $75 \mathrm{~g}$ were purchased from local supermarkets in Wageningen. At the start of every experiment, samples of corn salad were taken for microbial analysis before artificial contamination (inoculation) to examine the counts of Listeria spp., Escherichia coli, and APC originally present.

\section{Preparing strains and inoculum}

Unless stated otherwise, the strains of nonpathogenic E. coli and Listeria spp. used in this study were from the Leibniz Institute DSMZ - German Collection of Microorganisms and Cell Cultures. E. coli strains were DSM 498, DSM 1756 and O2K (from Laboratory of Food Microbiology, Wageningen University). Listeria spp. strains were L. seeligeri (DSM 20751), L. welshimeri (DSM 20650), L. innocua (DSM 20649). Methodology for preparing of the inoculum was based on previous studies $(26,27)$ with slight modifications. The stock culture of each bacterial strain from cryovials $\left(-80^{\circ} \mathrm{C}\right)$ were streaked separately on brain heart infusion (BHI) agar (Oxoid Ltd., Basingstoke, UK) and incubated at $30^{\circ} \mathrm{C}$ for $24 \mathrm{~h}$. Thereafter, a colony from each strain was inoculated in $100 \mathrm{~mL}$ BHI broth and incubated at $30^{\circ} \mathrm{C}$ for $24 \mathrm{~h}$ with agitation at $160 \mathrm{rpm}$. The cell cultures $(10 \mathrm{~mL}$ each $)$ were transferred into sterile tubes and concentrated by centrifugation at $11000 \mathrm{x} \mathrm{g}$ for $2 \mathrm{~min}$ at $20^{\circ} \mathrm{C}$ and thereafter the supernatant was removed and washed in $10 \mathrm{~mL}$ of peptone physiological salt solution (PPS). The washing step was repeated twice and followed by resuspension with $10 \mathrm{ml}$ of PPS. Microbial population of each cell suspension was determined by spiral plating (Eddy jet spiral plater, Spain) $50 \mu \mathrm{L}$ portions $(-5,-7$ dilutions) on BHI agar and incubated at $30^{\circ} \mathrm{C}$ for $24 \mathrm{~h}$ (yielded levels of 6.5 to $9.5 \mathrm{cfu} / \mathrm{mL}$ ). The suspensions were stored at $4{ }^{\circ} \mathrm{C}$ for further use and freshly prepared every week. Equal numbers of each strain were combined to give a cocktail of strains containing approximately $9 \log \mathrm{cfu} / \mathrm{mL}$ of either E. coli or Listeria spp. To prepare the final inoculum, $5 \mathrm{~mL}$ of each cocktail were mixed with $1 \mathrm{~L}$ of sterile deionized water.

\section{Inoculating corn salads}

For each experimental unit, $365 \mathrm{~g}$ of corn salads were dipped for $10 \mathrm{~min}$ in $5 \mathrm{~L}$ of the final inoculum prepared as described in section 2.2.2. Thereafter, the corn salads were drained and kept overnight in sterile plastic bags for $24 \mathrm{~h}$ at $4^{\circ} \mathrm{C}$ to allow microbial attachment (26, 28). This step was followed by taking three analytical corn salad samples of $10 \mathrm{~g}$ to determine the counts of E. coli, Listeria spp. and APC attached to the leaves prior to the washing and sanitization treatments (laboratory trials).

\section{Screening sanitizers}

Eight different sanitizers (Table 5.1) were procured, including those observed in the field study in FSEs (Rwanda). Sanitizer solutions were prepared by mixing with tap water at room temperature $\left(20^{\circ} \mathrm{C}\right)$ in $15 \mathrm{~L}$ plastic vessels (disinfected with $70 \%$ ethanol). The tap water used in the laboratory was from the Dutch supply system, reported to distribute potable water (29) with a purification system that does not use chlorine disinfectants (29, 30). Unless stated otherwise the sanitization treatments were done by dipping $100 \mathrm{~g}$ of 
inoculated corn salad into $2 \mathrm{~L}$ of sanitizer solution $(1: 20(\mathrm{w} / \mathrm{v}))$ for $10 \mathrm{~min}$ while stirring manually with sterilized gloves. The corn salads were removed, drained and taken for microbial analysis without rinsing.

\section{Effect of rinsing after sanitization}

The possible effect of rinsing after sanitization on microbial counts was determined for the $100 \mathrm{ppm}$ of $\mathrm{NaClO}$ and 10 min contact time condition. After the treatment, $20 \mathrm{~g}$ of samples were dipped in $800 \mathrm{~mL}$ of tap water at $25^{\circ} \mathrm{C}$ in sterile zip lock plastic bags and constantly shaken for $30 \mathrm{~s}$ mimicking the practical situation in FSEs.

\section{Effect of sanitizer concentration and contact time}

Sodium hypochlorite $(\mathrm{NaClO})$ was selected as sanitizer for this part of the study. Inoculated corn salad (100 g) were dipped into $2 \mathrm{~L}$ of sanitizer solution. Occasional agitation by hand using sterile gloves during sanitization was done for the contact time of 2, 5, 10 and 15 min and concentration of 50, 75, 100, 150 and $200 \mathrm{ppm}$. Tap water was used as control.

\section{Effect of salad to sanitizer solution ratio}

Ratios evaluated were 1:10 (50 g salad in $500 \mathrm{~mL}$ solution), 1:20 (50 g salad in $1000 \mathrm{~mL}$ solution) and 1:50 (50 g in $2500 \mathrm{~mL})$. 


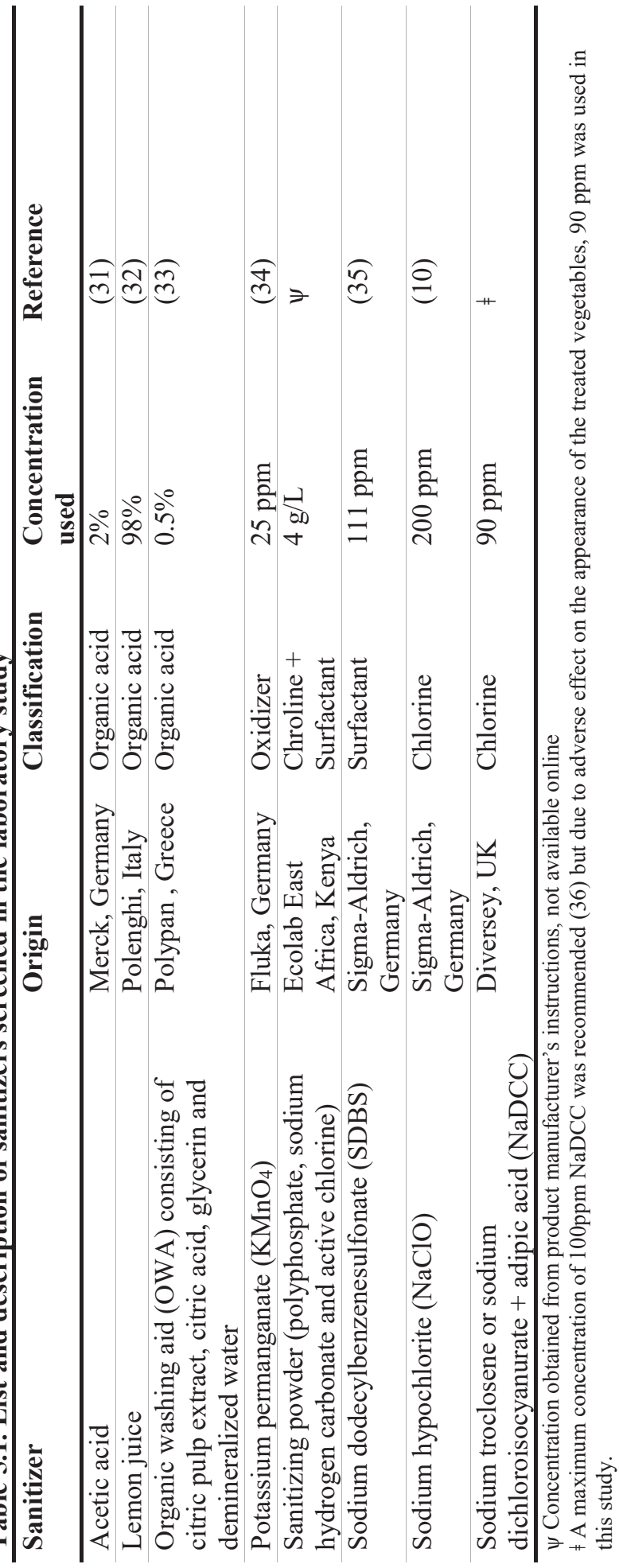




\section{Potential for cross contamination through used sanitizer solutions}

Five batches of inoculated corn salad (each $50 \mathrm{~g}$ ) were prepared and dipped one batch at a time in the same sanitizer solution of $1 \mathrm{~L} \mathrm{NaDCC} \mathrm{(} 90 \mathrm{ppm}$ ) for $5 \mathrm{~min}$. Samples of the $1^{\text {st }}, 3^{\text {rd }}$ and $5^{\text {th }}$ batch of corn salad were taken for microbiological analysis.

\section{Microbiological analysis}

In the laboratory study, $10 \mathrm{~g}$ of corn salad were weighed into the stomacher bag and stomached in $90 \mathrm{~mL}$ of MRD for $2 \mathrm{~min}$. Thereafter, tenfold serial dilutions were prepared as in section 2.1.2. and so was the enumeration of Listeria spp. and APC. For E. coli, enumeration was conducted according to ISO 16649-2:2001(37).

\section{Data analyses}

Changes in microbial counts of each indicator microorganism were computed by subtracting log transformed counts before and after washing treatment. Statistical analyses were performed in IBM SPSS Statistics 22. In the field study, one way ANOVA with Scheffe's post hoc tests was used to compare the efficacy of sanitizers used by different FSEs in washing salad vegetables. In the laboratory study, experiments were repeated three times on different days and the error bars on the generated figures represent standard deviation. One-way ANOVA followed by Tukey's post hoc tests was used to analyze the difference in efficacy of different washing treatments. Independent and paired t-tests were used to analyze the effect of contact time and rinsing respectively. Statistical significance was set at 0.05 .

\section{Results and discussion}

\section{Field study (salad washing and sanitization at FSEs in Rwanda)}

At reception, the FSE chefs grade and sort the different vegetables (beet root, cabbage, carrot, celery, cucumber, garlic, green pepper, lettuce, onion, parsley and tomato) to remove those vegetables which are not fit for salads (the bruised, rotten and broken). All vegetables are received as whole vegetables, no fresh cut vegetables are sold at the markets in Rwanda currently. Average initial microbial counts in vegetables received at FSEs before salad preparation were $6.8 \pm 0.7,6.0 \pm 0.8,5.1 \pm 0.7,4.6 \pm 0.7 \log \mathrm{cfu} / \mathrm{g}$ for APC, Enterobacteriaceae, Listeria spp. and CP. staphylococci respectively. We identified three major unit operations during salad preparation in which water was involved: prewashing, washing with or without sanitizers (sanitization step) and rinsing.

\section{Prewashing step}

The prewashing step was practiced in $56 \%$ of the visited FSEs, while the rest of FSEs skipped this step and straightaway proceeded to the sanitization or main wash step. Food handlers used running municipal tap water to wash whole vegetables.

\section{Sanitization or main wash step}

Practices varied from one FSE to another (Fig. 5.1); about $61 \%$ of the visited FSEs washed vegetables with sanitizers, while others did not use any sanitizer but washed 
vegetables with either boiled water or containerized drinking water. The salad treatment methods and the nature and concentration of sanitizers applied varied, some were used much more often (in 22 FSES) than others (even sometimes only once).

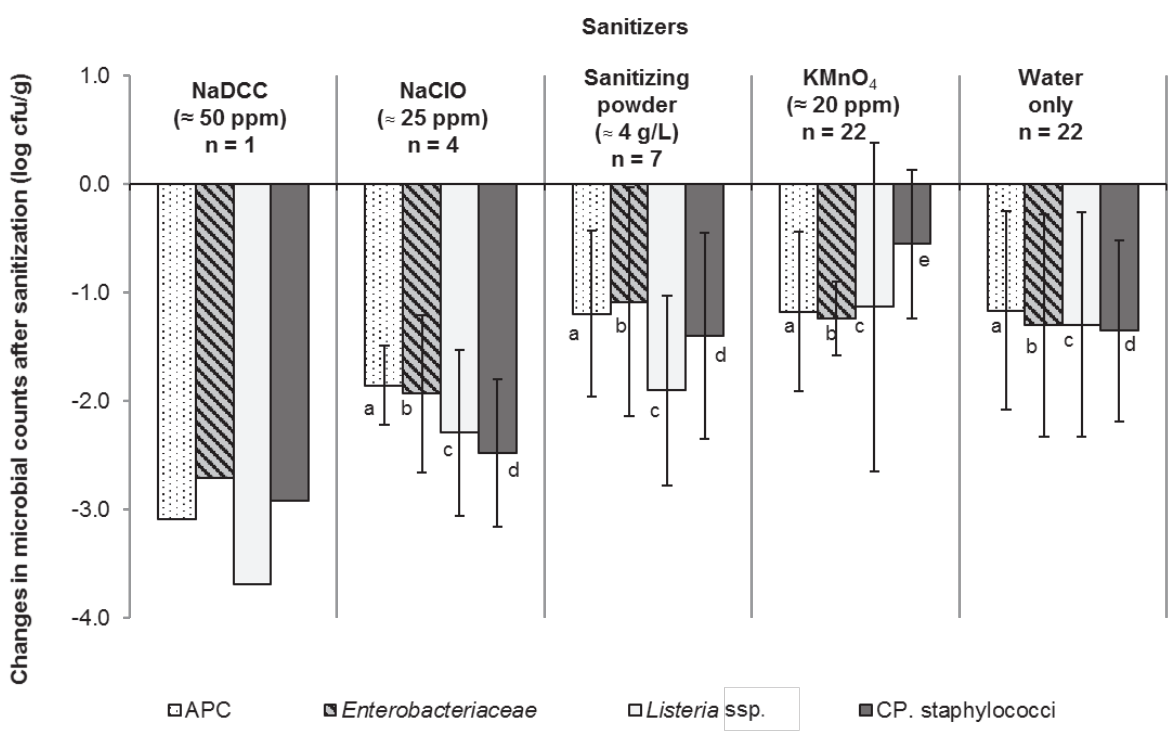

Figure 5.1: Microbial reduction due to washing with or without sanitizers during vegetable salad preparation in food service establishments (FSEs) $(n=56)$. Error bars represent the standard deviation in changes of microbial counts from one FSE to another. $\mathrm{NaDCC}=$ sodium dichloroisocyanurate, mixture of 20-30\% weight of adipic acid; $\mathrm{NaClO}=$ sodium hypochlorite; Sanitizing powder is a mixture of polyphosphate, sodium hydrogen carbonate and active chlorine; $\mathrm{KMnO}_{4}=$ potassium permanganate. Bars of the same microbial indicator with a common letter under the different sanitizers do not differ significantly. Significant differences in microbial counts for NaDCC sanitizer are not available $(n=1)$.

Sanitizers used were NaDCC (50 ppm), NaClO (20 - $30 \mathrm{ppm})$, sanitizing powder (polyphosphate, sodium hydrogen carbonate, active chlorine; $4 \mathrm{~g} / \mathrm{L})$ and $\mathrm{KMnO}_{4}(10-$ $30 \mathrm{ppm}$ ), applied in $2 \%, 7 \%, 13 \%$ and $39 \%$ of the visited FSEs respectively. Contact time of sanitizers was according to manufacturer instructions but varied between 1 to $10 \mathrm{~min}$. The sanitization method was by dipping and all FSEs used tap water (same as in prewashing step) to acquire the aqueous sanitizing solution. Food handlers had no information on the quantity of vegetables that can be sanitized for a given amount of sanitizer solution. Our investigation on the microbial efficacy of the applied sanitizers (Fig. 5.1) revealed that the highest overall microbial reduction in the field study was achieved with $\mathrm{NaDCC}$ (average, $3.1 \mathrm{log} \mathrm{cfu} / \mathrm{g}$ ) followed by $\mathrm{NaClO}$ (average, $2.1 \mathrm{log}$ $\mathrm{cfu} / \mathrm{g})$, sanitizing powder $(1.4 \mathrm{log} \mathrm{cfu} / \mathrm{g})$, water only $(1.3 \mathrm{log} \mathrm{cfu} / \mathrm{g})$ and the lowest for $\mathrm{KMnO}_{4}$ ( on average, $1.0 \mathrm{log} \mathrm{cfu} / \mathrm{g}$ ). Figure 5.1 also shows that reduction in counts of CP. staphylococci was significantly lower for FSEs that used $\mathrm{KMnO}_{4}$ compared to those FSEs that washed with $\mathrm{NaClO}$. 


\section{Rinsing step}

Rinsing was the final step in which water was involved during salad preparation. From one FSE to another, there were variations in the type and quality of water used. Out of the visited FSEs, $54 \%$ rinsed vegetables with boiled water, 6\% with containerized drinking water and $40 \%$ used municipal kitchen tap water (for microbiological quality see section 3.2.3).

\section{Laboratory trials (Laboratory study)}

\section{Microbial counts in corn salads}

Sanitizing and washing of vegetables salads in the field study was simulated in laboratory settings using artificially contaminated corn salad. Counts of APC in corn salad before inoculation ranged from 6.5 to $8.0 \log \mathrm{cfu} / \mathrm{g}$. In 7 out of $15 \mathrm{samples}$ of corn salad, Listeria spp. (not L. monocytogenes) were detected in the range of 2.3 to $3.5 \mathrm{log}$ $\mathrm{cfu} / \mathrm{g}$ while $E$. coli was not detected in any of the samples. Average initial microbial counts in vegetables before washing treatments were $6.3 \pm 0.3,6.6 \pm 0.1$, and $7.1 \pm 0.4$ $\log \mathrm{cfu} / \mathrm{g}$ for Listeria spp., E. coli and APC respectively.

\section{Sanitizer screening}

Figure 5.2, shows the reduction in counts of Listeria spp., E. coli and APC after sanitization of corn salad with different sanitizers and tap water. The highest mean microbial reduction was induced by $\operatorname{NaDCC}$ (3.4, 2.8 and 2.9 log cfu/g for Listeria spp., E. coli and APC respectively) followed by lemon juice (3.0 and $2.4 \log \mathrm{cfu} / \mathrm{g}$ for Listeria spp. and APC respectively) and sanitizing powder (1.9 log cfu/g for E. coli) while the lowest reduction was registered for tap water $(0.9,0.9$ and $0.4 \log$ cfu/g for Listeria spp., E. coli and APC respectively ). The mean microbial reduction due to washing corn salad with tap water alone, was significantly lower $(\mathrm{p}<0.05)$ than that of the sanitizers; NaDCC (90 ppm), lemon juice (98\%), NaClO (200 ppm), acetic acid (2\%) and sanitizing powder (4 g/L) for Listeria spp. and APC. For E. coli, only NaDCC (90 ppm) and sanitizing powder $(4 \mathrm{~g} / \mathrm{L})$ contributed to a significant higher reduction when compared to washing with only tap water.

Results from our field and laboratory study on washing with tap water (without sanitizers) were close to the $0.8 \mathrm{log}$ reduction in aerobic mesophilic bacteria reported by Nascimento et al. (31) in their study with lettuce leaves. Vijayakumar and Wolf-Hall (32) also reported a $0.6 \log$ reduction for $E$. coli when iceberg lettuce was washed with distilled water. In experimental studies, microbial quality and safety of water can be controlled but the situation may be different in practice. For example, in our field study different water sources were used during the prewashing and rinsing of salad vegetables in FSEs, yet studies (38) have reported that some water types were not potable in Rwanda. 


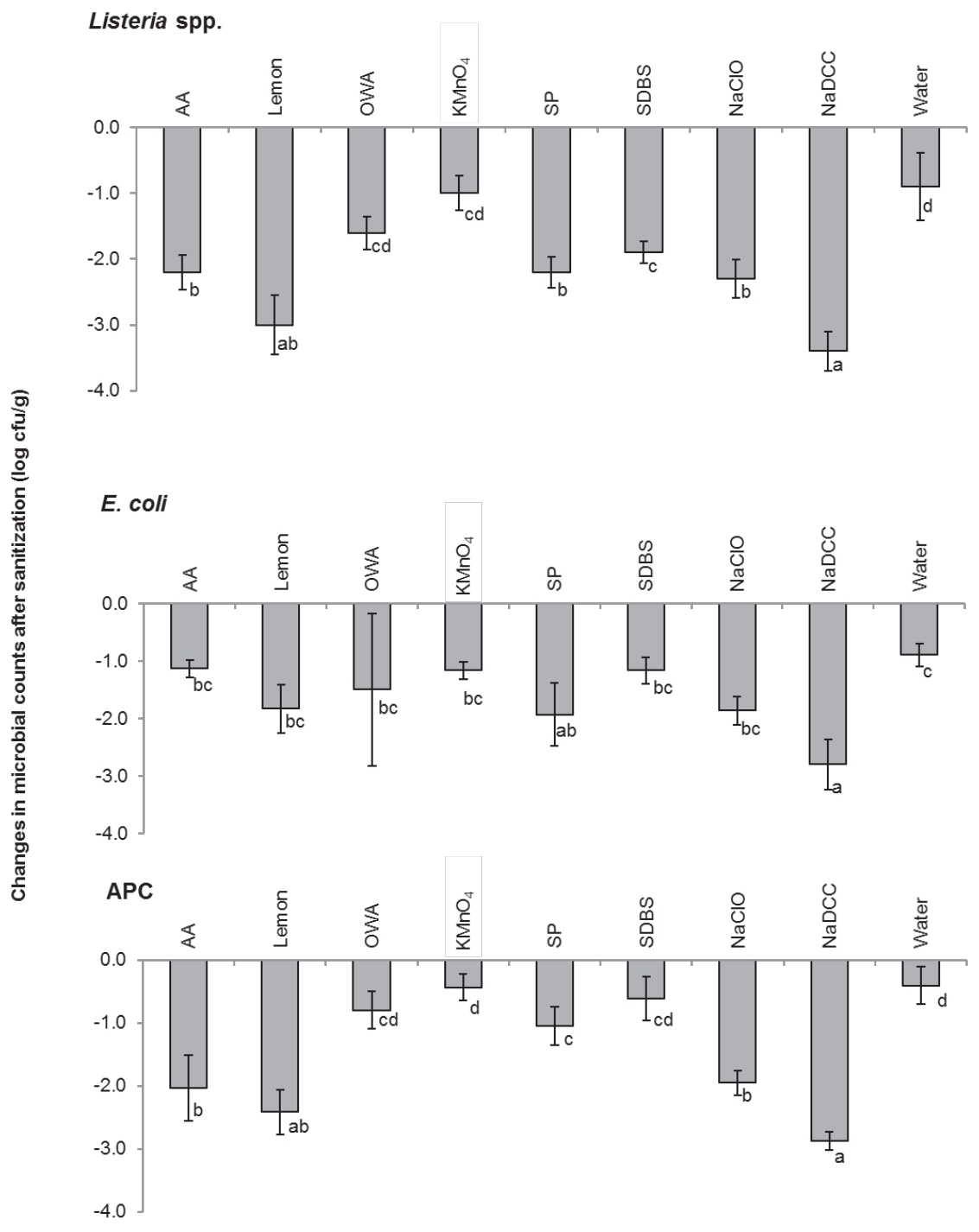

Sanitizers

Figure 5.2: Laboratory trials for the efficacy of different sanitizers on Listeria spp., E. coli and APC (aerobic plate count) during the sanitization of corn salad for 10 min contact time and vegetable to sanitizer ratio of 1: $20(\mathrm{w} / \mathrm{v})$, without rinsing. Sanitizers $A A=$ Acetic acid $(2 \%)$, Lemon $=$ lemon juice $(98 \%)$, OWA $=$ Organic washing aid $(0.5 \%)$ consists of citric pulp extract, citric acid, glycerin and demineralized water, $\mathrm{KMnO}_{4}=$ Potassium permanganate $(25 \mathrm{ppm}), \mathrm{SP}=$ Sanitizing powder $(4 \mathrm{~g} / \mathrm{L})$ is a compound of polyphosphate, sodium hydrogen carbonate and active chlorine, SDBS = Sodium dodecyl benzene sulphonate $(111 \mathrm{ppm}), \mathrm{NaClO}=$ Sodium hypochlorite $(200 \mathrm{ppm}), \mathrm{NaDCC}=$ Sodium dichloroisocyanurate $(90 \mathrm{ppm})$, contains $20-30 \%$ weight of adipic acid. Bars with a common letter are not statistically significant.

In our field study, $\mathrm{KMnO}_{4}$ (mean $20 \mathrm{ppm}$ ) was the most applied sanitizer during salad preparation in FSEs yet reduction in all counts were comparable to that of washing with only tap water. Similar results were obtained with $\mathrm{KMnO}_{4}(25 \mathrm{ppm})$ in the laboratory 
study. Sukul and Sheth (39) reported the effect of $\mathrm{KMnO}_{4}(50-100 \mathrm{ppm})$ after washing coriander leaves and microbial reduction varied from 0.4 to $1.4 \mathrm{log} \mathrm{cfu} / \mathrm{g}$. With a higher concentration (200 ppm $\mathrm{KMnO}_{4}$ ), Amoah et al. (16) reported a $2.5 \mathrm{log}$ reduction after washing lettuce. For all the sanitizers applied, $\mathrm{KMnO}_{4}$ had the lowest inactivation and was not significantly different from washing vegetables with potable tap water.

In this study, acetic acid (2\%) and lemon juice (98\%) were the organic sanitizers that caused significant reduction in microbial counts. For acetic acid (2\%), our results were in line with the study by Park et al. (40) where after washing lettuce, L. monocytogenes and $E$. coli $\mathrm{O} 157: \mathrm{H} 7$ counts were reduced by 1.7 and $1.4 \mathrm{log} \mathrm{cfu} / \mathrm{g}$ respectively. In other studies, a 5 and over $2 \log$ reduction was achieved for E. coli and APC counts respectively with $35 \%$ white vinegar (1.9\% acetic acid) (32). Our results obtained with lemon juice as a sanitizers were in range with the study by Santos et al. (41) where a 2 $\log$ reduction of $E$. coli $\mathrm{O} 157: \mathrm{H} 7$ was achieved by washing lettuce for $15 \mathrm{~min}$. In contrast, Sengun and Karapinar (42) reported that 100\% lemon juice reduced counts of $Y$. enterocolitica on carrot from $7.2 \mathrm{log} \mathrm{cfu} / \mathrm{g}$ to an undetectable level after $15 \mathrm{~min}$ treatment. Antimicrobial effect of organic acids depend on the $\mathrm{pH}$, type of acid and strain of microorganism (43) and these acids have GRAS status (10). However using higher concentrations of organic acids and long contact time targeting maximum microbial reduction, can also result to sour and wilted appearance of especially leafy vegetables (32), creating acceptability problems.

NaDCC gave the highest microbial inactivation rate (average $3 \log \mathrm{cfu} / \mathrm{g}$ ) for all the studied indicator microorganisms, compared to other sanitizers in both the field and laboratory study. These results are in line with a previous study (31) that found NaDCC (200 ppm) was able to cause $3.2 \mathrm{log} \mathrm{cfu} / \mathrm{g}$ reduction in aerobic microorganisms from lettuce. In Western Africa, the use of NaDCC (100 ppm) to wash lettuce, led to a 2.7 $\log$ reduction of faecal coliforms (16). NaDCC was more effective than other chlorine based sanitizers $(\mathrm{NaClO}$, sanitizing powder) in both the field and laboratory study. This advantage has been attributed to the ability of NaDCC to slowly decompose and liberate $\mathrm{HOCl}$ and the capacity to maintain an appropriate level of active chlorine without affecting the $\mathrm{pH}$ of the water $(44,45)$.

\section{Rinsing after sanitization}

In Figure 5.3, rinsing corn salads with potable water after applying a treatment of 100 ppm $\mathrm{NaClO}$ did not result to further significant reduction $(\mathrm{p}>0.05)$ in the counts of Listeria spp., E. coli and APC. Nevertheless, even though rising may not contribute to further reduction in microbial counts, it is considered to be essential for other purposes such as avoiding product quality deterioration (46) and removing undesirable sanitizer by-products (47). However, rinsing and prewashing of salad vegetables should be done with potable water to avoid recontamination. In many developing countries, water used for drinking and preparing food is not microbiologically safe (48). A recent national study in Rwanda has reported thermophilic total coliforms in the range of 4.3 (95\% CI: $1.9-8.5) \mathrm{TTC} / 100 \mathrm{~mL}$ for piped water and also raised concerns for possible microbial safety problems in drinking water sources (38). On site measures to disinfect or kill 
pathogenic microorganisms in the water before salad preparation should be uniformly practiced by all food handlers in these settings. In our field study some FSEs boil the water before salad preparation and this approach seems to be practical for small scale operations.

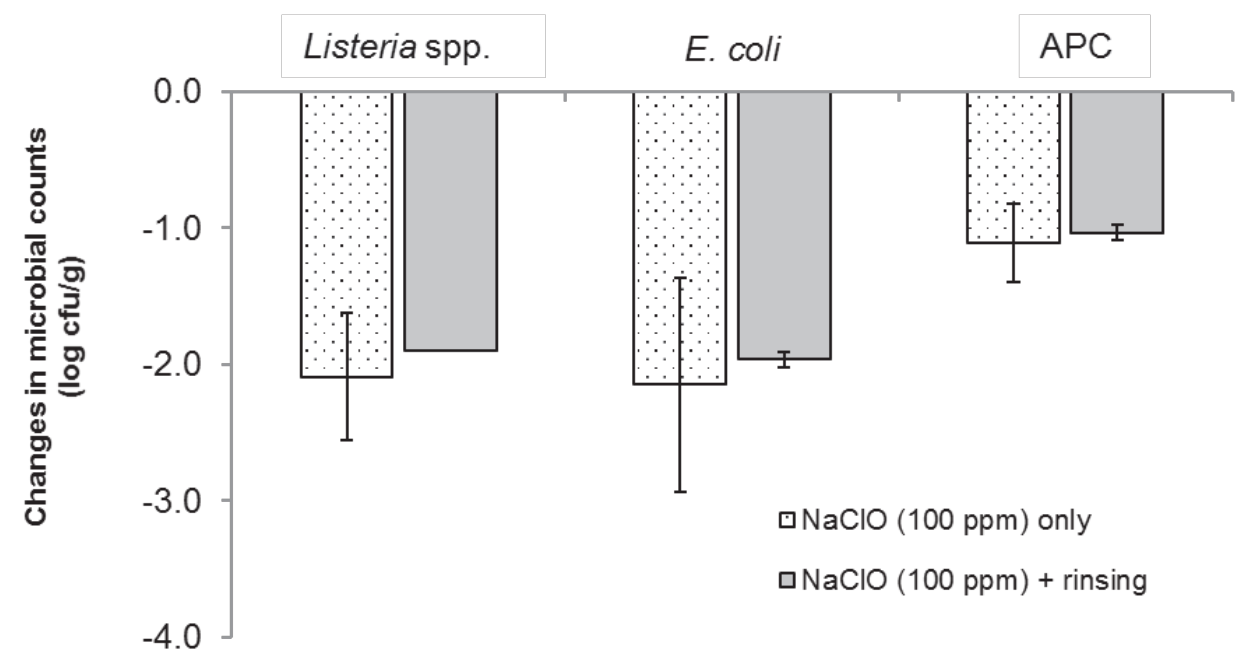

Figure 5.3: Effect of washing corn salads in sodium hypochlorite $(\mathrm{NaClO})$ with and without further rinsing on the counts of Listeria spp., E. coli and APC (aerobic plate count) for $10 \mathrm{~min}$ and vegetable to sanitizer solution ratio $(1: 20 \mathrm{w} / \mathrm{v})$.

\section{Sanitizer concentration}

Different batches of inoculated corn salads were washed in tap water and in 50, 75, 100, 150 and $200 \mathrm{ppm}$ of $\mathrm{NaClO}$ for 2, 5, 10 and $15 \mathrm{~min}$ at $25^{\circ} \mathrm{C}$ and $\mathrm{pH} 6.5$ (Fig. 5.4). At constant contact time, increasing concentration of $\mathrm{NaClO}$ from 50 to $200 \mathrm{ppm}$ did not result to significant higher inactivation. At the lowest contact time ( $2 \mathrm{~min}$ ), there was no significant effect of washing corn salad with either tap water or $\mathrm{NaClO}$ (all concentrations) for APC, while for Listeria spp. and E. coli, the $100-200 \mathrm{ppm}$ and the 50- 200 ppm $\mathrm{NaClO}$ respectively had a significant effect compared to tap water. APC inactivation was the lowest compared to other indicators and this resistance to sanitizers has been linked to the sufficient time of attachment and biofilm formation of natural microflora in leaf matrix $(32,49,50)$.

From our field study, a much lower concentration of $25 \mathrm{ppm}$ was applied for $\mathrm{NaClO}$ compared to the $50-200 \mathrm{ppm}$ in the laboratory study and inactivation levels were in the same range for both studies. Since increasing sanitizer concentration and washing time has limited effect on microbial inactivation, sanitizer concentration ranging from 25 ppm for chlorine based sanitizers $(\mathrm{NaClO}$ and $\mathrm{NaDCC})$ can best be adopted. 


\section{Listeria spp.}
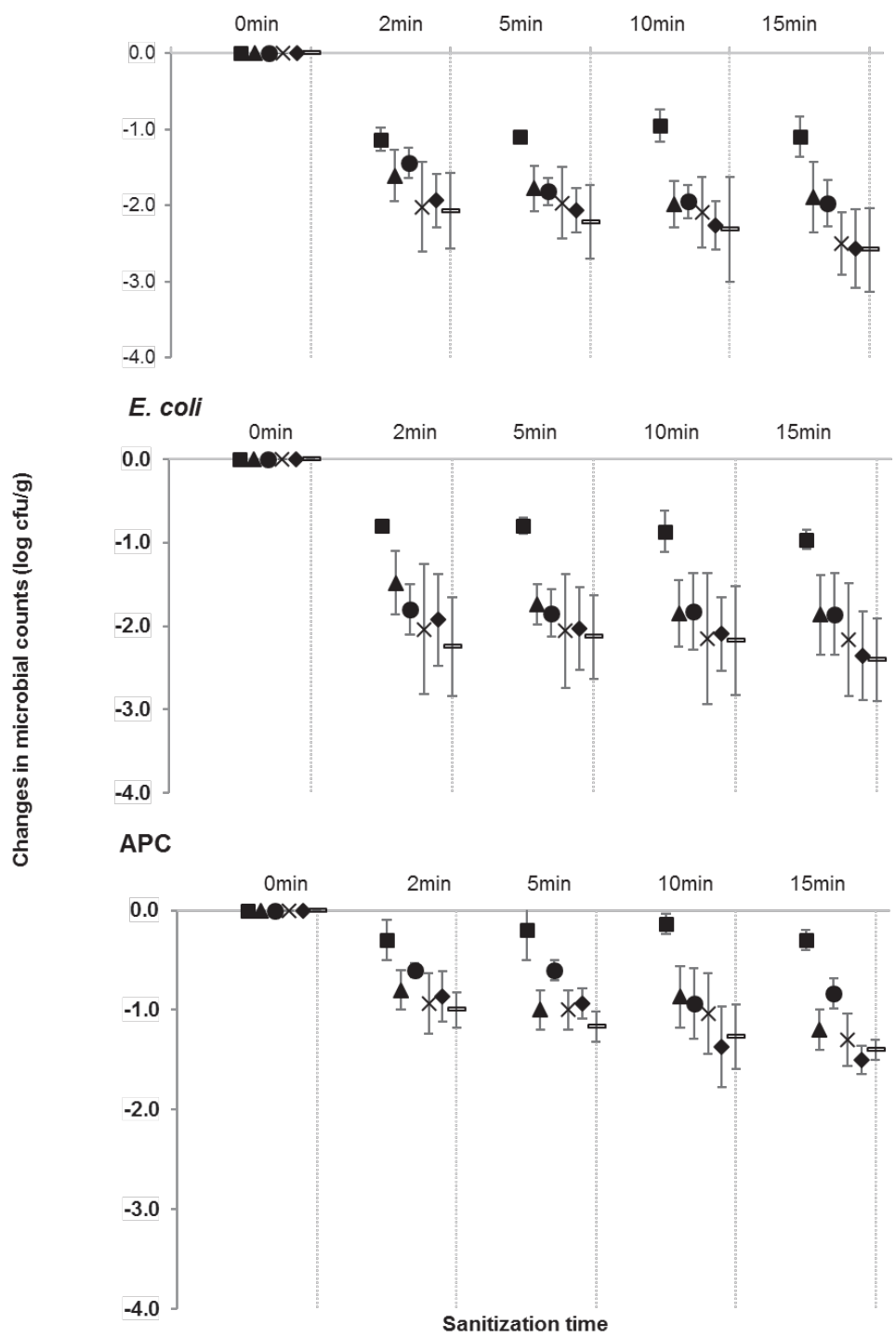

Figure 5.4: Effect of sodium hypochlorite (NaClO) on counts of Listeria spp., E. coli and APC (aerobic plate count) for different concentration and contact time with the same amount of vegetable to sanitizer solution $(1: 20 \mathrm{w} / \mathrm{v})$. 


\section{Sanitizer contact time}

Increasing contact time from 2, 5, 10 to $15 \mathrm{~min}$ did not significantly increase reduction in counts of Listeria spp. and E. coli (Fig. 5.4) by NaClO. In other studies, a marginal influence of longer exposure time was observed for chlorine sanitizer against $L$. monocytogenes counts on lettuce (51). Since varying sanitizer concentration from 50 to $200 \mathrm{ppm} \mathrm{NaClO}$ was still important at 2 min to have a significant difference between water and sanitizer, a contact time $5 \mathrm{~min}$ would be favorable for sanitization.

\section{Salad: sanitizer solution ratio}

Application of different ratios (1:10, 1:20, and 1:50) of corn salad to sanitizer solution (NaDCC or acetic acid) did not result in different inactivation of Listeria spp., E. coli and APC ( Fig. 5.5). However, at the 1: 10 ratio the leaves could not be submerged completely, which is why this dilution rate cannot be recommended. Consequently, targeting efficacy with minimal amount of sanitizer solution and avoiding excess waste water, a 1: 20 ratio, can be adopted with respect to leafy vegetables. Further studies are needed to determine the vegetable to sanitizer solution ratio for the different types of vegetables like tomatoes.

\section{Multiple batch sanitization}

Figure 5.6 shows that no significant difference in the inactivation for the three microbial indicators (Listeria spp. [ $p=0.903]$, E. coli $[p=0.817]$ and APC [ $p=0.082]$ ) was observed when 1 up to 5 consecutive batches of corn salad (1:20 salads to sanitizer solution (90 ppm NaDCC ) were washed for $5 \mathrm{~min}$ in the same sanitizer solution. Studies have shown that washing vegetables in water alone may result in transfer of pathogens from vegetables to wash water (52-54). Sanitizers have been reported to inactivate microorganisms in wash solutions once detached from vegetables surfaces (54) and also can prevent cross contamination. 
Listeria spp.
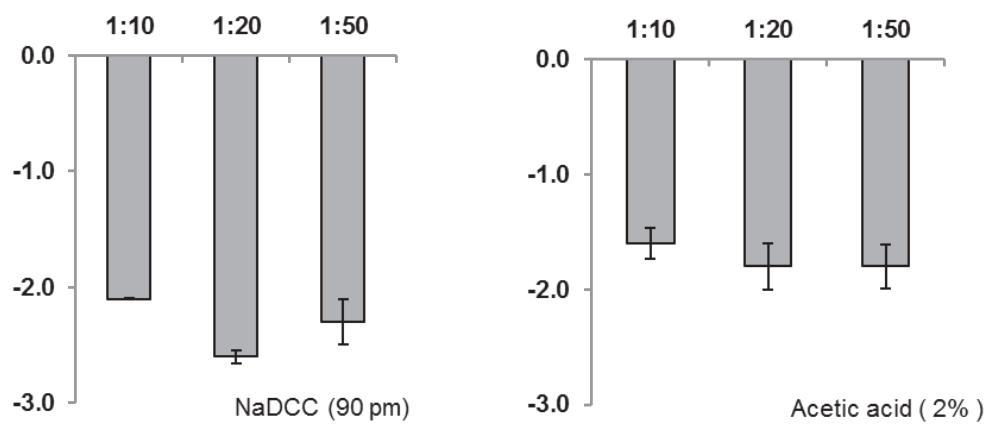

E. coli
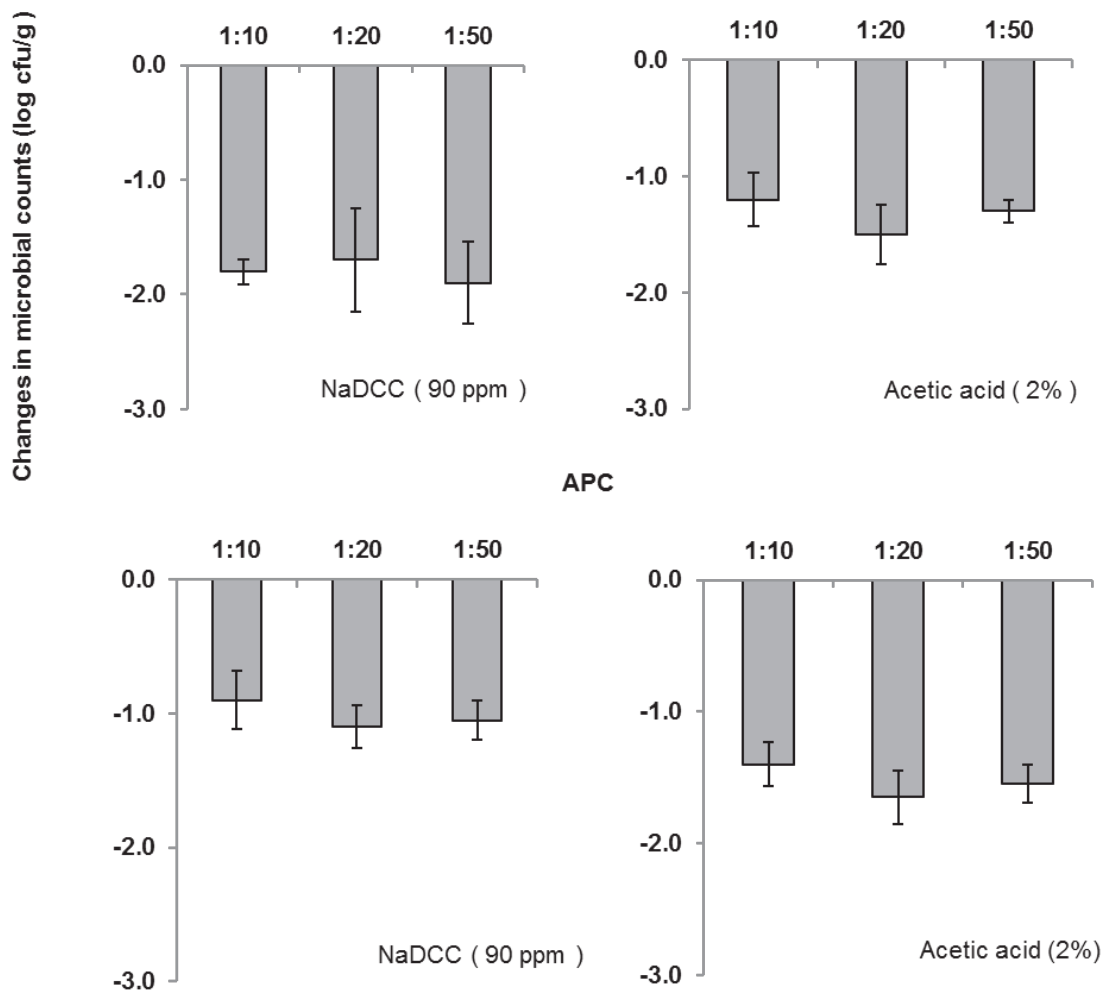

Salads to sanitizer solution ratio

Figure 5.5: Effect of washing a specified quantity of vegetables in varying volumes of sanitizer solution on counts of Listeria spp., E. coli and APC (aerobic plate count). Two sanitizers were used, sodium dichloroisocyanurate, (NaDCC, $90 \mathrm{ppm})$ and acetic acid ( $2 \%$ ). 


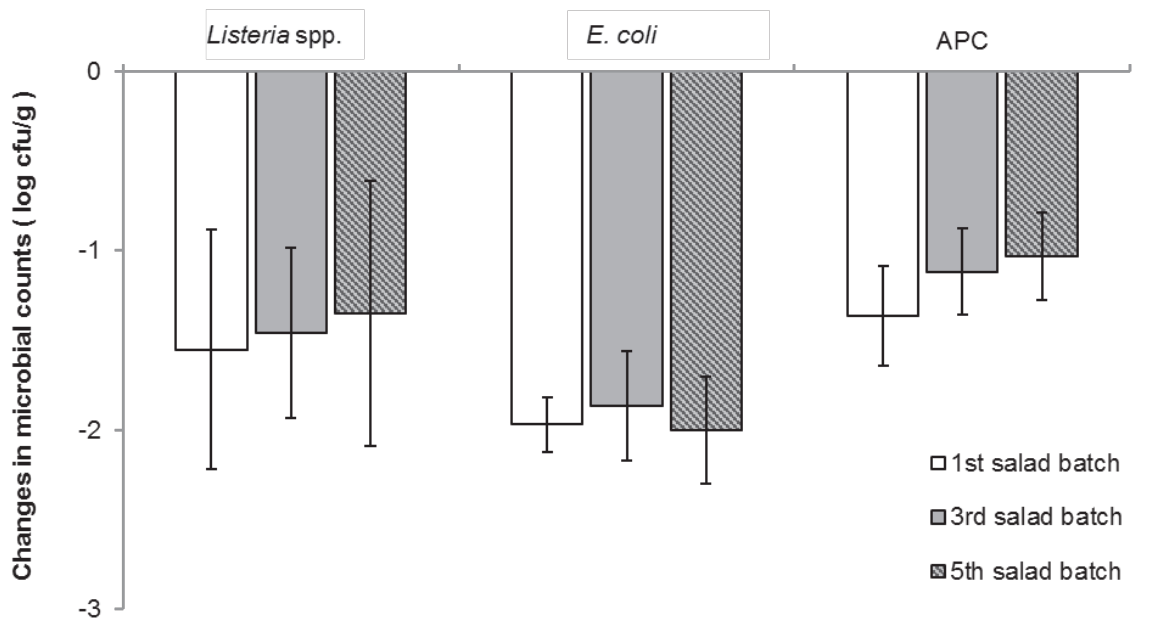

Figure 5.6: Reduction in counts of Listeria spp., E. coli and APC (aerobic plate count) after washing different batches of salads in the same quantity of sanitizer solution (sodium dichloroisocyanurate, 90 ppm) for $5 \mathrm{~min}$.

\section{Recommendations for salad preparation in FSEs}

Whereas this study has mainly focused on washing, sanitization and rinsing of fresh vegetables, it is important to note that other factors can also affect microbial safety during salad preparation in FSEs. Such factors include food handlers' food safety knowledge (55), health status (56) and personal behaviors like handwashing (57), cross contamination from other food items like meat (58), hygiene of food contact surfaces (59) and microbial safety of salad dressing ingredients.

As washing and sanitization is also affected by type of vegetables prepared (9), it is important to note that the findings in this study may be more relevant for leafy vegetables than for fruit vegetables. The practice at FSEs to mix different vegetables during salad preparation will also require that these vegetables are treated separately to carter for their structural differences that may affect the efficacy of washing and sanitization. This study also mainly focused on bacterial indicators but different results may be obtained with parasites and viruses that are reported to be more resistant to especially chlorine based sanitizers (60). We have observed that salad preparation practices vary from one FSE to another in the field study. To support harmonization of these FSE practices and guideline development, the steps for salad preparations have been reorganized as in Figure 5.7. 


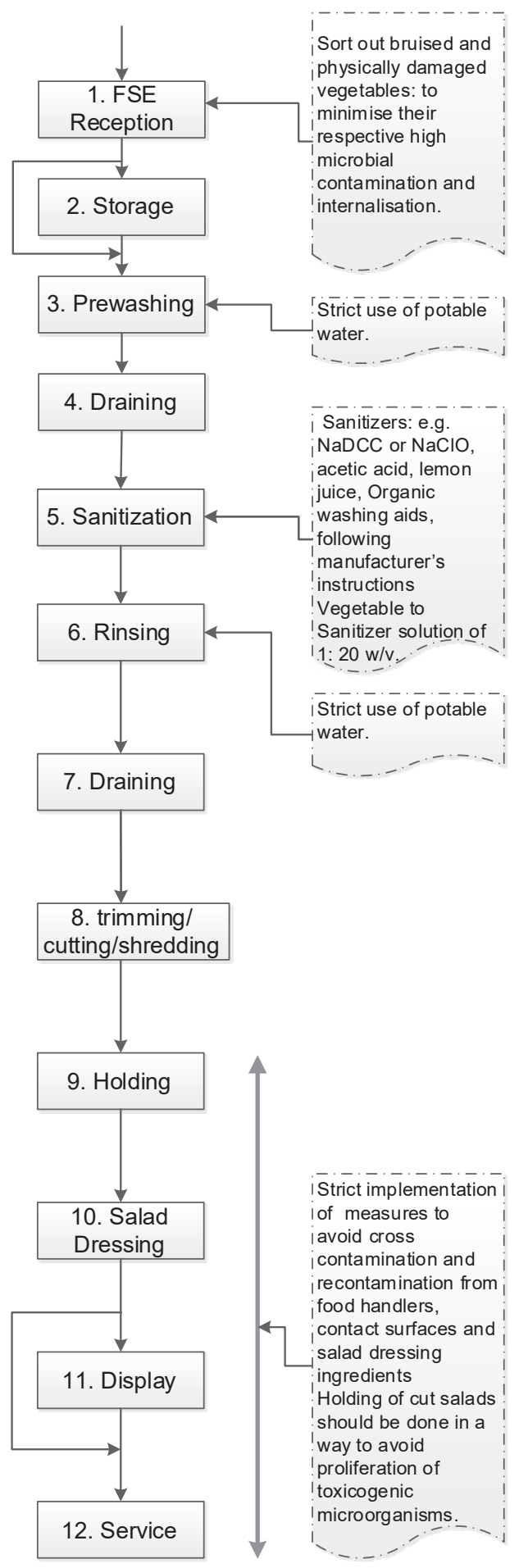

Figure 5.7: Harmonized flow diagram that can be adopted during kitchen scale salad preparation in food service establishments. 
At the reception step of FSEs, vegetables with damaged tissues should be removed as they can provide nutrients for microbial proliferation and or allow entry of pathogens to the interior of vegetable tissues (61) where this internalization can render washing and or sanitization less effective. Storage of salad vegetables at FSEs should be done in way to minimize cross contamination and growth of microbial hazards. Prewashing with potable water should be done on whole vegetables to remove soils and organic load as they can render the sanitization less effective (62).

As a major objective for FSEs during preparation, vegetable salads are supposed to be fresh, organoleptically attractive and microbiologically and chemically safe. To achieve these requirements during salad preparation, FSEs need to balance sanitization settings such as sanitizer concentration and contact time. From this study it can be concluded that for corn salads, a model for leafy vegetables, use of $\mathrm{NaDCC}(\approx 50 \mathrm{ppm})$ and $\mathrm{NaClO}$ $(25-50 \mathrm{ppm})$, sanitizing powder (4 g/L), lemon juice (98\%) and acetic acid ( $2 \%$ ) can be applied for $5 \mathrm{~min}$ and a vegetable to sanitizer ratio of 1: 20. If FSEs are using tap water, we strongly recommend onsite disinfection or boiling the water before sanitization and rinsing of salad vegetables in developing countries. 


\section{References}

1. He FJ, Nowson CA, Lucas M, MacGregor GA. 2007. Increased consumption of fruit and vegetables is related to a reduced risk of coronary heart disease: meta-analysis of cohort studies. Journal of Human Hypertension 21:717-728.

2. FAO STAT. 2015. Food and Agriculture Organization of the United Nations, Statistics Division. Available at: http://faostat3.fao.org/compare/E. Accessed on $03^{\text {rd }}$ May 2016.

3. Cook R. 2011. Tracking demographics and US fruit and vegetable consumption patterns. Department of Agricultural and Resource Economics, University of California, Davis.

4. Painter JA, Hoekstra RM, Ayers T, Tauxe RV, Braden CR, Angulo FJ, Griffin PM. 2013. Attribution of foodborne illnesses, hospitalizations, and deaths to food commodities by using outbreak data, United States, 1998-2008. Emerging Infectious Diseases 19:407-415.

5. Callejon RM, Rodriguez-Naranjo MI, Ubeda C, Hornedo-Ortega R, Garcia-Parrilla MC, Troncoso AM. 2015. Reported foodborne outbreaks due to fresh produce in the United States and European Union: trends and causes. Foodborne Pathogens \& Disease 12:32-38.

6. Soon JM, Seaman P, Baines RN. 2013. Escherichia coli O104:H4 outbreak from sprouted seeds. International Journal of Hygiene \& Environmental Health 216:346-354.

7. Bohaychuk VM, Bradbury RW, Dimock R, Fehr M, Gensler GE, King RK, Rieve R, Barrios PR. 2009. A microbiological survey of selected alberta-grown fresh produce from farmers' markets in Alberta, Canada. Journal of Food Protection 72:415-420.

8. Laura S, Irene R, Roberta B, Maria G, Serena S, Gabriella DM, Carlo E. 2012. Potential Risk of Norovirus Infection Due to the Consumption of "Ready to Eat" Food. Food \& Environmental Virology 4:89-92.

9. Sapers GM. 2009. Chapter 16 - Disinfection of contaminated produce with conventional washing and sanitizing technology, p. 393-424. In Sapers GM, Solomon EB, Matthews KR (ed.), The Produce Contamination Problem. Academic Press, San Diego.

10. Warriner K, Namvar A. 2014. 6 - Postharvest washing as a critical control point in fresh produce processing: alternative sanitizers and wash technologies A2 - Hoorfar, J, p. 71-102, Global Safety of Fresh Produce. Woodhead Publishing.

11. Banach JL, van Bokhorst-van de Veen H, van Overbeek LS, van der Zouwen PS, van der FelsKlerx HJ, Groot MNN. 2017. The efficacy of chemical sanitizers on the reduction of Salmonella Typhimurium and Escherichia coli affected by bacterial cell history and water quality. Food Control $81: 137-146$.

12. Abadias M, Usall J, Oliveira M, Alegre I, Vinas I. 2008. Efficacy of neutral electrolyzed water (NEW) for reducing microbial contamination on minimally-processed vegetables. International Journal of Food Microbiology 123:151-158.

13. Davidson GR, Buchholz AL, Ryser ET. 2013. Efficacy of commercial produce sanitizers against nontoxigenic Escherichia coli $\mathrm{O} 157: \mathrm{H} 7$ during processing of iceberg lettuce in a pilot-scale leafy green processing line. Journal of Food Protection 76:1838-1845. 
14. Holvoet K, Jacxsens L, Sampers I, Uyttendaele M. 2012. Insight into the prevalence and distribution of microbial contamination to evaluate water management in the fresh produce processing industry. Journal of Food Protection 75:671-681.

15. Kinsinger NM, Mayton HM, Luth MR, Walker SL. 2017. Efficacy of post-harvest rinsing and bleach disinfection of E. coli O157:H7 on spinach leaf surfaces. Food Microbiology 62:212-220.

16. Amoah P, Drechsel P, Abaidoo RC, Klutse A. 2007. Effectiveness of common and improved sanitary washing methods in selected cities of West Africa for the reduction of coliform bacteria and helminth eggs on vegetables. Tropical Medicine \& International Health 12:40-50.

17. Beuchat LR, Harris LJ, Ward TE, Kajs TM. 2001. Development of a proposed standard method for assessing the efficacy of fresh produce sanitizers. Journal of Food Protection 64:1103-1109.

18. Kilonzo-Nthenge A, Chen F-C, Godwin SL. 2006. Efficacy of home washing methods in controlling surface microbial contamination on fresh produce. Journal of Food Protection 69:330-334.

19. Ssemanda JN, Reij M, Bagabe MC, Muvunyi CM, Joosten H, Zwietering MH. 2017. Indicator microorganisms in fresh vegetables from "farm to fork" in Rwanda. Food Control 75:126-133.

20. Mukherjee A, Speh D, Diez-Gonzalez F. 2007. Association of farm management practices with risk of Escherichia coli contamination in pre-harvest produce grown in Minnesota and Wisconsin. International Journal of Food Microbiology 120:296-302.

21. ISO 21528-2: 2004. Microbiology of food and animal feeding stuffs -- Horizontal methods for the detection and enumeration of Enterobacteriaceae -- Part 2: Colony-count method. International Organization for Standardization, Geneva, Switzerland.

22. ISO 4833-1: 2013. Microbiology of the food chain -- Horizontal method for the enumeration of microorganisms -- Part 1: Colony count at 30 degrees C by the pour plate technique. International Organization for Standardization, Geneva, Switzerland.

23. ISO 6888-2: 1999. Microbiology of food and animal feeding stuffs -- Horizontal method for the enumeration of coagulase-positive staphylococci (Staphylococcus aureus and other species) -- Part 2: Technique using rabbit plasma fibrinogen agar medium. International Organization for Standardization, Geneva, Switzerland.

24. ISO 11290-2:1998/Amd 1: 2004. Microbiology of food and animal feeding stuffs - Horizontal method for the detection and enumeration of Listeria monocytogenes — Part 2: Enumeration method AMENDMENT 1: Modification of the enumeration medium. International Organization for Standardization, Geneva, Switzerland.

25. Berger CN, Shaw RK, Brown DJ, Mather H, Clare S, Dougan G, Pallen MJ, Frankel G. 2009. Interaction of Salmonella enterica with basil and other salad leaves. ISME Journal 3:261-265.

26. López-Gálvez F, Gil MI, Truchado P, Selma MV, Allende A. 2010. Cross-contamination of freshcut lettuce after a short-term exposure during pre-washing cannot be controlled after subsequent washing with chlorine dioxide or sodium hypochlorite. Food Microbiology 27:199-204.

27. Venkitanarayanan KS, Ezeike GO, Hung Y-C, Doyle MP. 1999. Efficacy of electrolyzed oxidizing water for inactivating Escherichia coli O157: H7, Salmonella enteritidis, and Listeria monocytogenes. Applied \& Environmental Microbiology 65:4276-4279. 
28. Beuchat LR, Adler BB, Lang MM. 2004. Efficacy of chlorine and a peroxyacetic acid sanitizer in killing Listeria monocytogenes on iceberg and romaine lettuce using simulated commercial processing conditions. Journal of Food Protection 67:1238-1242.

29. Vitens. 2016. Drinking water supply company for the Gelderland province, the Netherlands. Available at: https://www.vitens.com/. Accessed $28^{\text {th }}$ August 2016.

30. Smeets P, Medema G, Van Dijk J. 2009. The Dutch secret: how to provide safe drinking water without chlorine in the Netherlands. Drinking Water Engineering \& Science 2:1-14.

31. Nascimento M, Silva N, Catanozi M, Silva K. 2003. Effects of different disinfection treatments on the natural microbiota of lettuce. Journal of Food Protection 66:1697-1700.

32. Vijayakumar C, Wolf-Hall CE. 2002. Evaluation of household sanitizers for reducing levels of Escherichia coli on iceberg lettuce. Journal of Food Protection 65:1646-1650.

33. Citrox. 2016. Citrox 14W Plus - produce. Technical data sheet. Available at: http://www.citrox.co.nz/files/tech.sheet-14wp-produce-april-2013.pdf. Accessed $18^{\text {th }}$ July 2016.

34. Soriano JM, Rico H, Moltó JC, Mañes J. 2000. Assessment of the microbiological quality and wash treatments of lettuce served in University restaurants. International Journal of Food Microbiology 58:123-128.

35. FDA. 2016a. The Food and drug administration of the United States, department of health and human services. Code of federal regulations. Part 173 - Secondary direct food additives permitted in food for human consumption. Subpart D-Specific usage additives. 21CFR173.405. Silver Spring, Maryland, United States. Available at: https://www.accessdata.fda.gov/scripts/cdrh/cfdocs/cfcfr/CFRSearch.cfm?fr=173.405. Accessed $02^{\text {nd }}$ September 2016.

36. FDA. 2016b. The Food and drug administration of the United States, department of health and human services. Code of federal regulations. Part 178-indirect food additives: adjuvants, production aids, and sanitizers. Subpart B-substances utilized to control the growth of microorganisms. 21CFR178.1010. Silver Spring, Maryland, United States. Available at:

https://www.accessdata.fda.gov/scripts/cdrh/cfdocs/cfcfr/CFRSearch.cfm?fr=178.1010. Accessed $02^{\text {nd }}$ September 2016.

37. ISO 16649-2: 2001. Microbiology of food and animal feeding stuffs -- Horizontal method for the enumeration of beta-glucuronidase-positive Escherichia coli-- Part 2: Colony-count technique at 44 degrees C using 5-bromo-4-chloro-3-indolyl beta-D-glucuronide. International Organization for Standardization, Geneva, Switzerland.

38. Kirby MA, Nagel CL, Rosa G, Iyakaremye L, Zambrano LD, Clasen TF. 2016. Faecal contamination of household drinking water in Rwanda: A national cross-sectional study. Science of the Total Environment 571:426-434.

39. Sukul S, Sheth M. 2012. Can sanitizers reduce microbial load of coriander leaves? Nutrition and Food Science 42:12-20. 
40. Park SH, Choi MR, Park JW, Park KH, Chung MS, Ryu S, Kang DH. 2011. Use of organic acids to inactivate Escherichia coli O157: H7, Salmonella Typhimurium, and Listeria monocytogenes on organic fresh apples and lettuce. Journal of Food Science 76:M293-M298.

41. Santos YO, Almeida RCC, Guimarães AG, Almeida PF. 2010. Hygienic-sanitary quality of vegetables and evaluation of treatments for the elimination of indigenous E. coli and E. coli O157: $\mathrm{H} 7$ from the surface of leaves of lettuce (Lactuca sativa L.). Food Science \& Technology (Campinas) 30(4), 1083-1089.

42. Sengun IY, Karapinar M. 2004. Effectiveness of lemon juice, vinegar and their mixture in the elimination of Salmonella Typhimurium on carrots (Daucus carota L.). International Journal of Food Microbiology 96:301-305.

43. Parish M, Beuchat L, Suslow T, Harris L, Garrett E, Farber J, Busta F. 2003. Methods to reduce/eliminate pathogens from fresh and fresh-cut produce. Comprehensive Reviews in Food Science \& Food Safety 2:161-173.

44. Clasen T, Edmondson P. 2006. Sodium dichloroisocyanurate (NaDCC) tablets as an alternative to sodium hypochlorite for the routine treatment of drinking water at the household level. International Journal of Hygiene \& Environmental Health 209:173-181.

45. Hammond BG, Barbee SJ, Inoue T, Ishida N, Levinskas GJ, Stevens MW, Wheeler AG, Cascieri T. 1986. A review of toxicology studies on cyanurate and its chlorinated derivatives. Environmental Health Perspectives 69:287.

46. Szabo E, Simons L, Coventry M, Cole M. 2003. Assessment of control measures to achieve a food safety objective of less than $100 \mathrm{CFU}$ of Listeria monocytogenes per gram at the point of consumption for fresh precut iceberg lettuce. Journal of Food Protection 66:256-264.

47. Van Haute S, Sampers I, Holvoet K, Uyttendaele M. 2013. Physicochemical quality and chemical safety of chlorine as a reconditioning agent and wash water disinfectant for fresh-cut lettuce washing. Applied \& Environmental Microbiology 79:2850-2861.

48. Bain R, Cronk R, Wright J, Yang H, Slaymaker T, Bartram J. 2014. Fecal contamination of drinking-water in low-and middle-income countries: a systematic review and meta-analysis. PLoS medicine 11:e1001644.

49. Neo SY, Lim PY, Phua LK, Khoo GH, Kim S-J, Lee S-C, Yuk H-G. 2013. Efficacy of chlorine and peroxyacetic acid on reduction of natural microflora, Escherichia coli O157:H7, Listeria monocyotgenes and Salmonella spp. on mung bean sprouts. Food Microbiology 36:475-480.

50. Ölmez H, Temur SD. 2010. Effects of different sanitizing treatments on biofilms and attachment of Escherichia coli and Listeria monocytogenes on green leaf lettuce. LWT - Food Science and Technology 43:964-970.

51. Zhang S, Farber JM. 1996. The effects of various disinfectants against Listeria monocytogenes on fresh-cut vegetables. Food Microbiology 13:311-321.

52. Jensen DA, Friedrich LM, Harris LJ, Danyluk MD, Schaffner DW. 2015. Cross contamination of Escherichia coli O157:H7 between lettuce and wash water during home-scale washing. Food Microbiology 46:428-433. 
53. Holvoet K, De Keuckelaere A, Sampers I, Van Haute S, Stals A, Uyttendaele M. 2014. Quantitative study of cross-contamination with Escherichia coli, E.coli O157, MS2 phage and murine norovirus in a simulated fresh-cut lettuce wash process. Food Control 37:218-227.

54. Zhang G, Ma L, Phelan VH, Doyle MP. 2009. Efficacy of antimicrobial agents in lettuce leaf processing water for control of Escherichia coli O157: H7. Journal of Food Protection 72:1392-1397.

55. Abdullah Sani N, Siow ON. 2014. Knowledge, attitudes and practices of food handlers on food safety in food service operations at the Universiti Kebangsaan Malaysia. Food Control 37:210-217.

56. Kamau P, Aloo-Obudho P, Kabiru E, Ombacho K, Langat B, Mucheru O, Ireri L. 2012. Prevalence of intestinal parasitic infections in certified food-handlers working in food establishments in the City of Nairobi, Kenya. Journal of Biomedical Research 26:84-89.

57. Robinson AL, Lee HJ, Kwon J, Todd E, Rodriguez FP, Ryu D. 2016. Adequate hand washing and glove use are necessary to reduce cross-contamination from hands with high bacterial loads. Journal of Food Protection 79:304-308.

58. Redmond EC, Griffith CJ, Slader J, Humphrey TJ. 2004. Microbiological and observational analysis of cross contamination risks during domestic food preparation. British Food Journal 106:581597.

59. Gorman R, Bloomfield S, Adley CC. 2002. A study of cross-contamination of food-borne pathogens in the domestic kitchen in the Republic of Ireland. International Journal of Food Microbiology 76:143150 .

60. CDC. 2012. Center for Disease Control and prevention, Atlanta, Georgia, USA. Effect of Chlorination on Inactivating Selected Pathogen. Available at: https:/www.cdc.gov/safewater/effectiveness-onpathogens.html. Accessed on $25^{\text {th }}$ June 2017.

61. Beuchat LR. 2006. Vectors and conditions for preharvest contamination of fruits and vegetables with pathogens capable of causing enteric diseases. British Food Journal 108:38-53.

62. Shen C, Luo Y, Nou X, Wang Q, Millner P. 2013. Dynamic effects of free chlorine concentration, organic load, and exposure time on the inactivation of Salmonella, Escherichia coli O157: H7, and non-O157 Shiga toxin-producing E. coli. Journal of Food Protection 76:386-393. 
General discussion, conclusion and future perspectives 
Globalization has led to increased international travel, trade and tourism, implying that people from different countries now interact more often. This interaction among people has resulted to drastic changes in cultures, life styles, eating behavior and food preferences (1). Changes in life style include an increase in the consumption of convenient, ready to-eat foods and eating away from home in canteens, restaurants and hotels. Trends in eating behavior and food preferences show that a vegetable based diet is gaining popularity (2-4) year by year and a significant proportion of these vegetables are consumed raw.

While the exchange of life style, eating behavior and food preferences is global, the level of implementing food safety standards and guidelines (i.e.. GAPs, GHPs, HACCP ) continue to vary from one region or country to another. All countries have limited resources and at times experience a lapse in implementing food safety preventive and control measures leading to food contamination which may later emerge as foodborne illnesses and or outbreaks. Food service establishments (FSEs) have been implicated in foodborne outbreaks (5-10), yet it is not always clear whether contamination takes place in these eating places or elsewhere along the food supply chain.

This study was commissioned to analyze the microbial risk from "farm to fork" along the fresh vegetable supply chain in Rwanda to explore microbial safety options that can contribute to an integrated system to detect, control and prevent foodborne infections. In approaching this study, specific objectives were developed. The first objective was to estimate the burden of foodborne infectious illnesses using the available data to obtain insight into the general plight of food safety issues and to develop a framework for future investigations (Chapter 2). Second, an investigation into the microbial safety status, handling practices and risk exposure factors was conducted along the fresh vegetable supply chain (Chapters 3 to 5). This chapter discusses the link between the previous chapters ( 1 to 5) and activities critical to microbial safety and opportunities for improvement. Furthermore, the methodology and the outcome of analysing the microbial risk from "farm to fork" are presented next to the suggestions for approaching microbial safety of fresh vegetables and the way forward for an integrated food chain system.

\section{Burden of foodborne illnesses}

While foodborne illnesses have been described as an old and known problem $(11,12)$, these illnesses continue to cause substantial morbidity and mortality worldwide, burdening public health systems and impeding social-economic development (13). Reasons highlighted for the continuing burden of foodborne illnesses include: the insufficient implementation of effective control measures, the emergence and re-emergence of foodborne pathogens, the increasing potential of spread due to globalization, the changing patterns of microbial resistance to antibiotics and the surging number of susceptible population $(11,12)$. Consequently, estimating and reporting of foodborne illnesses is required to assess the burden nationally and globally to direct and prioritize food safety policies and interventions (14). In line with estimating the burden of foodborne illnesses, the World Health Organisation initiated a task group (FERG) in 2007 and also advised national governments to continually conduct studies on the burden of 
foodborne illnesses. To date, national studies on the burden of foodborne illnesses come from few countries; England (15), United States (16), Netherlands (17), Greece (18), Canada (19). The limited numbers of these studies has been associated with the challenges of operating an elaborate disease surveillance systems and lack of required expertise.

In order to support efforts of estimating burden of foodborne illnesses in Rwanda and other developing countries, we estimated the burden of food-related illnesses based on syndromic surveillance data (Chapter 2) which is commonly available and affordable in resource scarce settings. Study findings indicate that for the year 2013, watery diarrhea occurred all year round as by the national notifiable surveillance system data, resulting to an estimated 672 (95\% credible interval [CrI] 424 - 932) DALY per million inhabitants, bloody diarrhea was seasonal coinciding with the rainy months and caused an estimated $213(95 \%$ CrI $50-475)$ DALY per million, typhoid fever and cholera were sporadic with an estimated 73 (95\% CrI 57 - 91) and 1 (95\% CrI 0 - 2) DALY per million respectively. Data gaps always characterise these studies on estimates of burden of foodborne illnesses (20) and in Chapter 2 of this thesis, these data gaps have also been presented. One of the major data gaps in the present study was that we could not attribute the estimates of food related illnesses to any food vehicle based on the available data. However, foodborne pathogens and or their indicators have been detected and isolated from various food items in Rwanda, for example milk and milk products (21), raw meat (22) and drinking water $(23,24)$. In the present study (Chapter 4), foodborne pathogens (Salmonella ssp., Listeria monocytogenes, Campylobacter spp. and pathogenic Escherichia coli ) were detected in farm vegetables. Investigating the microbial safety of different food sources along the supply chains and coupling with epidemiology data will improve burden of foodborne illness estimates.

\section{Microbial safety concern of fresh vegetables}

Attribution studies have shown fresh vegetables among the major upcoming food vehicles for foodborne pathogens leading to foodborne illnesses, but most studies and data come from developed countries $(25,26)$. While production and consumption of fresh vegetables is increasing in developing countries (4), there is limited information on their safety and attribution to the burden of foodborne diseases. Farm vegetables in open fields can be contaminated with human zoonotic pathogens through agronomic factors such as irrigation water, flooding, soil, manure, human biosolids, dust, domestic and wild animals, human activities (27-30). Studies indicate that, once introduced, human pathogens can attach $(31,32)$ and or internalize in- $(33,34)$ and persist on the vegetable structures. In Chapter 4 we have reported the prevalence of pathogens, Salmonella spp., Campylobacter jejuni, pathogenic E. coli and L. monocytogenes in farm vegetables in Rwanda in comparison with studies from studies from other countries. Although there can be postharvest contamination, it has been argued that pathogens once introduced to vegetables during primary production, are difficult to remove later by washing and sanitization (35). In chapter 3, we used indicator microorganisms to investigate what happens to the microbial counts in fresh vegetables from "farm to fork". Our results show that microbial counts slightly increased from farm to market and to reception at FSEs, but while at FSEs, salad preparation led to an average reduction of $2.1 \mathrm{log} \mathrm{cfu} / \mathrm{g}$. For 
pathogens like Salmonella spp. (where ingestion of one cell can cause Salmonellosis) (36) and selected $E$. coli strains, their presence in farm vegetables even in low numbers means that they can present a health risk to the consumers. Moreover in Chapter 5, field and laboratory trials to identify the most effective sanitizer and washing technique showed that the maximum possible microbial inactivation was around $3 \operatorname{logs}$ with sodium dichloroisocyanurate as a sanitizer. Pathogens, however, may be present in high numbers, so it is important not to rely on only washing and sanitization but on a range of measures across the whole supply chain to prevent and control pathogens from contaminating fresh vegetables. In order to estimate the risk to consumers, microbial safety data along the vegetable supply chain was gathered and an analysis of the microbial risk was conducted from "farm to fork" for the vegetable supply chain in Rwanda as presented in the next section.

\section{"Farm to fork" risk analysis along the fresh vegetable supply chain}

Risk analysis as fostered internationally by the WHO and FAO, is a systematic, disciplined approach for making evidence based food safety decisions by competent authorities. Risk analysis comprises of three overlapping components (Fig. 6.1); risk assessment, risk management and risk communication (37). In risk assessment, science based information is generated for risk managers to develop food safety policies from the available scientific options (risk management). While exchange of information between risk assessors, risk managers, consumers and other stakeholders is referred to as risk communication (37).

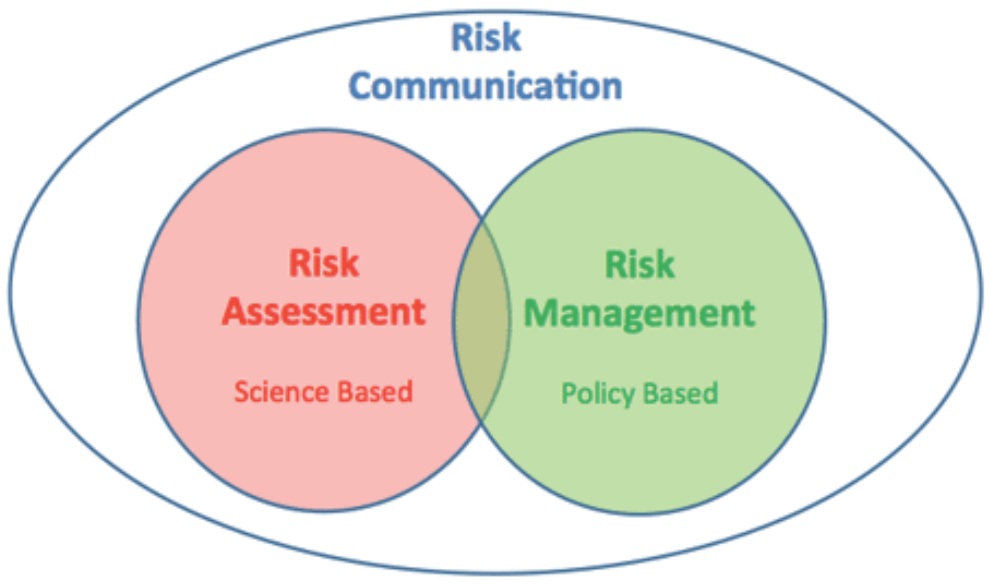

Figure 6.1: Components of Risk analysis [Source: FAO (38)].

\section{Risk assessment}

A quantitative microbial risk assessment was conducted in this study by using the data gathered in Chapters 3 to 5. The processes of hazard identification, exposure assessment, hazard characterization and risk characterization that are involved in risk assessment were followed and presented in the following sub-sections of this chapter. 


\section{Hazard identification}

In the "farm to fork" continuum, fresh vegetables can be exposed to three categories of pathogenic microorganisms; bacteria (39), parasites (40) and viruses (41). In Chapter 4, we tested farm vegetables and agricultural water for the presence of foodborne pathogens. Prevalence of pathogens in farm vegetables varied from $1.0 \%$ (1/99) for L. monocytogenes, 3.0 $\%$ (3/99) for thermo-tolerant Campylobacter spp., $5.1 \%$ (5/99) for Salmonella spp. to $6.1 \%$ (6/99) pathogenic E. coli. In agricultural water from rivers, lakes, lagoons, ground and marshlands, prevalence of DNA from pathogens varied from $3 \%(1 / 30)$ for Enteroinvasive $E$. coli (EIEC); 7 \% (2/30) for Enteroaggregative E. coli (EAEC); $13 \%$ (4/30) for Enterotoxigenic E. coli. (ETEC) and Vibrio cholera; $20 \%$ (6/30) for Yersinia pestis; $27 \%$ (8/30) for Francisella tularensis; $40 \%$ (12/30) for Cyclospora to $87 \%$ (26/30) for thermo-tolerant Campylobacter spp. Table 6A.1 shows a summary of the pathogens detected in farm vegetables and agriculture water in Rwanda and their associated health outcomes.

The findings on the prevalence of foodborne pathogens associated with farm vegetables in Rwanda as presented in Chapter 4 can point to several pathogens as candidates for risk assessment. The risk assessment in this study focused on pathogenic E. coli due to their high prevalence, public health impact and association with the vegetable supply chain. Further details on hazard identification of pathogenic E. coli are presented in the Appendix section of this chapter.

\section{Exposure assessment}

Figure 6.2 shows the various routes in the vegetable supply chain in Rwanda. In chapters 4 and 5 of this thesis, findings are presented for the microbial risk exposure factors of fresh vegetables from "farm to fork". Based on these findings and other information from literature, such as that from the Pang et al. study (42), a quantitative microbial risk assessment (QMRA) model was developed for pathogenic E. coli from "farm to fork". This QMRA was based on leafy vegetables (lettuce) model developed in previous studies (42-45). The exposure assessment part of the QMRA model was built in 4 modules: at farm, during transport, at market and at food service establishments as discussed in details in the next sub-sections of this chapter. The summary of variables, distributions, formula and data sources are presented in Table 6.1. All simulations were conducted in @ risk 7.5 software (Palisade Corp., Ithaca, NY)) using 100,000 iterations making use of the Monte Carlo simulation technique (44). 


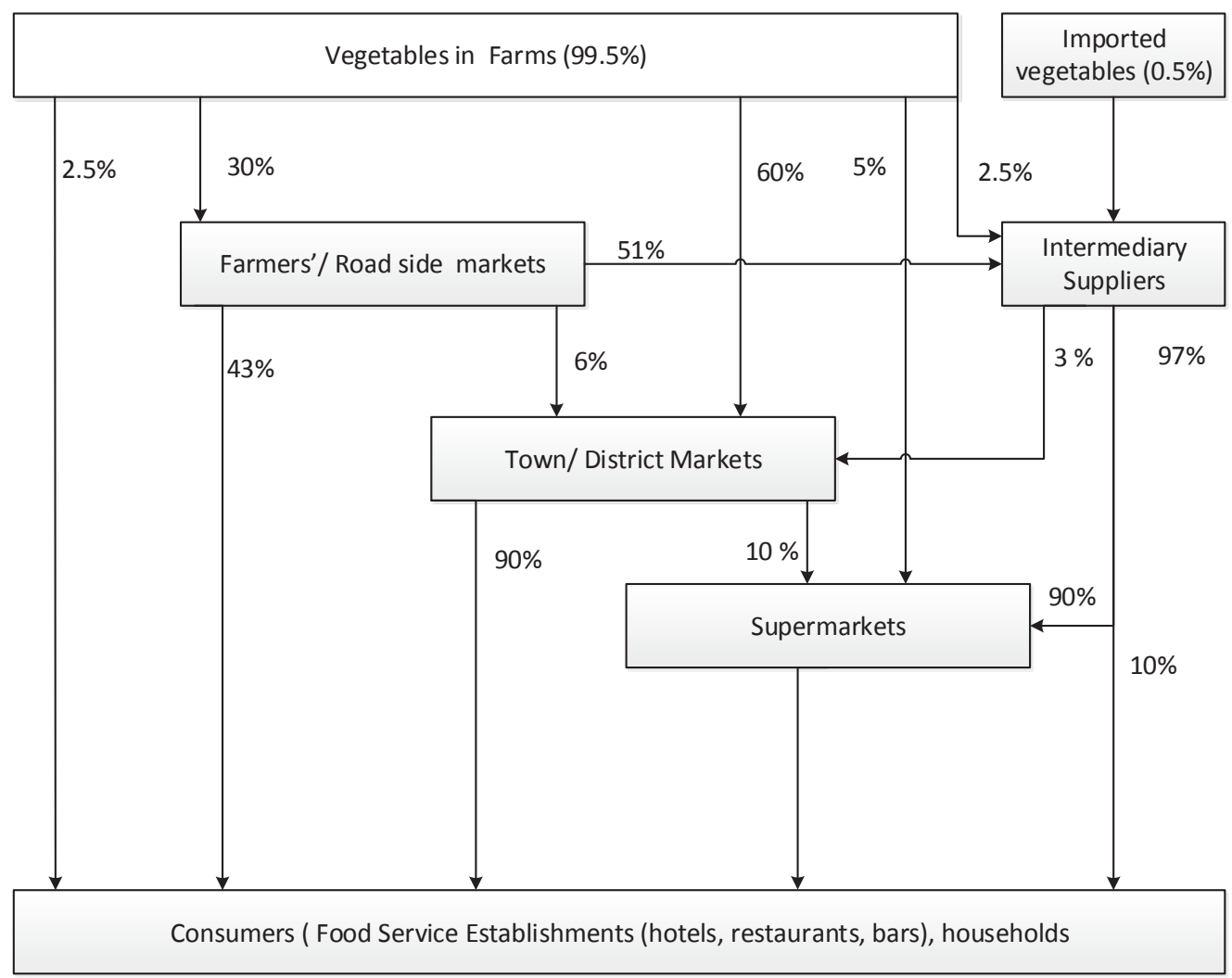

Figure 6.2: Structure of the vegetable supply chain in Rwanda. The consumers (hotels, restaurants, households) can receive vegetables from any step of the chain. The percentages indicate the proportions of vegetables channeled through specific routes.

\section{At farm}

Details of our evaluation of microbial hazards and risk exposure factors at farm level were largely taken from Chapter 4 of this thesis. To estimate the prevalence and concentration of pathogenic $E$. coli in vegetables at farm level, the approach was as follows:

In the QMRA model, there was no individual quantification of the risk from pre-harvest factors like irrigation water, manure, and environmental pollution (Tab. 6.1), like it was in the study of Ding et al (45). We assumed that these pre-harvest factors contributed to $6.1 \%(6 / 99)$ prevalence of pathogenic $E$. coli in farm vegetables reported in Chapter 4. Initial concentrations of $E$. coli in farm leafy vegetables were adopted from a previous study in Lebanon $(46,47)$ a country with conditions of the vegetable supply chain similar to Rwanda. The E. coli (generic) levels (in positive vegetables) were reorganized into a Risk Pert distribution with the mean (1.3 $\log \mathrm{cfu} / \mathrm{g}$ ) as the most likely value while the lowest and highest value were 0.7 and $7 \mathrm{log} \mathrm{cfu} / \mathrm{g}$ respectively. Furthermore, microbial counts in farm vegetables are reported to reduce with time till harvest (43). In their study, Maffei et al.(43) modelled log reduction in Salmonella spp. as 
a function of 60 days between the initial contamination and the time of harvest. The approach of Maffei et al. (43) was also applied in this study. Risk Uniform and Risk Normal distributions were respectively used to model the days in the field after contamination and the log reduction in the field.

At harvest, the prevalence and concentration of $E$. coli can also be affected by cross contamination from contact surfaces of harvest containers and harvesters hands, on-farm washing and refreshing of vegetables. These on-farm practices at harvest were also modelled in this QMRA study (summarised in Table 6.1). During on-farm washing using the surrounding surface waters, it is also possible there can be reduction in E. coli counts. Water alone led to a $0.9 \pm 0.2 \log$ reduction during the washing of leafy vegetables (Chapter 5, this thesis) and this $\log$ reduction was described by a Normal distribution. On the other side, on farm washing and refreshing can also result to contamination of farm vegetables. In the study of Pang et al. (42) as shown in Table 6.1, this contamination was computed as a function of levels of E. coli in refreshing water, water holding capacity on a lettuce model (Risk Normal(0.108, 0.019, Risk Truncate $(0),) \mathrm{ml} / \mathrm{g}$ ) and the ratio of pathogenic E. coli to generic E.coli in washing water. Levels of $E$. coli in surface water surrounding farm vegetables in Rwanda were reorganized into a risk Pert distribution with the mean $(2.0 \mathrm{log} \mathrm{cfu} / 100 \mathrm{ml})$ as the most likely value while the lowest and highest value were 0.0 and $3.6 \mathrm{log} \mathrm{cfu} / 100 \mathrm{ml}$ respectively (unpublished results, this study). The ratio of pathogenic E. coli to generic E. coli in agricultural water in Rwanda used in the study was $7 / 27$, from Chapter 4 where the prevalence of pathogenic E. coli was $7 / 30$ and from unpublished results where $3 / 30$ samples had $0.0 \mathrm{cfu} / 100 \mathrm{ml}$ levels of generic E.coli. The algorithm also caters for cross contamination by estimating and quantifying the number of cells of E. coli transferred from and to farm vegetables (Tab. 6.1). Transfer rates of E. coli from contaminated leafy vegetables to hands were adopted from Verhaelen et al. (48) by taking a Risk Pert distribution of the transfer rate estimates of human norovirus from lettuce to hands. A risk triangle distribution was applied to the transfer rates of E. coli form leafy vegetables to harvest surfaces by assuming that the these surfaces are similar to those of the conveyor belt surfaces in the Pang et al. study (42). Chen et al. (49) quantified transfer rates of bacterial cross contamination from hand to lettuce in a RiskWeibull distribution, these transfer rates were also adopted for this study. In their study, Jensen et al. (50) quantified transfer rates of E. coli O157: $\mathrm{H} 7$ between fresh cut produce and common kitchen surfaces. This study adopted the transfer rates from contaminated plastic surfaces in the Jensen et al. (50) study to represent harvest containers to lettuce and described in a Risk Pert distribution. Furthermore, due to cross contamination, for each washing or refreshing step the prevalence of pathogenic E. coli in farm vegetables was multiplied by a factor of spread of cross contamination with a Risk Pert $(1,1.2$, 2) distribution from the Pang et al. study (42). A summary of associated functions and calculations is presented in Table 6.1.

\section{Transportation}

Vegetables are transported by farmers, suppliers or traders using several means, non-specialized vehicles, bicycles, carts and head carrying, and no refrigeration is involved. Vegetables are transported at temperatures between 14 to $25^{\circ} \mathrm{C}$ [common temperature range in Rwanda] (51) and in this study a Risk Pert distribution of 14 (low), 20 (most likely ) and 25 (high) ${ }^{\circ} \mathrm{C}$ was 
applied. Figure 6.2 shows the transportation routes. Major transportation routes include the transportation of vegetables from farms to markets to FSEs $(97.5 \%)$, while in some cases vegetables are directly transported from farms to FSEs $(2.5 \%)$.

In this QMRA study, the transportation time was described by a Risk Uniform distribution as from previous studies (45). It was assumed that during transport there is growth and like from previous studies $(42,44)$, primary and secondary models were used:

The primary model used to describe the growth of pathogenic E. coli was as shown in Equation 1.

$\log \mathrm{N}_{\mathrm{t}}=\log \mathrm{N}_{0}+\mu \times \mathrm{t} \cdots \cdots \cdots \cdots \cdots \cdots \cdots \cdots \cdots \cdots \cdots \cdots \cdots \cdots$ Eq. 1

where $\mathrm{N}_{\mathrm{t}}$ is the concentration at time $\mathrm{t}(\mathrm{CFU} / \mathrm{g}), \mathrm{N}_{0}$ is the concentration at time $0(\mathrm{CFU} / \mathrm{g})$ and $\mu$ is the growth rate at a specific temperature $(\log \mathrm{CFU} / \mathrm{g} / \mathrm{h})$. To determine $\mu$, a secondary model was used as in equation (Eq. 2) proposed by Ratkowsky et al. (52)

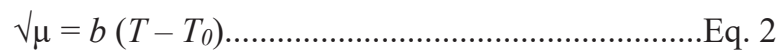

where $\mathrm{T}$ is the temperature (in degrees Celsius), and $b$ and $T_{0}$ are regression constants. These growth equations (Eq. 1 and Eq. 2) were used where applicable in other modules of this QMRA study.

It was also assumed that the microbial growth rate due to transportation of vegetables between farms and markets was equal to that between markets and FSEs. Transportation time from farms to markets was about 0.5 to $3 \mathrm{~h}$ and the same time was assumed to be spent between markets and FSEs. Therefore, the microbial growth due to transportation between farms and markets was assumed to be equal to that growth due to transportation between market and FSEs. Microbial contamination of fresh vegetable during transportation was considered minimal and not included in the QMRA study.

\section{At market}

At market level, about $90 \%$ of vegetables are sold in town and farmer markets, which are open air structures with raised platforms and more than 20 vendors while the rest go through supermarkets where vegetables are sold under refrigeration (This study). The overall concentration of $E$. coli at market was generated from three modules; growth during display, contamination during refreshing of fresh vegetables and cross contamination. The contribution of these three modules to the concentration and prevalence of E. coli at market stage was thereafter computed.

Depending on the vegetable type and market infrastructure, vegetables can be retained at market from 1- 5 days and display temperatures are between 14 and $25{ }^{\circ} \mathrm{C}$ (51) for open air markets (This study). Growth in E. coli levels during display at market was also modelled in a similar way as during transportation. In these markets, vendors also refresh leafy vegetables with water from nearby water sources (streams, rivers and tap water). Like during harvest at farm level, this contamination was computed as a function of levels of $E$. coli in refreshing water, water 
holding capacity on a lettuce model (Risk Normal $(0.108,0.019$, RiskTruncate $(0),) \mathrm{ml} / \mathrm{g}$ ) and the ratio of pathogenic $E$. coli to generic E. coli in washing water (Tab. 6.1). Cross contamination can occur at market between fresh vegetables and market handlers and display surfaces. The same distributions and variables for cross contamination at harvest in the farm module were used for the market module (Tab. 6.1). In addition due to cross contamination, the prevalence of pathogenic $E$. coli in vegetables at market stage was obtained by multiplying the prevalence after the farm stage by a factor of spread of cross contamination as used in the Pang et al. study (42).

\section{At food service establishments (FSEs)}

Figure 6A.1 summarises the steps involved at FSEs (This study). Details of the unit operations involved at FSEs are presented as findings from the field study in Chapter 5. In the QMRA study, growth rate of E. coli during storage at FSEs was modelled using the same approach as in the previous steps (Eq. 1 and Eq. 2). The storage temperatures and time were around $2-8^{\circ} \mathrm{C}$ and 2 to $48 \mathrm{~h}$ and were described by a Risk Pert distribution (Tab. 6.1). In previous studies(42, 53), a die off model (Equation 3) was applied for E. coli $\mathrm{O} 157: \mathrm{H} 7$ at temperature below $5{ }^{\circ} \mathrm{C}$ and the same approach was used where applicable in this study.

$\log \left(\mathrm{N}_{\mathrm{t}} / \mathrm{N}_{0}\right)=-\mathrm{k} \times \mathrm{t} \cdots \cdots \cdots \cdots \cdots \cdots \cdots \cdot$ Eq. 3

where $\mathrm{N}_{\mathrm{t}}, \mathrm{N}_{0}$ and $\mathrm{t}$ are as described in Eq. 1, while $\mathrm{k}$ is the death rate $(\log \mathrm{cfu} / \mathrm{g} / \mathrm{h})$.

Washing and sanitization is a crucial step in reducing microbial counts as was observed in Chapter 3 and 5. A Risk Normal distribution was used to model the reduction of counts of Enterobacteriaceae reported in Chapter 5 due to washing and sanitization of vegetables in the field study with FSEs and it was assumed that the $E$. coli would be reduced similarly as Enterobacteriaceae. A cross contamination module was also added in the same way as at harvesting (Farm level) to represent possible exchange of E. coli during salad preparation in kitchen surfaces and hands of handlers. Contamination due to washing water was not included in the QMRA study, it was also assumed that the water used for washing and sanitization was fit for purpose. The concentration of E. coli after the FSE stage was computed as presented in Tab. 6.1. All counts of $E$. coli above $\log 7 \mathrm{cfu} / \mathrm{g}$ at FSES were truncated in further steps of the QMRA study (Tab.6.1) as from previous studies $(42,43)$ to minimize unrealistic estimates of the risk. It was assumed that all E. coli behaved like E. coli $\mathrm{O} 157: \mathrm{H} 7 \mathrm{on}$ fresh vegetables which was reported to seldom grow above $7 \mathrm{cfu} / \mathrm{g}$ at room temperature $\left[25^{\circ} \mathrm{C}\right](54)$. The contribution of cross contamination was computed using the same approach as at market and farm modules. 


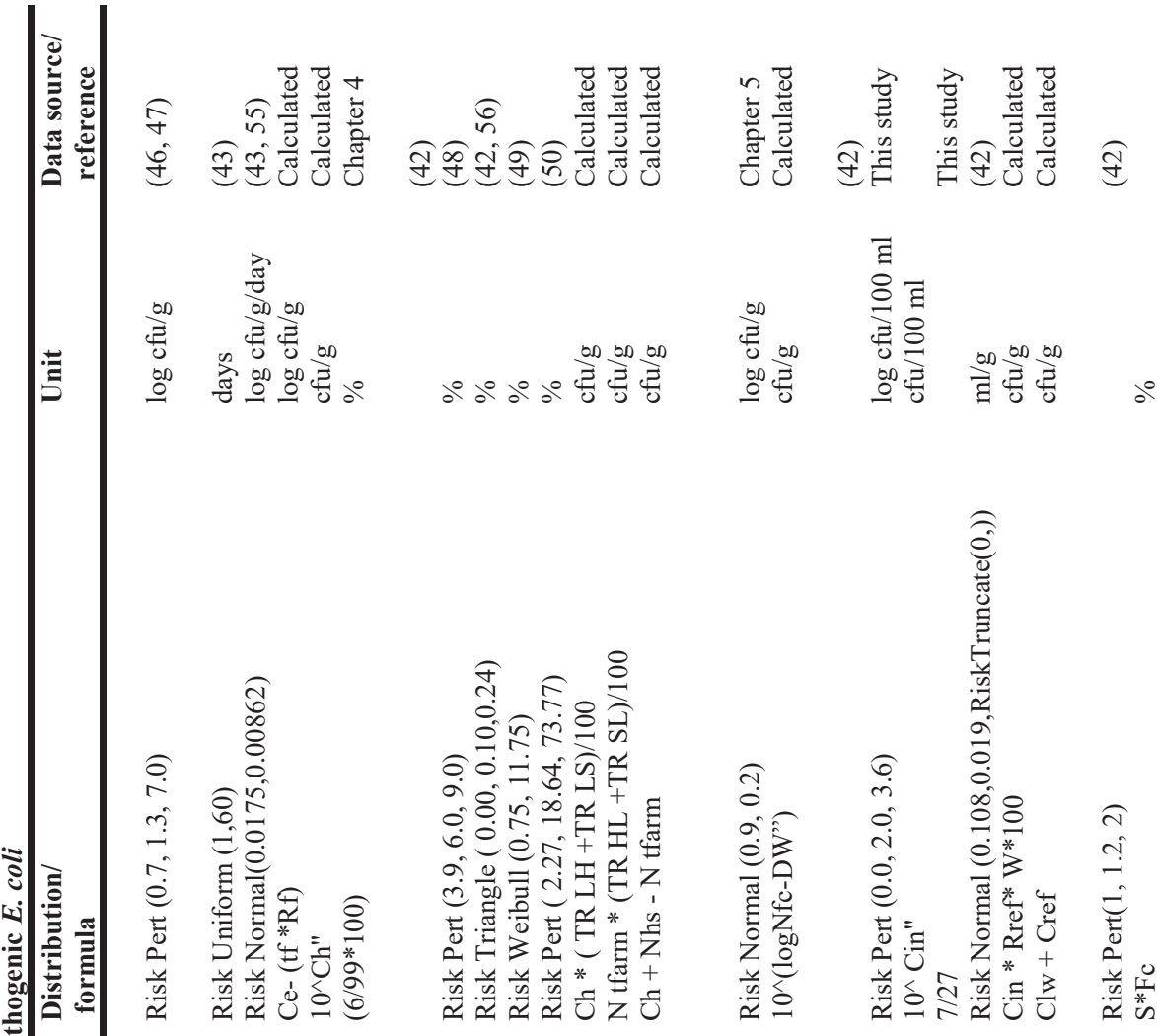

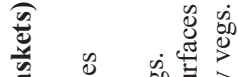

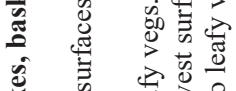

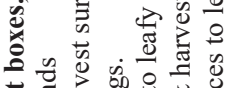
ज्ञ 워월

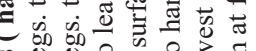
$0 \%$

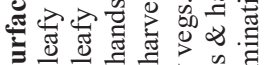

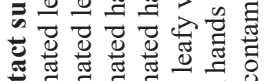

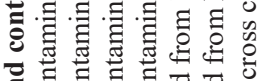

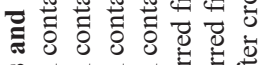

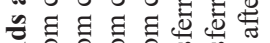

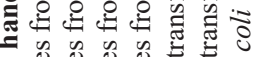

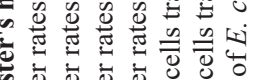

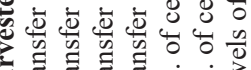

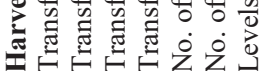

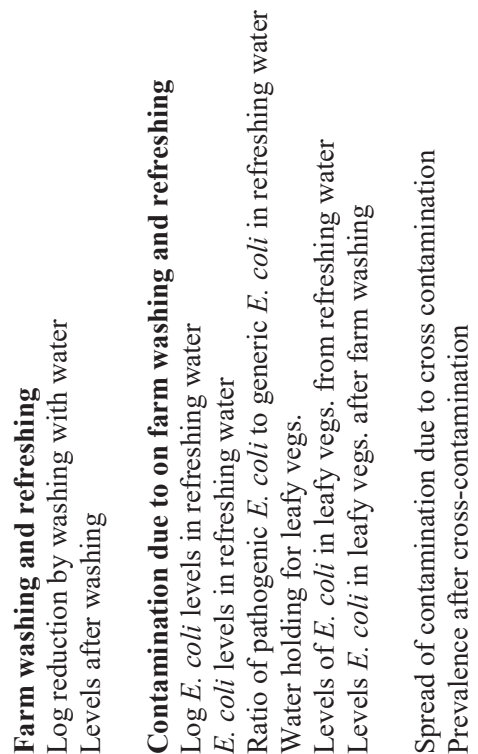

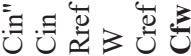
u 


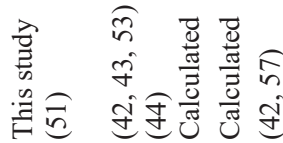

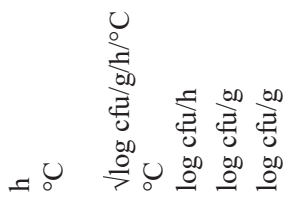

ช

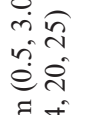

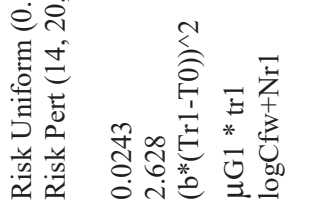

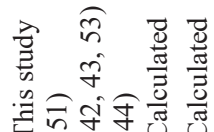

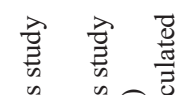

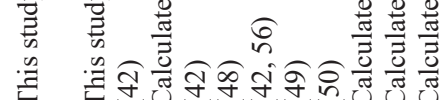

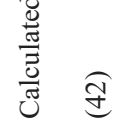

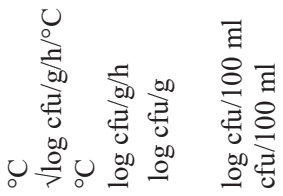

हो $\sum_{0}^{\infty}$

50
$\sum_{0}^{5}$
80
0

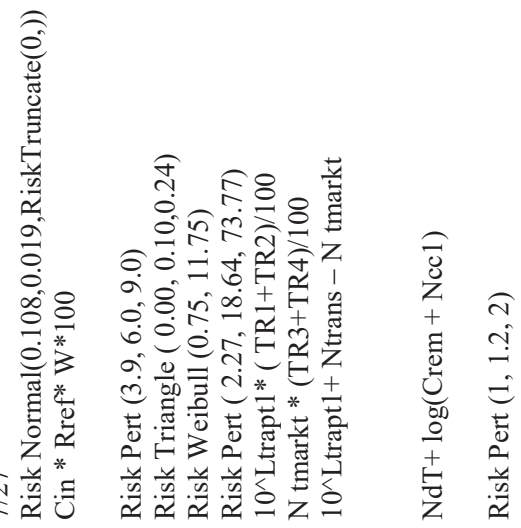

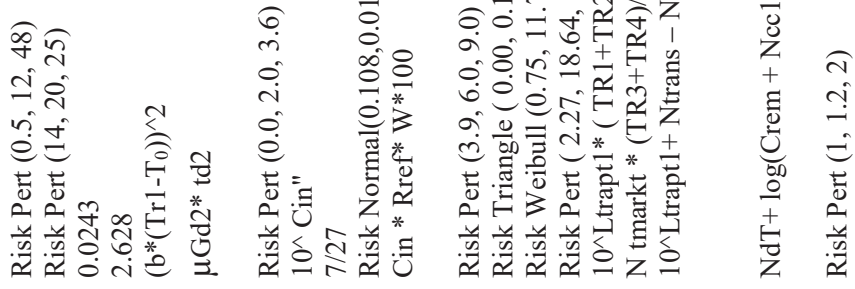

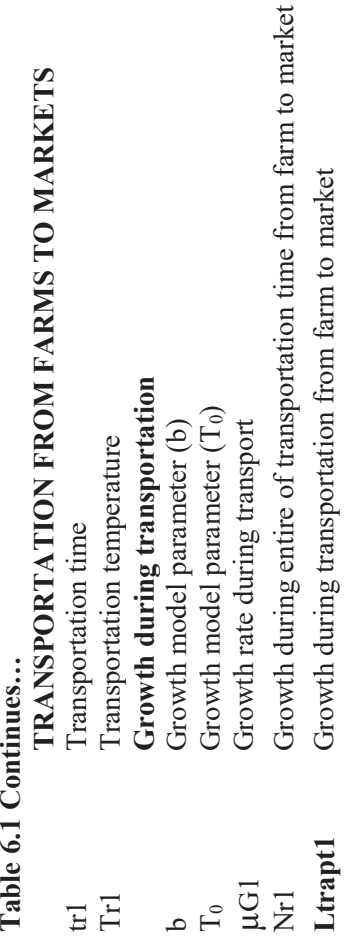

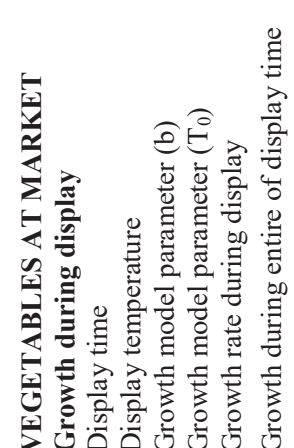

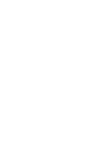

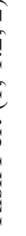




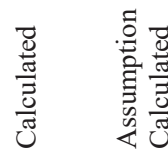

an an

랑 랑

요응

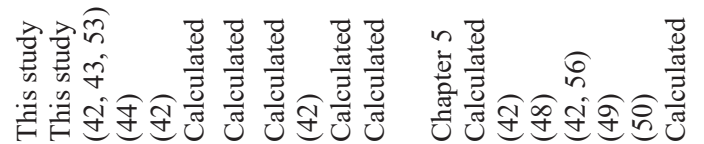

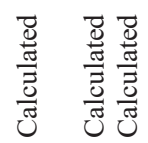

Iิ

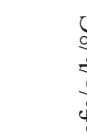

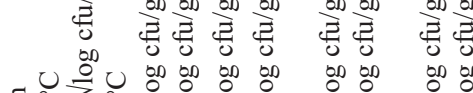

do ådo

a
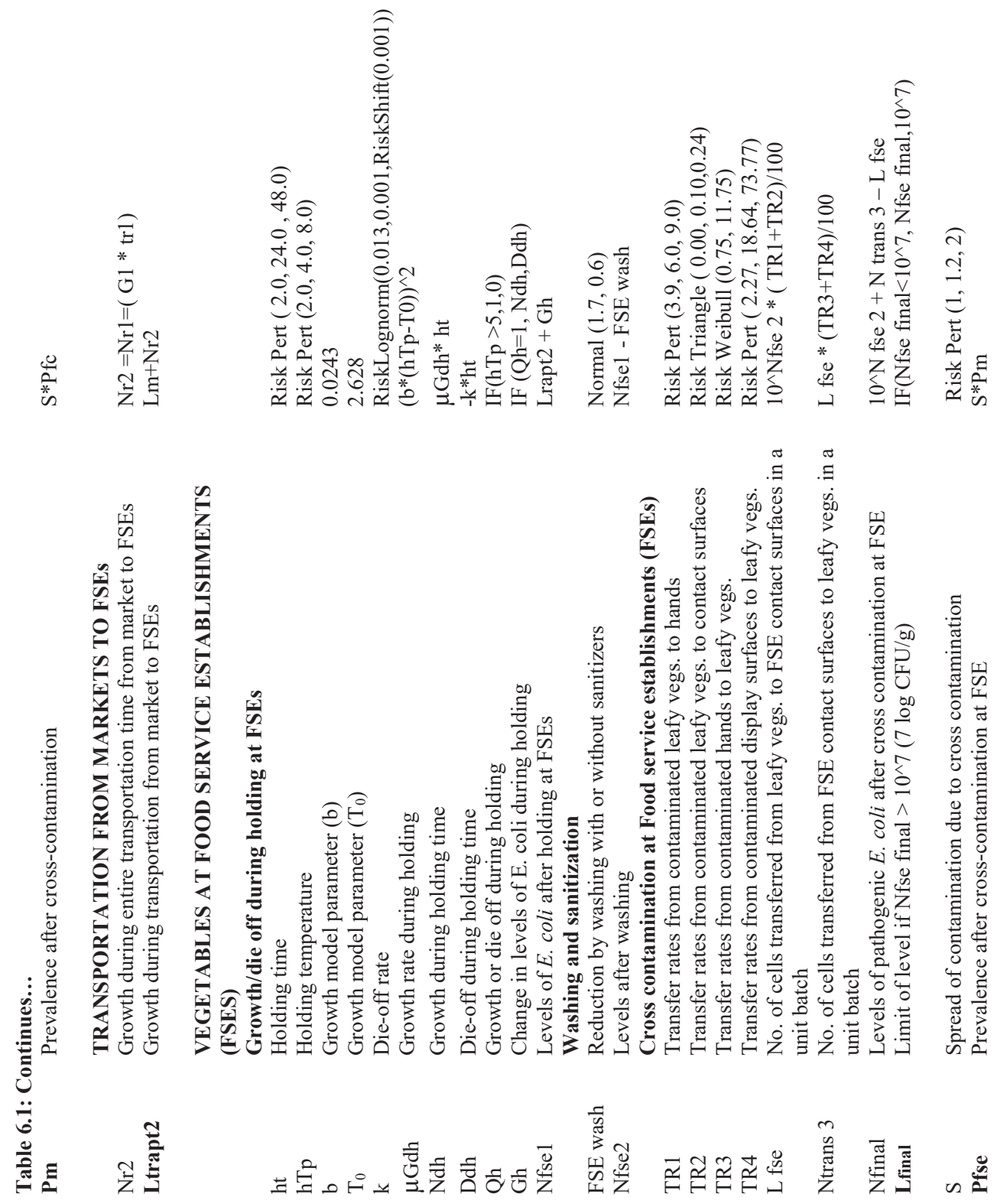


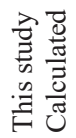

ชิ

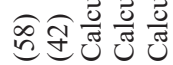

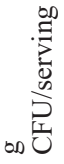<smiles>C1CCC(C2CCCCC2)CC1</smiles>

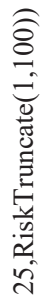

$\stackrel{2}{5}$

苛

点

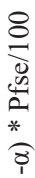

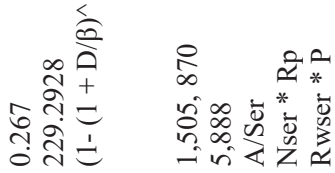

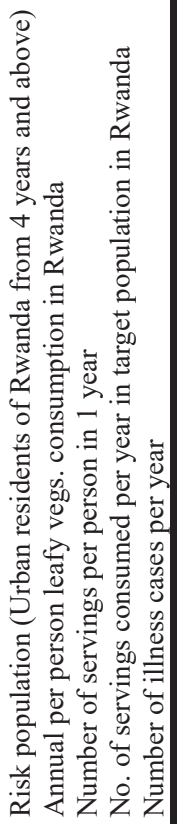




\section{Dose-response relationship and risk characterization}

A serving size of 50 to $100 \mathrm{~g}$ per person was used in the QMRA based on observation from the field study with FSEs (This study). The serving size was described by a Risk Normal distribution with average set at $75 \mathrm{~g}$ and truncated at 1 and 100 to minimize extremely low and high estimate outcomes. To obtain the number of pathogenic E. coli cells ingested per contaminated serving of leafy vegetables, the levels of pathogenic E. coli after FSEs salad preparation was multiplied by the serving size (42). The dose response model used in this study (Equation 4) was according to previous related studies $(42,44)$ which were based on E. coli O157:H7 strain behavior in leafy vegetables. This study assumed that all pathogenic E. coli strains behaved like E. coli O157:H7 on leafy vegetables.

$P=1-(1+D / \beta)^{\alpha}$ Eq. 4

where $P$ is the probability of illness per contaminated serving, $D$ is the number of organisms ingested per contaminated serving, $\alpha$ and $\beta$ are model parameters.

Annual per capita estimates for lettuce consumption in the United States of 5,888g used by Pang et al. (42) were adopted for this study. In Rwanda, the majority of the work force especially in urban centers have meals in FSEs (canteens, restaurants and hotels) during the day. It was assumed that salad serving is mainly concentrated in urban centers in Rwanda, so the urban population of Rwanda (58) for age of 4 and above were used in the calculations of the annual number of servings consumed per year. Children below 4 years of age were most likely assumed not be served with salads at FSEs. All further calculations for hazard and risk characterization are presented in Table 6.1.

\section{Intervention strategies (What if scenarios)}

In the previous sections of this QMRA study, modules were developed based on the description of conditions in which over $90 \%$ of the fresh vegetables go through along the supply chain and herein referred to as the baseline model or route 1 . Based on the pre-harvest and postharvest factors as described in previous studies $(28,29)$, intervention strategies (what if scenarios) summarized in Table 6.2 were assumed so as to observe the fold changes in the predicated risk (estimated probability of illness and number of illnesses) compared to the baseline model. 


\section{Table 6.2: Summary of measures and intervention (what if scenarios) as alternatives to the base line model}

\begin{tabular}{ll}
\hline No. & What if scenarios \\
\hline 1 & Modifying supply chain (Route 2) \\
2 & Modifying supply chain (Route 3) \\
3 & $\begin{array}{l}\text { Modifying supply chain (Introduction of } \\
\text { cold chain) }\end{array}$
\end{tabular}

Assumption

All vegetables are channelled straight from farms to food service establishments (FSEs) without going through markets

All vegetables are channelled from farms via supermarkets (built closed markets with specialized refrigeration systems) to food service establishments (FSEs)

All vegetables are kept under refrigeration temperatures $(2$ and $8^{\circ} \mathrm{C}$ ) from "farm to fork". Introduction of a die off model (Eq. 3)

$4 \quad$ Improving washing and sanitization at FSEs

All vegetables are effectively washed and sanitized. A $3 \pm 0.5$ $\log$ reduction was used in the simulation compared to $1.7 \pm 0.6$ $\log$ reduction applied in the baseline model (Chapter 5 of this thesis).

$5 \quad$ Avoiding cross contamination along the supply chain

Assuming no contamination and cross contamination between vegetables and other surfaces at farm harvest, market, and at FSEs.

6 Farm interventions

Assuming that preventive measures and interventions (29) are implemented at farm level to reduce prevalence and levels of pathogenic $E$. coli in the base line model by $90 \%$.

$7 \quad$ Farm to fork measures and interventions

Assuming that the scenarios 4, 5, 6 are combined.

\section{Risk estimates}

From the baseline model (represents over $90 \%$ of the current vegetable supply chain), the number of cases per year and the probability of illness per serving of leafy vegetables contaminated pathogenic $E$. coli were estimated with a mode of 12.1 million and 0.1 respectively. Compared to risk estimates from previous studies (Tab. 6.3), the estimates of the probability of illness per serving in this study were high. In Colombia, the probability of illness was set at a propounded benchmark $10^{-4}$ per year for Salmonella ssp. with lettuce, cabbage and broccoli (60). However it should be acknowledged that these estimates include mild illness from less harmful pathotypes of pathogenic E. coli viz. enterotoxigenic E. coli (ETEC) and enteropathogenic E. coli (59). The estimates in this study were in close range with estimates from countries with settings similar to Rwanda for other pathogens ie. Ghana (for Norovirus) and Colombia (for Salmonella spp.) (Tab 6.3). 
Table 6.3: Comparison of the estimates for the probability of illness per serving of fresh vegetables due to various foodborne pathogens in different countries

\begin{tabular}{llll}
\hline Foodborne pathogen & $\begin{array}{l}\text { Average probability of } \\
\text { illness per serving }\end{array}$ & Country & Reference \\
\hline Pathogenic E. coli & $1.0 \times 10^{-1}$ & Rwanda & This study \\
Norovirus & $8.6 \times 10^{-1}$ & Ghana & $(61)$ \\
E. coli O157: $\mathrm{H} 7$ & $9.87 \times 10^{-8}$ & USA & $(42)$ \\
Salmonella spp. & $7.4 \times 10^{-1}$ & Colombia & $(60)$ \\
Norovirus & $3 \times 10^{-4}$ & EU & $(62)$ \\
Hepatitis A & $3 \times 10^{-8}$ & EU & $(62)$ \\
Salmonella spp. & $1.9 \times 10^{-4^{*}}$ & Brazil & $(63)$ \\
L. monocytogenes & $2.7 \times 10^{-7^{*}}$ & Brazil & $(63)$ \\
L. monocytogenes & $1.42 \times 10^{-7}$ & Korea & $(45)$ \\
E. coli O157: H7 & $6.04 \times 10^{-6}$ & Netherlands & $(64)$ \\
Salmonella spp. & $6.83 \times 10^{-6}$ & Netherlands & $(64)$ \\
L. monocytogenes & $1.23 \times 10^{-8}$ & Netherlands & $(64)$ \\
\hline
\end{tabular}

*Estimates of probability of illnesses adjusted to per serving

Figure 6.3 and Table 6.4 summarise the results of the QMRA conducted in this study, while further graphs are provided as supplementary material (risk assessments outputs). 

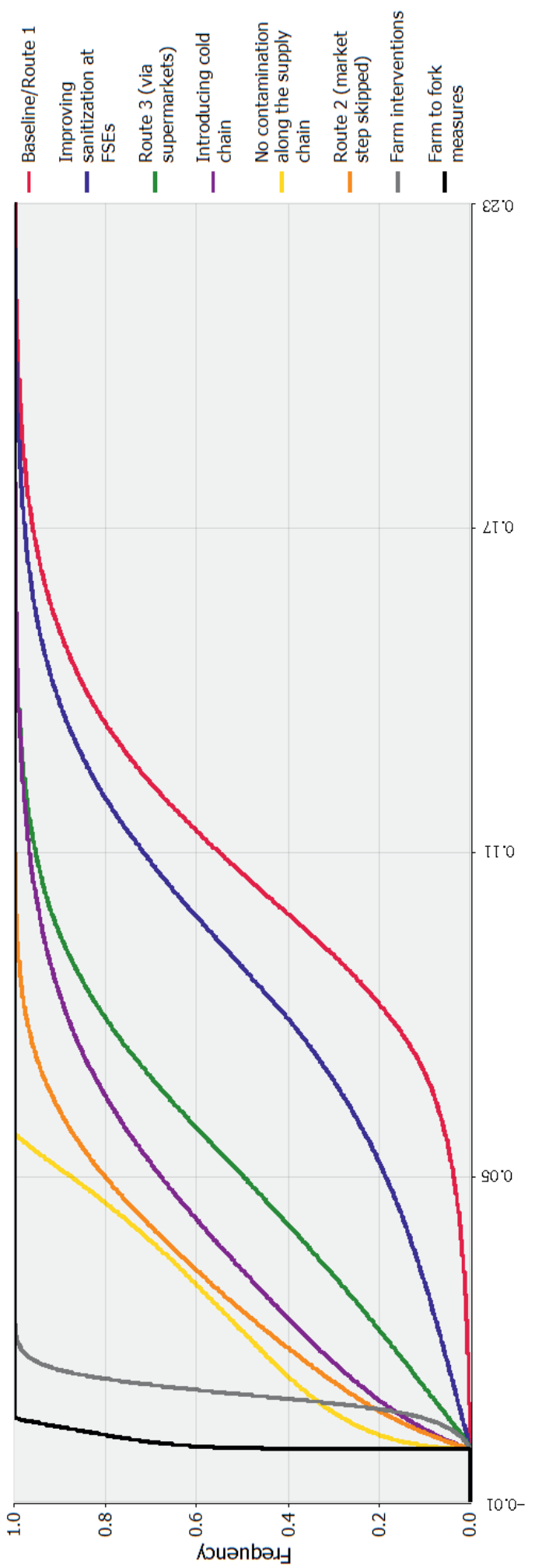

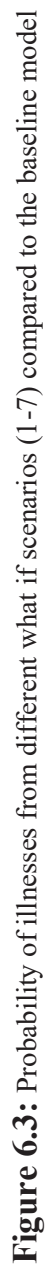




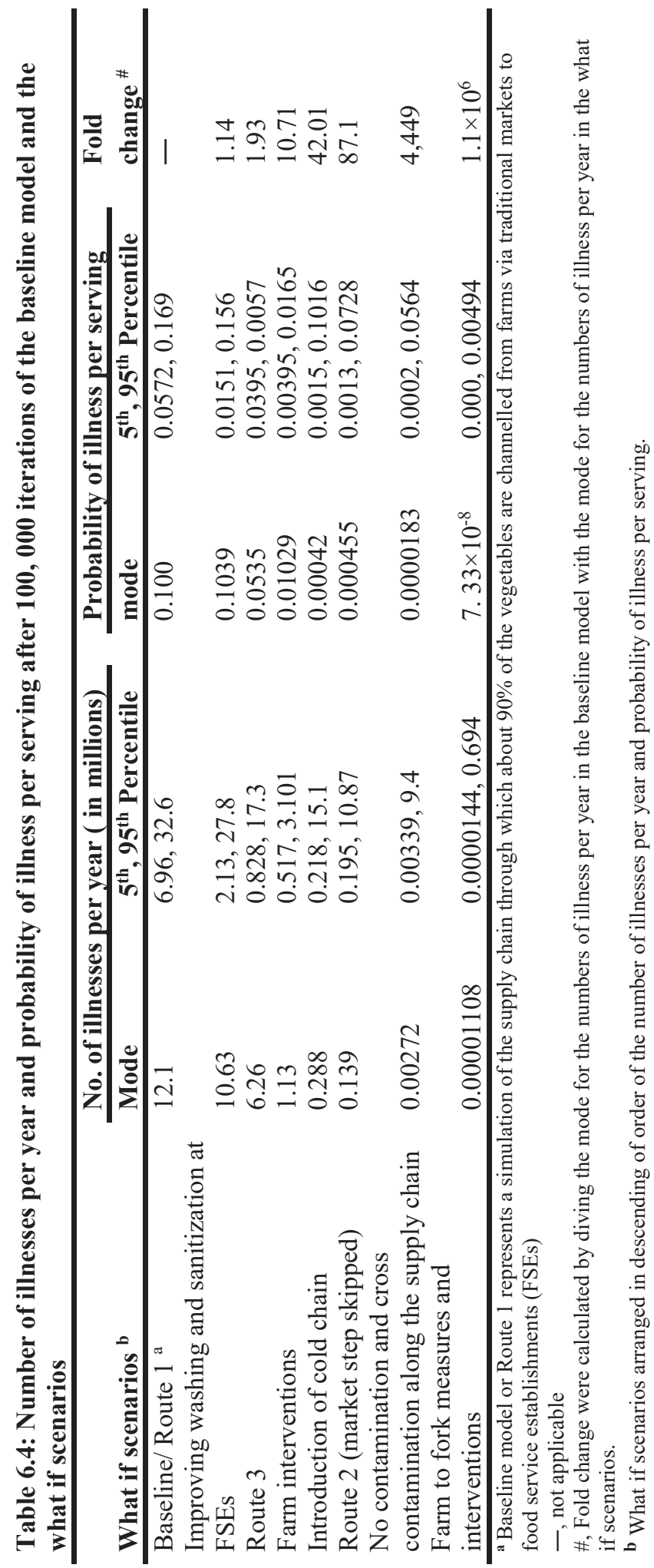


Compared to the baseline model, simulation of the 7 what if scenarios resulted to varying fold changes in the predicted microbial risk (Tab. 6.4). The what if scenario of improving washing and sanitization at FSEs resulted to a less than 2 fold change in the predicted microbial risk. While a twofold change was observed for the what if scenario of channelling all vegetables through supermarkets instead of traditional markets. Farms interventions to reduce the prevalence and levels of pathogenic E. coli in the base line model by $90 \%$, introducing a cold chain and skipping the market step (Route 2) resulted to a tenfold reduction in predicted microbial risk. The what if scenario of reducing of avoiding contamination and cross contamination along the supply chain led to 1000 fold reduction in the predicted microbial risk. Lastly, combing what if scenarios 4, 5, 6 in Tab. 6.2 (farm to fork measures) resulted to the highest fold reduction of 1 million.

\section{Food safety management options}

Risk estimates should be analyzed and weighted in order to prioritize risk management measures and interventions, not only for their effectiveness in improving public health, but also for their feasibility and affordability. From the predicted risk results of this QMRA study, approaches to change the type of supply chain in Rwanda may not be given priority by risk managers except for the scenario of skipping the market step so that FSEs get vegetables straight from farms. It can be observed from this study that changing the supply chain by introducing a cold chain or refrigeration at market (supermarkets) may not address the microbial risk associated with fresh vegetables. Instead, risk managers can focus on addressing the factor leading to contamination and cross contamination from "farm to fork". In Chapter 3, it was reported that the washing and sanitization of salad vegetables at FSEs was the only step along the supply chain where significant inactivation of indicator organisms was observed. From this QMRA study and Chapter 5, it has been demonstrated this sanitization step alone cannot be enough to address microbial safety concerns. Consequently, risk assessors and risk manager should identify all the possible sources of microbial hazards along the entire supply chain and device measures and interventions to address them and spearhead risk communication strategies among stakeholders.

\section{Aspects for risk communication along the vegetable supply chain}

\section{Farm level}

Several factors such as irrigation water (65), organic manure (66), domestic and wild animal (35) and human activity have been documented among the factors that can expose fresh vegetables to microbial risk at farm level in various studies $(28,29)$, the WHO $(30)$ and the FAO $(27,67,68)$. In Chapter 4 of this thesis, risky farming practices were observed in addition to detection foodborne pathogens in farm vegetables and their DNA markers in agricultural water. Moreover the findings in Chapter 3 with indicator microorganisms suggest that the microbial levels at farm level greatly influence the microbial levels in ready-to-vegetables at FSEs. In the QMRA study, applying farm measures and interventions targeting reduction of the factors of spread and contamination by $90 \%$, resulted to a tenfold decrease in the estimates of the number of illnesses per year due to pathogenic E. coli. 
It is therefore important for stakeholders to implement guidelines that have been reported to be effective and efficient in preventing microbial hazards at farm level. Various countries such as Ireland (69) and United States (70) have developed guidelines while internationally, the WHO (30) and the FAO $(27,67,68)$ have continued to provide mitigation measures in addressing the microbial hazards associated with farm vegetables. For each microbial risk exposure factor, mitigation measures have been provided. For example, compost manure can only be used after passive and or active treatment (67), agricultural water has to be protected from contamination (68), domestic and wild animals have to be restricted from accessing the vegetable farms (27, 30). Ways of controlling the possible microbial contamination from vegetable harvest equipment, containers and storage facilities have also been provided (30). Because majority of the vegetable farmers in Rwanda are small scale, competent authorities should take a lead in:

* Developing microbial safety standards and guidelines for agricultural water, soils and manure,

* Enforcing farm hygiene policies and provide training in sanitation to all farmers,

* Registering vegetable farmers for targeted extension services and identifying farming areas to enable traceability in case of aggravated field microbial contamination,

* Assessing the vulnerability of agricultural water to microbial contamination to ascertain the suitability of water for the intended use,

* Conducting continuous field research to understand the trends in pathogens by seasons or the factors leading to their variation,

* Dissemination of information about microbial safety of vegetables at farm level.

\section{Vegetable markets}

In Chapter 3, it was reported that counts of indicator microorganisms increased slightly $(<1.0$ $\log \mathrm{cfu} / \mathrm{g}$ ) at market compared to the counts at farm level. In the QMRA study skipping the market resulted to 100 fold decrease in the microbial risk, indicating that this step also presents a major avenue for the contamination of fresh vegetables. To address the possible microbial safety concerns, it is important to implement GHPs aimed at hygiene of vendors and market infrastructure. Avoiding cross contamination from other food items especially those of animal origin. Measures to keep dust and flies away from open markets, wash fresh vegetables with potable water, are all essential to improve the microbial safety of fresh vegetables at market level

\section{Food service establishments (FSEs) level}

In this study, it has been reported in Chapter 3 and Chapter 5 that FSE is the only current step where washing and sanitization of salad vegetables is done in addition to preparation steps (Fig. 6A.1 in the Appendix). Whereas it was reported in Chapter 3 that there was a significant reduction in microbial counts of indicators microorganisms at FSEs, the salad preparation processes varied greatly from one FSEs to another (Chapter 5). Major issues of concern to the microbial safety of salad vegetables were, the type and conditions of sanitization application (Chapter 5); microbial quality of vegetable wash water, cross- contamination and contamination of salad vegetables from kitchen surfaces. To prevent and control microbial safety problems 
that can occur during salad preparation at FSEs, existing international $(71,72)$ and countries guidelines (73) can be adopted.

In the QMRA study, improving washing and sanitization at FSEs by assuming that vegetables were effectively washed and sanitized $(3 \pm 0.5 \log$ reduction) resulted 1 fold decrease in the number of illnesses per year. However, the $3 \mathrm{log}$ reduction during washing and sanitization was only achieved by less than $2 \%$ of the visited FSEs. In chapter 5 , potassium permanganate $\left(\mathrm{KMnO}_{4}\right)$ was reported to be the most applied sanitizer yet field and laboratory studies showed that it resulted in the lowest microbial inactivation during salad vegetable washing. Chapter 5 also presents further recommendations which can be adopted during washing and sanitization of fresh vegetables. For example, a contact time of $5 \mathrm{~min}$ and salad-sanitizer ratio of 1: 20 were considered optimal for kitchen based washing of the studied leafy vegetables using Sodium dichloroisocyanurate $(\mathrm{NaDCC})$ and Sodium hypochlorite $(\mathrm{NaClO})$ sanitizers. Therefore, competent authorities should develop a policy on the use of sanitizers and a guideline for kitchen based preparation of vegetables salads.

Competent authorities should also develop regulation for the design of kitchens in FSEs so that they can comply to the minimum standards during construction and installation. These standards and regulations will help in implementing measures to prevent cross contamination. For example there should be a sufficient kitchen size to allow space for a separate salad preparation area for the area were other food items like meat and fish are prepared.

\section{Conclusion and future perspective}

In Chapter 2 of this thesis, the estimates of the burden of illnesses from food-related pathogens are presented and these estimates indicate the potential threat associated with foodborne illnesses in Rwanda, as was reported in other parts of the Globe (13, 18, 74-76). Different food sources can be responsible for these burden estimates $(21,23,24,77)$ but this study focused on the potential contribution of microbial hazards associated with fresh vegetables. It has been reported in Chapter 3 that there was an upward trend in pathogens' indicator microorganisms for fresh vegetables from farm to FSEs. Moreover zoonotic foodborne pathogens were detected in farm vegetables at a prevalence of 15/99 (Chapter 4) in addition to the detection of pathogen DNA markers in agricultural water some of which are known to be highly virulent. Investigations of pre-harvest (Chapter 4) and postharvest (Chapter 5) sources of microbial hazards along the vegetable supply chain reveal a lapse in implementing GAPs and GHPs. Also in Chapter 3, we indicated that of the three main stages of the vegetable supply chain, farm, market and FSEs, measures and interventions to prevent microbial threats are concentrated at FSEs during washing and sanitization. In Chapter 5, however, it has was demonstrated through field and laboratory trials that the settings, conditions and efficacy of washing and sanitization at FSEs remain contentious. Following our findings in this study and the continued global reports $(27)$ and studies $(25,26,78)$ about the potential threat posed by microbial hazards in fresh vegetables, it is inevitable that every country should put in place measures and intervention towards the assurance of microbial safety of fresh vegetables.

To attain microbial safety of vegetables eaten raw, the sources and factors that introduce human pathogens into fresh vegetables in the "farm to fork" continuum have to be identified and 
targeted for preventive measures and interventions. In Chapter 1, the pre-harvest and postharvest sources of human pathogens in fresh vegetables were discussed. What is characteristic with these sources of human pathogens along the vegetable supply chain is that they can all be traced back to the complex interconnectedness between plants, animals, humans, and their ecosystem. Consequently, microbial safety of fresh vegetables cannot be isolated from public and animal health. Zoonotic human pathogens crossover from domestic and wild animals to fresh vegetables via direct contact, fecal droppings, manure and biosolids, sewage, irrigation and other pathways and establish a new niche with epiphytic microorganisms. There is therefore a need for strategic approaches to manage these pathogens in terms of drivers and sources, factors of spread and persistence, and biology in different systems. One of the suggested approaches so far include the "Global One Health" (GOH) (79), proposed by a group of researchers at Wageningen university (Fig. 6.18) and the Manhattan Principles on "One World One Health" (OWOH) (80).

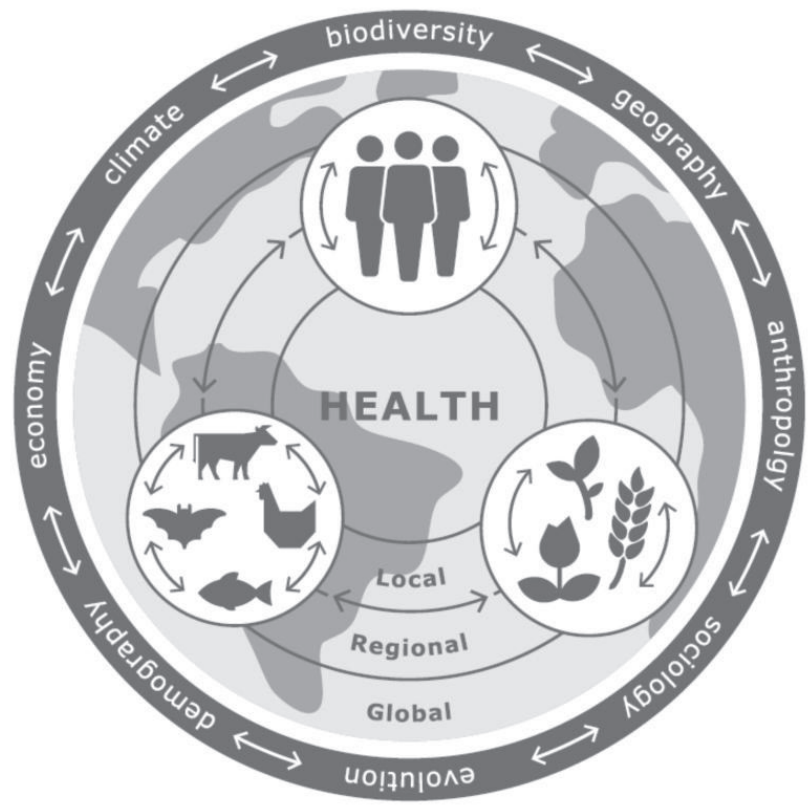

Figure 6.4: Determinants of Global One Health and their interactions [ source: Fresco et al. 2015 (79)].

The GOH and the $\mathrm{OWOH}$ approaches both propose the need for combined multidisciplinary efforts to improve the health of humans, animals and plants within sustainable ecosystems at global level by using an integrated system to come to transnational and global policy, research and practices $(79,80)$. As shown in Figure 6.4, the determinants of GOH interconnect; the animal, plant and human interfaces are intra and extra linked and offsets at any level/factor, can trigger a cascade of effects that can lead to highly undesirable health situations at local, regional, continental and global scale (79). For example, due to excessive use of antibiotics in livestock, antibiotic resistant human zoonotic pathogens have been introduced in the environment some of which can now be traced in fresh vegetables. The encroachment on forest reserves have 
increased the wandering of wildlife into farming areas and as a consequence zoonotic pathogens contaminate crops and irrigation water. It is global because the world is now a small village, trade in fresh vegetables is international, travels have increased and tourism is a major economic activity, vegetables salads are now very popular part of the menu in hotels and in households especially in family celebrations. One meal with vegetable salads if contaminated has high probability of causing illnesses to many people at once.

To achieve Global One Health $(\mathrm{GOH})$ and move towards microbial safety, there is need for political awareness and international agreements to bring together governments, the private sector, researchers and educationists at both at national and international level to develop an integrated system. Key areas for these actors include trade, health, agriculture, environment, water management and rural development. This integrated system should aim at early warning, monitoring, risk management and prevention of diseases at all stages of the vegetable supply chain and the entire ecosystem. Key activities include:

* understanding the role of biodiversity in maintaining healthy environments and the functioning of ecosystems;

* determining the impact of land and water use in aiding the shifts in patterns of pathogens;

* conducting wild health surveillance and management;

* linking public health management to environmental conservation;

* developing new tools for diagnosis, estimating the burden- and prevention of foodborne pathogens;

* solving institutional complexities and variability to identify synergies and areas of overlap and stimulate institutional collaboration.

Currently in Rwanda, there is a need to establish or mandate an existing institution to coordinate all public and private stake holders in matters relating to this integrated food chain system. Education and awareness raising of stakeholders towards influencing socialeconomic/cultural practices i.e. there are many challenges that will require a major shift in what is considered normal to the culture in Rwanda. The culture of animal moving freely in farms and sharing water with irrigation sources and wash water, hygiene in farms, the culture of washing vegetables with surface and tap water yet people know that this water is not safe for drinking, adjusting land tenure systems and settlements.

In conclusion, the study involved detecting foodborne pathogens and an investigation of the handling practises and risk exposure factors. Indicator microorganisms were detected from "farm to fork" and their counts can be used as signal for possible contamination at a given level of the supply chain for urgent interventions. The food safety information generated from any food chain should be relevant to food safety policy makers in developing evidence based policies. In this study, a methodology to estimate the burden of foodborne illness was proposed in Chapter 2 besides the QMRA study in this Chapter. This study focused on bacterial foodborne pathogens commonly implicated in outbreaks attributed to fresh vegetables. Future studies should focus on parasites and viruses and how handling practices affect their prevalence and levels from farm to fork. Further work remains to be done regarding bacterial pathogens such as the current global concerns of the raising trends in antibiotic resistance. Over all the 
approach used in this study can be adopted as a research framework for the integrated food chain system to detect control and prevent foodborne illnesses along the fresh vegetables supply chain and other food supply chains. 
Appendix 


\section{Further details on Hazard identification: Pathogenic E. coli}

In public health, pathogenic E. coli are among the major agents contributing to the global burden of disease. In 2010, the WHO estimates show that pathogenic E. coli (ETEC, EPEC and STEC) resulted to about 110 million illnesses, 60,000 deaths and 5 million DALYs (13). Epidemiologically, ETEC has been highlighted among and the main causes of traveller's diarrhea and diarrhea in children under 5 years of age in developing countries $(81,82)$ and also listed among foodborne pathogens associated with raw vegetables (83) and other unsafely prepared foods. In a review of leafy vegetables associated outbreaks between 1973 and 2012, the Centres for Disease Control and Prevention (CDC) reported that in the United States, EHEC was the leading cause of leafy vegetable outbreaks with a confirmed aetiology (84). In 2011, there was a large outbreak (total of 3816 cases, including 54 deaths) in Germany characterized by haemolytic-uremic syndrome (HUS) and bloody diarrhea caused by EHEC O104: H4 with the food vehicle being sprouts (85). A number of recent multistate outbreaks in the USA associated with fresh vegetables includes the outbreak linked to organic spinach and spring mix blend in which 33 person were infected and two persons suffered from HUS (86) and another outbreak of E. coli O157:H7 infections linked to alfalfa sprouts reported by the CDC in March 2016 during which eleven people were infected and two hospitalized (87). In 2007, there was a shiga toxin-producing E. coli (STEC) outbreak in The Netherlands and Iceland linked to contaminated lettuce, shredded and pre-packed in a Dutch food processing plant (88), and a lettuce outbreak in Sweden in 2005 (89). Furthermore, in July 2016, the WHO was notified about the E. coli O157: H7 outbreaks related to mixed leafy salads in United Kingdom where 105 patients were confirmed, four patients were hospitalized and two deaths (90).

Escherichia coli are Gram negative, facultative anaerobic bacteria of the family Enterobacteriaceae, commonly associated with the intestinal micro flora of humans and other warm blooded animals. Most E. coli are harmless, however in immunosuppressed individuals or when gastrointestinal barriers are disrupted, even non-pathogenic strains can cause infection $(59,91)$. The infection due to pathogenic $E$. coli are generally classified into three syndromes; urinary tract infection, sepsis/meningitis, and enteric/diarrheal disease (59). Pathogenic E. coli strains can be identified in several ways. Most commonly, E. coli are serotyped on the basis of their O (somatic), $\mathrm{H}$ (flagellar), and $\mathrm{K}$ (capsular) surface antigen profiles, for example E. coli O157: H7 (59) or according to their virulence properties, mechanisms of pathogenicity, clinical syndrome and or antigenic characteristics for which the six pathotypes of E. coli have been categorized. In these six pathotypes, E. coli are further classified into enterotoxigenic E. coli (ETEC), enteropathogenic E. coli (EPEC), enterohemorrhagic E. coli (EHEC), enteroaggregative E. coli (EAEC), enteroinvasive E. coli (EIEC) and diffusely adherent $E$. coli (DAEC) (59). The strategy of infection for these $E$. coli pathotypes is similar to that of other mucosal pathogens i.e. colonization of a mucosal site, evasion of host defences, multiplication, and host damage (59). Specifically, diarrhea as one of the major illnesses due to pathogenic E. coli, is caused through enterotoxin production (ETEC and EAEC), invasion (EIEC), and intimate adherence with membrane signalling (EPEC and EHEC), although the pathogen-host interaction is quintessential of each pathotype. 


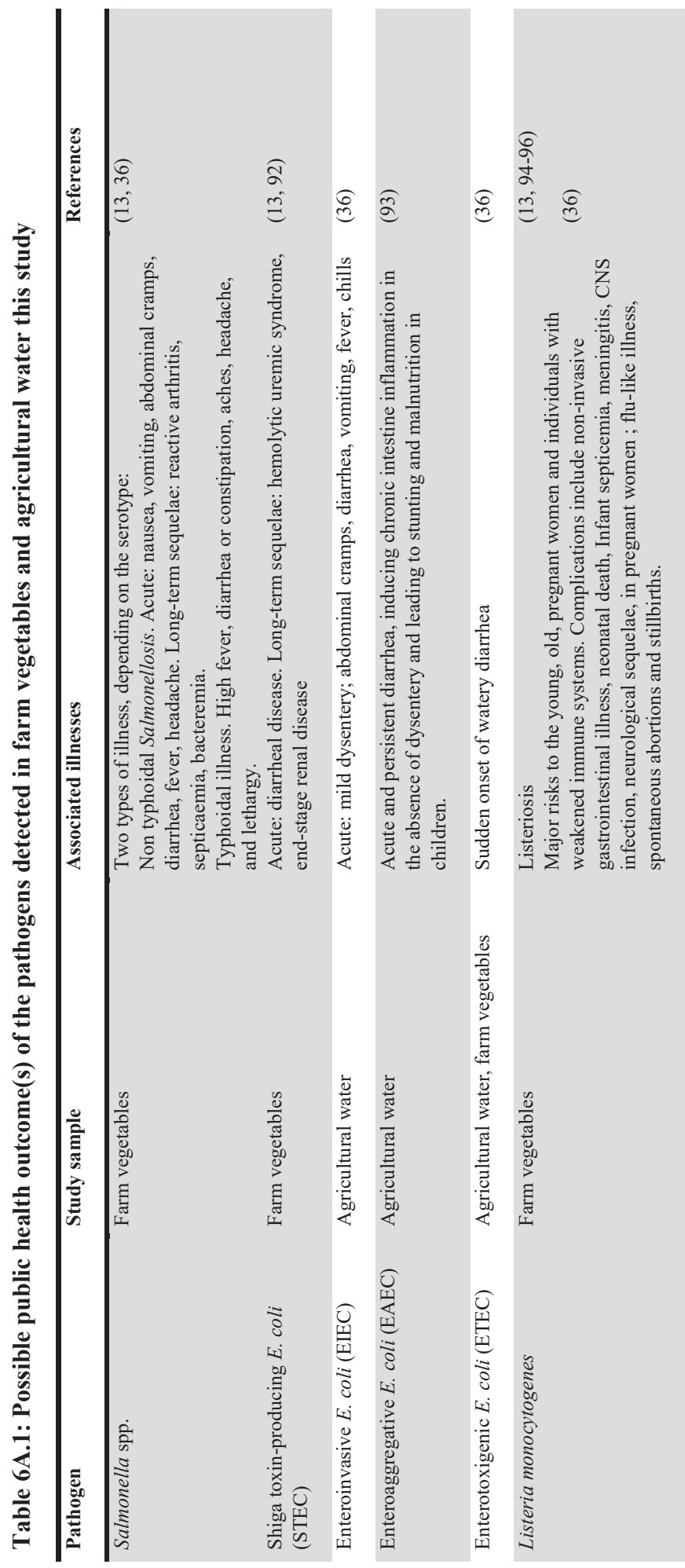




$$
\mathbb{\|}
$$




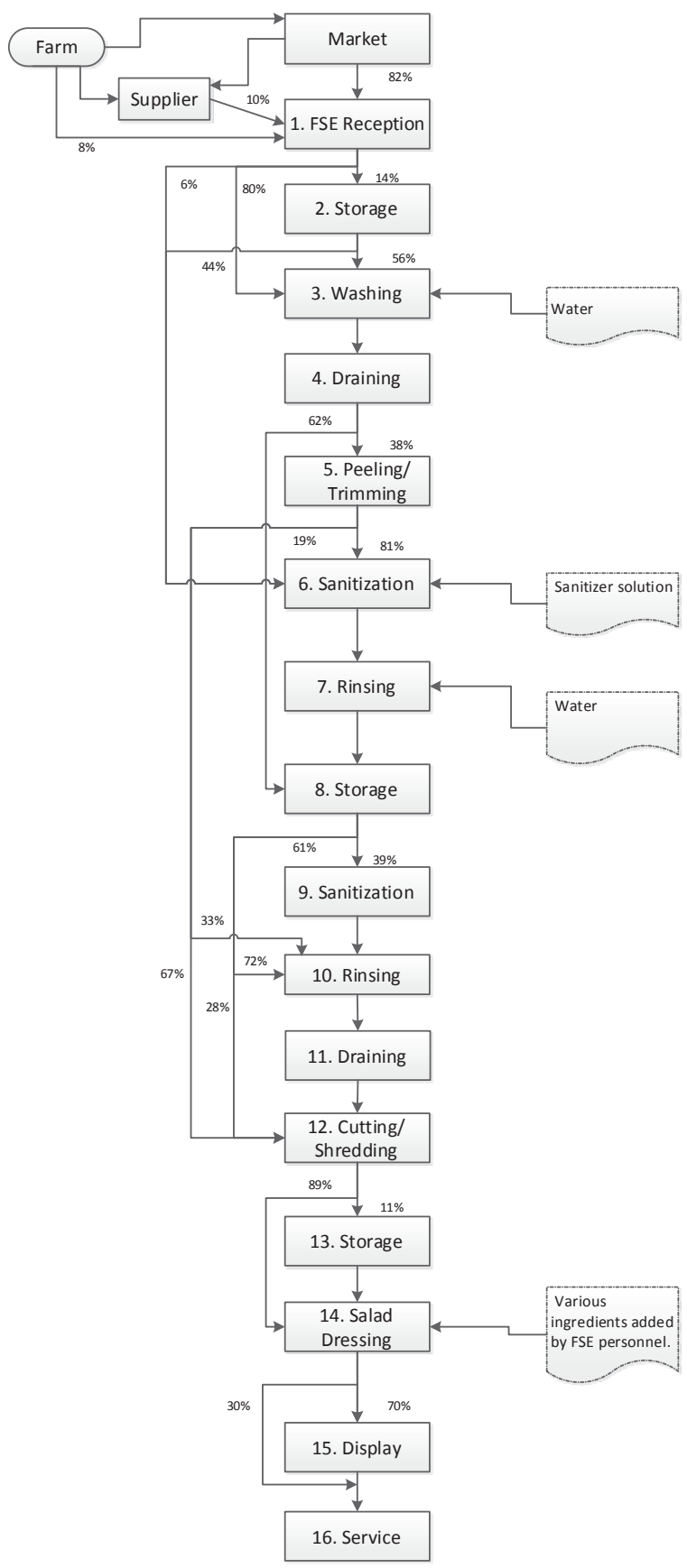

Figure 6A.1: Flow diagram for salad preparation in Food Service Establishments (FSEs). Percentages indicate the proportion of FSEs which practise a specific process- step or route. 


\section{Stakeholders' roles to address microbial safety issues along the fresh vegetable the supply chain}

In this section, some important activities for a typical integrated food chain system are suggested with focus on the vegetable supply chain.

\section{At farm level}

* Registration of vegetable farmers for targeted extension services, identifying farming areas to enable traceability in case of aggravated field microbial contamination.

* Assessment of proposed vegetables growing area for possible microbial hazards by looking at the topography, climate and geology.

* Assessing the vulnerability of agricultural water to microbial contamination to ascertain the suitability of water for the intended use.

* Developing microbial standards and guidelines for agricultural water, soils and manure

* Conducting corrective action activities to address soil and water microbial contamination

* Ensuring that on-farm washing and rinsing of vegetables is done hygienically.

* Ensuring farmers health and growing field sanitation

* Reinforcing GAPs at farm level

* Training of farmers on land preparation, manure use, good irrigation practices, and handling of domestic and wild animals on farms

* Enforcing and initiating measures to restrict access of livestock to the source of crop irrigation water.

* Monitoring vegetable farms for the presence or signs of wild or domestic animals entering the growing area.

* Assessing the microbial quality of water used for irrigation.

* Proper treatment and storage of manure prior to use in the farms to lower the expected level of pathogens

* Conducting microbial analysis of composted manure/treated biosolids.

* Conducting continuous field research to understand the trends in pathogens by seasons or the factors leading to their variation.

* Dissemination of information about microbial safety of vegetables at farm level

At market level

* Infrastructural development including market structures, sanitation facilities, microbiologically safe water and measure to restrict cross contamination.

* Registering of vegetable vendors to enable food safety training programmes and traceability along the supply chain.

* Training of market vendors about food safety.

* Developing and enforcing hygiene standards and guidelines.

* Research and disseminating information about food safety at market.

\section{At food service level}

* Infrastructural development including hygienic design of FSEs, sanitation facilities, microbiologically safe water and measure to restrict cross contamination in kitchens.

* Registering of FSEs to enable food safety training programmes and traceability along the supply chain.

* Training of food handlers about food safety.

* Periodic medical screening of food handlers

* Developing and enforcing hygiene standards and guidelines.

* Research and disseminating information about microbial food safety at FSEs.

\section{At consumer level}

* Conducting consumer studies to understand food consumption trends and behavior. 
* Training the general public about food safety and safe handling of food.

* Educating general population to provide an essential function in the recognizing and reporting of foodborne illness to public health authorities.

* Surveillance of foodborne illnesses in the general population.

* Estimating the burden of foodborne illness and their contribution to overall burden of disease. 


\section{Other risk assessments outputs and graphs}

1. Route 1

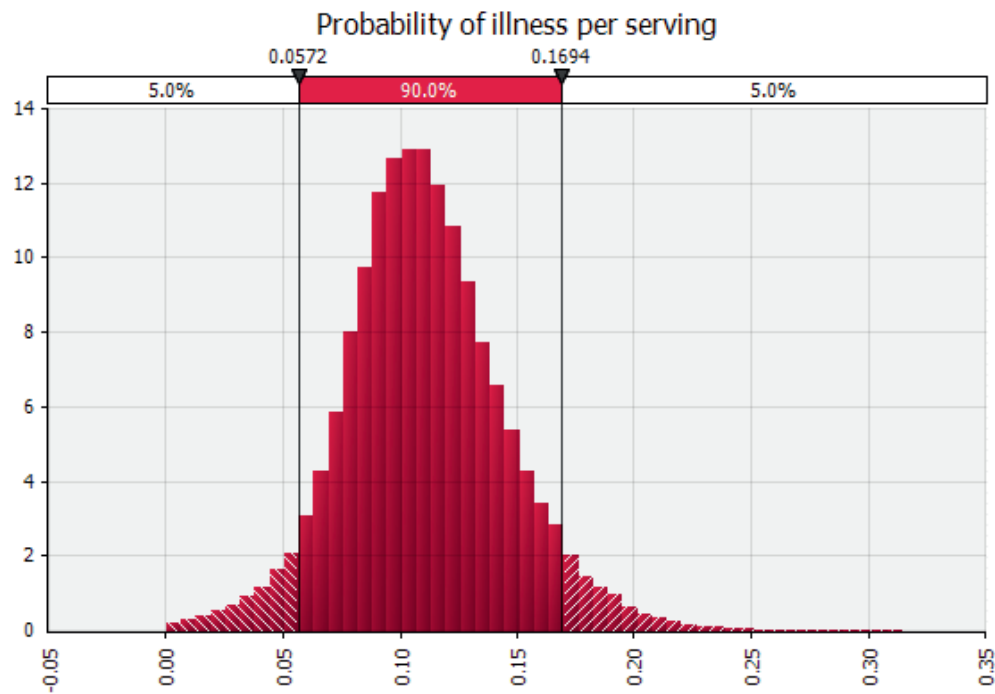

\begin{tabular}{|l|r|}
\hline & $\begin{array}{l}\text { Probability of } \\
\text { illness per serving }\end{array}$ \\
\hline Cell & Route 1 most commo.. \\
\hline Minimum & 0.000233 \\
\hline Maximum & 0.31497 \\
\hline Mean & 0.11063 \\
\hline 90\% CI & \pm 0.000178 \\
\hline Mode & 0.10000 \\
\hline Median & 0.10884 \\
\hline Std Dev & 0.03426 \\
\hline Skewness & 0.2561 \\
\hline Kurtosis & 3.7415 \\
\hline Values & 100000 \\
\hline Errors & 0 \\
\hline Filtered & 0 \\
\hline Left X & 0.0572 \\
\hline Left P & $5.0 \%$ \\
\hline Right X & 0.1694 \\
\hline Right P & $95.0 \%$ \\
\hline Dif. X & 0.11220 \\
\hline Dif. P & $90.0 \%$ \\
\hline .. & ---- \\
\hline
\end{tabular}

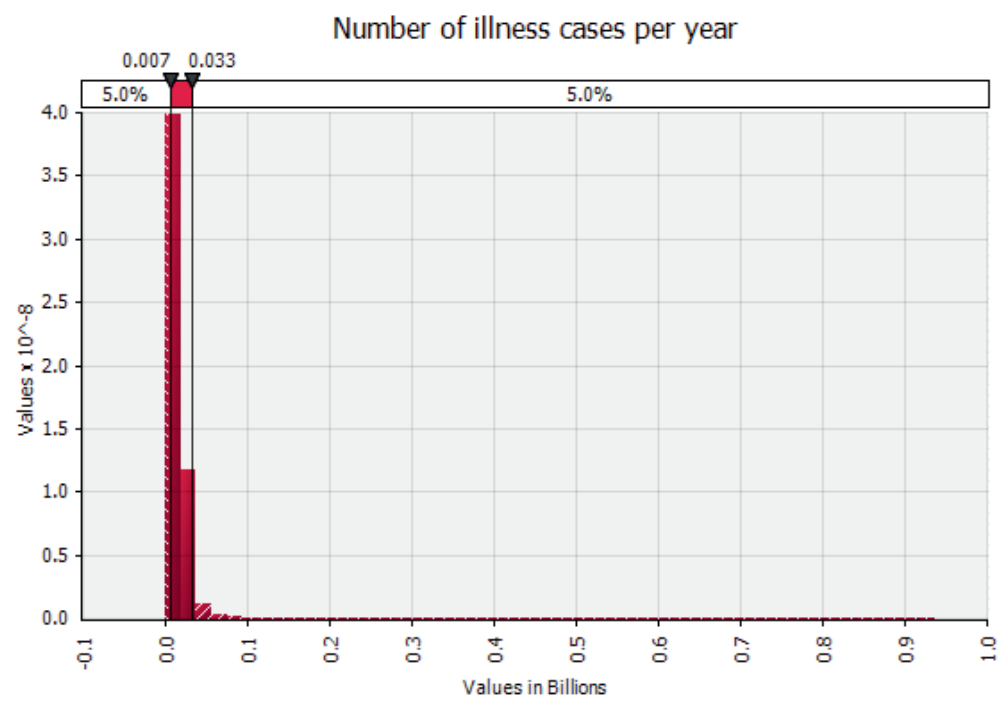

\begin{tabular}{|c|c|}
\hline & $\begin{array}{l}\text { Number of illness } \\
\text { cases per year }\end{array}$ \\
\hline Cell & Route 1 most commo. \\
\hline$\overline{\text { Minimum }}$ & $93,694.20$ \\
\hline Maximum & $937,360,737.19$ \\
\hline Mean & $16,706,662.08$ \\
\hline $90 \% \subset \mathrm{CI}$ & $\pm 79,979.68$ \\
\hline Mode & $12,050,095.95$ \\
\hline Median & $14,136,935.56$ \\
\hline Std Dev & $15,376,176.52$ \\
\hline Skewness & 18.8517 \\
\hline Kurtosis & 703.4876 \\
\hline Values & 100000 \\
\hline Errors & 0 \\
\hline Filtered & 0 \\
\hline Left $X$ & $6,959,424.80$ \\
\hline Left $P$ & $5.0 \%$ \\
\hline Right $X$ & $32,639,813.90$ \\
\hline Right $P$ & $95.0 \%$ \\
\hline Dif. $X$ & $25,680,389.10$ \\
\hline Dif. $P$ & $90.0 \%$ \\
\hline
\end{tabular}




\section{Route 2}
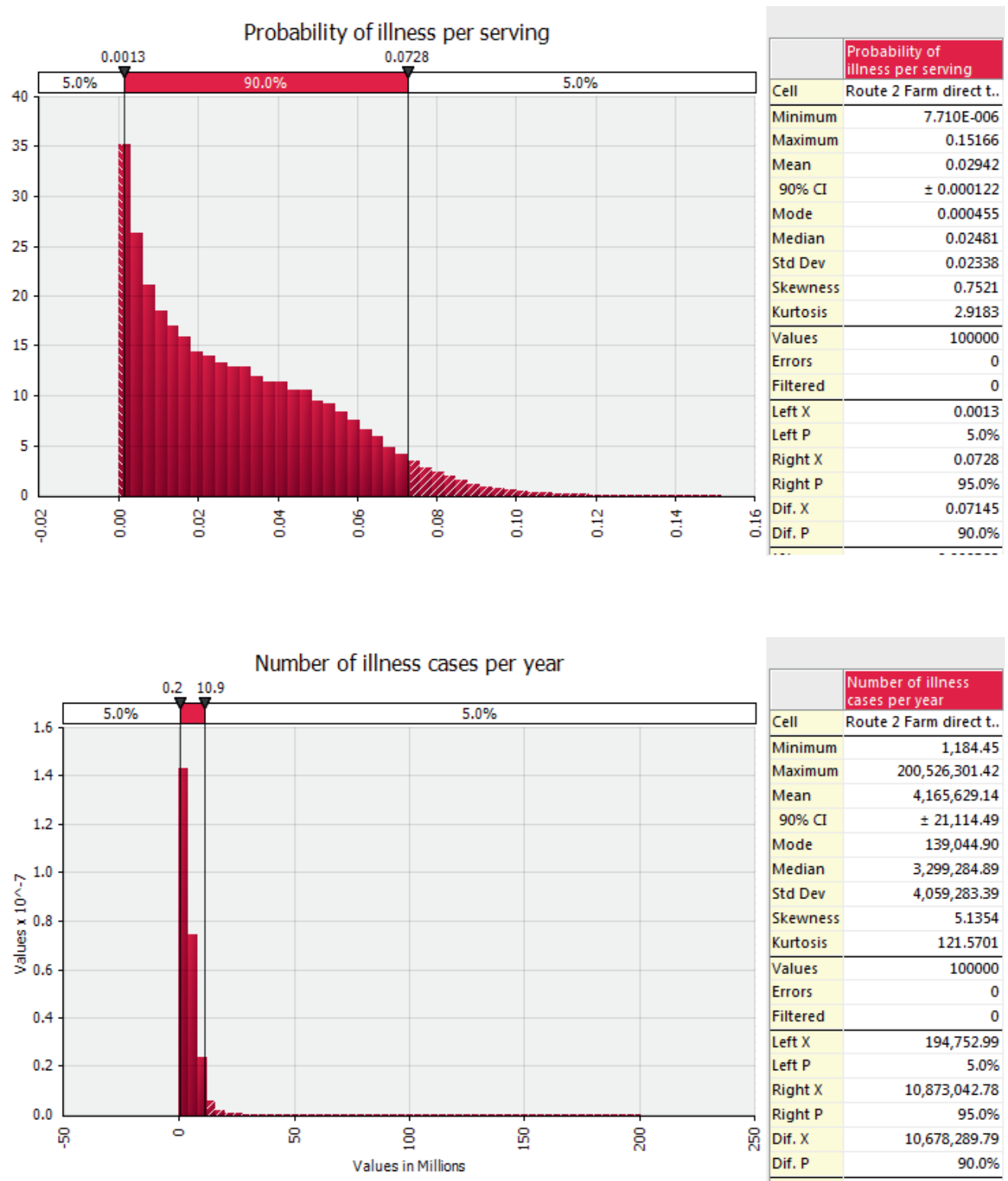

\begin{tabular}{|l|r|}
\hline & $\begin{array}{l}\text { Number of illness } \\
\text { Cases per year }\end{array}$ \\
\hline Cell & Route 2 Farm direct t.. \\
\hline Minimum & $1,184.45$ \\
\hline Maximum & $200,526,301.42$ \\
\hline Mean & $4,165,629.14$ \\
\hline $90 \%$ CI & $\pm 21,114.49$ \\
\hline Mode & $139,044.90$ \\
\hline Median & $3,299,284.89$ \\
\hline Std Dev & $4,059,283.39$ \\
\hline Skewness & 5.1354 \\
\hline Kurtosis & 121.5701 \\
\hline Values & 100000 \\
\hline Errors & 0 \\
\hline Filtered & 0 \\
\hline Left X & $194,752.99$ \\
\hline Left P & $5.0 \%$ \\
\hline Right X & $10,873,042.78$ \\
\hline Right P & $95.0 \%$ \\
\hline Dif. X & $10,678,289.79$ \\
\hline Dif. P & $90.0 \%$ \\
\hline .. & ---- \\
\hline
\end{tabular}


$184 \mid C$ h a p te r 6

3. Route 3

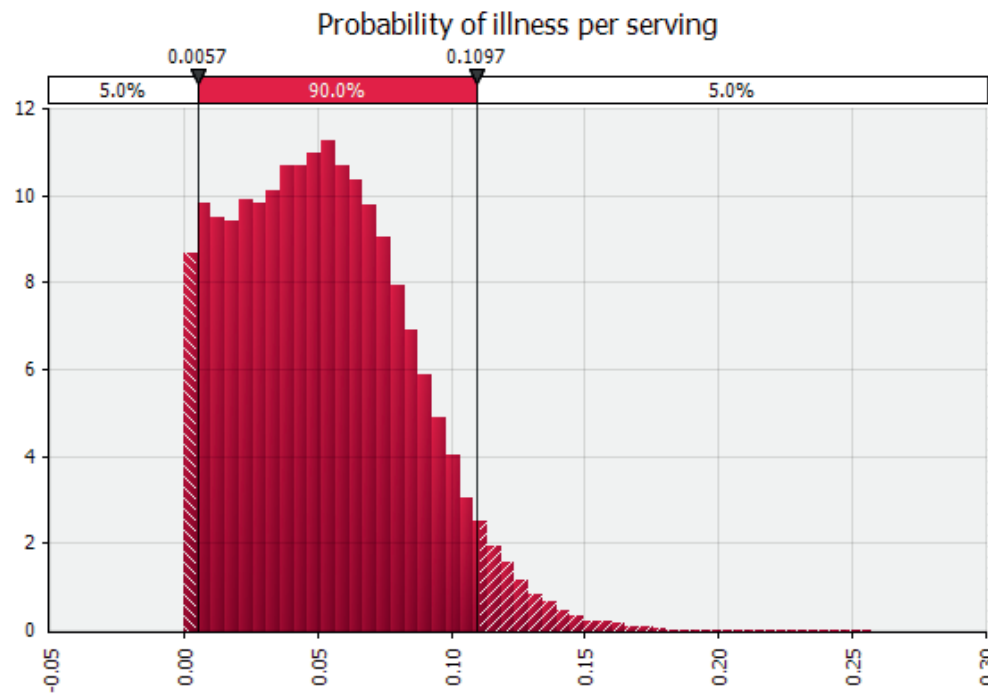

\begin{tabular}{|l|r|}
\hline & $\begin{array}{l}\text { Probability of } \\
\text { illness per serving }\end{array}$ \\
\hline Cell & Route $3 ! E 109$ \\
\hline Minimum & $3.363 E-005$ \\
\hline Maximum & 0.25822 \\
\hline Mean & 0.05259 \\
\hline 90\% CI & \pm 0.000169 \\
\hline Mode & 0.05349 \\
\hline Median & 0.05042 \\
\hline Std Dev & 0.03251 \\
\hline Skewness & 0.5265 \\
\hline Kurtosis & 3.0064 \\
\hline Values & 100000 \\
\hline Errors & 0 \\
Filtered & 0 \\
\hline Left X & 0.0057 \\
Left P & $5.0 \%$ \\
\hline Right X & 0.1097 \\
Right P & $95.0 \%$ \\
\hline Dif. X & 0.10394 \\
Dif. P & $90.0 \%$ \\
\hline .. & $--\cdot-$ \\
\hline
\end{tabular}

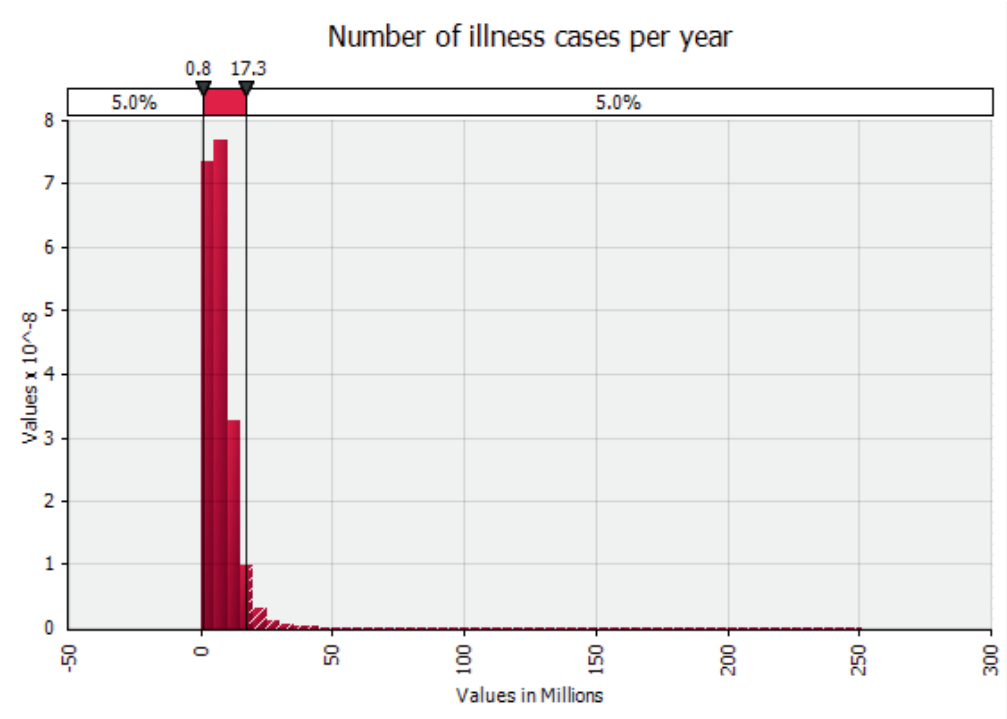

\begin{tabular}{|c|c|}
\hline & $\begin{array}{l}\text { Number of illness } \\
\text { cases per year }\end{array}$ \\
\hline Cell & Route 3!E115 \\
\hline$\overline{\text { Minimum }}$ & $6,708.26$ \\
\hline Maximum & $251,306,797.36$ \\
\hline Mean & $7,529,762.94$ \\
\hline $90 \% \mathrm{CI}$ & $\pm 32,921.82$ \\
\hline Mode & $6,263,563.63$ \\
\hline Median & $6,556,583.60$ \\
\hline Std Dev & $6,329,253.54$ \\
\hline Skewness & 6.1536 \\
\hline Kurtosis & 131.4340 \\
\hline Values & 100000 \\
\hline Errors & 0 \\
\hline Filtered & 0 \\
\hline Left X & $828,430.44$ \\
\hline Left $P$ & $5.0 \%$ \\
\hline Right X & $17,258,582.81$ \\
\hline Right P & $95.0 \%$ \\
\hline Dif. $X$ & $16,430,152.37$ \\
\hline Dif. $P$ & $90.0 \%$ \\
\hline
\end{tabular}


4. Farm interventions (reduction of prevalence of pathogenic E. coli by $90 \%$ )

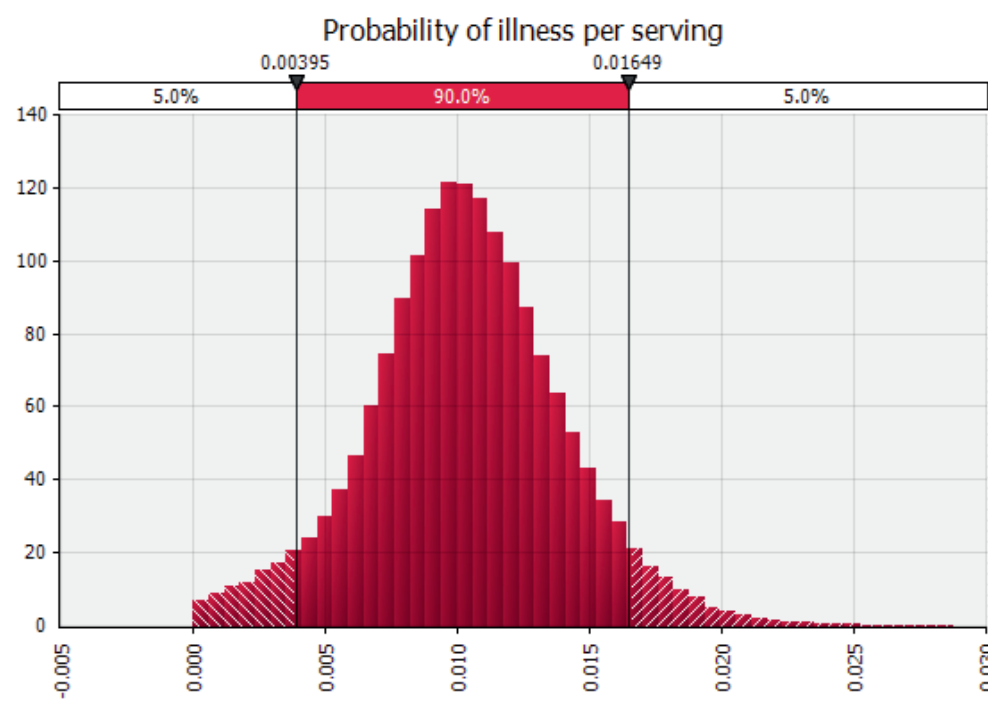

\begin{tabular}{|l|r|}
\hline & $\begin{array}{l}\text { Probability of } \\
\text { illness per serving }\end{array}$ \\
\hline Cell & Farm interventions!E.. \\
\hline Minimum & 1.417 E-005 \\
\hline Maximum & 0.028765 \\
\hline Mean & 0.010338 \\
90\% CI & 2.160 E-005 \\
\hline Mode & 0.010331 \\
\hline Median & 0.010293 \\
\hline Std Dev & 0.003718 \\
\hline Skewness & 0.0899 \\
\hline Kurtosis & 3.4877 \\
\hline Values & 80157 \\
Errors & 19843 \\
\hline Filtered & 0 \\
\hline Left X & $5.0 \%$ \\
\hline Left P & 0.01649 \\
\hline Right X & $95.0 \%$ \\
\hline Right P & 0.012541 \\
\hline Dif. X & $90.0 \%$ \\
\hline Dif. P & $-\cdot-\cdot$ \\
\hline -. & 0.00395 \\
\hline
\end{tabular}

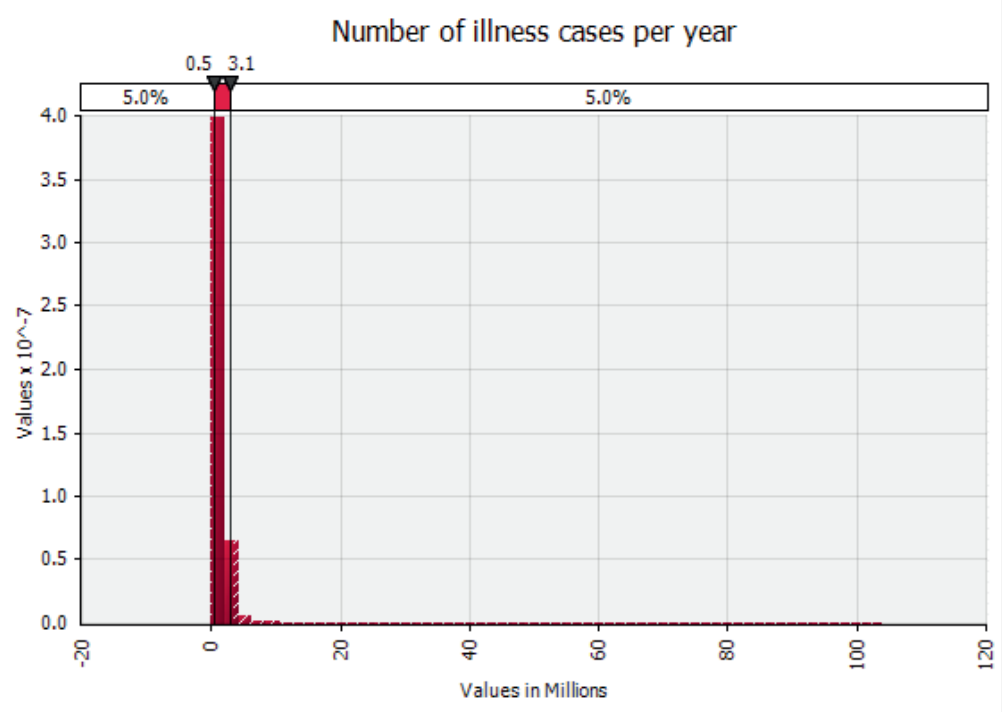

\begin{tabular}{|l|r|}
\hline \multicolumn{1}{|l|}{} & $\begin{array}{l}\text { Number of illness } \\
\text { cases per year }\end{array}$ \\
\hline Cell & Farm interventions!E.. \\
\hline Minimum & $2,006.46$ \\
Maximum & $103,855,232.86$ \\
\hline Mean & $1,554,796.78$ \\
\hline $90 \%$ CI & $\pm 8,395.37$ \\
Mode & $1,132,175.61$ \\
\hline Median & $1,329,212.26$ \\
\hline Std Dev & $1,445,034.84$ \\
\hline Skewness & 18.6326 \\
\hline Kurtosis & 747.7264 \\
\hline Values & 80157 \\
Errors & 19843 \\
\hline Filtered & 0 \\
\hline Left X & $517,244.25$ \\
\hline Left P & $5.0 \%$ \\
\hline Right X & $3,100,988.33$ \\
\hline Right P & $95.0 \%$ \\
\hline Dif. X & $2,583,744.08$ \\
Dif. P & $90.0 \%$ \\
\hline .. &.$---\cdot$ \\
\hline &
\end{tabular}


5. Assuming no contamination and cross contamination along the supply chain

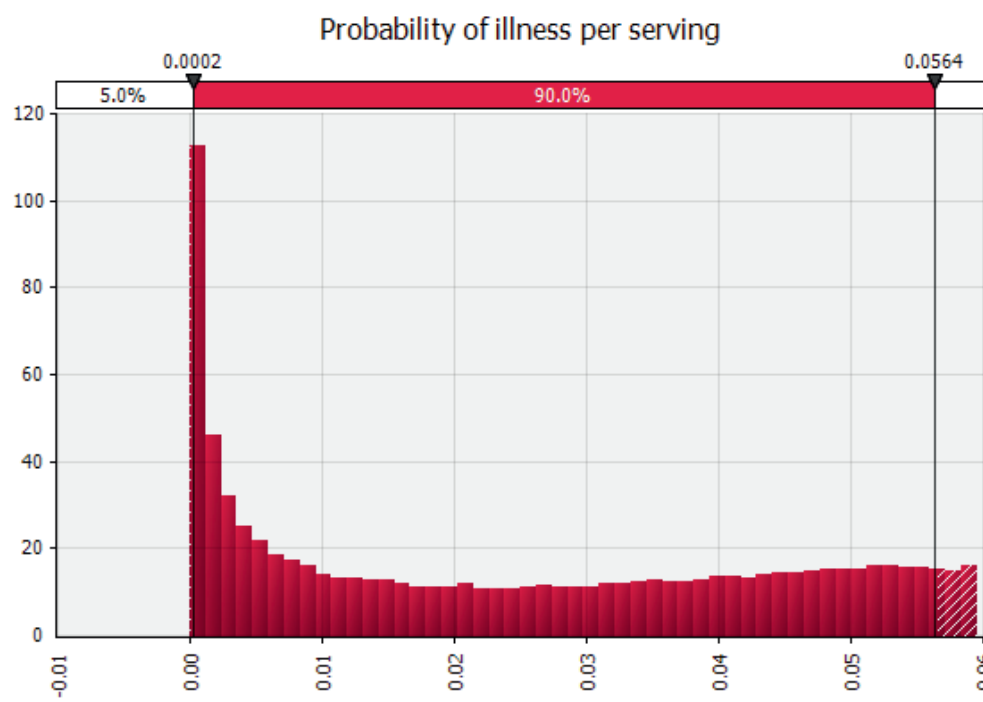

\begin{tabular}{|c|c|}
\hline & $\begin{array}{l}\text { Probability of } \\
\text { illness per serving }\end{array}$ \\
\hline Cell & No contamin at all le.. \\
\hline Minimum & $1.117 \mathrm{E}-007$ \\
\hline Maximum & 0.059583 \\
\hline Mean & 0.024612 \\
\hline $90 \% \mathrm{CI}$ & \pm 0.000103 \\
\hline Mode & $1.827 \mathrm{E}-005$ \\
\hline Median & 0.022349 \\
\hline Std Dev & 0.019832 \\
\hline Skewness & 0.2369 \\
\hline Kurtosis & 1.5923 \\
\hline Values & 100000 \\
\hline Errors & 0 \\
\hline Filtered & 0 \\
\hline Left $X$ & 0.0002 \\
\hline Left $P$ & $5.0 \%$ \\
\hline Right $X$ & 0.0564 \\
\hline Right $P$ & $95.0 \%$ \\
\hline Dif. $X$ & 0.056114 \\
\hline Dif. $P$ & $90.0 \%$ \\
\hline
\end{tabular}

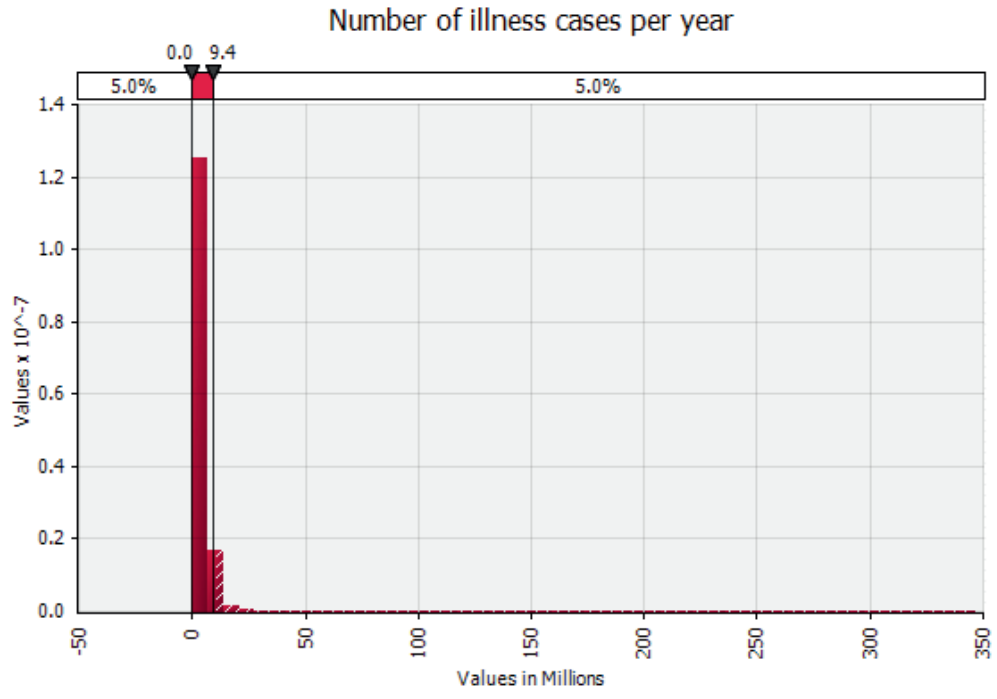

\begin{tabular}{|l|r|}
\hline & $\begin{array}{l}\text { Number of illness } \\
\text { cases per year }\end{array}$ \\
\hline Cell & No contamin at all le.. \\
\hline Minimum & 49.03 \\
\hline Maximum & $346,749,144.34$ \\
\hline Mean & $3,616,466.19$ \\
\hline $90 \%$ CI & $\pm 23,688.70$ \\
\hline Mode & $2,719.19$ \\
\hline Median & $2,928,958.39$ \\
\hline Std Dev & $4,554,177.48$ \\
\hline Skewness & 16.8606 \\
\hline Kurtosis & 830.1690 \\
\hline Values & 100000 \\
\hline Errors & 0 \\
\hline Filtered & 0 \\
\hline Left X & $33,937.61$ \\
\hline Left P & $5.0 \%$ \\
\hline Right X & $9,398,825.16$ \\
\hline Right P & $95.0 \%$ \\
\hline Dif. X & $9,364,887.55$ \\
\hline Dif. P & $90.0 \%$ \\
\hline ... &.--- \\
\hline
\end{tabular}


6. Maximizing Sanitization at FSEs
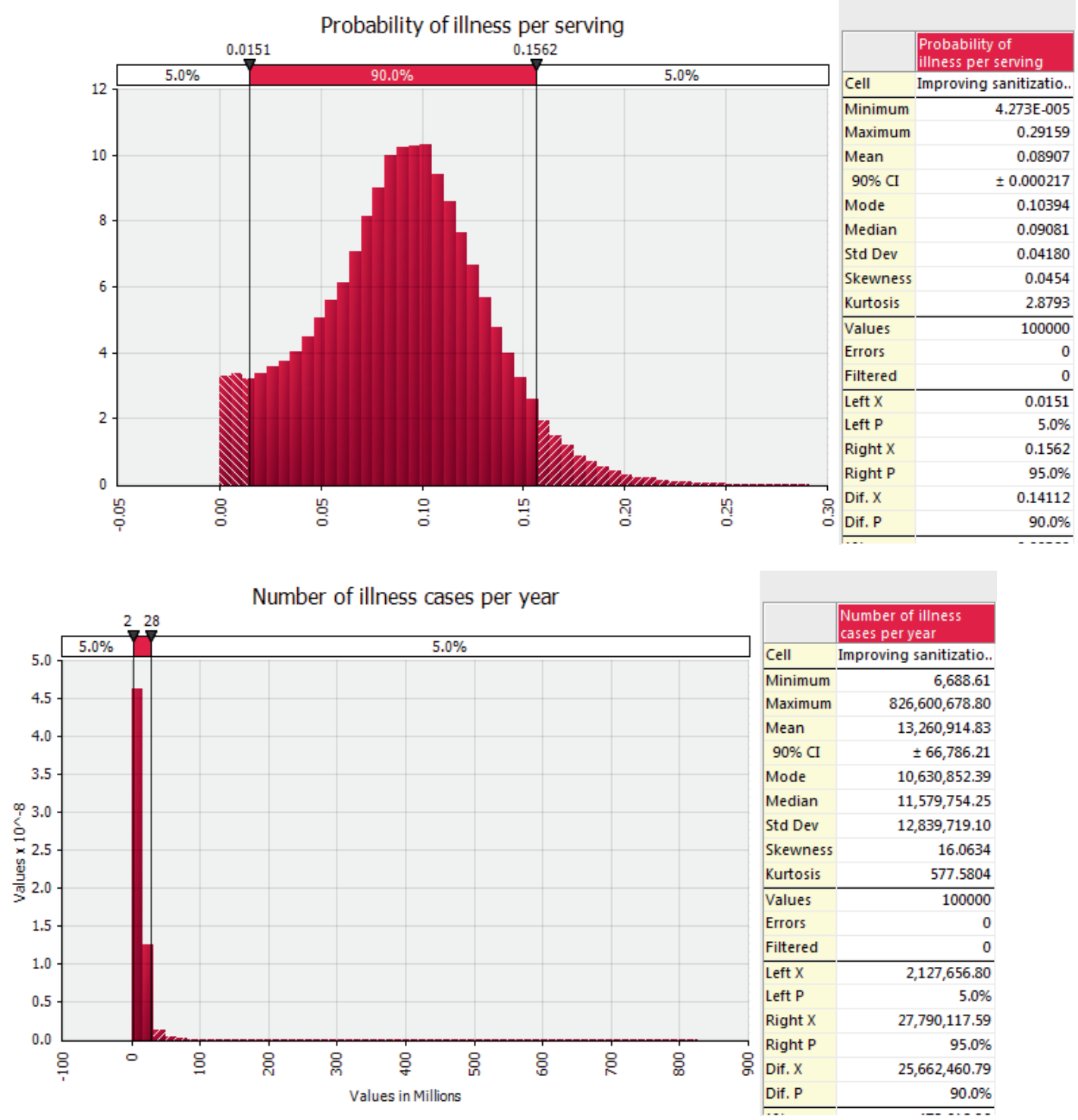
7. Introducing cold chain

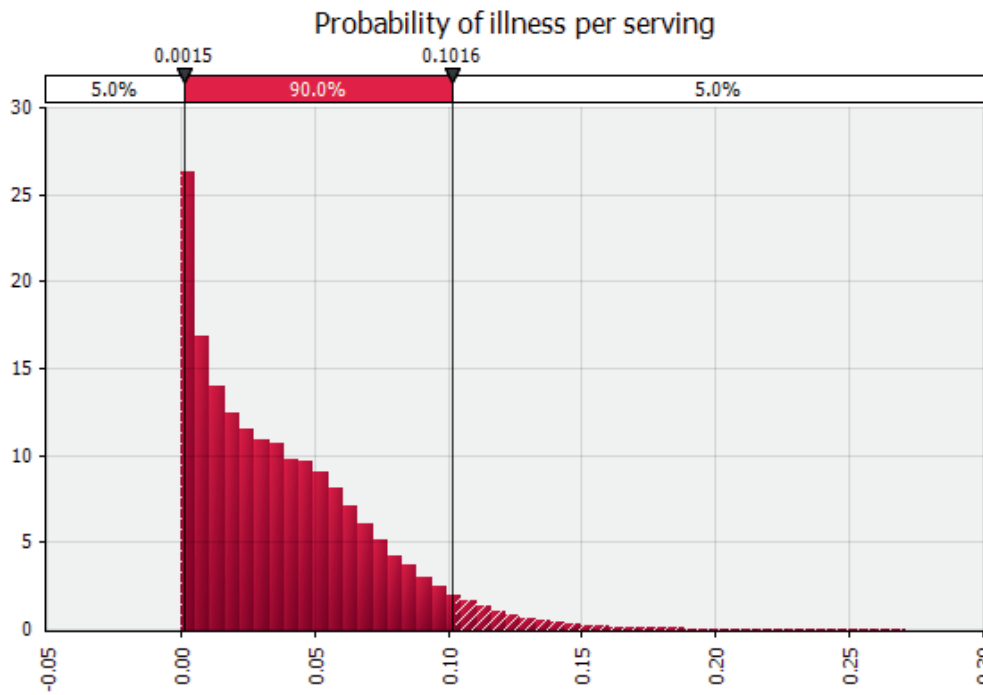

\begin{tabular}{|l|r|}
\hline & \multicolumn{1}{|l}{$\begin{array}{l}\text { Probability of } \\
\text { illness per serving }\end{array}$} \\
\hline Cell & Introducing cold cha.. \\
\hline Minimum & $7.354 E-008$ \\
\hline Maximum & 0.27127 \\
Mean & 0.03904 \\
\hline 90\% CI & \pm 0.000179 \\
\hline Mode & 0.000420 \\
\hline Median & 0.03235 \\
\hline Std Dev & 0.03272 \\
\hline Skewness & 1.0832 \\
\hline Kurtosis & 4.2730 \\
\hline Values & 90576 \\
\hline Errors & 9424 \\
\hline Filtered & 0 \\
\hline Left X & 0.0015 \\
Left P & $5.0 \%$ \\
\hline Right X & 0.1016 \\
Right P & $95.0 \%$ \\
\hline Dif. X & 0.10008 \\
\hline Dif. P & $90.0 \%$ \\
\hline .. & $--\cdot--$ \\
\hline
\end{tabular}

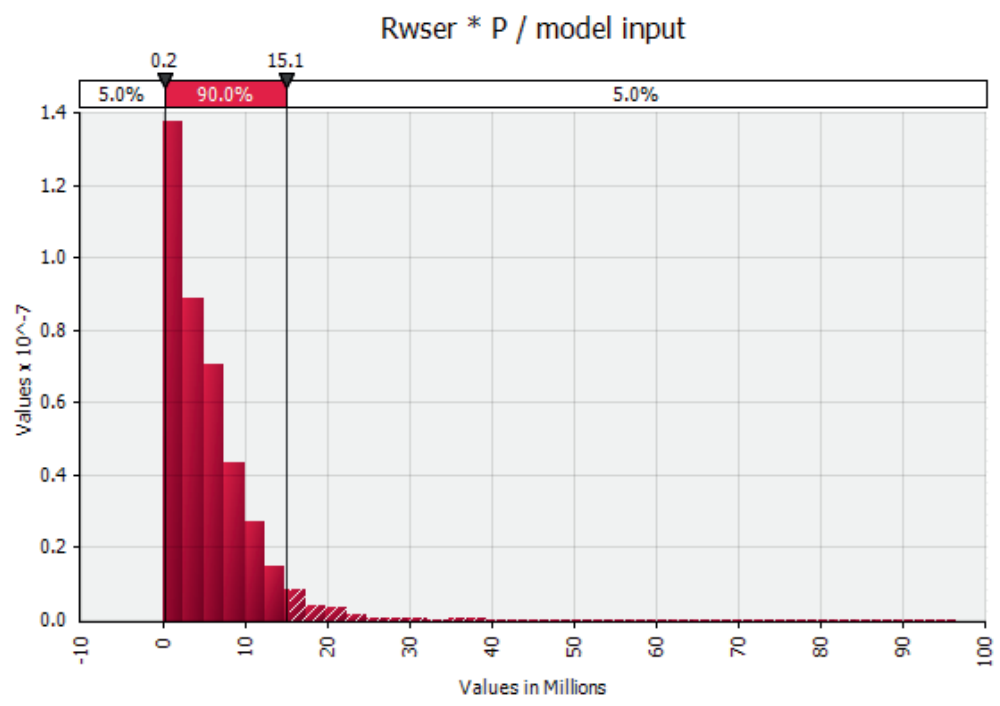

\begin{tabular}{|l|r|}
\hline & $\begin{array}{l}\text { Rwser * P / model } \\
\text { input }\end{array}$ \\
\hline Cell & Introducing cold cha.. \\
\hline Minimum & 5.13 \\
Maximum & $96,694,756.21$ \\
\hline Mean & $5,555,122.36$ \\
\hline $90 \%$ CI & $\pm 106,475.44$ \\
Mode & $288,249.80$ \\
\hline Median & $4,189,461.72$ \\
\hline Std Dev & $5,850,020.30$ \\
Skewness & 4.0240 \\
\hline Kurtosis & 39.5025 \\
\hline $\begin{array}{l}\text { Values } \\
\text { Errors }\end{array}$ & 8169 \\
\hline Filtered & 831 \\
\hline Left X & 0 \\
Left P & $217,858.65$ \\
\hline Right X & $5.0 \%$ \\
\hline Right P & $15,097,368.88$ \\
Dif. X & $95.0 \%$ \\
\hline Dif. P & $14,879,510.23$ \\
\hline & $90.0 \%$ \\
\hline
\end{tabular}


8. Combing farm to fork measures
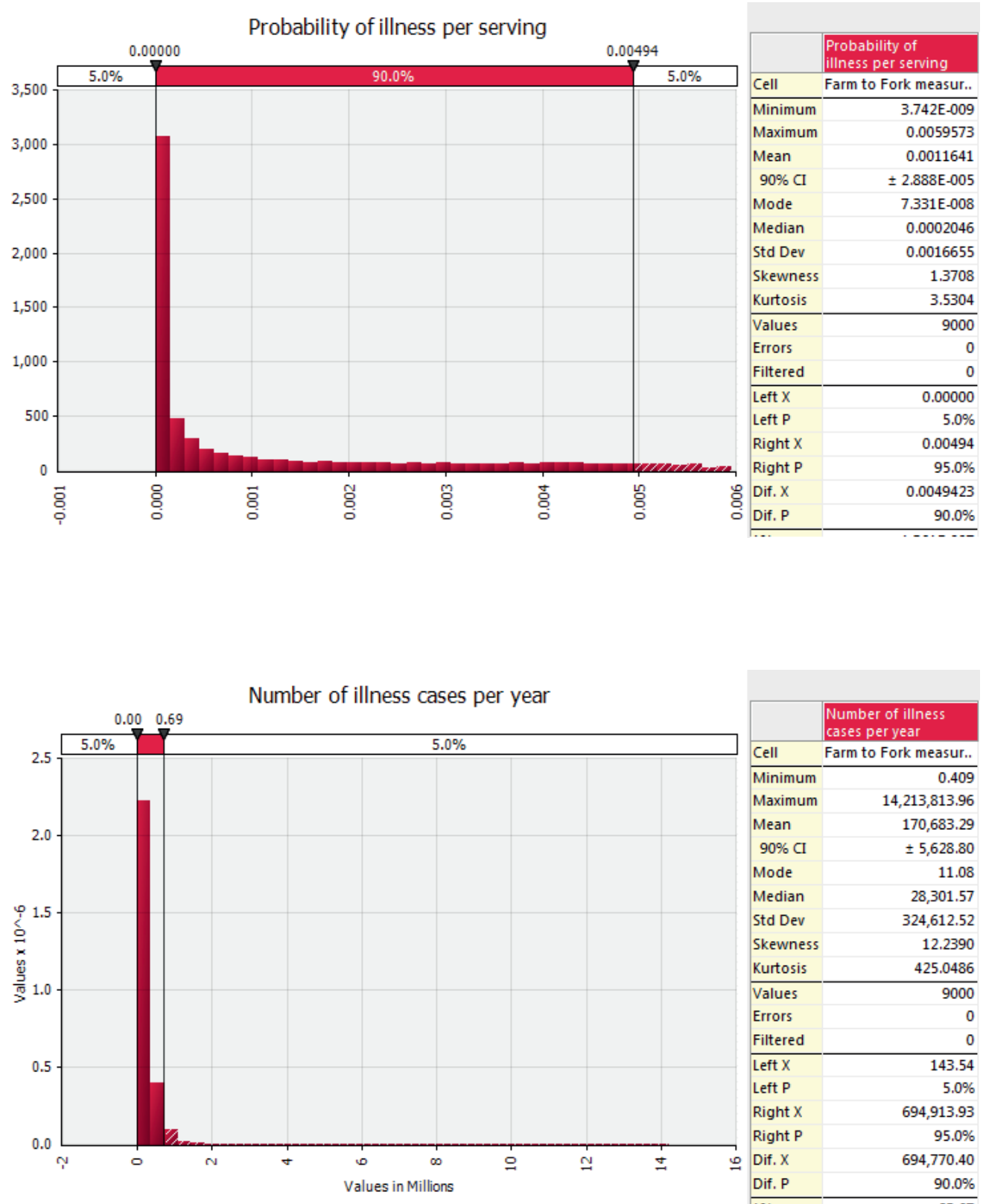

\begin{tabular}{|l|r|}
\hline \multicolumn{1}{|c|}{} & $\begin{array}{l}\text { Number of illness } \\
\text { cases per year }\end{array}$ \\
\hline Cell & Farm to Fork measur.. \\
\hline Minimum & 0.409 \\
\hline Maximum & $14,213,813.96$ \\
\hline Mean & $170,683.29$ \\
\hline $90 \%$ CI & $\pm 5,628.80$ \\
\hline Mode & 11.08 \\
\hline Median & $28,301.57$ \\
\hline Std Dev & $324,612.52$ \\
\hline Skewness & 12.2390 \\
\hline Kurtosis & 425.0486 \\
\hline Values & 9000 \\
\hline Errors & 0 \\
\hline Filtered & 0 \\
\hline Left X & 143.54 \\
\hline Left P & $5.0 \%$ \\
\hline Right X & $694,913.93$ \\
\hline Right P & $95.0 \%$ \\
\hline Dif. X & $694,770.40$ \\
\hline Dif. P & $90.0 \%$ \\
\hline . & ---- \\
\hline
\end{tabular}




\section{References}

1. Broglia A, Kapel C. 2011. Changing dietary habits in a changing world: Emerging drivers for the transmission of foodborne parasitic zoonoses. Veterinary Parasitology 182:2-13.

2. Satia JA, Kristal AR, Patterson RE, Neuhouser ML, Trudeau E. 2002. Psychosocial factors and dietary habits associated with vegetable consumption. Nutrition 18:247-254.

3. Jacxsens L, Ibañez IC, Gómez-López VM, Fernandes JA, Allende A, Uyttendaele M, Huybrechts I. 2015. Belgian and Spanish consumption data and consumer handling practices for fresh fruits and vegetables useful for further microbiological and chemical exposure assessment. Journal of Food Protection 78:784-795.

4. Miller V, Mente A, Dehghan M, Rangarajan S, Zhang X, Swaminathan S, Dagenais G, Gupta R, Mohan V, Lear S. 2017. Fruit, vegetable, and legume intake, and cardiovascular disease and deaths in 18 countries (PURE): a prospective cohort study. The Lancet 390: 2037-2049.

5. Lowry PW, Levine R, Stroup DF, Gunn RA, Wilder MH, Konigsberg Jr C. 1989. Hepatitis A outbreak on a floating restaurant in Florida, 1986. American Journal of Epidemiology 129:155-164.

6. Jackson LA, Keene WE, McAnulty JM, Alexander ER, Diermayer M, Davis MA, Hedberg K, Boase J, Barrett TJ, Samadpour M, Fleming DW. 2000. Where's the beef? The role of crosscontamination in 4 chain restaurant-associated outbreaks of Escherichia coli $\mathrm{O} 157: \mathrm{H} 7$ in the pacific northwest. Archives of Internal Medicine 160:2380-2385.

7. Kimura AC, Mead P, Walsh B, Alfano E, Gray SK, Durso L, Humphrey C, Monroe SS, Visvesvera G, Puhr N, Shieh WJ, Eberhard M, Hoekstra RM, Mintz ED. 2006. A large outbreak of Brainerd diarrhea associated with a restaurant in the Red River Valley, Texas. Clinical Infectious Diseases 43:55-61.

8. Bradley KK, Williams JM, Burnsed LJ, Lytle MB, McDermott MD, Mody RK, Bhattarai A, Mallonee S, Piercefield EW, McDonald-Hamm CK, Smithee LK. 2012. Epidemiology of a large restaurant-associated outbreak of Shiga toxin-producing Escherichia coli O111:NM. Epidemiology \& Infection 140:1644-1654.

9. Raj P, Tay J, Ang LW, Tien WS, Thu M, Lee P, Pang QY, Tang YL, Lee KY, Maurer-Stroh S, Gunalan V, Cutter J, Goh KT. 2016. A large common-source outbreak of norovirus gastroenteritis in a hotel in Singapore, 2012. Epidemiology \& Infection 145(3), 535-544.

10. Angelo KM, Nisler AL, Hall AJ, Brown LG, Gould LH. 2016. Epidemiology of restaurantassociated foodborne disease outbreaks, United States, 1998-2013. Epidemiology \& Infection 145(3), 523-534.

11. Lasky T. 2002. Foodborne illness - Old problem, new relevance. Epidemiology 13:593-598.

12. Kasowski EJ, Gackstetter GD, Sharp TW. 2002. Foodborne illness: new developments concerning an old problem. Current Gastroenterology Reports 4:308-318.

13. Havelaar AH, Kirk MD, Torgerson PR, Gibb HJ, Hald T, Lake RJ et al. 2015. World Health Organization global estimates and regional comparisons of the burden of foodborne disease in 2010. PLoS Medicine 12:e1001923. 
14. Wallace RB, Oria M, Council NR. 2010. Adopting a risk-based decision-making approach to food safety. National Research Council (US) Committee on the Review of Food and Drug Administration's Role in Ensuring Safe Food. National Academies Press (US). Washington (DC)

15. Adak G, Long S, O'Brien S. 2002. Trends in indigenous foodborne disease and deaths, England and Wales: 1992 to 2000. Gut 51:832-841.

16. Scallan E, Hoekstra RM, Angulo FJ, Tauxe RV, Widdowson MA, Roy SL, Jones JL, Griffin PM. 2011. Foodborne illness acquired in the United States--major pathogens. Emerging Infectious Diseases 17:7-15.

17. Havelaar AH, Haagsma JA, Mangen MJJ, Kemmeren JM, Verhoef LPB, Vijgen SMC, Wilson M, Friesema IHM, Kortbeek LM, van Duynhoven YTHP, van Pelt W. 2012. Disease burden of foodborne pathogens in the Netherlands, 2009. International Journal of Food Microbiology 156:231238.

18. Gkogka E, Reij MW, Havelaar AH, Zwietering MH, Gorris LGM. 2011. Risk-based estimate of effect of foodborne diseases on public health, Greece. Emerging Infectious Diseases 17:1581-1590.

19. Thomas MK, Murray R, Flockhart L, Pintar K, Pollari F, Fazil A, Nesbitt A, Marshall B. 2013. Estimates of the burden of foodborne illness in Canada for 30 specified pathogens and unspecified agents, Circa 2006. Foodborne Pathogens \& Disease 10:639-648.

20. Lake RJ, Cressey PJ, Campbell DM, Oakley E. 2010. Risk ranking for foodborne microbial hazards in New Zealand: Burden of disease estimates. Risk Analysis 30:743-752.

21. Kamana O, Ceuppens S, Jacxsens L, Kimonyo A, Uyttendaele M. 2014. Microbiological quality and safety assessment of the Rwandan milk and dairy chain. Journal of Food Protection 77:299-307.

22. Niyonzima E, Ongol MP, Brostaux Y, Korsak Koulagenko N, Daube G, Kimonyo A, Sindic M. 2017. Consumption patterns, bacteriological quality and risk factors for Salmonella contamination in meat-based meals consumed outside the home in Kigali, Rwanda. Food Control 73, 546-554.

23. Kirby MA, Nagel CL, Rosa G, Iyakaremye L, Zambrano LD, Clasen TF. 2016. Faecal contamination of household drinking water in Rwanda: A national cross-sectional study. Science of the Total Environment 571:426-434.

24. Uwimpuhwe M, Reddy P, Barratt G, Bux F. 2014. The impact of hygiene and localised treatment on the quality of drinking water in Masaka, Rwanda. Journal of Environmental Science and Health - Part A Toxic/Hazardous Substances \& Environmental Engineering 49:434-440.

25. Painter JA, Hoekstra RM, Ayers T, Tauxe RV, Braden CR, Angulo FJ, Griffin PM. 2013. Attribution of foodborne illnesses, hospitalizations, and deaths to food commodities by using outbreak data, United States, 1998-2008. Emerging Infectious Diseases 19:407-415.

26. Callejon RM, Rodriguez-Naranjo MI, Ubeda C, Hornedo-Ortega R, Garcia-Parrilla MC, Troncoso AM. 2015. Reported foodborne outbreaks due to fresh produce in the United States and European Union: trends and causes. Foodborne Pathogens \& Disease 12:32-38. 
27. The World Health Organization (WHO) and the Food and Agriculture Organization (FAO) of the united nations. 2008. Microbiological hazards in fresh leafy vegetables and herbs. Meeting report. Available at : http://www.fao.org/3/a-i0452e.pdf, Accessed 15 ${ }^{\text {th }}$ November 2015.

28. Beuchat LR, Ryu JH. 1997. Produce handling and processing practices. Emerging Infectious Diseases 3:459-465.

29. Gil MI, Selma MV, Suslow T, Jacxsens L, Uyttendaele M, Allende A. 2015. Pre- and postharvest preventive measures and intervention strategies to control microbial food safety hazards of fresh leafy vegetables. Critical Reviews in Food Science \& Nutrition 55:453-468.

30. The World Health Organisation (WHO) of the United Nations. 2012. Five keys to growing safer fruits and vegetables. Promoting health by decreasing microbial contamination. Available at: http://apps.who.int//iris/bitstream/10665/75196/1/9789241504003_eng.pdf?ua=1. Accessed $15^{\text {th }}$ November 2014.

31. Gorski L, Palumbo JD, Nguyen KD. 2004. Strain-specific differences in the attachment of Listeria monocytogenes to alfalfa sprouts. Journal of Food Protection 67:2488-2495.

32. Solomon EB, Sharma M. 2009. Chapter 2 - Microbial attachment and limitations of decontamination methodologies, p. 21-45. In Sapers GM, Solomon EB, Matthews KR (ed.), The Produce Contamination Problem. Academic Press, San Diego.

33. Warriner K, Ibrahim F, Dickinson M, Wright C, Waites WM. 2003. Internalization of human pathogens within growing salad vegetables. Biotechnology \& Genetic Engineering Reviews 20:117136.

34. Deering AJ, Mauer LJ, Pruitt RE. 2012. Internalization of E. coli O157:H7 and Salmonella spp. in plants: A review. Food Research International 45:567-575.

35. Beuchat LR. 2006. Vectors and conditions for pre-harvest contamination of fruits and vegetables with pathogens capable of causing enteric diseases. British Food Journal 108:38-53.

36. Food and Drug Administration of the United States (US FDA). 2012. Bad Bug Book, Foodborne Pathogenic microorganisms and natural toxins. Second edition. New Hampshire, United States.

37. The World Health Organisation (WHO)/ Food and Agriculture (FAO) of the United Nations. 2006. Food safety risk analysis: A guide for national food safety authorities. Available at: http://www.fao.org/docrep/012/a0822e/a0822e.pdf. Accessed 10 $0^{\text {th }}$ September 2013.

38. Food and Agriculture (FAO) of the United Nations. 2017. Capacity development: Risk analysis. Available at: http://www.fao.org/food/food-safety-quality/capacity-development/risk-analysis/en/. Accessed 02 $2^{\text {nd }}$ July 2017.

39. Holvoet K, Sampers I, Callens B, Dewulf J, Uyttendaele M. 2013. Moderate prevalence of antimicrobial resistance in Escherichia coli isolates from lettuce, irrigation water, and soil. Applied \& Environmental Microbiology 79:6677-6683.

40. Adamu NB, Adamu JY, Mohammed D. 2012. Prevalence of helminth parasites found on vegetables sold in Maiduguri, Northeastern Nigeria. Food Control 25:23-26. 
41. Aw TG, Wengert S, Rose JB. 2016. Metagenomic analysis of viruses associated with field-grown and retail lettuce identifies human and animal viruses. International Journal of Food Microbiology 223:50-56.

42. Pang H, Lambertini E, Buchanan RL, Schaffner DW, Pradhan AK. 2017. Quantitative microbial risk assessment for Escherichia coli O157:H7 in fresh-cut lettuce. Journal of Food Protection 80:302-311.

43. Maffei DF, Sant'Ana AS, Franco BDGM, Schaffner DW. 2017. Quantitative assessment of the impact of cross-contamination during the washing step of ready-to-eat leafy greens on the risk of illness caused by Salmonella. Food Research International 92:106-112.

44. Danyluk MD, Schaffner DW. 2011. Quantitative assessment of the microbial risk of leafy greens from farm to consumption: Preliminary framework, data, and risk estimates. Journal of Food Protection 74:700-708.

45. Ding T, Iwahori Ji, Kasuga F, Wang J, Forghani F, Park M-S, Oh D-H. 2013. Risk assessment for Listeria monocytogenes on lettuce from farm to table in Korea. Food Control 30:190-199.

46. Faour-Klingbeil D, Murtada M, Kuri V, Todd ECD. 2016. Understanding the routes of contamination of ready-to-eat vegetables in the Middle East. Food Control 62:125-133.

47. Wood JL, Chen JC, Friesen E, Delaquis P, Allen KJ. 2015. Microbiological survey of locally grown lettuce sold at farmers' markets in Vancouver, British Columbia. Journal of Food Protection 78:203-208.

48. Verhaelen K, Bouwknegt M, Carratalà A, Lodder-Verschoor F, Diez-Valcarce M, RodríguezLázaro D, de Roda Husman AM, Rutjes SA. 2013. Virus transfer proportions between gloved fingertips, soft berries, and lettuce, and associated health risks. International Journal of Food Microbiology 166:419-425.

49. Chen Y, Jackson KM, Chea FP, Schaffner DW. 2001. Quantification and variability analysis of bacterial cross-contamination rates in common food service tasks. Journal of Food Protection 64:7280 .

50. Jensen DA, Friedrich LM, Harris LJ, Danyluk MD, Schaffner DW. 2013. Quantifying transfer rates of Salmonella and Escherichia coli O157: H7 between fresh-cut produce and common kitchen surfaces. Journal of Food Protection 76:1530-1538.

51. Rwanda Meteorology Agency. 2017. Climatology of Rwanda. Available at: http://www.meteorwanda.gov.rw/index.php?id=30. Accessed $05^{\text {th }}$ June 2017.

52. Ratkowsky D, Olley J, McMeekin T, Ball A. 1982. Relationship between temperature and growth rate of bacterial cultures. Journal of Bacteriology 149:1-5.

53. McKellar RC, Delaquis P. 2011. Development of a dynamic growth-death model for Escherichia coli O157: H7 in minimally processed leafy green vegetables. International Journal of Food Microbiology 151:7-14. 
54. Koseki S, Isobe S. 2005. Prediction of pathogen growth on iceberg lettuce under real temperature history during distribution from farm to table. International Journal of Food Microbiology 104:239248.

55. Islam M, Doyle MP, Phatak SC, Millner P, Jiang X. 2004. Persistence of enterohemorrhagic Escherichia coli O157: $\mathrm{H7}$ in soil and on leaf lettuce and parsley grown in fields treated with contaminated manure composts or irrigation water. Journal of Food Protection 67:1365-1370.

56. Pérez Rodríguez F, Campos D, Ryser ET, Buchholz AL, Posada-Izquierdo GD, Marks BP, Zurera G, Todd E. 2011. A mathematical risk model for Escherichia coli O157:H7 crosscontamination of lettuce during processing. Food Microbiology 28:694-701.

57. Buchanan R, Whiting R, Damert W. 1997. When is simple good enough: a comparison of the Gompertz, Baranyi, and three-phase linear models for fitting bacterial growth curves. Food Microbiology 14:313-326.

58. National Institute of Statistics of Rwanda (NISR), Ministry of Finance and Economic Planning, Rwanda. 2012. Rwanda Fourth Population and Housing Census. Thematic Report: Data quality assessment . Available at: http://www.statistics.gov.rw/publication/rphc4-final-report-data-qualityassessment. Accessed $05^{\text {th }}$ February 2015.

59. Nataro JP, Kaper JB. 1998. Diarrheagenic Escherichia coli. Clinical microbiology reviews 11:142201.

60. Henao-Herreño LX, López-Tamayo AM, Ramos-Bonilla JP, Haas CN, Husserl J. 2017. Risk of illness with Salmonella due to consumption of raw unwashed vegetables irrigated with water from the Bogotá river. Risk Analysis 37:733-743.

61. Owusu-Ansah Ed-GJ, Sampson A, Amponsah SK, Abaidoo RC, Dalsgaard A, Hald T. 2017. Probabilistic quantitative microbial risk assessment model of norovirus from wastewater irrigated vegetables in Ghana using genome copies and fecal indicator ratio conversion for estimating exposure dose. Science of The Total Environment 601-602:1712-1719.

62. Bouwknegt M, Verhaelen K, Rzeżutka A, Kozyra I, Maunula L, von Bonsdorff C-H, Vantarakis A, Kokkinos P, Petrovic T, Lazic S, Pavlik I, Vasickova P, Willems KA, Havelaar AH, Rutjes SA, de Roda Husman AM. 2015. Quantitative farm-to-fork risk assessment model for norovirus and hepatitis A virus in European leafy green vegetable and berry fruit supply chains. International Journal of Food Microbiology 198:50-58.

63. Sant'Ana AS, Franco BDGM, Schaffner DW. 2014. Risk of infection with Salmonella and Listeria monocytogenes due to consumption of ready-to-eat leafy vegetables in Brazil. Food Control 42:1-8.

64. Franz E, Tromp SO, Rijgersberg H, Van Der Fels-Klerx HJ. 2010. Quantitative microbial risk assessment for Escherichia coli O157:H7, Salmonella, and Listeria monocytogenes in leafy green vegetables consumed at salad bars. Journal of Food Protection 73:274-285.

65. Amponsah-Doku F, Obiri-Danso K, Abaidoo RC, Andoh LA, Drechsel P, Kondrasen F. 2010. Bacterial contamination of lettuce and associated risk factors at production sites, markets and street food restaurants in urban and peri-urban Kumasi, Ghana. Scientific Research \& Essays 5:217-223. 
66. Strawn LK, Gröhn YT, Warchocki S, Worobo RW, Bihn EA, Wiedmann M. 2013. Risk factors associated with Salmonella and Listeria monocytogenes contamination of produce fields. Applied \& Environmental Microbiology 79:7618-7627.

67. Joint Institute for Food Safety and Applied Nutrition, University of Maryland and Food and Drug Administration (US FDA). 2002. Improving the safety and quality of fresh fruits and vegetables: a training manual for trainers. Available at:

http://www.fao.org/ag/agn/CDfruits_en/others/docs/maryland_manual.pdf. Accessed $4^{\text {th }}$ September 2014.

68. The Food and Agriculture Organization (FAO) of the united nations. 2012. On-farm practices for the safe use of wastewater in urban and peri-urban horticulture. A training handbook for farmer field schools. Available at: http://www.fao.org/docrep/016/i3041e/i3041e.pdf. Accessed 17 $7^{\text {th }}$ July 2013.

69. Food Safety Authority of Ireland. 2016. Guidance Note No. 31. Fresh Produce Safety in Primary Production in Ireland. Available at: https://www.fsai.ie/publications GN31 fresh produce/. Accessed $20^{\text {th }}$ October 2016.

70. U.S. Department of Health and Human Services Food and Drug Administration, Center for Food Safety and Applied Nutrition (CFSAN). 1998. Guidance for industry. Guide to minimize microbial food safety hazards for fresh fruits and vegetables. Available at: http://wcmorris.com/gap/files/prodguid.pdf. Accessed $17^{\text {th }}$ July 2013.

71. The World Health Organisation (WHO)/ Food and Agriculture (FAO) of the United NAtions, Codex Alimentarius Commission, international standards. 1969. General principles of food hygiene. Available at:

http://www.fao.org/fao-who-codexalimentarius/sh proxy/ar/?lnk=1\&url=https\%253A \%252F\%252Fworkspace.fao.org\%252Fsites $\% 252 \mathrm{~F}$ codex $\% 252 \mathrm{~F}$ Standards\%252FCAC\%2BRCP\%2B1-1969\%252FCXP_001e.pdf. Accessed 30 $0^{\text {th }}$ November 2015.

72. The World Health Organisation (WHO)/ Food and Agriculture (FAO) of the United Nations, Codex Alimentarius Commission, international standards. 2003. Code of hygienic practice for fresh fruits and vegetables (CAC/RCP 53-2003). Available at:

www.fao.org/input/download/standards/10200/CXP_053e_2013.pdf. Accessed 30 $30^{\text {th }}$ November 2015.

73. Royal United Hospital Bath (RUH), NHS Trust. 2010. Hygiene and food safety policy for food production and food service. Available at:

http://www.ibrarian.net/navon/paper/HYGIENE_AND_FOOD_SAFETY_POLICY_FOR_FOOD_ PRODUCTIO.pdf?paperid=20779658. Accessed 06 ${ }^{\text {th }}$ February 2014.

74. Havelaar AH, Haagsma JA, Mangen M-JJ, Kemmeren JM, Verhoef LPB, Vijgen SMC. 2012. Disease burden of foodborne pathogens in the Netherlands, 2009. International Journal of Food Microbiology 156: 231-238.

75. Adak GK, Meakins SM, Yip H, Lopman BA, O'Brien SJ. 2005. Disease risks from foods, England and Wales, 1996-2000. Emerging Infectious Diseases 11:365-372. 
76. Scallan E, Kirk M, Griffin PM. 2013. Estimates of disease burden associated with contaminated food in the United States and globally, p. 3-18. In: J. G. Morris, Jr. and M. E. Potter (Eds.) Foodborne Infections and Intoxications (Fourth Edition), Elsevier Inc.

77. Niyonzima E, Ongol MP, Brostaux Y, Koulagenko NK, Daube G, Kimonyo A, Sindic M. 2016. Daily intake and bacteriological quality of meat consumed in the households of Kigali, Rwanda. Food Control 69:108-114.

78. Herman KM, Hall AJ, Gould LH. 2015. Outbreaks attributed to fresh leafy vegetables, United States, 1973-2012. Epidemiology \& Infection 143:3011-3021.

79. Fresco, L.O., Bouwstra, R.J., de Jong, M.C.M., van der Poel, W.H.M., Scholten, M.C.T., Takken, $W$. and the global one health task force of Wageningen University and Research Centre. 2015. Global one health - a new integrated approach Available at: http://www.wur.nl/upload_mm/e/a/c/d734f322-b66d-4ec0-aa5b3ceb31001fe0_GOH_Final_20150602.pdf. Accessed 20 $0^{\text {th }}$ September 2016.

80. The Food and Agriculture Organisation of the United Nations (FAO). 2008. Contributing to "One World, One Health". A strategic framework for reducing risks of infectious diseases at the animal-human-ecosystems Interface. Available at:

ftp://ftp.fao.org/docrep/fao/011/aj137e/aj137e00.pdf. Accessed 01 ${ }^{\text {st }}$ October 2013.

81. Daniels NA. 2006. Enterotoxigenic Escherichia coli: traveler's diarrhea comes home. The University of Chicago Press.

82. Qadri F, Svennerholm A-M, Faruque A, Sack RB. 2005. Enterotoxigenic Escherichia coli in developing countries: epidemiology, microbiology, clinical features, treatment, and prevention. Clinical Microbiology Reviews 18:465-483.

83. Beuchat LR. 1996. Pathogenic microorganisms associated with fresh produce. Journal of Food Protection 59:204-216.

84. Herman KM, Hall AJ, Gould LH. 2015. Outbreaks attributed to fresh leafy vegetables, United States, 1973-2012. Epidemiology \& Infection 143:3011-3021.

85. Frank et al. 2011. Epidemic profile of Shiga-toxin-producing Escherichia coli O104: H4 outbreak in Germany. New England Journal of Medicine 365:1771-1780.

86. Center for Disease Control and Prevention of the United States. 2012. Multistate outbreak of shiga toxin-producing Escherichia coli $\mathrm{O} 157: \mathrm{H} 7$ infections linked to organic spinach and spring mix blend. Available at: http://www.cdc.gov/ecoli/2012/O157H7-11-12/index.html. Accessed $22^{\text {nd }}$ October 2016.

87. Center for Disease Control and Prevention of the United States. 2016. Foodborne outbreak tracking and reporting. Available at: https:/www.cdc.gov/foodsafety/fdoss/. Accessed on $23^{\text {rd }}$ October 2016.

88. Friesema I, Sigmundsdottir G, Van Der Zwaluw K, Heuvelink A, Schimmer B, De Jager C, Rump B, Briem H, Hardardottir H, Atladottir A. 2008. An international outbreak of Shiga toxinproducing Escherichia coli O157 infection due to lettuce, September-October 2007. Euro surveillance: European Communicable Disease Bulletin 13:3029-3035. 
89. Söderström et al. 2008. A large Escherichia coli O157 outbreak in Sweden associated with locally produced lettuce. Foodborne Pathogens \& Disease 5:339-349.

90. The World Health Organization of the United Nation (WHO). 2016. Enterohaemorrhagic Escherichia coli - United Kingdom. Available at: http://www.who.int/csr/don/20-july-2016-ehecuk/en/. Accessed $10^{\text {th }}$ October,2016.

91. Adams, Moss. 2008. Food Microbiology, Third ed. The Royal Society of Chemistry, Thomas Graham House, Science Park, Milton Road, Cambridge CB4 0WF, UK.

92. Tozzi AE, Caprioli A, Minelli F, Gianviti A, De Petris L, Edefonti A, Montini G, Ferretti A, De Palo T, Gaido M. 2003. Shiga toxin-producing Escherichia coli infections associated with hemolytic uremic syndrome. Emerging Infectious Diseases 9:107.

93. Okhuysen PC, DuPont HL. 2010. Enteroaggregative Escherichia coli (EAEC): A cause of acute and persistent diarrhea of worldwide importance. Journal of Infectious Diseases 202:503-505.

94. Farber JM, Peterkin PI. 1991. Listeria monocytogenes, a food-borne pathogen. Microbiological Reviews 55:476-511.

95. Jemmi T, Stephan R. 2006. Listeria monocytogenes: Food-borne pathogen and hygiene indicator. Scientific \& Technical Review of the Office International des Epizooties 25:571-580.

96. Wang S, Orsi RH. 2013. Listeria, Chapter 11, p. 199-216. Elsevier Inc.

97. Epps SVR, Harvey RB, Hume ME, Phillips TD, Anderson RC, Nisbet DJ. 2013. Foodborne Campylobacter: infections, metabolism, pathogenesis and reservoirs. International Journal of Environmental Research \& Public Health 10:6292-6304.

98. Silva J, Leite D, Fernandes M, Mena C, Gibbs PA, Teixeira P. 2011. Campylobacter spp. as a Foodborne Pathogen: A Review. Frontiers in Microbiology 2:200.

99. Murugaiah C. 2011. The burden of cholera. Critical Reviews in Microbiology 37:337-348.

100. Petersen JM, Mead PS, Schriefer ME. 2009. Francisella tularensis: an arthropod-borne pathogen. Veterinary Research 40:07.

101. Perry RD, Fetherston JD. 1997. Yersinia pestis--etiologic agent of plague. Clinical Microbiology Reviews 10:35-66.

102. Ortega YR, Sanchez R. 2010. Update on Cyclospora cayetanensis, a food-borne and waterborne parasite. Clinical Microbiology Reviews 23:218-234. 

Summary

Acknowledgements

About the author

List of publications

Overview of training activities 



\section{Summary}

Global consumption of vegetables and the associated reported foodborne illnesses have been increasing in tandem. This study was commissioned to analyze the microbial risk from "farm to fork" along the fresh vegetable supply chain in Rwanda to explore microbial safety options that can contribute to an integrated system to detect, control and prevent foodborne infections. Specific study objectives were developed, the first being to estimate the burden of foodborne infectious illnesses using the available data to obtain insight into the general plight of food safety issues and to also develop a framework for future investigations. Second, to investigate the microbial safety status, handling practices and risk exposure factors along the vegetable supply chain.

To understand the overall impact of foodborne illnesses on human health in Rwanda the burden of food related illnesses in year 2013 was estimated using the DALY (disability adjusted life year) metric, as encouraged by the World Health Organization. DALY is a measure that combines years of life lost due to premature death and healthy years lost due to disability during sickness. Study findings indicate that for the year 2013, watery diarrhea occurred all year round as by the surveillance system data, resulting to an estimated 672 (95\% credible interval [CrI] 424 - 932) DALY per million inhabitants, bloody diarrhea was seasonal coinciding with the rainy months and caused an estimated 213 (95\% CrI 50 - 475) DALY per million, typhoid and cholera manifested as outbreaks with an estimated 73 (95\% CrI 57 - 91) and 1 (95\% CrI 0 2) DALY per million respectively. These data show that the health burden is high and we suspect that a large proportion is caused by consumption of contaminated food.

Also investigated in this study, was the prevalence of foodborne pathogens in farm vegetables and agricultural water (used for irrigation and on-farm washing of vegetables) in Rwanda. In agricultural water from rivers, lakes, lagoons, ground and marshlands, traces in the form of DNA from a wide variety of virulent pathogenic organisms were detected, including enteroinvasive, enteroaggregative, and enterotoxigenic E. coli, Vibrio cholera, Yersinia pestis and the parasite Cyclospora. DNA from thermo-tolerant Campylobacter spp. was found in $87 \%$ of the samples. Although this does not mean that all these pathogens were still alive by the time of detection; presence of DNA is an indication that the pressure of pathogens in agricultural water and the environment is high. Indeed from 99 samples of farm vegetables, different viable foodborne pathogens were isolated viz. Listeria monocytogenes (1\%), Campylobacter spp. (3\%), Salmonella spp. (5\%) and pathogenic E. coli (6\%).

In addition to tracing the pathogens at farm level, selected indicator microorganisms were investigated, to get an impression of their survival, growth and/or inactivation along the vegetable supply chain. The latter was complemented with a detailed observation of handling practices along the supply chain. The mean count of Enterobacteriaceae in 11 types of vegetables increased slightly from farm to markets to reach an average of $6.0 \mathrm{log} \mathrm{cfu} / \mathrm{g}$ upon arrival at FSEs. During food preparation microbial counts were significantly reduced by washing with or without sanitizers, trimming/peeling, with an average of $2.1 \mathrm{log} \mathrm{cfu} / \mathrm{g}$ from start to end of salad preparation. Ready-to-eat salads prepared by FSEs met the guidelines by 
$91 \%$ and $22 \%$ for coagulase-positive staphylococci $\left(10^{4} \mathrm{cfu} / \mathrm{g}\right)$ and presumptive Listeria spp. $\left(10^{2} \mathrm{cfu} / \mathrm{g}\right)$ respectively. Because washing and sanitization procedures differ from one FSE to another, a laboratory study was designed to mimic the practices at FSEs with the aim to select optimal washing and sanitization procedures. Findings in the field study with FSEs revealed that about $61 \%$ of the visited FSEs used sanitizers during washing of fresh vegetables, in particular, potassium permanganate $\left(\mathrm{KMnO}_{4}\right)$ in $39 \%$ of FSEs, sanitizing powder (a mixture of polyphosphate, sodium hydrogen carbonate and active chlorine), 13\%; sodium hypochlorite $(\mathrm{NaClO}), 7 \%$; and sodium dichloroisocyanurate $(\mathrm{NaDCC})$ in $2 \%$. Average reduction ranged from $1.0 \log$ (for $\mathrm{KMnO}_{4}$ ) to $3.1 \log$ ( for $\mathrm{NaDCC}$ ). In the laboratory study, average inactivation observed with indicator microorganisms ranged from $0.7 \mathrm{log}$ (for water alone) to $3.0 \mathrm{log}$ (for $\mathrm{NaDCC}$ ). Out of the 8 sanitizers that were evaluated, 5 sanitizers ( $\mathrm{NaDCC}$ [90 ppm], $\mathrm{NaClO}$ [200 ppm], lemon juice [98\%], acetic acid [2\%] and sanitizing powder [4 g/L]) resulted in significantly higher inactivation compared to water alone. A contact time of 5 minutes and a salad-sanitizer ratio of 1:20 were considered optimal for kitchen based washing of the studied leafy vegetables with $\mathrm{NaDCC}$ and $\mathrm{NaClO}$ sanitizers. This study also reveals that the most widely used sanitizer $\left(25 \mathrm{ppm} \mathrm{KMnO}_{4}\right)$ was not more effective than washing with only water and an indication that a policy, guideline or regulation on kitchen based washing and sanitization of salad vegetables should be enacted.

The high prevalence $(15 \%)$ of foodborne pathogens associated vegetables at farm level and increasing trends in levels of indicator microorganisms from farm to FSEs, raises concern about the potential presence of foodborne pathogens in ready-to-eat salads. By using @risk software (Palisade Corporation, Ithaca, NY, USA) and Monte Carlo simulation (100,000 iterations), the number of cases due to serving leafy vegetables contaminated pathogenic $E$. coli have been estimated with a mode of 12 million cases of illness per year and 0.1 probability of illness per serving. These estimates can be considered high compared to previous risk assessments in other countries. However it should be acknowledged that these estimates also include mild illness from less harmful pathotypes of pathogenic E. coli. viz. enterotoxigenic E. coli (ETEC) and enteropathogenic E. coli. To further advise risk managers, seven "what if scenarios" were simulated to compare with the baseline model. The scenario of improving washing and sanitization (3.0 log reduction) at FSEs resulted to a less than 2 fold change in the predicted microbial risk. While a 2 fold change was observed for the scenario of channelling all vegetables through supermarkets instead of traditional markets. Farm interventions reducing the prevalence and levels of pathogenic $E$. coli in the base line model by $90 \%$, the introduction of a cold chain and skipping the market step, all resulted to a 10 fold reduction in predicted microbial risk. The scenario of reducing or avoiding contamination and cross contamination along the supply chain led to 1000 fold reduction in the predicted microbial risk. Lastly, farm to fork measures combining three different scenarios ( avoiding contamination from farm to fork, farm interventions ( $90 \%$ reduction) and improving sanitization) were predicted to reduce microbial risk by a factor of 1 million.

Risk estimates should be analyzed and weighted in order to prioritize risk management measures and interventions, not only for their effectiveness in improving public health, but also for their feasibility, acceptability and affordability. From the predicted microbial risk in this 
study, approaches to change the routes or temperatures of supply chain in Rwanda may not be given priority by risk managers except for the scenario of skipping the market step so that FSEs get vegetables straight from farms. It can be observed from this study that changing the supply chain by introducing a cold chain or refrigeration at market (supermarkets) may not address the microbial risk associated with fresh vegetables. Instead, risk managers can focus on addressing the factors leading to contamination and cross contamination from "farm to fork". It has been demonstrated in this study that washing and sanitization at FSEs alone (current practise) is not enough to address microbial safety concerns. Consequently, risk assessors and risk manager should identify all the possible sources of microbial hazards along the entire supply chain and devise measures and interventions to address them and spearhead risk communication strategies among stakeholders. This study recommends embracing the concepts of "Global One Health" in order to move towards sustainable microbial safety of fresh vegetables in Rwanda and the Globe.

We hope that the results from this study will be helpful for policy makers and risk managers, not only in approaching the microbial safety concerns of vegetables along the supply chain but also in developing national integrated food chain systems. 



\section{Acknowledgements}

With profound gratitude, I take this opportunity to thank the Royal Embassy of the Netherlands in Rwanda for funding this study. I also thank the top management and staff of the National Capacity Building Secretariat (NCBS) in Rwanda for coordinating this research project. Dr Kees van 't Klooster thank you for connecting me to the Professors at Wageningen University and Research Centre.

Acknowledgement with thanks also goes to:

Prof. Dr Marcel H. Zwietering, for the education, training and mentorship. Marcel, your ability to combine strictness, humbleness and a high sense of humour, made the whole study very interesting and boosted my energy levels to push up to the end. I will always "dare to estimate" and also try to "pay attention to the small details" as you always emphasized. Furthermore, as I continue with my world expeditions, I will always aspire to be a Marcel H. Zwietering student and represent you with honour.

Prof. Dr Han Joosten, for the dedication, writing skills and reawakening. Han, you are a very thorough and hardworking person. Your quick and meticulous reviews of my study drafts was a strong pillar of this study. With you, I learnt that no word in a draft can escape unnoticed. I tried to devise a mechanism of answering your questions before you ask them and in the end this mechanism turned out to be an invisible motivational force. Whenever I was approaching the traps of the comfort zone, a question from you would change the whole situation. Your worker ethics will shape my future undertakings.

Dr Martine W. Reij, for the positivity, hospitality, supervision, summarizing and organization skills. Martine your contribution to this study has no monetary value. From you, I have learnt a lot about the positive power of positive energy. In 2013, you told me that this is going to be a successful project, I did not know what you meant, but now I know. Your organisational skills are second to none. I remember you in procuring and shipping laboratory materials to Rwanda. I remember you in organising to receive pathogens from Rwanda to the Netherlands. Your ability to get a global picture of my drafts within five minutes, was a strong litmus test to proceed or not. Thank you also for inviting me to your home to meet your wonderful family, these invitations created a home environment in the Netherlands. Because of you, I will always try to be kind and helpful to the people I meet in future.

Dr Mark Cyubahiro Bagabe, for the study proposal, recommendation, guidance, supervision, English language skills and field work support. Mark, I have no words to describe your high level skills in personnel capacity building. Without your support, this study may not have started or even progressed. You advised me to take up this study task and went on to support me all the way especially in laboratory and field work arrangements and contributing to study proposal. Your strong command of English language was immeasurable during the study. You have completely changed my life and in future, I will always look upon you and try my level best to impact life and behaviour change in other individuals. 
My former Professors and Lecturers at KU Leuven and Ghent University in Belgium and Makerere University Kampala in Uganda for initiating me in the field of food science and technology. Prof. Charles K. Muyanja, thank you for recommending and encouraging me to continue with further studies.

Staff and students at the Laboratory of Food Microbiology of Wageningen University. Gerda van Laar-Engelen, you always arranged my numerous travels, accommodation and other support activities on time, I am very grateful for your dedication. Gerrieke and Ingrid thank you for your support, help and advice during the lab work at Wageningen. Wilma, thank you for the advice on detecting Campylobacter spp. Ioanna (mama Aristides), thank you for the jokes, advice and taking me to buy my first Dutch bicycle. Many thanks to Marcel T., Judith, Ida, Augustine, Karin, Mónica, Hasmik, Alicja, Maciek, Diah, Oscar and Irma (our drivers), Bernard (Prof.), Natalia, Jeroen, Yue, ...for the great time I had with you especially during the PhD trips. Prof. Dr Eddy Smid, Prof. Dr Tjakko Abee, Dr Heidy Den Besten and Dr Richard Notebaert, it was nice to meet you. Last but not least, many thanks also go to MSc. Students, Anooja, Arini, Silvia and Jiao for participating in the laboratory experiments.

The top management and staff of Rwanda Standards Board (RSB) for supporting and facilitating this study. Mr. Raymond Murenzi (Director General) thank you for allowing me to combine my daily work with the last part of writing this thesis. Mr. Mukunzi Antoine, thank you for the facilitation, logistics and collaboration while at the microbiology laboratory. Mr. Kayiranga Aimable, you are my "superstar". Aimable, you acted as a GPS during the field study, you knew every part of Rwanda and your directions were very vital for field work in vegetable farms, markets and food service establishments. The RSB staff in the microbiology laboratory; Mbabazi Alphonse, Nkuranga Innocent, Mugeni Françoise and Mamia Gertrude, thank for your support during the laboratory work. Innocent, your energy levels and motivation were exception during the study. My appreciation also goes to the former Director Generals of RSB, Dr Tito Migabo and Prof. Anastase Kimonyo. Tito, thank you for recruiting me into public service, I was possibly the youngest by that time, but my age was not a problem and the confidence you accorded me, has pushed me this far.

My family for the inspiration, encouragement and support. My Parents, thank you for training me to work hard, endure and taking up opportunities when they become available. My Siblings, thank you for the encouragement. Many thanks go to Uncle Joseph \& Auntie May, Uncle Charles \& Auntie Patience, Uncle Naph \& Auntie Rose, Uncle Denis, Auntie Jane Matsiko, Auntie Mada, for your support and advice. The Kaberuka family, thank you for your love. Rev. Father Rwemarika you're a great blessing to our family. Paul Senkusi, Eng. Charles Bugirande, Eddy Muhini, Joseph Mutabazi, Peter Kasaija, Vincent Nsereko, Maggie Nantale, Immaculate Mukarumongi Busulwa, Jackie Kyomugisha you are great people. Bridget K. Nyiraneza and Jackie Mbabazi thank you for taking care of my domestic issues, while I was in the Netherlands, I love you so much.

To all my friends, members of the African choir at Wageningen, the winning team (Mitsue, Vera, Joao), Students at Wageningen University; Eric Matsiko, Alli, Ben, James, Ephrem, 
Edward, Vincent, Antoinette Mbabazi, Rosine, Gloria, Leah, Doris, Robert, thank you for the great company. Dr John Paul Buyondo, Dr Adrian Muwonge, Eng. Alex Bahati, Eng. Silas Birangwa, Geoffrey Kabuye you rock. Brenda Shenute thank you for the advice and encouragement.

Thesis committee members, I am very grateful to Prof. Dr Ernst J. Woltering, Prof. Dr Liesbeth Jacxsens, Dr Ine van der Fels-Klerx, Dr Juanita A. Haagsma for accepting the invitation to be part of the committee that critically reviewed my thesis.

Other contributors to the study. Prof. Dr Arie H. Havelaar and Dr Brecht Devleesschauwer commented on the DALY estimates and calculator in chapter 2, Dr Eelco Franz advised on detection of pathogens in chapter 4 and Dr Claude Mambo Muvunyi contributed to chapter 2, 3 and 4. We thank Dr Thierry Nyatani and Dr José Nyamusore for information on the surveillance of infectious foodborne diseases in Rwanda, Dr Vincent Mutabazi for advice on ethics approval. Pharmacist Tom T. Mudenge advised on the pharmacy system in Rwanda. Dr Martin Scholten and WUR Global One Health team, thank you for contributing to the thesis cover page. 



\begin{abstract}
About the author
Born $19^{\text {th }}$ March 1981 in Mpigi, Uganda, James Noah Ssemanda graduated at Makerere University Kampala, Uganda in 2005 with a BSc. of Food Science and Technology. In the same year, he was recruited at Rwanda Standards Boards (RSB) in what would later turn out to be an extended career in food quality and safety. James Noah has since contributed to the enhancement of the quality infrastructure in Rwanda and East Africa. While at RSB, James Noah has served in different roles; as a Food quality and safety inspector for local industries and imported foods, Laboratory analyst, Laboratory quality manager and as a HACCP/FSMS certification officer. James Noah is a trained auditor of conformity assessment standards and quality management systems (ISO 17025:2005 ISO 17021:2006 and ISO 22000:2005). In 2008, James Noah was a recipient of the VLIR-UOS scholarship to study at KU Leuven in cooperation with Ghent University, Belgium and graduated cum laude with a Masters of Food Technology in 2010. Thereafter, James Noah returned to RSB where he became team leader in documenting the laboratory quality system in preparation for accreditation. In 2012, James Noah was a coordinator of a RSB project to develop local capacity in HACCP and GMPs in collaboration with the British Standard Institute and Trade Mark East Africa (NGO). In 2013, James Noah accepted a PhD study entitled, 'Towards microbial safety of fresh vegetables in Rwanda', at the Laboratory of Food Microbiology of Wageningen University and Research, Kingdom of the Netherlands. The results of his PhD work are described in this thesis. Currently, James Noah has returned to RSB, to further contribute to the development and implementation of microbial safety guidelines and standards along the food chain in Rwanda and East Africa.

James Noah can be contacted through his private email: jamesnoah.ssemanda@gmail.com
\end{abstract}





\section{List of publications}

James Noah Ssemanda, Martine Reij, Mark Cyubahiro Bagabe, Claude Mambo Muvunyi, José Nyamusore, Han Joosten, Marcel H. Zwietering. (2018). Estimates of the burden of illnesses related to foodborne pathogens as from the syndromic surveillance of 2013 in Rwanda. Microbial Analysis (https://doi.org/10.1016/j.mran.2018.02.002).

James Noah Ssemanda, Martine Reij, Gerrieke van Middendorp, El Bouw, Rozemarijn van der Plaats, Eelco Franz, Claude Mambo Muvunyi, Mark Cyubahiro Bagabe, Marcel H. Zwietering, Han Joosten. (2018). Foodborne pathogens and risk exposure factors associated with farm vegetables in Rwanda. Food Control 89: 86-89.

James Noah Ssemanda, Han Joosten, Mark Cyubahiro Bagabe, Marcel H. Zwietering, Martine Reij. (2018). Reduction of microbial counts during kitchen scale washing and sanitization of salad vegetables. Food Control.85: 495- 503.

James Noah Ssemanda, Martine Reij, Mark Cyubahiro Bagabe, Claude Mambo Muvunyi, Han Joosten, Marcel H. Zwietering. (2017). Indicator microorganisms in fresh vegetables from "farm to fork" in Rwanda. Food Control 75: 126 - 133.

Muyanja C, Birungi S, Ahimbisibwe M, Ssemanda J and BS Namugumya. (2010). Traditional processing, microbial and physicochemical changes during fermentation of Malwa. African Journal of Food Agriculture and Nutrition 10:4124-4138. 



\section{Overview of completed training activities}

\section{Discipline specific courses}

Governance and Food safety in international food chains

Genetics and physiology of food-associated microorganisms

Management of Microbial Hazards Foods

Multivariate analysis for food data

Applied Statistics

$\begin{array}{lll}\text { CDI } & \text { Wageningen } & 2012 \\ \text { VLAG } & \text { Wageningen } & 2013 \\ & & \\ \text { VLAG } & \text { Wageningen } & 2014 \\ \text { VLAG } & \text { Wageningen } & 2014 \\ \text { VLAG } & \text { Wageningen } & 2016\end{array}$

\section{Meeting and conferences}

Epidemiology of foodborne illnesses

Global Burden of Disease: Foodborne

Pathogens, The FERG Approach

$\begin{array}{lll}\text { RIVM/WHO } & \text { Amsterdam } & 2015 \\ \text { KNVM } & \text { Wageningen } & 2016\end{array}$

\section{General courses}

Information Literacy including endnote

introduction

Philosophy and Ethics of Food science

Scientific Writing

Writing Grant Proposals

Project and Time Management

Presenting with impact

Research integrity

$\begin{array}{lll}\text { WGS } & \text { Wageningen } & 2013 \\ \text { WGS } & \text { Wageningen } & 2014 \\ \text { WGS } & \text { Wageningen } & 2016 \\ \text { WGS } & \text { Wageningen } & 2016 \\ \text { WGS } & \text { Wageningen } & 2016 \\ \text { WGS } & \text { Wageningen } & 2016 \\ \text { WGS } & \text { Wageningen } & 2016\end{array}$

\section{Optional courses}

Preparation of research proposal

WUR

Wageningen

2013

PhD study tour to Ireland

FHM

Cork, Dublin

2014

PhD study tour to Italy

FHM

Bolgna, Parma,

Food Microbiology department seminars

FHM

Milan, Alba,

Turin

Wageningen 

Studies in this thesis were conducted within the framework of capacity building for Rwanda in food security and safety.

Acknowledgement with thanks goes to the Royal Netherlands Embassy in Rwanda through the National Capacity Building Secretariat for funding this study.

Cover design: The Global One Health task force of Wageningen University \& Research, and James Noah Ssemanda

Printed by: Digiforce || ProefschriftMaken 

